\title{
A KAUPAPA MĀORI ANALYSIS OF THE USE OF MĀORI CULTURAL IDENTITY IN THE PRISON SYSTEM
}

by

Riki Mihaere

\author{
A thesis \\ submitted to Victoria University of Wellington \\ in fulfilment of the \\ requirements for the degree of \\ Doctor of Philosophy in Criminology \\ Victoria University of Wellington
}

2015 


\section{ABSTRACT}

Māori are $15 \%$ of the New Zealand population, and yet are $45.3 \%$ of annual police apprehensions and $51 \%$ of the prison population. This status of Māori 'overrepresentation' in the criminal justice system has remained steady for the last 34 years. One principle explanation of this status is that Māori have limited access to a secure Māori cultural identity. As a result, criminal justice authorities, especially the Department of Corrections, have progressively focused policies and programmes towards the perceived Māori cultural related needs of Māori offenders and prisoners. This focus is undertaken not only to reduce rates of recidivism but also to provide culturally relevant environments for Māori prisoners and increased opportunities for successful rehabilitation.

The result is that New Zealand's prison system now contains a number of unique strategies such as the Māori Therapeutic Programme, the New Life Akoranga Programme and Māori Focus Units. Despite these developments, there remains a dearth of clearly articulated descriptions of how, why or even if Māori cultural identity has a positive effect on reducing Māori offending and imprisonment. This thesis is designed to address this gap in the research.

The thesis pursues a kaupapa Māori methodology, using in-depth interviews with key Māori associated with the development of the theory, policy and practice of Māori cultural identity in the criminal justice system. This focus provides an opportunity for those Māori whose careers or, in some cases, life works have been dedicated to the development and implementation of cultural responses to crime to speak for themselves. This approach allows a full exploration of the underlying rationale and meaning of the Māori cultural identity policies and resultant programmes sprinkled throughout New Zealand’s system.

The thesis develops two key arguments. Firstly, despite strongly held criminal justice beliefs about the potential validity of Māori cultural identity in relation to reducing Māori offending and imprisonment, the broader context regarding the status of Māori as the most marginalised population in New Zealand is largely ignored. Rather than accepting that Māori offending is likely to be ignited by a broad array of socioeconomic factors which are the result of generations of colonising Pākehā practices, 
the Correctional response has been to individualise Māori offending by focusing on the degree of Māori cultural identity inherent in specific Māori offenders. Secondly, that the authenticity of Māori cultural identity policies and programmes designed and delivered by Corrections is questionable. While the Department argues that Māori cultural identity nestles comfortably within western-based therapeutic programmes, professional Māori disagree. In their view, the Māori cultural identity programmes delivered in New Zealand's prisons do not resemble Māori culture at all. Given these two arguments, the thesis questions whether the criminal justice use of Māori cultural identity is more a measure of official attempts to meet 'Treaty' obligations rather than a genuine effort to reduce Māori offending and imprisonment. 


\section{HE MIHI}

Tau ake au ko te tau nei, ko Ruatīpua, ko Ruatāwhito

Ngārue i runga, ngārue i raro, ngārue i te ihu o Tāne, te ihu o Tāne

Ko taku waka ko Tākitimu!

Rere mai te maramara, ko ihi nui, ko ihi roa

Ko Te Āwhiorangi

E ko wai kei runga e tupa whai ake

E ko au, ko Uenuku e tupa whai ake

E Rata, e Rata he aha tau e hanga e tupa whai ake.

Unumia te kawa, tākina te kawa

He kawa tūānihinihi te kawa, he kawa tūārangaranga te kawa

Ko te kawa o wai? Ko te kawa o Tākitimu!

Unumia te kawa o Tìrari, unumia te kawa o Tīrara

Unumia te kawa o Rongokako, Unumia te kawa o Tamatea-mai-tāwhiti!

Tūrūki tūrūki, pāneke pāneke

Tūrūki tūrūki, pāneke pāneke

Haramai te toki! Haumi è, hui è taiki ē!

Tēnei rā te aro atu rā ki te hunga nō nākuanei ka riro ki te whāriki whakairo o ngaromanga. Ka tuku te ia o whakaaro kia rere makuru roimata atu ki te kāhui ngū kua hoki atu ki te waro huanga roa o te wairua. Koutou rā kua whakairotia ake e te toki waihanga i te tā moko kai te pō. Anā rā te whakatauākītanga kōrero a taku tipuna, a Tamatea Ariki Nui, 'he ranga maomao ka taka i tua o Nukutaurua, e kore ā muri e hokia'. Nā reira koutou rā ngā ihoiho o tua i ngā maunga, te riro tītapu o raurangi, 
haere, takoto, okioki! Ka hoki anō rā ki a tātau, ngā waihotanga iho o rātau mā. Mauri ora ki a tātau katoa.

Ka mawhiti rā taku haere ki te tihi tapu, ki Kahurānaki. Ka titiro iho au ki te mānia o Heretaunga haukū nui, ara rau, hāro o te kāhu, takoto noa è, ko Te Whatuīāpiti. Noho ana au $\mathrm{i}$ te nohoanga o te tipua. Ka tīkoko iho rā te kapu o taku ringa ki roto o Poukawa, te wai tuku kiri o taku iwi è, ko Te Rangikoiānake. Ka whakatauākī ake au, ko Kahurānaki te maunga, ko Ngaruroro te awa, ko Tākitimu te waka, ko Kahurānaki te marae, ko Ngāti Kahungunu te iwi.

Tēnei ka anga atu rā ki te hunga nā rātau tēnei, a Taitamariki nei i tautoko, i poipoi i roto i ngā tau kua hipa. Ko koutou tēnei i tuku i ō koutou nā whakaaro, ngā wheako, ngā kitenga anō hoki mei kore e puta, mei kore e pūāwai mai êtahi hua hai hākari mō te hunga whakaaro nui. Ko tō koutou nā hā tēnei i aro ake rā ki te kaupapa nei, koia ko aroha tēnei i tuku mai nei. He aroha tēnei e hāngai pū ana te rere ki te ngākau tonu o tangata. Ko tō koutou nā reo ka rangona, huri noa i te tuhinga nei. Mei kore ake ko koutou i aro mai, kua kore te tuhinga nei nā reira e mihi ake ana, e mihi ake ana. $\mathrm{Na}$ reira ki ngā maunga kōrero, ngā uri tuku o ngā mātā waka, e kore te tai o mihi e mimiti noa.

Nō reira ka huri aku kanohi ki ngā maunga kai reira te āwhina mōku. Ki Moumoukai, te wāhi i tini ai te kai e, ko Kahungunu, ko Rongomaiwāhine. Ka rere tonu taku haere ki Puketapu, ki te whare o Te Mana o Tūranganui i tangohia e Ruawharo e, ko Rongowhakaata. Ka nāwaki rā taku haere ki Maungahaumi, te rerenga mai o te mimi o Paoa e, ko Mahaki. Ka rere arorangi taku haere ki te pū o te rāwhiti. Ki Hikurangi, te maunga e mihi ake ana ki te pū hīhī o Tamanui-te-rā e, ko Porourangi. Ka aokapua taku haere ki te rohe e kiia nei, Mai i Ngā Kurī ā Wharei ki Tihirau e, ko Tūhoe Pōtiki, ko Awanuiārangi, ko Te Whakatōhea, ko Ngāi Te Rangi, ko Ngāti Pūkenga. Ka topa whakararo taku haere ki te mānia o Hauraki, ki ngā uri o Hoturoa e, ko Tamaterā. Ka nau ake rā taku haere ki Te Hiku o te Ika. Pūhanga-Tohorā titiro ki Te Ramaroa. Te Ramaroa titiro ki Whiria, ko te paiaka o te riri, te kawa o Rāhiri. Whiria titiro ki Panguru ki Papata, te rākau e tū papata ki Te Tai Hauāuru. Pangaru-Papata titiro ki Maunga Taniwhā-whakarongorua. Maunga-Taniwhā titiro ki Tokerau, Tokerau titiro ki Rākaumangamanga. Rākaumangamanga titiro ki Manaia, Manaia titiro ki Tūtāmoe. Tūtāmoe titiro ki Maunganui. Maunganui titiro ki Pūhanga-Tohorā 
e, ko Te Whare Tapu o Ngā Puhi Nui Tonu. Ka rere atu rā taku haere ki Te Puku o te Ika, ki Tongariro e, ko Ngā Pūmanawa e waru o Te Arawa waka. Ka heke iho rā taku haere ki Te Tuara-nui o Te Ika ā

Maui, ki Ruahine e, ko Rangitāne, ko Kauwhata. Ka whakawhiti atu rā i te awa i tū te manawa kia tae atu rā ki te wāhi i takina ai te tokotoko e, ko Raukawa. Ka rere atu rā taku haere ki Te Mana o Kupe, ki te whānga o Porirua ē, ko Toa Rangatira. Ka hoki atu au ki te mauri o taku waka, o Tākitimu. Ki Tauranga ko Ranginui, ki Nukuraurua ko Kahungunu, Ki Heretaunga ko Te Whatuīāpiti. Ko te mauri i herea mai nei hai whakaoho i taku moe. E ko, ko ia, e ara e.

Whakatau mai rā, whakatau mai rā, whakatau mai rā. E te kaipānui, haere mai ki tēnei kohinga kōrero nāku. He mea tito ēnei kupu i runga anō i te ngākau iti mei kore e kitea tētahi ara hai whakatika i te parekura kua tau ki ngā pakihiwi o Ngāi tātau, arā, ko te tini o ngā Māori kua riro ki ngā whareherehere o te motu. E mōhio pū ana tātau ki te parekura nei. Ia pō, ia pō ka kitea te mahi o ngā Māori kua riro i te ture. Ae rānei me hanga i ngā whareherehere hou, à, ka whiua te kii kia waiho rātau kia noho ana, ae rānei me rapa e tātau te whakapapa o te parekura nei kia kitea ai he rongoā mō tātau katoa? E hia kē nei te tahua pūtea $\mathrm{i}$ whakapaua e te Kāwanatanga $\mathrm{i}$ runga anō i te kaupapa nei, ā, tē piki kē ai a Ngāi Māori ki paku kō atu! Nā reira e te kai pānui, nau mai haere mai ki ēnei kōrero e rapu ana i te ara tika mō tātau katoa. Ā kāti. 


\section{ACKNOWLEDGEMENTS}

There have so many people and organisations that have contributed so much to me on this journey. As much as I might try I am sure I cannot possibly remember everyone here with these few words. But over time I am sure I will be provided with the opportunity to show you all how much your support has meant.

I would like to take the opportunity here to thank the people who participated in this study. Literally, this study would not have been completed without you. It is a testimony of faith that the people who opened their homes and gave their time were also the first people that I asked to take part. I hope that I have completed a thesis that is reflective of your voices, rather than mine alone.

I have been fortunate to have received much appreciated financial support. My thanks go to Victoria University of Wellington for the PhD Scholarship and the Tū Horomata Scholarship; to the Māori Education Trust for the Professions Scholarship; my iwi, Ngāti Kahungunu Iwi Incorporated, thank you for the Research Scholarship; and to the Trustees of the will of Philippa Therese Williams for the Philippa \& Morvyn Williams Post-Graduate Scholarship.

As well, I would also like to thank the following people who in their professional capacity have contributed towards the successful completion of my study. My thanks go to Elizabeth Stanley, my primary supervisor, who steadfastly remained to see the study through. Thank you, both for sticking with it and for the guidance. As well, Robert Webb, my secondary supervisor who despite the distance seemed to pick just the right time to support and guide.

And I would also like to thank those people who have always been there at the other end of the phone, on Skype, over dinner, or who supplied me with a couch to crash so that I could get out of the city on occasion. Thank you all so very much: Rachael, Bronwyn for the endless cups of coffee, dinners, lunches and chats; Te Kawa a Māui and Te Herenga Waka: Te Ripowai Higgins, Monoa Taipa, Kathy Samuels, Tū Temara, Matu Stevens and Paul Meredith e te whānau, Te Herenga Waka, ko koe rā tēnā e whakatinanahia te manaakitanga, te whanaungatanga, kei tua atu ko te aroha; And also to Keith and Cherie, Pete and Rena, PJ and Pania for always being there. 
And to my girls, Te Oranga and Awhitia. 


\section{CONTENTS}

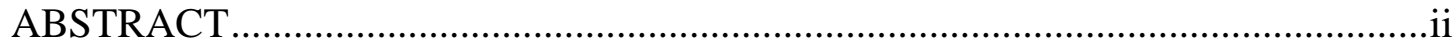

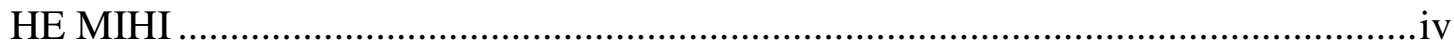

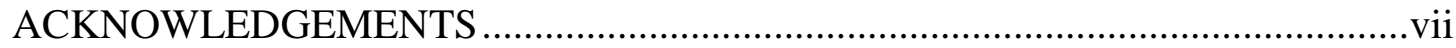

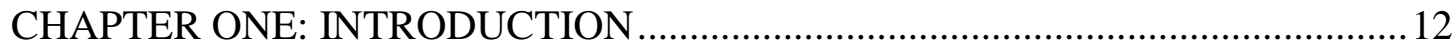

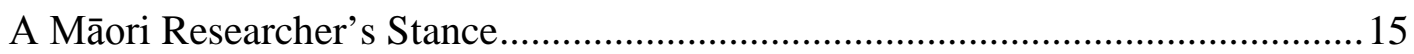

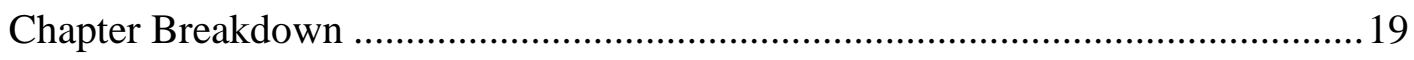

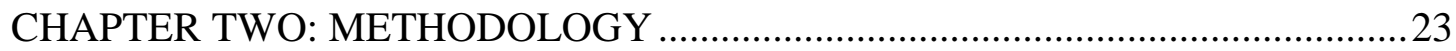

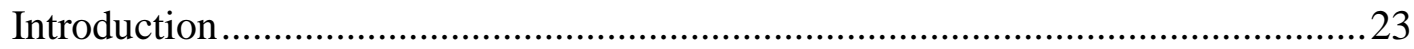

Kaupapa Māori: A Māori Cultural Foundation ........................................................225

Overview of Kaupapa Māori Research ...............................................................225

Kaupapa Māori and a Māori Cultural Stance ....................................................28

Kaupapa Māori Research and Ethical Boundaries........................................... 29

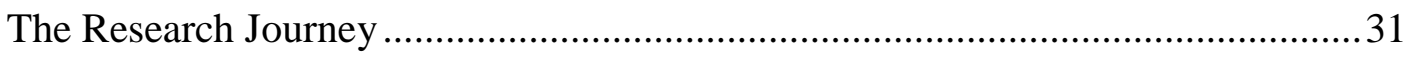

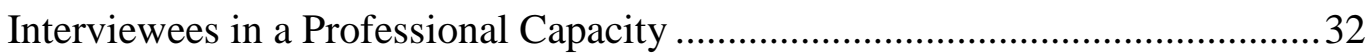

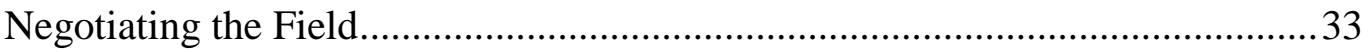

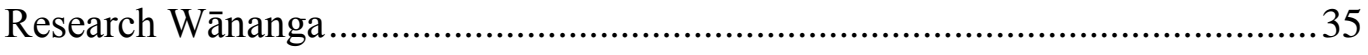

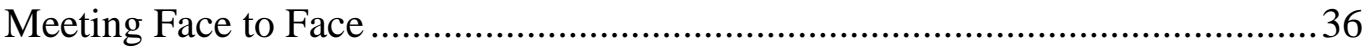

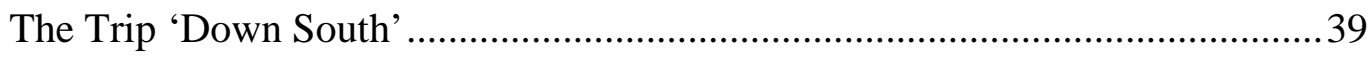

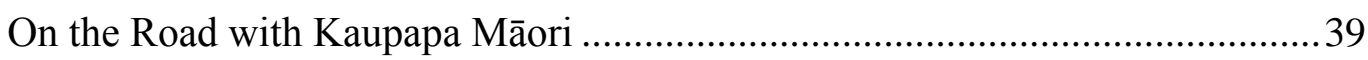

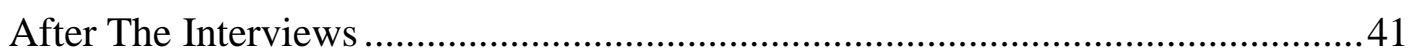

Digital Recordings and the Transcription Process.............................................. 41

Transcribing Māori Language Interviews......................................................... 42

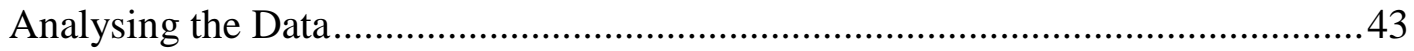

The Identification of Respondents in the Final Report ..........................................46

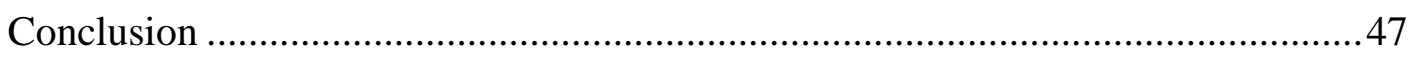

CHAPTER THREE: COMPROMISED MĀORI CULTURAL IDENTITY...............52

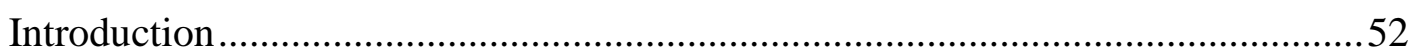

Māori Cultural Identity and Colonialism............................................................. 54

Māori Cultural Identity and Urbanisation............................................................59

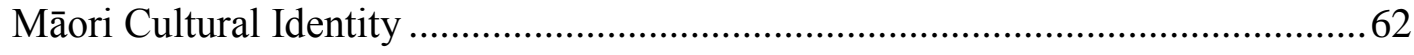

Māori Cultural Identity: Critical Elements ...............................................................65

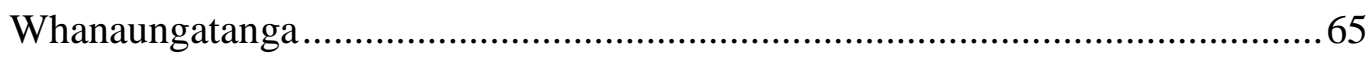

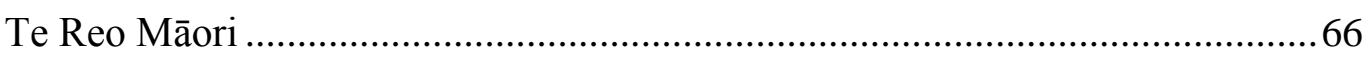

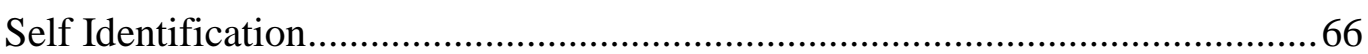

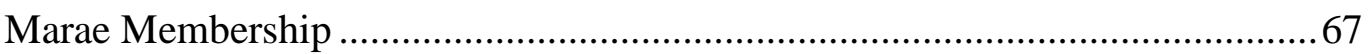


Conclusion

CHAPTER FOUR: MĀORI CULTURAL IDENTITY: THEORY AND PRACTICE

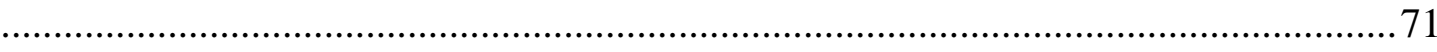

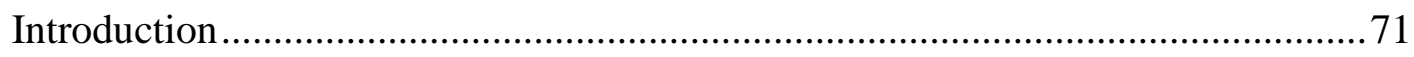

Māori Cultural Identity: A Response to Rising Māori Imprisonment ..................... 73

Māori Culture at the Rock Face: Maranga Cultural Group ................................ 74

Embedding Māori Cultural Identity in Criminal Justice Policy ............................. 79

Māori Calls for Change in the Criminal Justice System.....................................8 81

Department of Corrections: Systemising Māori Cultural Identity .............................85

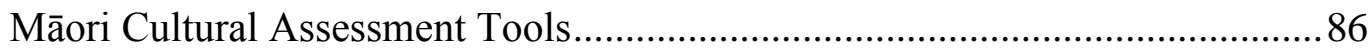

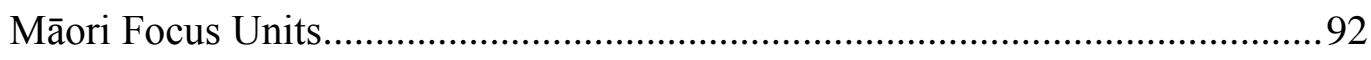

Māori Therapeutic Programmes .................................................................96

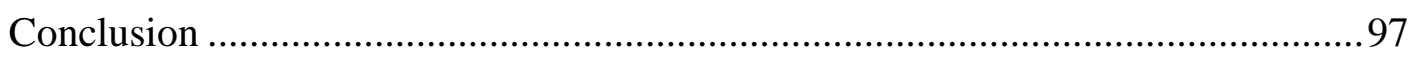

CHAPTER FIVE: THE VALIDITY OF MĀORI CULTURAL IDENTITY ..............99

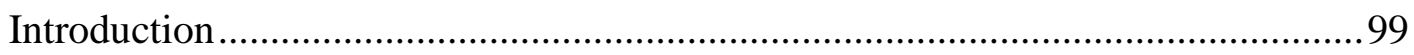

Māori Cultural Identity as a Response to Māori Offending ...................................102

Māori Status and Māori Offending Rates ...............................................................109

Prison as a Venue for Māori Cultural Identity.....................................................114

Working With the Department of Corrections...................................................117

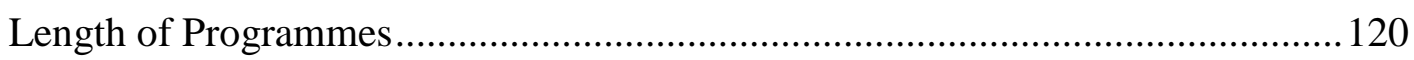

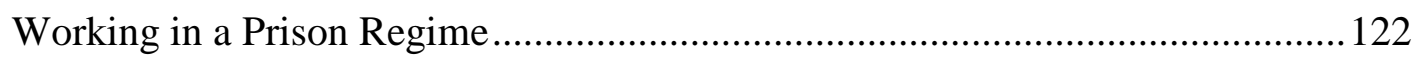

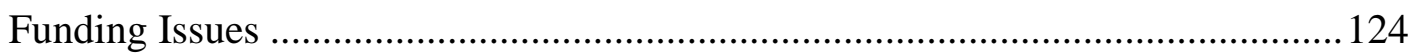

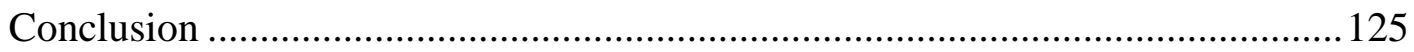

CHAPTER SIX: THE AUTHENTICITY OF MĀORI CULTURAL IDENTITY ...127

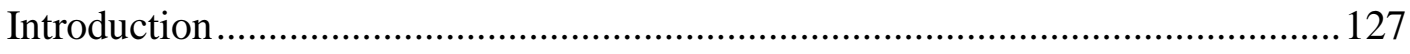

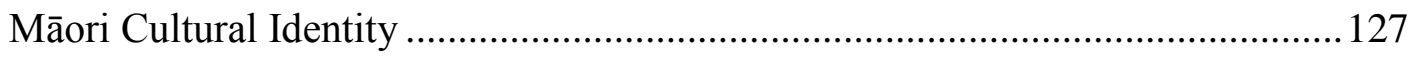

Māori Cultural Identity and Strengthening the Self............................................131

Key People Making a Difference ....................................................................... 136

Narrow Focus of Current Practices ........................................................................138

Māori Cultural Identity and the Psychological Influence .......................................141

Māori Cultural Identity and Further Development ...............................................149

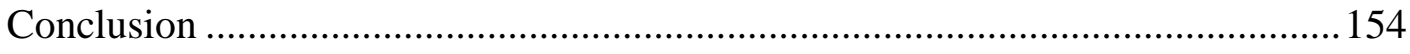

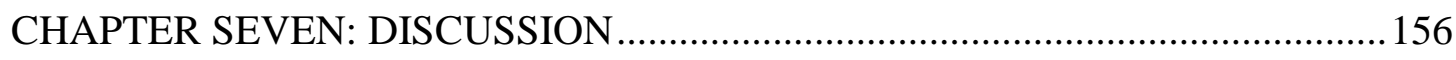

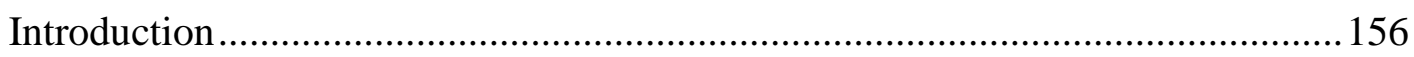

Māori Cultural Identity Loss...........................................................................157

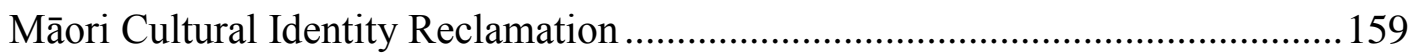




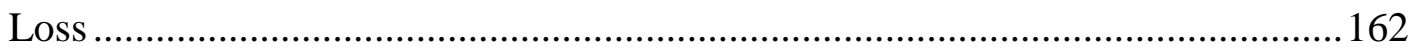

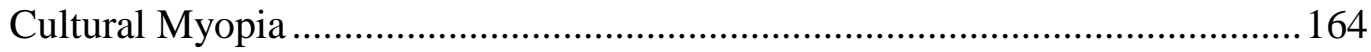

Freezing Māori Cultural Identity .....................................................................165

Misappropriation of Māori Cultural Identity ........................................................165

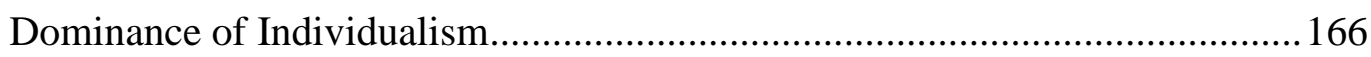

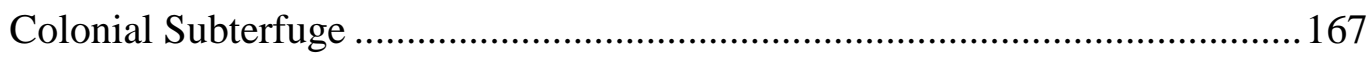

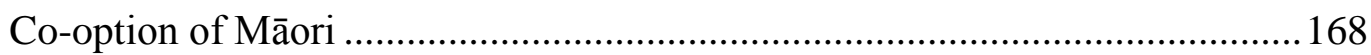

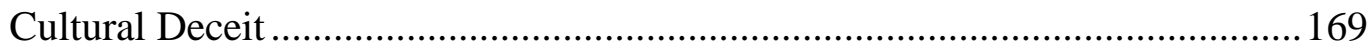

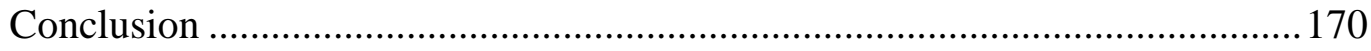

Reclamation .............................................................................................. 171

CHAPTER EIGHT: CONCLUDING WORDS …………....................................174

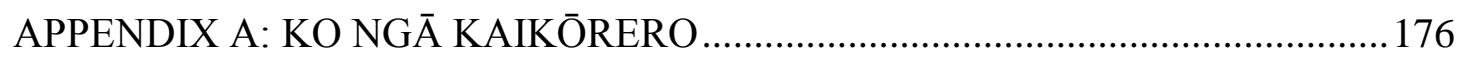

APPENDIX B: EMAIL COVER LETTER SENT TO KAIKŌRERO .......................191

APPENDIX C: INFORMATION SHEET SENT TO KAIKŌRERO.........................194

APPENDIX D: CONSENT FORM SENT TO KAIKŌRERO ...................................196

APPENDIX E: A GLOSSARY OF MĀORI TERMS ………………………….....197

APPENDIX F: THE TREATY OF WAITANGI ………………………………......201

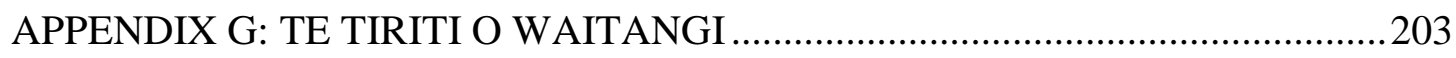

APPENDIX H: DECLARATION OF INDEPENDENCE OF NEW ZEALAND....205 APPENDIX I: HE WAKAPUTANGA O TE RANGATIRATANGA O NU TIRENE .

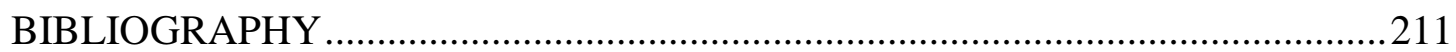




\section{CHAPTER ONE: INTRODUCTION}

This Criminology $\mathrm{PhD}$ thesis examines the theory, policies and practices that have emerged in response to the assertion that, for Māori offenders and prisoners, there is a relationship between Māori cultural identity and the reduction of Māori offending.

For approximately four decades, the most predictable feature of the New Zealand criminal justice system has been that Māori will be the most apprehended, convicted, imprisoned and victimised group in the statistics. Despite the fact that Māori are only 15.7\% of New Zealand's total population (Statistics New Zealand 2014b), Māori account for approximately $45.3 \%$ of annual Police apprehensions (Statistics New Zealand 2014a) and 50\% of annual prison numbers (Department of Corrections 2014a). Regardless of the degree of political, media, literary and academic attention that has been focused on this phenomenon, this status, of Māori being the most disproportionately represented population in crime statistics, has remained steady over many generations (Department of Corrections 2012c:7).

The dominant theory argues that, with the colonisation and subsequent urbanisation of Māori society, Māori have been subjected to a state of widespread cultural identity loss, the inevitable result of the cultural, political, social and economic marginalisation that Māori have experienced since Pākehā ${ }^{1}$ contact in New Zealand. This, in turn, has resulted in generations of Māori who have little or no knowledge of Māori cultural identity. As a result, those Māori who experience Māori cultural identity isolation are considered to be less likely to be able to succeed in both Pākehā and Māori societies, while those Māori who have a strong sense of Māori cultural identity are considered to be more likely to succeed in both Māori and Pākehā societies. In criminological terms, those Māori who have a poor sense of Māori cultural identity are more likely to offend while those with a strong sense of Māori cultural identity are less likely to offend. As a result there have been many responses to this 'problem' over the last few decades.

\footnotetext{
${ }^{1}$ Pākehā is a term used by Māori people to describe anyone who is not Māori. While there are recent instances where the term has been considered offensive, King (2004) correctly points out that it has been used as a purely descriptive term since the first contact between Māori and non-Māori. There are many instances, such as Rev Henry Williams' translation of the Treaty of Waitangi from the English language into the Māori language in February 1840, where Pākehā referred to themselves as such (Government Printer 1976). My repeated usage of the term Pākehā throughout this thesis adopts both King's and Williams' usage.
} 
Māori cultural identity has been at the heart of many policies; and many programmes and practices have been designed and delivered towards the perceived Māori cultural identity 'needs' of Māori offenders, particularly Māori prisoners. Based on the assumption that offending and reoffending are attributable, at least in part, to an impaired access to a secure Māori cultural identity, these programmes introduce Māori offenders and prisoners to tikanga Māori beliefs and practices. This is undertaken not only to reduce rates of recidivism amongst offenders but also to provide more relevant prison environments for Māori prisoners and greater opportunities for successful rehabilitation.

The result is that New Zealand's criminal justice system now contains a number of unique Māori-focused strategies such as: a Specialist Māori Cultural Assessment, that aims to identify the cultural needs and strengths of Māori offenders; Māori Therapeutic Programmes, which are cognitive behavioural therapy programmes integrated with tikanga Māori; Bicultural Therapy programmes, that are delivered by service providers in conjunction with iwi and hapū; Whānau Liaison Workers, who aim to strengthen the relationship between Māori prisoners and their whānau, hapū and iwi; kaiwhakamana, whereby kaumātua are provided with access to prisoners to help them identify and make contact with their whānau, hapū and iwi, or trace their whakapapa, or learn tikanga, and provide spiritual support in order to help their reintegration back into the community; Māori Focus Units, which are 60-bed prison units established to test the effectiveness of using Māori culture as a medium in reducing Māori offending ${ }^{2}$; and the New Life Akoranga programme, a four day/three night residential prison programme which aims to systematically change criminal behaviour by empowering Māori prisoners with traditional Māori knowledge.

Regardless of the fact that there is an ever increasing list of research reports on Māori cultural identity policies and programmes there remains a dearth of clearly articulated descriptions of how, why or even if Māori cultural identity has a positive effect on Māori offending. This research project has been designed as a response to this gap in the field.

\footnotetext{
${ }^{2}$ There are Maori Focus Units at Hawkes Bay, Rimutaka, Waikeria, Tongariro/Rangipō and Whanganui Prisons.
} 
The following three objectives have been developed in order to provide a focus to the research project: Firstly, the thesis aims to critically analyse the concept of Māori cultural identity. Relatedly, it seeks to document the fundamental features of Māori cultural identity; the significance of colonisation, and the subsequent urbanisation of Māori society, upon Māori cultural identity; and, the perceived importance and role of Māori cultural identity in contemporary Māori society. Secondly, the thesis aims to consider the development and institutionalisation of Māori cultural identity in the New Zealand prison system. Throughout the historical rise, and on-going application, of Māori cultural identity there has been: a lack of a theoretical basis; a scarcity of scientific development; little, or no, research applied to the subsequent policies and programmes; and, importantly, too little Māori engagement in the implementation of Māori cultural identity programmes and research. Given this, it is unclear how these programmes actually operate and one wonders whether they are useful additions or whether they are a reflection of ad hoc political strategies that are focused on providing the appearance that the Department of Corrections is meeting its Treaty of Waitangi obligations. Thirdly, in response to the dearth of research in comparison to the degree of policy focus, the thesis aims to articulate a kaupapa Māori analysis of Māori cultural identity policies and programmes delivered in prison. It will do this by providing a critical narrative space for Māori who have been at the 'rock face' of introducing and developing the 'idea' of Māori cultural identity and implementing the resultant policies and programmes.

Adopting a kaupapa Māori research methodology to envelop the research project in an 'about Māori by Māori for Māori' framework, qualitative data has been collected through semi-structured, in depth interviews with 43 key Māori informants, that I have named as a collective 'the kaikōrero's'. Together with this, I engaged in six hui at four marae, one Māori tertiary institution and one Māori health provider (see Appendix $\mathrm{A}^{4}$ ). This collective of Māori voices are people who have had some form of

\footnotetext{
${ }^{3}$ For a very long time I have struggled with finding a term that could describe the group of people who gave their time to me to talk on this subject. Initially I had described them as 'the research participants'. This was a term that I did not like. It seems rigidly formal, and to me it oozed 'academic ivory tower'. This was a stance that I have sought to distance myself from in this research. I wanted the research to better reflect that I was positioning myself as a Maori conducting research among my own community. I finally settled on 'kaikōrero'. Kōrero means 'talk' or 'speak', the addition of the prefix 'kai' changes the term to 'talker' or 'speaker'. Therefore, when I am referring to the group of people who took part in this research I refer to them as 'kaikōrero', if I am referring to research participants in the wider context of the term then I refer to 'research participants'.

${ }^{4}$ Appendix A provides a complete list of the kaikōrero who agreed to take part in this research project, as well as a list of hui venues.
} 
interest, or career, or view on the subject of tikanga Māori in relation to reducing Māori offending.

In the main, the outcomes of this thesis are that the historical genesis, and ongoing development and implementation, of tikanga Māori in relation to reducing offending behaviour among Māori will be subject to critical examination from a Māori perspective. The finished thesis provides key Māori kaikōrero with the opportunity to 'reclaim' from institutions, such as the Department of Corrections, the ongoing theoretical development and implementation of tikanga Māori in relation to reducing Māori offending. Importantly, this research will be a Māori response to the fact that crime is an area that is increasingly, and unfortunately, perceived as a defining characteristic of Māori society.

\section{A Māori Researcher's Stance}

A fact that will be clear from the beginning of this thesis is that I speak in the 1st person and use subjective phrases such as 'I' and 'my'. There are two main reasons for positioning myself in this way. Firstly, while objectivity is generally considered a usual practice when writing within a field of social science, there is a view, a predominantly Māori view, that it is not possible to achieve a real understanding of Māori people, values or culture from an objective position:

The route to Māoritanga through abstract interpretation is a dead end. The way can only lie through a passionate, subjective approach. That is more likely to lead to a goal (Marsden 1992:117).

Marsden's statement was written when Māori were beginning to advocate for the importance of engaging in research from a Māori perspective. At that time, kaupapa Māori research methodology emerged in response to a long history of research conducted among Māori communities by Pākehā researchers applying what are considered by Māori to be questionable ethical standards. Further, that research among Māori communities has repeatedly come under fierce critical analysis because "Western researchers and intellectuals can assume to know all that it is possible to know of us, on the basis of their brief encounters with some of us” (Smith 1999:1). Marsden's response was that Pākehā research on Māori emerging from that perspective failed to accurately portray Maori society and values. His argument was 
that the sought after objective stance treasured by Pākehā academia was an inadequate position to adopt in research among Māori, and the results of those labours produced a poorly crafted output that failed to portray an accurate version of Māori society and culture. In his view, engagement among Maori was the key and researchers need to immerse in Māori culture rather than stand back simply observe.

Secondly, the fundamental building block of Māori society is the collective and the system of familial relationships that relates "every individual in some degree with every other one, at varying degrees of remove from whānau, hapū and iwi, and linking every individual to a line of ancestors stretching back to Ranginui and Papatūānuku" (Ministry of Justice 2001:41). The key to Māori collective structures and relationships is whakapapa, or genealogical descent from an ancestor. Whakapapa provides the foundation upon which Māori society continues to be organised and maintained (Barlow 1991).

How this relates to me and my subjective stance in this thesis is that my view of the world is formed with whakapapa at the forefront. When I meet another Māori for the first time the thought that comes to mind is 'nō hea koe' which literally means 'where are you from?' but implies a much deeper meaning of 'who are your ancestors?', 'what are your iwi and hapū?', and 'how do we relate to one another?'. Therefore my stance is that I am Māori, and I know that as Māori I am bound together genealogically with all Maori. As well, I am conducting a research project on Māori offending and imprisonment, a phenomenon that has been wounding Māori society for decades. Therefore I am affected by this work, and no doubt, I will affect this work. I will not present a facade to the contrary.

\section{Language}

In the main this thesis is written in the English language. However, despite the thesis being for a degree in criminology, the research that has led to it is focused on Māori cultural identity. As a result there is a large Māori language content in the thesis. Most paragraphs have a word or two of Māori language content dispersed throughout. At times though there are quite large passages of Māori language. Therefore it is appropriate here to describe how I intend to use more than one language throughout this thesis. 
Firstly, in a situation such as this where there is more than one language in the body of a thesis there is a guideline that outlines that there is an expectation that terms in a language other than English are indicated by presenting the 'other' language, in this case 'other' would refer to the Māori language, in italics. However, I have decided not to italicise the Māori language content of the thesis. My reason for this decision is the following.

There are two official spoken languages in New Zealand ${ }^{5}$, English and Māori. While the number of speakers of te reo Māori remains an ever present concern for the long term survival of te reo Māori, with each emerging generation there are signs that te reo Māori is finding a greater degree of everyday usage in broader New Zealand society.

However, as I will show in Chapter Three, te reo Māori came very close to being silenced by the brutality that was meted out to Māori children who spoke te reo Māori at school. In 1905, schools were instructed that all lessons were required to be in the English language and all schools were instructed to "encourage children to speak only English in school playgrounds" (ibid:147). Subsequently, this directive was interpreted as meaning that there was effectively a ban on the use of te reo Māori on school grounds, and corporal punishment was the means by which it was enforced. The result was that for decades, Māori children considered schools a place of "misery and pain” (Selby 1999:19) and instead of "education being embraced as a process of growth and development, it became an arena of cultural conflict” (Walker 1990:147).

In 1985 New Zealand's statutory body to address the injustices that Maori received throughout colonialism, the Waitangi Tribunal, heard a claim that the Crown had failed in its responsibilities to protect the Māori language and in doing so had breached the terms of the Treaty of Waitangi. The claimant's argument was that the 1840 Treaty of Waitangi granted Māori specific rights in regards to 'valued possessions', which in their interpretation included te reo Māori. As a result of an extensive claims process, the Waitangi Tribunal eventually found in favour of the claimants by stating that the guarantee in the Treaty required that there was an obligation on the Crown as a Treaty partner for "affirmative action to protect and

\footnotetext{
${ }^{5}$ In total there are three official languages of New Zealand: English, Māori and Sign language.
} 
sustain the language, not a passive obligation to tolerate its existence and certainly not the right to deny its use in any place” (Waitangi Tribunal 1986:1). While the Tribunal's response was especially aimed at the New Zealand Government, the responsibility for affirmative action was not confined to them alone, but also included “...the courts, government departments, and local bodies, and in all other spheres of New Zealand society” (Durie 1998:59). In my view therefore, other spheres of New Zealand society includes academic institutions. My argument then is that there are two languages of equal status in New Zealand, and it is appropriate that the equal status of te reo Māori and the English language be recognised in everyday use. Therefore I intend to present both Māori and English languages together in my thesis as equals. Neither will be afforded a status as an 'other' language.

Despite that, I do recognise that in the context of the population of New Zealand or beyond, there are a low number of people who speak or understand te reo Māori so it is responsible for me to provide a translation of the Māori terms that I have used throughout the thesis. As such, a glossary of Māori words has been included as Appendix E.

Also, the Māori language has two main forms of vowel sounds, long and short. Long vowel sounds are indicated by the use of a macron above the vowel; $\overline{\mathrm{a}} / \overline{\mathrm{e}} / \mathbf{1} / \overline{\mathrm{o}} / \overline{\mathrm{u}}$. This is an important distinction because whether a word has a long or short vowel can change the meaning of a word significantly. For instance, I was helping my niece move into a new house in a neighbourhood that has been nicknamed 'the bird sanctuary' because all the streets have the names of native birds. As I was standing looking up at the street sign, which read 'Kaka Street', she stood next to me and remarked, "I've moved into Parrot Street”. At which point I replied "no, the native parrot is actually spelt with long vowels 'kākā'. 'Kaka' means faeces. So if I was to translate that sign correctly, you've literally just moved into Shit Street”. An important distinction. So I have macronised all Māori words.

A final point regards the subject of some words that were used by the kaikōrero, notably, swearing throughout some of the interviews. I have not edited out the swearing that marked the interviews that I conducted. As I describe in Chapter Two, presenting the findings of the interviews with the kaikōrero in a manner that is consistent with kaupapa Māori principles is a fundamental aspect in this thesis. I 
decided that if I was to indiscriminately edit out what is essentially their choice of language then I would risk removing too much of the context of the narrative. At that moment, they were passionately engaged in making a statement, and as a result I have chosen to present the quotes in a manner that reflects that passion.

\section{Chapter Breakdown}

In the following Chapter Two: Methodology, I begin by more fully unpacking kaupapa Māori research methodology. This is an important opening statement because kaupapa Māori research methodology has provided a Māori cultural foundation, and to a very real degree a guiding ethical code, to the entire research project. Therefore the chapter begins by presenting an historical overview of certain critical factors, notably Māori concerns about Pākehā researchers and the outputs they produce, that led to the emergence of kaupapa Māori research methodology as a Māori response. As the chapter will show, Māori have continued to be portrayed in a manner that offends many Maori. Generations of Pākehā researchers have conducted their research within Western scientific perspectives, a positioning that is considered culturally inadequate to produce an accurate reflection of Māori (Jahnke and Taiapa 2003). As well, the chapter explores a series of key Māori cultural concepts that Smith (1999) argues provide a Māori ethical framework to guide me as a Māori researcher. Smith's ethical guidelines have come to play a critical role in the research process, and the thesis I produce, and have contributed to me positioning myself in a stance that ensures that I remain mindful that my primary responsibility as a Māori researcher is to both the people that have taken part in this research project and the wider Māori community. As well, the methodology chapter provides the reader with practical aspects of the research process that I have taken in order to successfully gather and analyse the data. The section describes the process of developing a list of potential kaikōrero to take part in the research project, how I navigated making contact with them, and finally a description of the journey I took across much of the North Island in order to conduct face to face interviews with them. As this section will explore, the journey illuminated the manner in which the ethical framework of kaupapa Māori research guided the practical aspects of the research process and importantly provided me with a research environment that was couched in kaupapa Māori. 
Following that, Chapter Three: Compromised Māori Cultural provides an historical analysis of Māori cultural identity. This is done to provide important background context to the emergence of Māori cultural identity policies and practices throughout the agencies of the criminal justice system in New Zealand, especially the Department of Corrections. The Māori cultural practices are believed to be an important factor in reducing the high numbers of Māori in prison. This chapter shows that the history of the interaction between Māori and Pākehā has been violent and destructive, socially, politically, and culturally. Where Māori existence prior to contact with Pākehā was marked by a culture that defined us as a distinct people, what followed since contact with Pākehā has played a key role in the widespread loss of Māori cultural identity amongst Māori people. This chapter highlights key areas of Māori cultural identity: whanaungatanga, te reo Māori, self identification, and marae membership. These Māori cultural identity elements are considered important building blocks of Māori identity, and ultimately self-esteem, and form a critical component of many Māori cultural policies.

Chapter Four: Mãori Cultural Identity begins with an historical analysis in order to document the background context that initiated Māori cultural changes. It reveals that Māori cultural identity initiatives occurred in the criminal justice system as the result of the convergence of two main factors: the Māori renaissance, in which Māori fought to ensure the ongoing survival of Māori culture; and, Māori activism, where Māori fought for rights that we believe were guaranteed in the 1840 signing of the Treaty of Waitangi. The chapter progresses to show how this Māori renaissance had an impact on the introduction of a range of cultural interventions across government agencies. Within the Correctional sphere, this has included cultural assessments, focus units and therapeutic programmes. Māori cultural identity initiatives are now deeply embedded in Correctional practices.

Chapter Five: The Validity of Māori Cultural Identity opens the results of the interviews that I conducted for this thesis. It draws upon the experiences and views of the kaikōrero, and it questions the validity of the use of Māori cultural identity prison initiatives as a response to the high rates of Māori imprisonment. Validity, in the context of this thesis, relates to the application of a kaupapa Māori lens with which to investigate the use of Māori cultural identity policies and programmes in a prison 
setting. The kaikōrero indicate a range of responses. All saw that Māori cultural identity was a positive contribution to Māori personal wellbeing. Further, they saw that strengthening the Māori cultural identity status of Māori people regardless of their circumstances contributes to a positive outcome. Nonetheless, there was a note of caution among the kaikōrero that Māori cultural identity not be perceived as a panacea that will miraculously reduce the offending behaviour of Māori. On the contrary, there was almost universal accord among the kaikōrero that the cause of Māori offending was the social, political and cultural devastation that has resulted from generations of enforced marginalisation of Māori people by Pākehā throughout colonisation. Against that backdrop, the idea that Māori cultural identity loss should form the criminal justice system's fundamental response to Māori offending while the wider social environment that sees Māori continuing to scratch out a marginal existence at the socio-economic fringes of New Zealand society elicited responses of contempt.

Chapter Six: The Authenticity of Māori Cultural Identity continues the analyses from the interviews with the research participants. The chapter progresses a critical view of what impact Māori cultural identity programmes and policies are having on the high rates of Māori crime. It considers the manner and means in which cultural programmes have been implemented within prison environments. It shows that contemporary programmes provide a narrow, and highly formal, version of Māori culture that does not have resonance for many participants. Further, this chapter shows that the dominance of Western frames of knowledge has resulted in a situation in which Māori cultural programmes have not fully engaged with Māori culture. The chapter concludes by detailing the incremental changes, suggested by kaikōrero, to address these problems.

Chapter Seven: Discussion considers the findings of the research that I conducted amongst the kaikōrero, and merges the results of their stories with existent knowledge on Māori and offending. The chapter reveal the competing themes that have weaved their way through this study: historical Māori cultural identity loss and reclamation; and, contemporary forms of Māori cultural identity loss and reclamation. The chapter focuses upon the new loss of Māori cultural identity, and shows its divergence from previous historical forms of colonisation. It argues that the current losses have been 
covert, yet widespread. The chapter shows that (i) Māori cultural identity is being 'taught' within an environment of cultural myopia; (ii) Māori cultural identity has become 'frozen' through official incorporation; (iii) Māori cultural identity has been misappropriated, as a cover for psychological engagements; (iv) Māori cultural programmes have been distorted through the dominance of individualized narratives of offending; (v) the incorporation of cultural programmes, with their attendant Western frames, have hidden the social and structural disadvantages experienced by Māori; (vi) Māori have been co-opted into these processes of cultural 'attack', and (vii) Māori have been unable to transparently view how cultural identity is articulated or implemented; in short, this is a deceitful process. The overall argument is that Māori cultural identity programmes within Corrections are damaging, not just to Māori prisoners, but to prison workers, as well as to the whole basis of Māori culture. In response, the chapter concludes with suggestions on how cultural identity can be reclaimed once more.

Taken together, these chapters demonstrate that the formal implementation of Māori cultural identity programmes have not served Māori well. In conclusion, it is necessary to fully engage with the broader context regarding the status of Māori as the most marginalised population in New Zealand. In addition, we have to be honest about the nature of current Correctional practices towards Māori offending. The Correctional response that individualises Māori offending and prioritises psychological interventions is inherently flawed in focus. The kaikōrero to this thesis have shown that what is currently delivered in New Zealand's prisons does not resemble Māori culture at all. It is an ineffective and inappropriate effort that fails to reduce Māori offending and imprisonment. 


\section{CHAPTER TWO: METHODOLOGY}

\section{Introduction}

The purpose of this thesis is to explore the genealogy, theoretical basis and function of Māori cultural identity in relation to criminal justice responses to crime undertaken by Māori. With this focus in mind, the entire project draws upon kaupapa Māori methodology, which aims to ensure that the process, and importantly the outcome, of the research project is 'by Māori, about Māori and for Māori'. Given that the topic under investigation is Māori cultural identity, and that kaupapa Māori research is a Māori cultural construct, the research project is provided with an appropriate and important contextual foundation.

The research methodology has also been designed from a qualitative approach, using in-depth interviews with key kaikōrero ${ }^{6}$ who have been associated with the development of the theory, policy and practice of Māori cultural identity in the criminal justice system. This critical focus provides an opportunity for those Māori whose careers or in some cases life works have been dedicated to the development and implementation of cultural responses to crime to speak for themselves. The qualitative approach allows the thesis to more fully explore the underlying rationale and meaning of the Māori cultural identity policies and resultant programmes sprinkled throughout New Zealand's criminal justice system. In doing so, the thesis attempts to validate both the participant's views as well as the theory of Māori cultural identity as a useful response to high Māori crime rates. This is an important step as Māori cultural identity, in relation to responding to high rates of Māori crime, has been subject to almost no academic investigation.

In this sense this research project is exploratory; and the semi-structured interviews, by allowing me and the kaikōrero to digress from the interview schedule while still having access to a predetermined guide to remain focused on the overall research goal, provides an appropriate means of gathering contextual data that is needed to explore Māori cultural identity and Māori crime. By having a purposeful sample as kaikōrero, or in other words, by interviewing people who reflect the genealogical

\footnotetext{
${ }^{6}$ I have defined my use of the phrase 'kaikōrero' to describe the Maori research participants in Chapter One: Introduction.
} 
development and ongoing implementation of Māori cultural identity, the data gathered will seek to provide accurate, important and a much needed narrative to Māori cultural identity.

This is not the first time that I have drawn upon kaupapa Māori research as a methodological framework for a thesis. In my Masters thesis (Mihaere 2007), I argued that kaupapa Māori was an appropriate methodological stance for a Māori researcher undertaking a qualitative research project amongst a Māori community. I coupled kaupapa Māori with narrative research as a method to gather the data. I argued that kaupapa Māori and narrative research formed an appropriate accord as they both place a strong emphasis on community centric research, whereby the researcher represents the research community in a dominant position and presents as honest account of the participants' voices as is possible. I believed then, as I do now, that the research project was successful as a result of an appropriate use of kaupapa Māori research methodology. In developing this $\mathrm{PhD}$ research, with a focus on Māori cultural identity and drawing upon the expertise of Māori kaikōrero, I knew instinctively that I would once again gravitate towards kaupapa Māori as a research methodology to envelop the research journey.

In this chapter, I begin by more fully unpacking kaupapa Māori research methodology. This is an important beginning to the thesis proper because kaupapa Māori provides a Māori cultural foundation, and to a very real degree an ethical code, to the entire research project. An historical overview of kaupapa Māori research methodology is therefore presented that illustrates the critical origins of kaupapa Māori research methodology as a Māori response to Western researchers and the outputs they produce. As the chapter will show, these outputs have portrayed Māori in a negative manner. Generations of Pākehā researchers have conducted their research within Western scientific perspectives, a positioning that is considered culturally inadequate to produce an accurate reflection of Māori (Jahnke and Taiapa 2003). As well, the chapter explores a series of key Māori cultural concepts that Smith (1999) argues provide a Māori ethical framework to guide me as a Māori researcher. This is an important aspect of the research process, and the thesis I produce, because my stance is to remain constantly aware that my primary responsibility as a Māori researcher is to both the people that have taken part in this research project and the 
wider Māori community. It is my aim that in some way the work that I produce as a researcher is perceived as providing some positive contribution to Māori.

Following the theoretical analysis of the research methodology, the chapter then outlines a description of practical aspects of the research process that I have taken in order to successfully gather data to complete the thesis. The section describes the process of developing a list of potential kaikōrero to take part in the research project, how I navigated making contact with them, and finally a description of the journey I took across much of the North Island in order to conduct face to face interviews with them. As this section will explore, the journey illuminated the manner in which the ethical framework of kaupapa Māori research guided the practical aspects of the research process and importantly provided me with a research environment that was couched in kaupapa Māori. As a necessary start to this chapter, the following section unpacks kaupapa Māori, its history, meaning, purpose and fundamental basis.

\section{Kaupapa Māori: A Māori Cultural Foundation}

Kaupapa Māori methodology emerged as part of the Māori cultural renaissance that blossomed in the late 1970's in New Zealand and that has defined Māori social and cultural efforts in the ensuing decades. At a conceptual level, this research approach provides a good 'fit' with the focus on Māori cultural identity. However, personally, after spending thirteen years studying and teaching at a kaupapa Māori tertiary institution, it is a comfortable fit and is a natural choice of methodological stance for me to adopt in this thesis. The purpose of this section is to explore the historical genesis of kaupapa Māori research methodology, its fundamental features, purpose, theoretical framework and ethical guidelines. Finally, the section argues for the appropriateness of kaupapa Māori research as the methodological framework that encompasses and guides this research project.

\section{Overview of Kaupapa Māori Research}

For the 200 years or so of contact between Māori and Pākehā, Māori experiences of researchers and their produce have been largely negative. Māori have found ourselves serving as the focus of research by Pākehā researchers defining the research, collecting the data and then, detrimentally for Māori society and culture, analysing the research "to fit in with a Eurocentric framework" (Jahnke and Taiapa 2003:41). 
As a result, many Māori have increasingly come to view Pākehā research and its results in a negative light because it has been a colonising tool that accentuates the superiority of Pākehā knowledge (Smith 1999) at the expense of Māori knowledge (Cram 2001).

According to Smith's (1999) critical gaze, Māori society's incessant exposure to anthropologists emerging out of the 19th century's positivist school of thought with its 'mono-culturally' scientific looking glass has played a key role in maintaining Māori as a lucrative research community. Such researchers, Smith (ibid) argues, engage in research among Māori communities by framing their research within their own cultural traditions, Eurocentric values and biases, as well as an assumed belief in the superiority of their own knowledge and its fruit. Inevitably, researchers on Māori have been held responsible for nourishing notions of the racial superiority of Pākehā values, processes and knowledge and, inevitably, Māori values, processes and knowledge have been presented as inferior (Bishop 1997).

Consequently, historically, Māori have had little participation into research projects despite the fact that Māori form the central focus. Māori have traditionally been the researched community, but have had little input into research design, process or final analysis. The result, according to Te Ariki and Spoonley (1992), is that research on Māori tends towards focusing on Māori deficit. For instance, Māori are continually portrayed as having a negative status in contrast to non-Māori, and research outputs have few suggestions as to how the negative status of Māori might be improved. In this sense, research on Māori has been perceived as having little measurable benefit to Māori society. Rather, the results of research on Māori people are seen as being beneficial to non-Māori researchers who use Māori society as a springboard for the development of non-Māori researcher's educational aspirations and careers. As Stokes (1985:3) pointed out:

There is an increasing awareness in the Māori world that Māoris have been guinea pigs for academic research; that some academics have made successful careers out of being Pākehā experts on Māoris; but that some Māoris have not gained a great deal by this process. 
While a wide range of social issues have been negatively affected by non-Māori researchers 'capitalising' on Māori focused research projects, an area that is perceived as being especially problematic is in relation to Māori culture. According to Smith (1999), non-Māori researchers are responsible for making sense of Māori culture by referencing their own cultural traditions as an ethnocentric standpoint. The result is Māori finding ourselves locked within a non-Māori research vortex where Māori and Māori culture are constantly redefined in such a manner that at times we barely recognise the mass produced definitions of our own cultural heritage. In this sense, research has been and continues to be perceived by Māori as a critical element within the colonisation experience that has defined Māori existence since contact with Pākehā began. As such, Māori like many other indigenous communities around the World approach researchers and their research with cynicism (Jahnke and Taiapa 1999) and as a point of cultural conflict whereby Māori resist against Pākehā research and its fruits (Smith 1999).

Throughout the 1970's and 1980's, during a period of time in New Zealand that has been known as the Māori renaissance, many Māori voices joined in chorus under the uniting catch phrases of 'tino rangatiratanga' and 'Māori self-determination' (Durie 1998). There was an increasing Māori awareness of, and open resistance to, the ongoing and insidious nature of colonialism. While the New Zealand Wars that ravaged the landscape of New Zealand over the course of the 1840's and 1860's, together with the resultant large-scale Māori land losses, are often perceived as the defining characteristics of colonialism, the Māori lived experience over the course of time since the 1840 Treaty of Waitangi was signed has demonstrated that the negative impacts are ongoing.

It is against this backdrop that an increasing number of Māori have developed research methodologies that are considered more able to reflect a Māori world view and embody Māori aspirations for the future, and address the negative manner in which Māori perceive research (Bishop 1996; Hohepa and Smith 1992; Nepe 1991; Irwin 1994; Te Ariki and Spoonley 1992; Te Awekōtuku 1991). Sited within the halls of academia, they have been conveniently placed to engage with the subject of research at both a practical and theoretical level. The fruits of their toils have been an ever growing field of Māori who in turn began making their contribution towards 
defining and applying research from a Māori cultural perspective (Cram 2001; Irwin 1994; Jahnke and Taiapa 1999; Moewaka-Barnes 2000; Pihama 1993; Smith 1996; Smith 1999; Taki 1996).

Of particular note has been the ongoing articulation and development of a distinctly Māori research paradigm, known as kaupapa Māori research. Emerging as a result of a need by Māori academics to develop a 'Māori space' from which to engage in research from a Māori perspective (Smith 1996) as well as a challenge to non-Māori researchers' ubiquitous notions of cultural superiority (Bishop 1999), kaupapa Māori has developed into a distinctly Māori cultural research paradigm (Smith 1999). To Nepe (1991:15), it reflects the emergence of the "conceptualisation of Māori knowledge". While kaupapa Māori as a research methodology remains at an early stage of development, the phrase kaupapa Māori, including its constituent terms 'kaupapa' and 'Māori', are not.

Kaupapa is a key Māori term and has a wide variety of interrelated meanings, notably, 'plan', 'philosophy' and a 'way to proceed' (Williams 1992). The word kaupapa is composed of two core words and, according to Māori philosopher Māori Marsden, "kau means 'to appear for the first time, to come into view, to disclose'. Papa means ground or foundation” (Marsden 2003:66). Royal (2000) defines this interpretation further by stating that kau means to appear and papa is a shortened form of Papatūānuku which means ground. In his interpretation, kaupapa means 'te kau o Papatūānuku' or the ground that rises into view or the rise of fundamental values into a person's consciousness (Royal 2000:4). Kaupapa, as a Māori philosophical basis, is an important Māori concept and is essential to how Māori view the world.

\section{Kaupapa Māori and a Māori Cultural Stance}

Since its initial genesis, when kaupapa Māori emerged as an important feature in the field of New Zealand research, there have been ongoing developments that have defined and redefined the theoretical position of kaupapa Māori and importantly its practical role in analysing Māori society. At the core of this work is a focus on positioning kaupapa Māori as a theoretical foundation for Māori researchers to critically analyse the historical and contemporary power imbalances that continue to exist between Māori and Pākehā in New Zealand. In this sense kaupapa Māori is 
perceived by many Māori as an empowering stance from which Māori might engage in research (Bishop and Glynn 1999; Pihama 1993; Smith 1999):

When kaupapa Māori came to be coined_-if you want to use that term in the context of research-it didn't just come out of a nowhere space. It came out of a particular struggle over the legitimacy of our identity, and the legitimacy that we as Māori want to do things (Smith 2011:10).

With regard to the Māori cultural stance for this thesis, kaupapa Māori provides me with a fundamental basis as a Māori researcher investigating a Māori topic from a Māori perspective. As a result, the kaupapa Māori stance helps to determine: that the overall design of the research project is and remains reflective of a Māori perspective of the world; that the questions developed throughout the research project are positively responsive to what I have already shown is the disproportionate Māori representation in all spheres of the criminal justice system; that the gathering of the data is cognisant of a Māori ethical perspective on researching amongst a Māori community; that the analysis of the data is an accurate and honest representation of the kaikōrero, and importantly that the research goes beyond contributing towards the deficit picture of Māori, rather that the research makes a more positive contribution towards Māori social well-being.

\section{Kaupapa Māori Research and Ethical Boundaries}

One of the natural outcomes to emerge as a result of drawing upon kaupapa Māori methodology is the manner in which kaupapa Māori provides an ethical framework to envelop my research project. As a university student gathering data by interviewing kaikōrero this is an essential consideration that needs to be addressed at the beginning of the research project and, in order to ensure that I maintain an ethical position throughout, constantly referred back to.

Beyond the fact that I am required to meet a stringent ethical code at Victoria University of Wellington ${ }^{7}$, the fact that I am a Māori researcher who is going amongst his own people in order to conduct research demands that I act in a manner that is ethical not just as a member of the University community but also, and importantly to

\footnotetext{
${ }^{7}$ I was also granted ethical approval for this research project: VUW Ethical Approval Number 16235.
} 
me, as a Māori researcher. While there are similarities between the University's ethical code and a Māori view of ethics, there are also differences.

The Victoria University of Wellington code of ethics is focused on what Tolich and Davidson (1999:71) describe as to “do no harm”. Further, the Ethics Committee illustrate that this is an objective that is achieved by focusing on several main areas, including: voluntary participation, informed consent, and privacy. Voluntary participation means that research participants are not coerced into taking part in a research project. The participants are informed about the research project: its purpose; who is involved; the methodology used; the anticipated outcomes; and, importantly, that there is a written thesis outcome at the conclusion of the research project. Once the research participants have been supplied with a clear understanding of the research, they are then provided with an opportunity to voluntarily participate in the project and subsequently give their informed consent and are also provided with an understanding that they may elect to be identified in the final thesis, or that they may have their privacy maintained by not being identified.

While the University has actively looked over my ethical responsibilities throughout this research, adhering to Māori ethics by contrast is self administered. Nonetheless, as a Māori researcher I accept a strong sense of responsibility that I adhere to a Māori ethical code of conduct. The route to an articulated definition of kaupapa Māori ethics began when Māori academic Ngāhuia Te Awekōtuku argued that "there is an expressed need for some form of ethical framework in conducting policy-motivated research in the Māori community" (Te Awekōtuku 1991:7). While kaupapa Māori is often described in terms of being "intellectual, theoretical, and imaginative spaces" (Smith 2006:156) from which Māori might develop research, what Te Awekōtuku provided was an important shift towards outlining steps from which kaupapa Māori be engaged with in a practical sense. The three key ethical principles that she raises highlight the importance of responsibility, to the group of people who form the focus of the research, to the wider Māori community and to the funding body (Te Awekōtuku 1991:17). Subsequently, a list of seven ethical principles for Māori researchers that Smith (1999:120) argued emerge from a Māori world view have come to form the ethical foundation of research involving Māori (Pihama and 
Penehira 2005; Pipi, Cram, Hawke, Hawke, Huriwai, Mataki, Milne, Morgan, Tuhaka and Tuuta 2004).

1. Aroha ki te Tangata;

2. He Kanohi Kitea;

3. Titiro, Whakarongo...Kōrero;

4. Manaaki ki te Tangata;

5. Kia Tūpato;

6. Kaua e Takahia te Mana o te Tangata;

7. Kia Ngākau Māhaki.

With an ethical focus that centres on the community under investigation as well as responsibilities to the wider Māori community, these principles have formed a critical component of my research. Central to this stance is the ever-present reminder of the negative experience that Māori have endured as a researched community. In order to illustrate how I strived to maintain this stance what I present in the following section, which has a focus on the actual data gathering methods that I conducted, is an analysis of how the above kaupapa Māori ethical principles formed a critical Māori framework that enveloped the research process.

\section{The Research Journey}

Throughout the following section I will outline practical aspects of the research I conducted towards this thesis. Despite the fact that these details are quite mundane, I believe they are an important aspect of the final thesis and act as a means to allow both the kaupapa Māori processes that I have used throughout the research as well as the finished written product to come under scrutiny, especially from the wider Māori community. Being held accountable to Māori is perceived as a critical aspect of kaupapa Māori research and has remained a key guiding factor as I have conducted the research: 
Accountability for our research is primarily to our relations and, as such, we engage in research that addresses real issues so as to inform and promote real solutions that will facilitate Māori wellness (Lawton, Cram, Makowharemahihi, Ngata, Robson, Brown and Campbell 2013:249).

Like the above authors, I too endeavour to advance Māori wellbeing. With the already mentioned negative status of Māori contact with the criminal justice system in New Zealand as a driving force, it is important to me that my work is seen as adhering to kaupapa Māori principles in practice as well as in theory.

\section{Interviewees in a Professional Capacity}

Initially, this research project began with a focus on exploring the relationship between Māori cultural identity and desistance from crime. To do this I had intended interviewing Māori people who had been involved in the design and delivery of Māori cultural identity initiatives in order to investigate the theory of Māori cultural identity and how it might initiate desistance from crime. As well, I had intended interviewing Māori ex-prisoners who had taken part in Māori cultural identity programmes in prison in order to then test the degree to which the theory underlying the Māori cultural identity developments was reflected in practice.

However, the further into the project that I delved the more aware I became that there is a limited degree of literature that unpacks the inherent meaning and underlying theory on Māori cultural identity as a response to Māori offending and imprisonment. I began to see that focusing my research on the relationship between Māori cultural identity and desistance from crime was premature. Rather than investigate the degree that Māori cultural identity might influence Māori desistance from reoffending, I needed to take a step back and focus my research gaze towards a more critical gap in the knowledge, to clearly articulate how and why Māori cultural identity practices developed in the criminal justice system, what Māori cultural identity means in relation to criminal justice, and importantly why there is such a strongly held view that Māori cultural identity might have an important role in reducing the disproportionate rates of Māori offending and imprisonment.

Therefore I decided to confine my data collection to Māori people who had been involved in the historical development and practice of Māori cultural identity policies 
and programmes in the criminal justice system, especially the prison system. I also decided that interviewing ex-prisoners could form the focus of further research following the $\mathrm{PhD}$ research project.

\section{Negotiating the Field}

I began this stage of the research by maintaining a list of anyone whose name I struck, either within the dearth of literature on the subject of Māori cultural identity and the criminal justice system, or in many instances by recording the names of those who may have been mentioned to me as a person of interest during one of the myriad of conversations with friends and colleagues on the subject of 'what I was doing'. As well, the principal criteria for the process of developing a list of potential kaikōrero was based upon a key factor, the primary purpose of this thesis is the articulation of a Māori view on the way in which the agencies of the criminal justice system, notably the Department of Corrections, have adopted Māori cultural identity as a response to high rates of Māori offending and imprisonment, therefore all of the kaikōrero are Māori.

Once the list contained approximately 100 people, I started to put some semblance of order to them: who they were; their pepehā; their contact details and their work histories (did they work for the Government, were they non-Governmental officials, were they working in prisons, did they deliver tikanga Māori programmes on marae, were they programme developers, or advocates of the idea of Māori cultural identity, was I able to find contact details for them and so on). This process was in a constant state of revision until I became relatively satisfied with the end product. As well, this process occupied much more of my time than I had anticipated. However, the result of my efforts became a very valuable resource, and ultimately provided a pivotal role in how the entire research project evolved over time.

Simultaneously, I began to develop an interview schedule to be used throughout the interviews themselves. Similar to the list of kaikōrero, the interview schedule was also constantly reworked. As my reading revealed gaps in the research on how Māori cultural identity policies and programmes were being utilised by the criminal justice system agencies in response to high rates of Māori crime and imprisonment, I 
constantly reworded both the areas that I intended to cover in the interviews and the resultant questions that developed.

Once I had developed what I believed was a clear idea of how the research was proceeding I started to make contact with each of the kaikōrero in turn. The contact took a different form depending upon whether or not I personally knew the particular participant. For eight of the kaikōrero then my initial contact was informal; they knew me in both a personal and professional capacity, they knew that I was a PhD student and we had many occasions where both my work and theirs had formed the basis of conversations on this subject. For these kaikōrero an informal phone call was the contact method. I told them I would be honoured if they would be involved in my research as a participant, I described the details of the research including the key aims and that I would like to interview them based upon their understanding of Māori cultural identity and how it has found a focus in the criminal justice system. If they agreed I then sent them an email I had prepared and will describe below.

For the remainder of the kaikōrero I took a more formal approach. If I was able to find a work phone number I rang them during working hours and introduced myself, my whakapapa connections, the nature of my research project, my hope that they would be kaikōrero and so on. I was aware during these phone conversations that I was making contact in a professional capacity and that I was drawing upon their valuable time, therefore I was mindful to keep these initial descriptions brief. I would then ask if I was able to email them a more detailed description.

When I made initial contact with the respondents I was always respectful of the fact that ultimately I was going to be asking them to share their time with me, and if they agreed to do so, they would be providing me with the opportunity to draw upon and record their experiences in relation to the disproportionate rates of Māori offending and what relationship, if any, Māori cultural identity might play as a positive response. Receiving a cold call from a stranger is, probably, a situation that would elicit such a guarded response. Given that many Māori have begun to use the phrase 'the deficit theory' to describe the seemingly endless amount of research, especially research by non-Māori, where we are more often than not portrayed in a negative light, it is little wonder. 
In order to overcome this barrier and guide me in a positive manner I gravitated naturally towards what was described by Smith (1999:120) as "aroha ki te tangata" literally a respect for people. Throughout the initial contact I always started the phone call with 'tēnā koe' which is a more formal greeting than the more commonly used 'kia ora' which is more appropriate between people who are familiar with each other. From that point on, the contact maintained that stance. I named myself, my pepehā, the fact that I was a PhD student in criminology, and that I would like to speak briefly to them for about five minutes if they could spare the time. I also always said that I would be happy to ring back at a more appropriate time if they would prefer. I also finished the phone calls by asking for their email contact details in order to provide written details of the research project and as soon as the phone calls ended I sent it immediately.

The emails I sent contained three parts, a cover letter, an information sheet, and a consent form (see Appendices B, C, and D). The cover letter introduced myself, my pepehā, my student status, the names of my supervisors and our contact details. The cover letter also gave an overview of the research project and highlighted the key aims of the research, to critically analyse the concept of Māori cultural identity as well as the institutionalisation of Māori cultural identity in the criminal justice system; and, to provide a critical narrative space for Māori, who have been at the 'rock face' of Māori cultural identity policies and programmes, an opportunity to articulate their conceptualisation of Māori cultural identity in relation to responding to Māori offending and imprisonment.

Before sending each email I reworded each cover letter to personalise it by briefly describing how the particular participant had contributed to the area of Māori cultural identity and crime, and how I believed their participation would be helpful to me and the research itself. I explained that I was taking a kaupapa Māori methodology and again asked for their participation as an interviewee towards a thesis.

\section{Research Wānanga}

Beyond my encounters with kaikōrero in this research, I have been fortunate to have been provided with uncountable opportunities to deeply engage with people who have also showed a genuine interest in my research, and who often showed great concern 
about the proportion of Māori, especially Māori men, who are in prison. This became apparent when I was invited to have hui at different venues, notably Ora Toa Mauriora ki Porirua, Te Hurunui-o-Rangi Marae, Tūkorehe Marae, Te Puke Marae, Te Hika-o-Papauma Marae, and Te Wānanga-o-Raukawa, where after I presented an outline of my research these occasions then turned into wānanga that had an in-depth focus on my research. On each marae visit, that involved between 20 and 50 people, I was welcomed on to the marae with a formal pōwhiri, and on one occasion there was a wero. I have been immensely humbled and honoured with the contribution of so many people to my research, especially because none of these wānanga were directly instigated by me. Rather, they were a response by the wider Māori community towards what is clearly an area of immense social concern, as well as, I believe, a statement of confidence in my contribution in this area.

\section{Meeting Face to Face}

The phrase "he kanohi kitea” (Smith 1999:120) literally means 'the face seen' however it is the value of researchers and their participants meeting in a face to face context that is implied in the meaning. The belief that Māori communities prefer to take part in research projects that are designed with face-to-face interviews or focus groups in mind rather than survey based methodologies is widely held "to be the most compatible with Māori tikanga" (James 2000:8), as a result Māori focused research is increasingly being designed with this thought at the methodological forefront. As a major focus of this research project is to articulate a Māori perspective on Māori cultural identity in relation to crime, I have remained cognisant that it is important for me to get out amongst the Māori community that have been involved in this area and meet face to face. In doing so, I have also been mindful that it is important to gather as wide a representation of iwi across New Zealand as possible.

With this in mind the interview process included travelling across the entire North Island of New Zealand. I began the data gathering by interviewing people in and around the greater Wellington, Wairarapa and Kāpiti areas (in the lower North Island). In a very real sense, this part of the interview process was a test run, and I spent a lot of time reworking my interview schedule in order to be sure I 'got it right'. Despite the fact that I ultimately never held the interview schedule in my hands for any of the interviews towards this $\mathrm{PhD}$, I did have recourse to it before each interview 
in order to be clear about what I was asking each of the kaikōrero and why I was asking it.

Once I had completed the interviews in the lower North Island, I began to make arrangements to travel further afield. Due mainly to a lack of funds, this was a very difficult period of the data gathering process. Despite the fact that I had secured the agreement of the kaikōrero to take part in the research project, I had not made a definite date or time with any of them. I still had no idea how I was going to get around the breadth of the North Island to the interviews, and certainly no idea at all when I might try to do so. I spent a lot longer than I intended trying to work my way through this dilemma.

My solution was to buy a four wheel drive, strip it out of all the seats except for the driver's seat and convert the remaining space into a liveable motor home, albeit a very small one. This became known affectionately as 'the truck', and served two main purposes: firstly I was provided with the means to actually travel to each of the interviews at my own pace at low cost and simultaneously I was provided with a mobile home that provided relatively cheap living quarters; the truck also allowed me to move out of my actual flatting arrangements, put my household belongings in storage, channel my living costs which were the majority of my income and utilise them as travel costs for the research project instead. In other words, I began living in the truck from this point on.

Before my departure on my hīkoi, I used a valuable month or so to find out whether I could actually survive in this manner for an indeterminate length of time. Throughout this period of discovery I determined that I could not, under any circumstances, sleep on a paper thin blow-up camping mattress directly on top of an uneven metal car floor. So I built a bed down the length of the passenger's side, bought a mattress and made it fit. With a sheepskin underlay, feather down mattress and couple of pillows, this made the nights just that little more bearable.

Importantly, I also found out that I did not like waking up in the morning to have commuters walking to work, looking in and watching me struggle to emerge from sleep. So I tinted the windows as dark as I was legally allowed and hung black curtains up so I could not be seen inside at all if I chose. As well, I built cupboards 
that allowed me to store clothes, food, books, cutlery and crockery and so on. I determined what I had to have to survive compared to what I didn't really need, and I also sorted out my life's essentials, how to charge my phone, iPod, and computer and how to read at night without flattening my battery. Once these, and so many other details were sorted, I left Wellington and headed to my first interview on my hîkoi which was in Hastings. My only problem at this point was the fact that I had calculated that I had enough money to get me to Bay of Plenty via the East Cape.

I travelled over the Rimutaka ranges, through the Wairarapa and began interviewing in Hastings and Napier, then up the East Coast to Gisborne and two more interviews, then around the East Cape to Whakatāne and Tāneatua and more interviews, across to Rotorua for more, up to Tauranga for another. It was here that my money finally ran out. I decided to call in to family there and have a few days of pampering and time to think about the problem and try not to worry. Unbelievably, I was only there for about three hours and I received a phone call from my former-employer to ask if I would be available, at short notice, to deliver part of a year one degree course the following weekend in Kaikohe. They would pay me for the delivery and, importantly for my research project, my travel from Tauranga to Kaikohe return, as well as accommodation in Kaikohe. Some mysterious force seemed to be at work.

From Tauranga I drove to Auckland to conduct three more interviews, then a big drive to Kaikohe for the delivery of classes that were now financing my hîkoi and a few days welcome rest in a Motor Lodge. Then, I travelled up to the tip of the North Island to Te Hāpua, back down to Kaitāia, then Whāngarei, and Auckland again, Hamilton, back to Rotorua, then home for interviews in Palmerston North and Wellington. Later I went up to the West Coast, stopping at Taranaki, Hāwera and Whanganui.

While I may have described this as quite a hectic time, it was at times far from it. As I was not able to make definite date and time arrangements with the kaikōrero, I spent a lot of time at different places waiting for interviews. Sometimes this waiting took a day or two. On a few occasions this took a week or more. The result was that despite the fact that the majority of the interviews were conducted throughout the course of the hîkoi, this was over a period of close to five months. I enjoyed this adventure immensely. 


\section{The Trip 'Down South'}

Initially I had planned to follow North Island based interviews by venturing to the South Island. There have been a number of Māori cultural identity initiatives that have been clustered around Christchurch's prisons such as the Mauri Hauora programme designed and delivered by Te Hata Ohlson (Department of Corrections 2002). I had included South Island based participants in my phone calling potential research participants phase of the research project and had received a positive response from those that I spoke too and had made plans to be arriving in the South Island in mid 2011.

However, these plans were curtailed when on 22 February 2011 Christchurch experienced a catastrophic earthquake that led to the loss of 185 lives, the central city defined as a public exclusion zone of as a result of large scale damage, the outlying suburbs experiencing widespread liquefaction, essential services almost non-existent over the months that followed, and the New Zealand Government declaring a national State of Emergency. As a result of this crisis, I decided that expecting people in the South Island to take part in interviews towards my $\mathrm{PhD}$ was inappropriate so I curtailed my South Island plans and worked with the data that I had already collected.

\section{On the Road with Kaupapa Māori}

Throughout the entire interview process I became struck by the degree of generosity that the kaikōrero extended to me. There were many occasions when I was offered quite lavish expressions of hospitality in the form of invitations to eat either in wharekai when interviewing at marae, in restaurants where I was forbidden to try and reach for the bill, in office dining areas, and in people's homes amongst whānau and friends of the kaikōrero. I was also repeatedly given very generous offers of accommodation with people in their own homes. Acts of generosity were repeatedly extended to me that at times left me overwhelmed with appreciation and humility. As a particular interview was drawing to a close I noticed the kaikōrero that I was talking to reach into his back pocket and pull out his wallet, rifle around inside it, and withdraw what seemed like all of the notes inside. I knew exactly what was about to occur and as we stood to shake hands, hongi, and say goodbye, a handful of notes was pressed into the palm of my hand. My pleas of “no, no, please no, I've asked so much of your time already; I can't accept such a lavish kindness” made little difference to 
the outcome. Once I had received a resolute "no Riki, you are taking it. This is in support of this important kaupapa and to ensure you're able to complete it”, I knew I was leaving with that money. Without ever mentioning this to any other kaikōrero, this was repeated on more than one occasion.

The term 'generosity' seems inadequate for me to describe these occurrences. While the giving of koha or money to help with the gathering of data towards this research project cannot be said to be a distinctly Māori act, in the context of me as a Māori researcher researching Māori cultural identity amongst my own people, the Māori cultural concept of "manaaki ki te tangata" (Smith 1999:120) seems infinitely more appropriate.

Manaaki is a very important concept in Māori society. The term is constructed from two words 'mana' and 'aki'. The first of these, the key word 'mana', is notoriously difficult to translate as there is no English language equivalent. Essentially mana is an intangible spiritual quality that has been described by Royal as:

...the heart of Māori, indeed human, health and wellbeing - the degree to which we feel empowered, illuminated and warm about ourselves and life around us. (Royal 2006:2)

The term 'aki' simply means to rise or elevate, therefore manaaki means to elevate mana or to empower people by elevating their mana. In the context of research therefore, the phrase manaaki ki te tangata demands that researchers act in a manner whereby the research community and their contribution are treated in a mana enhancing and generous manner. The context of kaikōrero forcing a gift of money upon me in order to contribute towards me completing my research project is an example of the reciprocal manner in which manaaki ki te tangata can be seen.

"Titiro, whakarongo and kōrero" (Smith 1999:120) literally means, look, listen, speak. Used in the context of a guide towards positive research amongst Māori, the terms advocate that researchers engaging with Māori communities do just that: engage. Research with Māori should be more akin to a collaboration between the researcher and the wider Māori community. In this sense research becomes an environment where relationships between the researcher and the researched are developed, or strengthened. The result is a research environment where the interview 
process becomes a: "relational activity that encourages others to listen, to share and to empathize” (Riessman 2002:2). It is a process where the emergent relationship between researcher and the researched is one that is based upon integrity and trust whereby the participants feel valued and validated throughout the research. Ultimately, this results in interviews in which participants' stories are developed organically, with little prompting from the researcher. These are interviews that are pockmarked with laughter or tears, and sometimes anecdotal stories that have seemingly little to do with the actual research topic. All of this builds towards the gathering of data that is rich with personal relevance and meaning.

\section{After The Interviews}

\section{Digital Recordings and the Transcription Process}

All of the interviews were recorded, with digital equipment that I purchased specifically for this research project. This allowed plenty of flexibility to be able to send MP3 recordings via the internet to a transcriber, with the knowledge that its format was easily accessible. As well, I was able to upload the interviews to my iPod and begin to audibly immerse myself in the interviews prior to analysing the data in hard copy.

I decided quite early into the research project that I would not attempt to transcribe the interviews. From a theoretical perspective I acknowledge the value of a researcher, especially a trainee researcher, transcribing qualitative interviews (Lucas 2010). The opportunity to immerse myself in the wealth of information that I anticipated gathering after talking to key informants might only expose itself throughout a systematic verbatim transcription of the interviews. Between 2005 and 2007, I had transcribed qualitative interviews towards my MA and had found the process a valuable and rewarding exercise. However, I only interviewed ten people for that research project, and as a person who types with two fingers at a laboriously slow pace it took me an extremely long time to complete ten transcripts. The idea that I might replicate that painstaking process with many more interviews was a daunting thought. As a result I applied for, and thankfully negotiated, a Victoria University of Wellington Faculty of Humanities and Social Sciences Research Grant that enabled me to pay for professional transcription of 29 of the completed interviews. 


\section{Transcribing Māori Language Interviews}

Given the kaikōrero (a Māori researcher interviewing key Māori workers) and the subject (of their experiences of Māori cultural identity and responses to crime), organising a transcriber was not a straight forward matter. While the interviews were mainly conducted in English there was a lot of te reo Māori spoken in all of the interviews. At the least there were occasional Māori words spread throughout the interviews, occasionally though some of the kaikōrero spoke quite large passages in Māori. This resulted in difficulties in finding someone who could transcribe interview recordings that contained a large degree of both English and Māori languages. This was not an easy task. While I do not imagine my search for a Māori transcriber was comprehensive, I struggled to find a Māori speaking transcriber at all. What I did secure was a well priced non-Māori transcriber who came highly recommended and with an impressive list of completed Māori research projects that she had already transcribed. Nonetheless, something that became evident throughout the process of checking through the completed professional transcriptions was the regularity with which the transcriber was unable to understand what was said in the audio recordings.

As a result I spent a large amount of time comparing the completed transcripts against the audio recordings in order to make absolutely sure that what was said in the interview matched what was written on paper. This was to me one of the most important elements of the entire data gathering exercise, given the importance I ascribed to the voices of the kaikōrero. The thought that I might misrepresent any of the words that the kaikōrero had entrusted to me is abhorrent. It would not matter if the fault was a misinterpretation by a professional transcriber, ultimately the responsibility to ensure the accuracy of the completed transcripts rests with me as the principal researcher. Kaupapa Māori research methodology with its inherent ethical guidelines both guides and binds me to this aspect of the research process.

Because of the degree of focus that I placed on checking the accuracy of the transcripts it became evident to me that, at times, Māori people speaking in English have a particular way of almost rolling whole phrases together quite quickly - so much so that phrases containing five or six words can sound as one or two syllables which resulted in passages almost sounding as a mumble. Interestingly, I do not remember having any difficulty understanding the kaikōrero during the interviews, 
and I certainly had no trouble deciphering what was said in the audio recordings themselves. Yet, this was clearly a problem for the transcriber.

For example, when transcribing one of the audio recordings the transcriber wrote, “....and you can say oh because the law says its he'll go ah you know. If we say because our tikanga says whare tapu the whare tapu or ngā wahi patu and gee whiz you know and all of a sudden...”. This was quite different to what was actually said which was “.... and you can say 'oh because the law says it' and he'll go 'oh faar' you, you know. But if we say 'bro because our tikanga says whare tapu, te whare tapu o ngā wāhine da da da kaua e patu he mea' and gee whiz you know and all of a sudden...”.

The previous passage, despite being relatively short, illustrates how transcriptions can have a profound effect on the overall meaning of an interaction and reinforces the imperative of ensuring accuracy at transcription. What the transcriber wrote was "Imagine no wonder we're fucking this country if those fellows...", whereas what was actually recorded was "Imagine the amount of money we would be saving as a country if those fellows...”.

Beyond the importance of checking the transcripts against the audio recordings in order to check for accuracy, repeatedly listening to the audio while simultaneously reading through the completed transcripts was a very valuable process. Doing this allowed me to be repeatedly and intimately immersed in the interviews again which was a very valuable process in its own right.

\section{Analysing the Data}

This was not the first time that I have analysed qualitative data. I had previously analysed the results of semi-structured interviews on the subject of Māori cultural identity and Māori offending that I had conducted among ten Māori men who had at some point been offenders and gang members. In that instance I had worked through the data systematically, by copying and pasting the responses according to the questions that I had asked and then clustering the responses accordingly. I then immersed myself in the data again and used two central themes, convergence and divergence to make sense of the results. I had been guided more by my instinct with the data rather than any systemic qualitative data analysis method. 
With this project though, much larger in scale, I knew that relying on instincts alone would not place me in a strong enough position to analyse data that resulted from the interviews. I began the task of sifting my way through texts on the subject of qualitative research, which is a very broad subject. I finally decided that the specific task that I was reading for was a thematic approach to data analysis, and I then focused my attention from the theoretical basis of qualitative research towards the actual method of data analysis, finally settling on a text to provide a systematic method to the task before me.

Auerbach and Silverstein's (2003) three step tiered approach to the coding of qualitative data takes a ground-up approach to theory development, known as 'grounded theory' (Strauss and Corbin 2008). The basis of their process of generating theory from data advances from a perspective of theory as "a description of a pattern that you find in the data" (Auerbach and Silverstein 2003:31). From there, the first stage of analysing the data begins with immersion in the transcripts of the interviews highlighting relevant text that they state is "related to your specific research concerns” (ibid:37). In the context of this research project, relevant text is anything that the kaikōrero said in interview that relates to Māori cultural identity and its application within the criminal justice system. Once the relevant text was highlighted, and the remainder had been discarded as not essential to this project, I began to cluster any words or phrases that kaikōrero used to "express the same idea. These ideas are called repeating ideas, and they shed light on our research concerns" (ibid:37). After spending a lot of time reworking the relevant texts into groupings that looked similar I ended up with thirty-one repeating ideas which I subsequently clustered together into Auerbach and Silverstein's final tier in their method of data analysis, themes.

At that point in the data analysis I went through a process of rereading, thinking about, and rereading the subsequent themes, immersing myself again in the data. By drawing upon what I had previously researched through the literature on Māori cultural identity, critically bearing in mind the gaps in the research, I developed the themes into two main narratives that form the focus of the two key findings chapters in the thesis, validity and authenticity. By validity I mean, 'how valid is the idea of Māori cultural identity in responding to high rates of Māori offending and 
imprisonment?', and by authenticity I mean 'how authentic are the subsequent policies and programmes that have come to pockmark the criminal justice system's responses?'. These two narrative constructs, validity and authenticity, will be unpacked further in later chapters.

An issue that would be appropriate to raise here is the use of a grounded research data analysis tool alongside kaupapa Māori research. A key point is that kaupapa Māori is a research framework that proceeds from a Māori centric world-view, it is not a research method with a prescribed method of accessing data. Given that there has been no critical theoretical development of Māori cultural identity in relation to responding to high rates of Māori offending and imprisonment, a method of data analysis that will provide me with the tools to contribute towards theoretical development in this area is critically important. Grounded research, as a research methodology that allows the data itself to develop theoretical narratives, finds an accord with kaupapa Māori. When Waitere-Ang (1999) argued towards the appropriate use of grounded research finding an accord with Māori centred research she believed that:

...for groups 'othered' by previous research, it [grounded research] potentially provides a slate cleansed of ideological and theoretical constructs that have traditionally framed understandings of self as other. It thus, theoretically, then allows an understanding of self to emerge.... It was seen as a positional space in which Māori theoretical positions could develop (Waitere-Ang 1999:11).

I have already described the list of ethical principles that Smith (1999:120) argues emerge from a Māori world view. Her list included, but is not confined to, concepts such as being face to face and engaging by listening and talking. Grounded theory, by placing such a critical emphasis on building theory from the data, or in the case with this thesis the interviews with key kaikōrero, is in line with these principles.

Finally in regards to data analysis, as I worked through the transcripts I took out all the 'um', 'aaah' and so on. There were a lot of them and they seemed to clutter the script. While I agree with the idea of allowing kaikōrero voices to be heard organically, I think in this instance I made the right choice in omitting them from the final write up. I have also been discerning with the interviews and the material that I 
won't put in to the final output; for instance, many of the kaikōrero would draw upon their own experiences, or whānau, or friends and use them as a practical examples to make a point. Any material of this nature I omitted from the final thesis. While I might draw upon that material myself in order to more fully understand the points they were making and the context of their stories, I believe that personal details of that nature are too private to include here.

\section{The Identification of Respondents in the Final Report}

All of the kaikōrero that I interviewed signed a consent form agreeing to be identified by name in the completed thesis. This was a welcome outcome. I believe that this was in part because the kaikōrero supported my assertion that a thesis uniting the collective voices of key people involved in this area would provide much needed credibility to both the idea of Māori cultural identity in the area of criminal justice as well as to the completed thesis itself. The question of why all of the kaikōrero, many of whom hold quite important positions in New Zealand society, would sign a consent form enabling me to identify them in the completed research output was never raised directly throughout the interviews. While I was always pleased that I did get consent to identify them, once the consent form was signed it was put aside as a preliminary formality and we then quite quickly moved onto the interview proper.

Nonetheless, a critical point that I have increasingly struggled with is the degree of responsibility that I accept towards the recorded and transcribed responses that the kaikōrero had given as a result of the interviews. I have always maintained that I would treat the data that I gathered with the utmost respect. My primary concern now is that I present the findings in as honest and accurate manner as I am able: that the quotes that I choose, and the words I use to weave the findings into coherent findings chapters, are an accurate reflection of the meanings that the kaikōrero asserted during the interviews as well as the context within which they were spoken. This leaves me in a position whereby I am compelled to ensure that I act with "moral integrity" (Ragin and Amoroso 2011:59) towards both the kaikōrero and their responses. The kaupapa Māori research methodology ethical standard of "kia tūpato" (Smith 1999:120), which literally means 'to be careful', demands this of me. 
With that cautionary note in mind I have decided that I will not ascribe any quotes from the kaikōrero in script that would identify them personally. In other words, I have decided to attribute each direct quote that I use in the body of the findings chapters by attributing the phrase 'kaikōrero' in footnote to indicate that the text is a quote resulting from the recorded interview with a kaikōrero. I will, though, name each of the people, and groups, who so willingly gave me their time and manaakitanga in Appendix 1: Ko Ngā Kaikōrero. At the heart of this decision was the responsibility that I felt to act with moral integrity towards them all. While they may have given their permission for me to identify them personally, I am also acutely aware that some, if not all, of them have careers in this area. These are my people and the thought that I might, even inadvertently, have a negative impact on any of their careers or, that I trample their mana is abhorrent to me as a Māori researcher. Mana is arguably one of the most important of Māori cultural concepts, and has been argued that the:

...greatest challenge facing 'Māori development' concerns the restoration and the fostering of an experience of mana [sic] in the lives of individual Māori and the Māori community as a whole. It is mana that lies at the heart of Māori, indeed human, health and wellbeing - the degree to which we feel empowered, illuminated and warm about ourselves and life around us (Royal 2006:2).

As a consequence, remaining mindful that any words that I ascribe to each of the people who took part in this project could trample their mana is at the forefront of my mind at this stage of the research, the final write up of the completed thesis. This is what Linda Tuhiwai Smith meant when she argued that researchers conducting research among Māori communities need to be alert that they do not trample the mana of people or as she worded it "kaua e takahia te mana o te tangata” (1999:120).

\section{Conclusion}

This chapter has analysed both the methodological framework that envelops this research project as well as the methods that were employed in order to gather and disseminate data from interviews conducted with key Māori people involved with 
Māori cultural identity throughout areas of the criminal justice system. The key focus of the chapter though has been the argument towards a Māori research methodology.

When I think about kaupapa Māori research, I see it really simply: it’s a plan; it's a programme; it's an approach; it's a way of being; it's a way of knowing; it's a way of seeing; it's a way of making meaning; it's a way of being Māori; it's a way of thinking; it's a thought process; it's a practice; it's a set of things you want to do. It is a kaupapa and that's why I think it is bigger than a methodology (Smith 2011).

This statement by Māori academic Linda Tuhiwai Smith encapsulates succinctly how I view kaupapa Māori, and more importantly, the manner in which I perceive that kaupapa Māori wraps around the entire research project that finds its fruition in this thesis. Like her, I see kaupapa Māori 'really simply'. Despite the fact that I have endeavoured to fully illustrate the kaupapa Māori methodology that has been adopted to frame this thesis, to me kaupapa Māori is more akin to a Māori lifestyle. I strive to approach life, with all of its implied intricacies, in a manner that is consistent with kaupapa Māori. This is, I am sure, the result of spending twelve years both studying and working at Te Wānanga-o-Raukawa, a kaupapa Māori based tertiary institution.

At a 2011 conference on the challenges of kaupapa Māori in the 21st Century, a former colleague Ani Mikaere presented a keynote speech in which she described her experience as a lecturer at Te Wānanga-o-Raukawa and how the community there:

...rarely, if ever, talk about kaupapa Māori research. Our work there is motivated primarily by a desire to re-search (re-investigate, reacquaint ourselves with) kaupapa as a means of contributing to the long-term survival of Māori, as Māori (Mikaere 2011:29).

I too have been struck by how little engagement we at Te Wānanga-o-Raukawa had with kaupapa Māori research methodology. This is despite the fact that we considered ourselves a kaupapa Māori tertiary institution. This belief stretched to the articulation and ongoing development of what have become known as the 'Guiding Kaupapa of Te Wānanga-o-Raukawa; a ten step prescription of how we as a kaupapa Māori institution draw upon a Māori philosophical view of the world in order to provide 
direction and surety in our everyday lives (Winiata P 2002; Winiata W 2002). It is like a Māori values compass.

A distinguishing feature of our experience at Te Wānanga-o-Raukawa was that it was an environment that was defined by kaupapa Māori, we were not in an environment stifled on a daily basis by the belief systems of Western academia. As such we never adopted a critical stance whereby we felt pressured to prove the validity of a Māori world view. A Māori world view was the norm and Western academia was the outsider. The result was that when we engaged in research it was a normal activity to be 'doing' Māori research. We were guided organically by ethical boundaries that were based upon kaupapa Māori ideals. We just 'did' research.

When I began post-graduate studies at Victoria University of Wellington though my view on the subject of kaupapa Māori research changed. Within the university confines I found that I was expected to articulate the methodological foundations to any research that I was engaged in. This led to me gravitating easily towards a research methodology that I felt most akin too, kaupapa Māori. This chapter has argued kaupapa Māori research methodology provides me with three distinct, and important, dimensions in this research project.

Firstly, kaupapa Māori supplies me with Māori cultural stance from which to proceed. I am drawing upon kaupapa Māori in order to ground me in a Māori world view in order to critically analyse the historical development and subsequent application of Māori cultural identity policies and programmes in the criminal justice system from a Māori perspective. Kaupapa Māori provides me with an opportunity to produce research that is by Māori, about Māori and for Māori. Kaupapa Māori is where I am coming from.

Secondly, drawing upon kaupapa Māori has provided me with a series of ethical boundaries that has both encompassed the entire research project and guided my actions throughout. This is an important point. The genesis of kaupapa Māori research methodology emerged amongst a historical backdrop of research conducted among Māori communities that is replete with questionable ethical standards. Further, that research among Māori communities has repeatedly come under fierce critical analysis because "Western researchers and intellectuals can assume to know all that it is 
possible to know of us, on the basis of their brief encounters with some of us" (Smith 1999:1). What kaupapa Māori provides me in this context is a sense that the research that I am doing among Māori needs to be grounded in ethical standards that embody Māori values.

As well, kaupapa Māori is a Māori culturally defined space that provides me with the opportunity to engage in research by following in the footsteps of my own people in an environment where I am instinctively comfortable, where I think I belong, where I am surrounded by my people's values and practices, In Māori this concept is known as whakaruruhau:

Kai taku whakaruruhau i ngā hau kino o te wā, i ngā tao tāwai, i ngā tao rangirangi, i ngā tao whakarōriki, tū mai rā $^{8}$.

By drawing upon kaupapa Māori research as a fundamental basis to the entire project, I aim to ensure that the process, and importantly the outcome, of the research project is provided with an appropriate and important contextual foundation. The qualitative approach will allow me to more fully explore the underlying rationale and meaning of the Māori cultural identity policies and resultant programmes sprinkled throughout New Zealand's criminal justice system. This is an important step in that Māori cultural identity in relation to responding to high rates of Māori crime has undergone very little in the way of academic investigation and theoretical development.

Finally this chapter has outlined the method of research analysis used to unpack 'the mountain' of data collected during the interviews and hui in the project. Drawing upon Auerbach and Silverstein’s (2003) grounded approach, I have argued towards this method as a valid means of data analysis that finds accord with kaupapa Māori research methodology. Both grounded research and kaupapa Māori share a view that the voices of the research participants are central to the academic endeavour and therefore empower both the kaikōrero and the wider Māori community.

This, Chapter Two: Methodology, is my account of the initial stages of this research project. It provides a context for the chapters that follow, beginning with the next chapter which analyses the concept of Māori cultural identity, its fundamental basis,

\footnotetext{
${ }^{8}$ My shelter from the evil winds of the time, from the taunts, from the annoyances, from the annoying criticisms, stand tall.
} 
its value to Māori people, and importantly for this thesis the many challenges that have threatened the ongoing survival of Māori cultural identity since contact with Pākehā. 


\section{CHAPTER THREE: COMPROMISED MĀORI CULTURAL IDENTITY}

\section{Introduction}

Māori are having to cope with what have become regular features in New Zealand statistics: that in comparison to all other ethnic groups Māori will experience lower rates of educational achievement, income, and home ownership, as well as higher rates of psychiatric illness, poverty, unemployment, poor health, suicide, alcohol abuse, illicit drug use, offending, imprisonment and victimisation (Alcohol Advisory Council and the Ministry of Health 2001; Benton 1988; Coupe 2005; Davies 1982; Durie 1999, 2001; Fergusson and Horwood 2000; Harpham 2012; Hill and Brosnan 1984; Justice Sector Strategy Group 2010; Statistics New Zealand 2014a; Te Puni Kōkiri 2000a; Waldegrave, King, Walker and Fitzgerald 2006).

The theories on the cause of these socio-economic disparities between Māori and Pākehā are diverse. One main theory is that, with the colonisation and subsequent urbanisation of Māori society, Māori have been subject to systemic and chronic disadvantage by a dominant European system of power. As this chapter demonstrates, since the 1840 signing of the Treaty of Waitangi, Māori have been placed at the margins of New Zealand society, and the political, economic and social system in New Zealand has, for many years, attempted to 'cleanse' Māori culture. In doing so, Māori society has suffered widespread cultural identity loss which, in turn, has resulted in generations of Māori who have little or no knowledge of Māori cultural identity. The result of this cultural confusion/loss is the socio-economic disarray that is described above.

It has been argued that those Māori who have a strong sense of Māori cultural identity are more likely to succeed in both Māori and Pākehā societies. For example, Pere states, “Taku taha Māori, my Māoriness, gives me a strong core, a force-field that can help me to stand up and do something for myself in today's world” (Pere 1979:25). Māori who can be said to have a strong sense of Māori cultural identity: experience the sense of belonging and mutual support that is found in large kin-based Māori communities; speak the Māori language; openly identify as Māori; engage with Māori society; and, have an active relationship in a marae community. Those with a strong sense of Māori cultural identity are believed to have a correspondingly strong sense of 
pride in themselves as Māori and have a high level of personal self-esteem. As a result, they are believed to be more likely to achieve educational success, gain meaningful employment, and be less likely to offend.

...Māori well-being depends not only on participation and achievement in the wider society but also participation and achievement in Māori society. Active participation in the Māori world is closely linked to a secure cultural identity. In fact the measurement of a secure cultural identity hinges around involvement with the range of institutions, activities and systems that underlie Māori society. Indicators include marae participation, involvement in Māori networks and knowledge of whakapapa (Durie 2006:9).

Conversely, those Māori who do not have an interest in kin-based Māori communities, speak the Māori language, identify as Māori, engage with Māori society or have a relationship with a marae have a Māori cultural identity that can be considered compromised or weak. It is thought that they will be less likely to be able to succeed in both Pākehā and Māori society, and subsequently more likely to feature in the negative statistics that have become embedded into the socio-economic fabric of New Zealand.

In order to address the perceived Māori cultural identity deficit, there have been many attempts to incorporate aspects of Māori cultural identity into social policies and programmes, especially in areas such as health, education and crime, from the mid1980’s onwards (Bishop and Glynn 1999; Cunningham 1997; Department of Social Welfare 1988; Durie 1998; Jackson 1988). These Māori cultural identity interventions aim to strengthen the Māori cultural identity status of Māori by increasing the pride, self esteem and well-being of Māori people (Royal Commission on Social Policy Research 1988). Similarly, Māori cultural identity policies and programmes have formed a critical focus of criminal justice responses to high rates of Māori crime.

Before detailing the growth of Māori cultural identity practices in criminal justice, this chapter will provide an historical analysis of Māori cultural identity. This is done to provide important background context, and to explain the manner in which Māori centric practices have come to form such a core focus of criminal justice policies in New Zealand. In order to do this, the chapter begins by centering on colonialism and 
urbanisation, two critical factors that have played a detrimental role in diminishing the Māori cultural status of contemporary Māori society.

Throughout this historical narrative, I will illustrate the negative role that contact with Pākehā played in reducing Māori to a state of social disarray that is reflected in the statistics noted above. This is a history that is defined by multiple generations of losses that have left Māori politically, socially and culturally marginalised. As will be shown, the resultant negative status of Māori has led to a large number of initiatives to improve Māori well-being, one of which is a focus on strengthening Māori cultural identity status.

Following that, the chapter will analyse the concept of Māori cultural identity, its defining features and fundamental values. The importance that Māori cultural identity played in traditional times as well its perceived importance today will be considered. In addition, specific elements of Māori cultural identity, whanaungatanga, te reo Māori, self identification, cultural connection, and marae membership that form the focus of the entire thesis will be outlined. These elements have been considered critical to the concept of Māori cultural identity and have been repeatedly described in the literature on Māori cultural identity, especially in regards to responding to Māori offending.

\section{Māori Cultural Identity and Colonialism}

Between 6,000 and 9,000 years ago, a people who have become known as 'Lapita' developed double-hull, deep sea sailing vessels and migrated from the west of the Pacific Ocean towards the eastern islands of the Pacific Ocean, the Cook Islands, the Society Islands and the Marquesas Islands (Biggs 1968; Green 1970; Lewis 1972). The descendants of Lapita who have subsequently settled a triangle that stretches from Hawai‘ $\mathrm{i}$ in its northernmost point to Easter Island in its most easternmost point to New Zealand in the southwest (Davidson 1984) became known as Polynesians. Māori is the name given to the Polynesian people who discovered and colonised New Zealand. Reflecting our ${ }^{9}$ Polynesian roots, therefore, the fundamental basis of Māori

\footnotetext{
${ }^{9}$ I would like to take the opportunity here to note the personal stance that I intend to adopt throughout the entire thesis. While objectivity is generally considered usual practice within academia, I intend to use subjective phrases such as 'I', 'our', 'we' or 'my' whenever the context requires it. There is a Māori view that it is not possible to achieve a real understanding of Māori people, values or culture from a purely objective position (Marsden 1992). I am a Māori researcher investigating a phenomenon that continues to have significant effect on Māori people. As I
} 
cultural identity lies in the Pacific Ocean (Biggs 1961). Over the one thousand years or so following our arrival on these shores, Māori lost contact with the rest of Polynesia and firmly established ourselves in New Zealand.

As a result, Māori lived in isolation from the rest of the World and developed a society that was based around genealogically based communities known as iwi, hapū, and whānau. This state continued for a period of about a thousand years between our arrival and the middle of the $17^{\text {th }}$ Century when contact with Pākehā started. The first Europeans to arrive included Abel Tasman in 1642 and James Cook in 1769. Their agenda was primarily exploration and, in Cook’s case, scientific. They remained long enough to acquire provisions, chart their observations and make early trade negotiations with Māori. Soon after Cook, commercial activities began to intensify with British and American sealers and whalers (Salmond 1990). By 1800, contact had become firmly established between Northern Māori and sailors coming to New Zealand harbours to take on supplies and for rest and recreation (Salmond 1997). By the 1820's, mutually beneficial commercial activities became the basis for the contact and in the 1830's permanent Pākehā residences began to dot the country's coastline (Firth 1972). Because of exposure to international trade and the advanced technologies of Europe, this was considered a period of relative prosperity and advancement for Māori (Firth 1972).

However, as the narrative of indigenous peoples the world over can attest to, contact with the Western world inevitably led to a colonial conclusion (Ferro 1997). For Māori, the beginning of a sustained period of Māori cultural loss can be said to have arrived together with Samuel Marsden and the Church Missionary Society in 1814, the Wesleyans in 1822, and the Catholics in 1838 (Elsmore 1985). Despite their primary mission being centred around the biblical teachings of Christianity, the missionaries also established the first formal schools and taught literacy as well as "carpentry, domestic management and agriculture" to a Māori student body (Walker 1990:86). While their activities seemed advantageous at the time, the missionaries have subsequently been described as the ideological "cutting edge of colonisation" (Walker 1990:86) because, as far as they were concerned, there was "seldom room for 
any cultural compromise" (Moon 2006:44). Those "aspects of Māori traditions and customs that the missionaries found distasteful were not only declared wrong, they were portrayed as an abomination to God" (ibid:44). After translating the Bible into Māori, they set about with religious fervour and began converting whole communities to their cause.

On the political front, official relations between Great Britain and New Zealand were restricted to informal cordiality (Adams 1977). While Great Britain had already embarked on a course of forcefully colonising Australia (Clarke 2003), the Crown had decided on a less aggressive approach in New Zealand. Partly in response to a Māori petition about the "drunkenness, debauchery and licentious behaviour" of British nationals (Walker 1990:86), and also to protect British trade interests and immigration intentions, James Busby was appointed as a British Resident in New Zealand in 1833 (Orange 2004). In 1834, acting outside the terms of reference defined by his colonial benefactors, Busby's first task was to organise the selection of a Māori national flag so Māori ships trading internationally would be protected according to international maritime law (Moon and Biggs 2004). A year later Busby invited Northern chiefs to sign a document known as the Declaration of Independence (see Appendix $\mathrm{H}$ ), a four article document that proclaimed New Zealand as an independent state. The Declaration's signatories, thirty four chiefs, named themselves the United Tribes of New Zealand and invited other iwi and hapū to join them as a united Māori body politic (ibid).

By 1840, there were estimated to be about 100,000 Māori, and about 2,000 permanent Pākehā settlers who resided mainly in the Bay of Islands (Belich 1986). While some Pākehā made cultural adaptations and integrated into Māori communities, their impact was limited and the country remained essentially Māori (Bentley 1999). Māori continued to exist in a traditional Māori manner, while voluntarily making major cultural adaptations as a result of contact with Pākehā (Belich 1986). However, the political events of February $6^{\text {th }} 1840$, when Captain William Hobson, a representative of Great Britain's monarch Queen Victoria, and selected Māori representatives entered into the Treaty of Waitangi (the Treaty), altered this relative accord and hastened political, social and cultural upheaval. 
Following the signing of the Treaty, New Zealand was officially considered a British colony. The Preamble of the Treaty contains specific reference to "the great number of Her Majesty's Subjects who have already settled in New Zealand and the rapid extension of Emigration both from Europe and Australia which is still in progress" (Government Printer 1976). This clause allowed for a vast change to the demographic landscape of New Zealand as, over a relatively short period of 60 years between 1840 and 1900, Māori became a sixteen to one minority (Poole 1991). Inevitably, as the number of migrants grew, so too did their insatiable hunger to acquire land.

With the ink on the Treaty barely dry, the 1841 Land Claims Ordinance "which declared land not actually occupied by Māori as 'Wasteland' and therefore the property of the Crown" (Walker 1996:68), allowed for the speedy transfer of Māori land into Pākehā hands. Whether by purchase, deception or illicit means, Pākehā quickly gained possession of the principal economic base that Māori relied on for survival. The explicit land clauses that the Treaty contained in order to protect Māori land interests had been breached, and the security that land ownership provides in an agrarian society quickly faded into memory, as Māori sustained such a degree of land loss that by 1960 only four of New Zealand's sixty-six million acres of land remained in Māori ownership (ibid:65).

Not concerned with the crippling effects of Māori land dispossession the migrant Pākehā settlers then exiled Māori politically by establishing, under the 1852 New Zealand Constitution Act, a Governmental body with voting rights that were confined to males over 21 years of age who had individual ownership of either freehold or leasehold land. Because Māori land was collectively owned in traditional Māori title, this property clause effectively crippled Māori society by denying Māori access to the machinations of political power (Walker 1990). The result was war between Māori and Pākehā.

The person credited with being responsible for quelling Māori resistance to Pākehā land grabbing and political disenfranchisement was Governor George Grey (Walker 1996). Equipped with a lethal combination of resources and brutal cunning, Grey took to his position as Governor by systematically driving his war machine throughout those parts of New Zealand that he considered a threat to Pākehā aspirations of political and economic dominance. Despite the fact that Māori resistance to Pākehā 
military frequently equalled, or bettered, Pākehā, the might of a continual stream of colonial forces arriving from Great Britain eventually saw the New Zealand Wars come to an end with Māori finally accepting defeat after the surrender of Te Kooti in 1872 (Belich 1986).

Despite a cease to hostilities, Pākehā influence remained confined to small communities primarily in the Bay of Islands, the Auckland Isthmus, New Plymouth, Wellington and Nelson areas. The rest of the country remained under Māori control and essentially operated within a Māori cultural context. However, this state was not destined to remain. Illustrating the prevailing beliefs about the interplay between Māori and Pākehā cultures, in 1856, the first Superintendent of the newly created Wellington Province Dr Isaac Featherstone made what has become a frequently quoted fatalistic reference to the anticipated status of Māori people and by extension Māori culture, "The Māoris [sic] are dying out, and nothing can save them. Our plain duty, as good compassionate colonists, is to smooth down their dying pillow. Then history will have nothing to reproach us with” (Sutherland 1940:28).

Featherstone's notion highlighted the influential role that Pākehā pedagogy played, by means of a formal education system, in forcefully acculturating Māori into Pākehā culture. In the initial stages of the abovementioned missionary schools, an English school curriculum was taught in the Māori language. During the late $19^{\text {th }}$ century, however, that practice was discontinued, "thereby speedily assimilating the Māori to the habits and usages of the European” (Barrington 1970 cited in Walker 1990:146). By 1905, all lessons were required to be in the English language and all schools were instructed to "encourage children to speak only English in school playgrounds" (ibid:147). Subsequently, a ban on the Māori language on school grounds was enforced, with the risk of corporal punishment for defaults. The result was that for decades, Māori children considered schools a place of "misery and pain" (Selby 1999:19) and instead of "education being embraced as a process of growth and development, it became an arena of cultural conflict” (Walker 1990:147).

Nationally, and despite experiencing the full impact of the great depression and the First and Second World Wars, Pākehā society began to flourish in the $20^{\text {th }}$ century (Dalley and Labrum 2000; Eldred-Grigg 1990). Urban sprawls began to pockmark New Zealand's landscape (McKinnon 1997) and newly constructed ports and 
railways were built providing a fast and efficient means of transport between them (Atkinson 2007). Reflecting both its colonial heritage and its continued Commonwealth status, New Zealand developed a political, religious and social society based on British models. Where once Māori culture was the norm against which all other cultural markers were measured, New Zealand developed a distinctly Euro-Christian culture and society. The cultural norms were diametrically reversed and Māori cultural identity began to wane.

For Māori, the late half of the 19th century heralded a period that seemed to reflect Featherston's dire prediction (Sutherland 1940). The combination of war and death from disease saw Māori numbers drop from what was estimated to be between 100,000 and 200,000 at Cook's arrival to an all time low of approximately 40,000 at the start of the $20^{\text {th }}$ century (Walker 1990). Nonetheless, Māori society continued to be distinctly Māori, with the majority of Māori living in rural, predominantly traditional, tribal areas. This meant that: the majority, if not all, Māori children grew up speaking or understanding at least some Māori language; Māori communities were still based upon traditional kin relationships; marae were the heart of Māori communities; as a body Māori people identified as Māori; and, cultural values and practices were still distinctly Māori (Waitangi Tribunal 1986). The end of the Second World War however initiated a sequence of events that was to dramatically change the face of Māori society and culture over the short period of one generation.

\section{Māori Cultural Identity and Urbanisation}

In New Zealand, ‘urban migration' and 'urbanisation' are frequently used interchangeably, yet there are distinct differences between the two terms. Urban migration reflects the movement of a generation of Māori people who were born and lived rurally to an urban environment that was geographically and socially distinct from their traditional origin (Metge 1964). The actual exodus occurred in stages, the boundaries of which were marked by the Second World War. Prior to the War, approximately eighty percent of Māori resided rurally in their traditional Māori communities. According to Bull (2001:55), "the move to the cities began in the 1920s, but was briefly postponed during the 1930s by the Depression and by Labour Government policies expanding the welfare state and land development schemes”. The rural to urban migration of Māori at this time was a relative trickle of people. 
However, over the relatively short period of two decades between 1945 and 1965, the exodus of Māori from rural to urban environs gained momentum. The result was seventy five percent of Māori now living in urban areas (McCreary 1968).

It is generally accepted that there were diverse reasons for this movement of such a large percentage of the Māori population. For many Māori there was the belief that moving increased their employment and, by extension, economic opportunities; that there would be better access to education, quality housing, health services, and so on (Walker 1999). However a voluntary pursuit of a better life was not the only reason. As Durie (1998) points out, across much of the country Pākehā had used local and national legislation to limit the ability of Māori to develop Māori land and communities. In this context, Māori had little option other than to move to urban environments that were designed for a large influx of blue collar workers. No longer able to sustain traditional work or food production practices, Māori had to become members of the paid workforce to survive.

Despite the fact that they had migrated to an urban environment, this population of Māori had grown up immersed in a Māori environment with all the cultural benefits this implies: they could understand the Māori language; had experienced the collectivism of Māori communities; and knew, and probably adhered to, Māori values and practices. As a result, this group of Māori were more likely to maintain a relationship with their traditional roots. Walker (1979:35) states that:

These people were clearly Māori. In no sense were they culturally divided and ashamed of their identity. Pākehās seldom appreciate how far migrant Māoris in the city are committed to maintaining their Māori identity. At work, at church, in their leisure activities, or in the shared social space of a housing estate they take positive steps to identify with other Māoris.

Urbanisation, in contrast, reflects the emergence of a Māori generation who were born and raised in an urban environment ${ }^{10}$. While their parents had been born into traditional rural Māori communities, the urban generation were born and raised in a Pākehā environment. It was a generation of Māori who for the first time: spoke

\footnotetext{
${ }^{10}$ Notwithstanding my argument that urban migration and urbanisation are distinct in their own right, it is important to bear in mind that chronologically both of these processes occurred between 1945 and 1965 (McCreary 1968).
} 
English as a first and often only language (Waitangi Tribunal 1986); had little, or no, contact with their traditional Māori communities (Waitangi Tribunal 1998); were no longer enveloped in the comfort of familiar kin-based relationships (Metge 1964); had little, or no, concept of Māori values and practices (Marsden 2003); and, for many, may have no longer identified as Māori (Durie, Black, Christensen, Durie, Fitzgerald, Taiapa, Tinirau and Apatū 1996). Still, this generation of urban born Māori were not completely acculturated into the dominant Pākehā culture either (O'Malley 1973). They may have spoken in the English language, gone to Pākehā schools, lived in an environment that emphasised the centrality of the individual at the expense of the community and worked alongside the rest of the New Zealand population but they struggled to adhere to Pākehā cultural values (Schwimmer 1968). As Walker (1979:38) reflected:

Urban transformation has exacted a high-price from the city-born offspring of the migrants. Without grandparents and elders the traditional teachers and minders of children in the extended family arrangement, the urban family unit is culturally cut off and disorganised. Financial commitments can strain the resources of a husband and wife to breaking point. Some resolve their difficulties by both parents going out to work. With no parents to receive them, children are left to their own devices after school. The street is their playground where they learn to become street-wise and aware of the existence of gangs. Without elders or grandparents to instruct them about things Māori, the city-born grow up in a world different from that of their migrant parents. They know they are stuck with a minority status as Māoris, but they know little or nothing about Māori values and pride in their cultural heritage.

While it was the urban migration that led to the urbanisation of Māori people, in a very real sense it was the experience of urbanisation that was to have more of a detrimental, and unforeseen, consequence upon both Māori society and Māori cultural identity. Born into urban isolation, and dislocated from Māori culture, the following generation of Māori have become colloquially known as 'the lost generation' (Department of Social Welfare 1988). They were not the same as their parents who had been able to speak and understand the Māori language, they never knew or adhered to their parent's Māori values and they never experienced the collective unity 
of their people. According to those who adhere to the compromised Māori cultural identity theory, this was also the Māori population who were at the forefront of what has become a seemingly permanent state of Māori disadvantage (Bennett 2002; Coupe 2005; Durie 2001; Maynard, Coebergh, Anstiss, Bakker and Huriwai 1999; Pere 2006; Selby 1996).

In summary, colonisation and urbanisation have had a detrimental effect on the cultural identity status of Māori society. While the individual elements of colonisation such as war, land loss, sadistic pedagogy and political disenfranchisement have been shown to be damaging to Māori in their own right, when acting in concert, they have conspired to leave Māori reeling beneath the inherited burden of inter-generational

cultural identity loss. In order to more fully understand the significance of this history in contemporary terms, what follows in the next section is an elementary description of Māori cultural identity beginning with a description of the terms 'Māori', 'culture' and 'identity'.

\section{Māori Cultural Identity}

As Māori society was organised into distinct social and political organisations along tribal lines, the emergence of the term 'Māori' to describe a national body of people did not occur until Pākehā contact in the late 1700's. Prior to that time "the word 'māori' simply meant normal or usual" (Meredith 2007:3). After Pākehā immigration intensified, it became increasingly apparent to the original inhabitants of New Zealand that not everyone else in the world was 'māori'. As a result, over time the term Māori came to signify the ethnic and cultural distinction between the original Māori inhabitants and the Pākehā who arrived on New Zealand shores.

More recently, there has been a differing range of criteria used to define who or what is a Māori. First is an approach that found both favour and legislative support in the 1950’s, a blood quantum approach (Moeke-Pickering 1996). Though largely discredited now, by this measurement Māori were defined by the percentage of 'Māori blood' that a person had. To Māori people born and educated in the 1950's and 1960's, the phrases 'half caste' and 'full blooded Māori' are very familiar terms. More recently however, identity has become a socially, "rather than biologically, constructed phenomenon” (Kukutai 2003:27). Determining ethnicity based on descent 
from a Māori ancestor is now a more common feature of contemporary censuses, surveys and research in New Zealand. As the ancestry approach mimics traditional Māori concepts, in which tribal structures and relationships are organised and maintained according to ancestral descent, it finds a certain degree of accord with Māori (Reilly 2004). Since the mid 1980's another dominant approach emerged that focuses on self-identification as a means of determining Māori ethnicity (Reid and Robson 1999). This final approach is important to the context of the following section on culture and identity because of the emphasis it places on Māori people identifying with Māori culture and the degree to which they may engage in Māori cultural activities (Durie 1998).

Culture is a fundamental part of the social world. The word culture derives from the Latin 'cultura' meaning care and cultivation (Kahler 1968). Despite its antiquated origin, culture is now widely perceived as the "customs, practices, languages, values and world views that define social groups such as those based on nationality, ethnicity, region or common interests” (Ministry of Social Development 2008:78). In this sense, culture is a social tradition communicated within and amongst groups by means of verbal and non-verbal language cues. As a result of people participating in a culture, individuals make sense of the world, they form values and beliefs, and develop an identity that reflects the culture that they experience. Because of this correlation between culture and identity, the concept of identity is often conflated with culture.

Charlesworth (2000) argues that the development of an identity begins in early childhood and continues throughout the lifetime. The development of an identity is considered an essential human need that internalises a sense of belonging and creates a foundation for individuals to build a sense of self which in turn forms the basis for an individual's resultant behaviour (Phinney 1990). Identity is the result of a combination of both self definition and external influence, achieved through an ongoing interaction with communal relationships amongst a cultural group (Weigert, Smith Teitge and Teitge 1986). Therefore, the strength of that identity will be determined by the degree to which the individual attaches and adheres to the cultural group (Tajfel 1981). In other words, the identity that an individual develops will reflect the dominant culture that the individual interacts with (Jenkins 1996). 
However, neither identity development nor developed identities are considered static, they are fluid and remain in a perpetual state of development and change (Willmott 1989). As society changes over time, so too does culture which in turn leads to individual identity change as the continual interaction between individuals and their culture is maintained (Babad, Birnbaun and Benne 1983).

Based on these explanations, the terms culture and identity when used in conjunction describe the sense of personal self-esteem that results from adhering to values and behaviours of cultural collectives. As the Ministry of Social Development (2008:78) details:

Cultural identity is an important contributor to people's wellbeing. Identifying with a particular culture makes people feel they belong and gives them a sense of security. It also provides access to social networks, which provide support and shared values and aspirations. Social networks can help to break down barriers and build a sense of trust between people - a phenomenon sometimes referred to as social capital. However, strong cultural identity expressed in the wrong way can contribute to barriers between groups. An established cultural identity has also been linked with positive outcomes in areas such as health and education.

Notwithstanding the fact that Māori society was traditionally organised into discrete genealogical collectives of varying sizes, known as iwi, hapū, and whānau, a cultural identity developed that to the rest of the world is considered distinctly Māori. Māori cultural identity was, and remains, the fundamental basis of Māori society. All aspects of Māori life, from everyday common activities through to complex philosophical explanations for the creation of the World, were bound up in, and an expression of, Māori cultural identity (see Best 1974, Buck 1955 and Makareti 1986 for a comprehensive description of traditional Māori society).

Marsden (2003:34) describes Māori cultural identity as a broad area which includes a “complex whole of beliefs/ attitudes/ values/ mores/ customs/ knowledge acquired, evolved and transmitted" by Māori society. His description, vastly broad, means that it would be beyond the scope of this thesis to describe every aspect of Māori culture. Nonetheless, Māori cultural identity is the principal focus of this research project, so 
it is critically important to provide analysis of key Māori cultural identity features. The following section presents Māori cultural elements that are considered critical to Māori cultural identity, including their key features and relevance to this study.

\section{Māori Cultural Identity: Critical Elements}

While the scope of Māori cultural identity encompasses a very broad range of factors, there have been repeated references to certain aspects of Māori cultural identity that have been linked to Māori well-being. Four of these elements are: whanaungatanga; te reo Māori; self identification; and, marae membership. These key Māori cultural identity elements have been highlighted due to their continual reference in literature on Māori cultural identity and its measurement (Barlow 1991; Borell 2005; Coupe 2005; Department of Social Welfare 1988; Durie 1993, 2006; Durie, Black, Christensen, Durie, Taiapa, Potaka, and Fitzgerald 1995; Durie, Black, Christensen, Durie, Fitzgerald, Taiapa, Tinirau and Apatu 1996; Marsden 1992, 2003; MoekePickering 1996; Pere L 2006; Pere R 1979, 1982; Reilly 2004; Thomas 1988a 1988b; Walker 1989; Winiata 1988). Importantly for this thesis, and as discussed in the next chapter, these four elements also find repeated focus in a criminal justice context (Bird 1998; Cram, Kempton and Armstrong 1998; Department of Corrections 1998, 2007a, 2007b, 2008b, 2008c, 2009, 2012a, 2012b; Durie 2003; Evaluation Associates

Ltd 2007; Jackson 1988; Kāhui Tautoko Consulting Ltd 2007, 2009; MFarlaneNathan 1999; Maynard, Coebergh, Anstiss, Bakker and Huriwai 1999; Ministry of Justice 2001; Ministry of Justice and Te Puni Kōkiri 1998; Nathan, Wilson and Hillman 2003; Pfeifer, Buchanan and Fisher 2005; Porima and Wehipeihana 2001; Taumata-Le Cleve 1992; Thomas, Cloher, Henare and Savage 1998; Webb 2003; Wehipeihana and Porima and Spier 2003). This section explains each of these key Māori cultural identity elements in turn.

\section{Whanaungatanga}

The intangible Māori cultural concept of whanaungatanga is an all-encompassing system of familial relationships that relates "every individual in some degree with every other one, at varying degrees of remove from whānau, hapū and iwi, and linking every individual to a line of ancestors stretching back to Ranginui and Papatūānuku" (Ministry of Justice 2001:41). Whanaungatanga relates to the sense of 
belonging and mutual support that is found in large kin-based Māori communities where an emphasis is placed on the collective at the expense of the individual (Reilly 2004). The key to whanaungatanga is genealogical descent from an ancestor, as it provides the foundation upon which Māori tribal structures and relationships are organised and maintained (Barlow 1991). Whanaungatanga is considered of critical importance in understanding Māori cultural identity and has formed the focus of much research (Durie 1993; Durie, Black, Christensen, Durie, Taiapa, Potaka, and Fitzgerald 1995; Winiata 1988).

\section{Te Reo Māori}

The Māori language is also considered a fundamental feature of Māori society (Biggs 1968), an essential indication of Māori cultural identity (Durie 2005) and in a landmark 1986 Waitangi Tribunal hearing was described as the "core of our Māori culture" (Waitangi Tribunal 1986:53). Te reo Māori forms the basis of most research on Māori cultural identity (Durie 1993; Durie, Black, Christensen, Durie, Taiapa, Potaka, and Fitzgerald 1995; Thomas 1988b; Winiata 1988). With no written language, the oral transmission of knowledge, traditions, values and behaviours was the paramount means to maintain a distinct Māori cultural identity (Pere 1982). Certainly because Māori society has a number of culturally distinct concepts such as mana and tapu for which there are no cross-language literal translations (Stokes 1985), the Māori "language is not only a form of communication but it helps transmit the values and beliefs of a people” (Pere 1991:9). Further, according to Durie, Fitzgerald, Kingi, McKinley and Stevenson (2002:43), the "degree of fluency in a language often indicates how and to what degree the values and beliefs of a culture are influencing an individual”. As a result of the focus that it has received, the status of te reo Māori has changed from concerns about its possible decline (Biggs 1968) to the relative optimism that the decline has stabilised (Te Puni Kōkiri 2002).

\section{Self Identification}

The next key determinant of Māori cultural identity is self-identification, which in the context of this thesis is openly identifying oneself as Māori. As Kukutai (2003:32) argues, self-identifying in this way is not necessarily guaranteed: 
...the way the state, media and ethnic groups themselves treat people can have a profound effect on whether individuals choose to identify with a specific group. In this way, stereotypes about the desirability or undesirability of certain ethnic characteristics may act as a deterrent or inducement to affiliation.

According to Durie, Black, Christensen, Durie, Fitzgerald, Taiapa, Tinirau and Apatu (1996), self identifying as Māori is considered important to understanding Māori cultural identity. They argue that when Māori "failed to identify as Māori it was considered that a Māori cultural identity was compromised, even when there was evidence of participation in cultural institutions and knowledge of whakapapa and te reo Māori” (ibid:9). Conversely, their argument implies that when Māori do selfidentify as Māori they have a stronger sense of Māori cultural identity. In this analysis, self-identification as Māori is an identification that emerges from within, a personal choice, rather than an image that is imposed by external factors like social stereotypes or prejudices. Therefore, in a sense, self-identification is a statement of self empowerment as Māori.

\section{Marae Membership}

As the formal rituals of the marae are primarily conducted in te reo Māori, the marae is the only place left in the world where Māori language is almost an essential requirement. Because Māori are the dominant community, marae kawa prevail whenever the marae is used as a forum (Karetu 1992). As a result, the degree of membership to marae has been considered an important element in a number of research projects to determine the degree of Māori cultural identity (Durie et al 1995; Winiata 1988). The fundamental belief is that a person who plays an active part in a marae community will have a greater degree of exposure to Māori culture and that this, in turn, has a positive effect on their sense of Māori cultural identity. Conversely, limited exposure to marae communities will have a negative effect on Māori cultural identity.

\section{Compromised Māori Cultural Identity}

Drawing upon Māori cultural identity elements, such as those described above, researchers have increasingly supported the assertion that a compromised Māori 
cultural identity has a relationship with Māori social disorder. For instance, Pere's (2006:268) research on Māori mental health tested the relationship between Māori cultural identity and Māori wellbeing and found that amongst her participants "cultural identity can contribute to the recovery process". Further, she found that a limited sense of Māori cultural identity will "increase the intensity of confusion and complexity that prevails when a person develops a mental illness” (ibid:268). Joseph's (1997) research on the subject of high rates of Māori youth suicide found that "the cause of increasing numbers of Māori youth suicide could be attributed to the process of colonisation, westernisation and the breakdown of traditional structures, values and attitudes present in Māori society" (cited in Coupe 2000:58). After interviewing 250 Māori suicide attempt survivors aged between 16 and 50 who were treated at hospitals in the greater Auckland region, and a control group of 250 Māori selected at random from the same geographical area, Coupe's (2005) research examined why suicide rates among Māori are so much higher than comparable rates among Pākehā $\bar{a}^{11}$. Her research, robust and broad in scope, found that (together with poor general health, cannabis use and physical abuse) not having some form of connection with Māori culture was a key factor behind the high rates of Māori suicide and attempted suicide. Her research participants were less likely to have contact with whānau, have knowledge of their whakapapa, and were less likely to speak in the Māori language than the control group. Coupe's analysis illustrated that Māori that attempt suicide lacked both a sense of belonging to a place and a secure Māori cultural identity. Further, she reasoned that rebuilding Māori cultural connections (such as developing links with the wider Māori community) and learning the Māori language, would contribute to reducing the risk of Māori suicide.

In the area of Māori education, research has also begun to provide important empirical support to the hypothesis that Māori students who identify with a secure Māori cultural identity have higher educational goals than those Māori who are less secure in their Māori cultural identity (Durie 1998). Thomas (1988a) found that Māori children who had some knowledge of Māori culture gained higher scores on achievement tests than Māori children who had either little or no knowledge of Māori culture. The relationship between Māori cultural identity and educational success at a

\footnotetext{
${ }^{11}$ In 1999, statistics for Māori males aged between 15 and 24, showed a 34 percent higher rate of suicide than nonMāori (38.9 per 100,000 compared with 29.2), while for young Māori women, the rate is 142 per cent higher than non-Māori (17.2 per 100,000 compared with 6.6) (Coupe 2000).
} 
tertiary level has also come under investigation. Selby’s (1996) research, investigating what factors contributed to the academic success of Māori women studying at a tertiary level, identified elements of Māori cultural identity that were defined as critical to their academic success, these were: whanaungatanga based relationships; knowledge of whakapapa; and, engagement with traditional areas such as marae. Finally, Bennett's (2002) research investigated Māori cultural identity and academic achievement among 72 Māori undergraduate students at Massey University found that:

...the grade point average of Māori students who had high cultural identity scores remained relatively stable under conditions of high levels of problems and under conditions of low levels of problems. On the other hand, the grade point average of students who had low cultural identity scores was significantly lower under conditions of high, than low, levels of problems (Bennett 2002:62).

Despite the cultural losses that have been inherited by multiple generations of Māori as a result of sustained policies of cultural denigration, Māori cultural identity remains a critical element of contemporary Māori society. As this section suggests, Māori cultural identity is considered necessary to provide Māori with improved educational opportunities and protection against poor health. This implies that Māori cultural identity and Māori well-being are intrinsically linked, whereas research indicates that alienation from Māori cultural identity links have been associated with Māori susceptibility towards drug and alcohol abuse, poor health and education, mental illness and suicide.

\section{Conclusion}

This chapter has analysed the concept of Māori cultural identity and its relationship with Māori well-being in contemporary New Zealand society. The chapter began by providing a historical background of Māori people, our origins, and settlement here in New Zealand, as well as our contact with, and ultimately the colonising experience of, contact with Pākehā. As this chapter has shown, the history of the interaction between Māori and Pākehā has been violent and destructive, socially, politically, and importantly for this thesis culturally. Where Māori existence prior to contact with 
Pākehā was marked by a culture that defined us as a distinct people, what followed since contact with Pākehā has played a key role in the widespread loss of Māori cultural identity amongst Māori people. This chapter has analysed the term Māori cultural identity in general terms, highlighting key areas of Māori cultural identity: whanaungatanga, te reo Māori, self identification, and marae membership. These Māori cultural identity elements are considered important building blocks of Māori identity, and ultimately self-esteem, and form a critical component of many Māori cultural policies. This chapter has provided a necessary Māori cultural identity background to the following chapter, which builds on what has been presented here by analysing how Māori cultural identity policies and programmes formed a key focus of rehabilitative efforts in order to respond to high rates of Māori offending and imprisonment. 


\section{CHAPTER FOUR: MĀORI CULTURAL IDENTITY: THEORY AND PRACTICE}

\section{Introduction}

In Chapter One: Introduction, I highlighted that Māori are over-represented in all of New Zealand's crime statistics. According to the 2013 census (Statistics New Zealand 2014b), Māori were 15\% of the population of New Zealand, and yet in the same year were $45.3 \%$ of annual apprehensions (Statistics New Zealand 2014a) and 51\% of the prison population (Department of Corrections 2014a). This status, of Māori being the most disproportionately represented population in crime statistics, has remained steady over the last 34 years (Department of Corrections 2012c:7).

One principle assertion with regards to this status has been that the high rate of negative contact between Māori and the criminal justice system may find its origins in a relationship with a compromised Māori cultural identity. In response, criminal justice authorities have progressively focused policies and programmes towards the perceived Māori cultural related needs of Māori offenders, particularly Māori prisoners (Cunningham 1997; Department of Justice 1994; Doone 2000; Jackson 1988; M Donald 1999, 2001; Maynard, Coebergh, Anstiss, Bakker and Huriwai 1999).

Founded on the belief that offending and re-offending are attributable, at least in part, to limited access to a secure Māori cultural identity, the Department of Correction has developed programmes that introduce Māori prisoners to Māori cultural values and practices. This focus is undertaken not only to reduce rates of recidivism but also to provide more Māori culturally relevant prison environments for Māori prisoners as well as increased opportunities for successful rehabilitation (Department of Corrections 2001a, 2001b, 2001c, 2001d; Department of Justice 1994; Kāhui Tautoko Consulting 2007, 2009; $\mathrm{M}^{\mathrm{C}}$ Donald 1999; $\mathrm{M}^{\mathrm{C}}$ Farlane-Nathan 1999; Mudford 1990). The result is that New Zealand's Corrections system now contains a number of unique strategies such as: (i) a Māori Therapeutic Programme, a prison programme that combines a Māori cultural focus with psychology based cognitive development programmes (Ministry of Justice 1998); (ii) Māori Focus Units, which are 60-bed 
prison units ${ }^{12}$ established to test the effectiveness of using Māori culture as a medium in reducing Māori offending (Cram, Kempton and Armstrong 1998; Department of Corrections 1998; $\mathrm{M}^{\mathrm{C}}$ Donald 2001); and, (iii) the New Life Akoranga programme, a four day/three night residential prison programme which aims to systematically change criminal behaviour by empowering Māori prisoners with traditional Māori knowledge (Bird 1998; Wehipeihana, Porima and Spier 2003).

Regardless of the fact that there is an ever increasing list of research reports on Māori cultural identity policies and programmes (Bird 1998; Cram, Kempton and Armstrong 1998; Department of Corrections 1998, 2001a, 2001b, 2001c, 2001d, 2007a, 2007b, 2008b, 2008c, 2009; Kāhui Tautoko Consulting Ltd 2007, 2009; Makwana 2007; Marie, Fergusson and Boden 2009; Maynard, Coebergh, Anstiss, Bakker and Huriwai 1999; Mudford 1990; Oliver, Porima and Akroyd 2008; Porima and Wehipeihana 2001; Wehipeihana, Porima and Spier 2003) there remains a dearth of clearly articulated descriptions of how, why or even if Māori cultural identity has a positive effect on reducing Māori offending and imprisonment. With this in mind, this chapter focuses on the Māori cultural developments in the criminal justice system in response to the disproportionate degree of negative contact with Māori. It will analyse the rise of Māori cultural initiatives that have occurred as well as the Department of Corrections' usage of Māori cultural identity as a fundamental element in responding to Māori imprisonment rates.

The chapter will begin with, importantly, a historical analysis in order to document the background context that initiated Māori cultural changes. As the section will reveal, Māori cultural identity initiatives occurred in the criminal justice system as the result of the convergence of two main factors: the Māori renaissance, in which Māori fought to ensure the ongoing survival of Māori culture; and, Māori activism, where Māori fought for rights that we believe were guaranteed in the 1840 signing of the Treaty of Waitangi but have been ignored by successive Governments and their policies.

\footnotetext{
${ }^{12}$ There are Māori Focus Units at Hawkes Bay, Rimutaka, Waikeria, Tongariro/Rangipō and Whanganui Prisons.
} 


\section{Māori Cultural Identity: A Response to Rising Māori Imprisonment}

Throughout the 1960's, two competing explanations began to emerge as a response to increasing Māori offending and imprisonment rates. Firstly, in 1961 a report that has become known as 'The Hunn Report' (after its writer Acting Secretary of Māori Affairs Jack Hunn) responded to what was perceived at the time as the "inordinately high incidence of law breaking by Māoris” (Hunn 1961:32). Hunn’s report, as Māori criminologist Robert Webb points out, portrays "Māori offending as a by-product of cultural maladaption to Pākehā society" (Webb 2012:73). The fundamental argument in the Hunn Report on crime is that a proportion of the newly urbanised Māori population struggled to integrate into the dominant Pākehā society. Reflecting the ideological notions of racial superiority of the time, the report is premised on the belief that European culture was superior to Māori culture, and that continued Māori survival was dependent upon Māori shedding the vestiges of Māori culture that remained following colonisation. According to Hunn, "there is at least a century of difference between the most advanced and the most retarded Māoris in their adjustment to modern life” (Hunn 1961:16).

While Hunn acknowledges the colonialism that Māori experienced, following the signing of the Treaty of Waitangi and the subsequent reshaping of the demographic landscape of New Zealand due to the mass immigration of Pākehā from the United Kingdom, what has been omitted from the report is the ubiquitous impact that resulted. In defiance of New Zealand's most enduring social fantasy, that "Māori/Pākehā relations are the best in the world" (McCreanor 1993:61), the newly urban Māori population were actually confronted with overt signs of racism whereby notices at the entrance to establishments were displayed that stated that "Māoris are not allowed" (Ausubel 1960:176), or where Māori struggled to find employment as a result of employers holding the belief that "Māoris are unreliable" (ibid:177). Despite this, Hunn argued that the rising Māori crime rates following urbanisation were attributable to Māori failing to successfully integrate into Pākehā society. It was seen that certain Māori lack a capacity to conform to Pākehā legal ideals, and that Māori failure is "due to their inability to cope in the modern world because of inherent flaws in their character or culture" (McCreanor 1993:61). In this context, with Māori being immersed in a hostile and racist environment that marginalised Māori, and barred 
entry into mainstream New Zealand society, Hunn's argument is nonsensical. Māori had no chance of coping in Hunn's 'modern world' because Pākehā did not want us in it. Māori hopes that migrating from our traditional rural roots towards the urban centres that seemed to hold so much promise for a more financially secure future were dashed by racist Pākehā practices that barred Māori from achieving positive outcomes.

Nonetheless, Hunn's argument initiated two key points relevant to the manner in which Māori offending was viewed. Firstly, Māori offending was individualised towards the western held view that an individual is held accountable for offending behaviour and the social context that may have given rise to such behaviours is left out of the analysis. Secondly, that offending behaviour was the result of Māori psychological deficiency that affects Māori ability to know or act in a manner that was considered consistent with Pākehā legal and social norms.

While Pākehā may have accepted Hunn's theory as valid and began to focus responses accordingly, Māori at that time were approaching the steadily increasing growth of Māori crime statistics in a different manner. What distinguishes the Māori approach was a fundamental difference of opinion of what had led to the negative status of Māori, the background context of Māori offending, and how to best respond in a manner that was believed to be relevant to Māori offending. The basis of this approach, which had a primary focus on the Māori cultural identity status of Māori people, was that it emerged as a part of the Māori cultural renaissance that was broadly occurring across the wider social spectrum of New Zealand at the time.

\section{Māori Culture at the Rock Face: Maranga Cultural Group}

As outlined in the previous chapter, the Māori renaissance emerged against a backdrop of concerns surrounding the ever increasing number of Māori who were struggling socially, politically, and culturally within the isolation of the urban environment. Consisting of an ever increasing number of strong Māori voices that identified issues that were detrimental to Māori wellbeing, they challenged the postcolonial status of Māori at the margins of New Zealand society and demanded change. Among these were Arapeta Awatere and Ana Tia, two people who played a 
critical role in defining future criminal justice system responses to the high numbers of Māori in prison.

Arapeta Awatere was born in 1910, and grew up immersed in a strong Māori cultural environment. In 1939, he enlisted in the army and rose to become commanding officer of the 28th Māori Battalion through to the close of World War II. Following the War, Awatere became committed to responding to the cultural isolation that was beginning to make its presence felt among the rising numbers of Māori living in the urban areas surrounding the Auckland city. In 1960, Awatere formed Maranga Cultural Group, an urban Māori cultural organisation that provided services towards the welfare of Māori as well as the wider community who were struggling financially, socially and culturally in central Auckland. Importantly for the shift towards a Māori cultural identity response to the apparent rising Māori offending rates, it was Arapeta Awatere, together with the Maranga Cultural Group, that initiated the idea that Māori cultural identity forms a critical component of a Māori person's identity. They saw that Māori culture loss had a bearing on the rising numbers of Māori appearing before the courts, and ending up in prison. Subsequently, Awatere began to introduce Māori prisoners to their cultural heritage by teaching te reo Māori, performing arts and taiaha to prisoners in Auckland's Mt Eden prison in the early 1960's (Awatere 2003). After Awatere himself was sentenced to prison in 1969, it was Awatere’s protégé, Anne Tia, who took over the leadership of Maranga Cultural Group and continued to teach weekly Māori cultural identity classes in Mt Eden and Pāremoremo prisons for the rest of her life.

Like Awatere, Ana Tia was fluent in te reo Māori, knowledgeable in Māori culture, strong in her own sense of Māori identity, and seemingly able to bridge the gap between the distinct Māori and Pākehā worlds that mark New Zealand society. Importantly, like many of her contemporaries she was embedded to the cause that marked the Māori renaissance. She understood that the intergenerational effects of colonialism were presenting large scale previously unknown social problems that were beginning to pockmark Māori society. Foremost among these was the emergence of an urban-born generation who were identified as Māori by blood, yet held little understanding of what that implied in real terms. 
Known as 'Te Whaea', or 'mother', Ana Tia was involved in establishing and running a number of community projects. The largest of these was the Auckland Māori Community Centre that was funded entirely by donations. Since the mid 1950's, this Centre provided a Māori cultural centric refuge for ex-prisoners, the homeless, soloparents, and the unemployed in inner city Auckland. Together with Centre work, Ana Tia was a pioneer volunteer court worker and acted as an advocate and support person for Māori appearing in the then Auckland magistrates court. However it was her prison work that she found the most satisfying: "I feel I've achieved something if I win one out of every five" (Mediawomen of New Zealand 1984:120). Ana Tia remained committed to making a positive contribution towards Māori in prisons; from the mid 1960s, she taught weekly Māori cultural identity classes to Māori prisoners for two and a half decades, across the three Auckland prisons. The key focus of her prison work was practical instruction in te reo Māori, kapa haka, pōwhiri, whaikōrero, karanga, as well as a constant engagement on the broader subject of Māori values, their meaning, and how they are expressed in everyday life. The goal of her contribution was to introduce prisoners to their Māori cultural roots, the outcome of which she argued led to them learning to "live like brothers, because of that unity of being in a culture group” (McCarthy 1992:14m:08s).

While performing a karanga during a pōwhiri at her home marae at Te Hāpua, Ana Tia used the occasion to describe the work she was undertaking in prisons, and in a manner that is an example of the Māori cultural identity programmes she delivered in prisons, she uses a karanga to call her ancestors to help by guiding her in her work. In this, Ana Tia succinctly describes the purpose of her work to rehabilitate Māori, from a Pākehā society and culture that has left them bereft of a sense of their own identity and back to a state of cultural wellbeing in the comfort of her ancestors world view.

"Hoki wairua mai rā ngā mātua tūpuna, tautokotia mai rā mātou e āwhina nei te rangatahi e taka ana ki te hē, hoki wairua mai rā" (I call on the spirit of our ancestors to help bring the youth in trouble back to the culture) (McCarthy 1992:2m:56s).

There are three key features that emerge from the Māori cultural identity programmes that Maranga Cultural Group, and Ana Tia especially, delivered that I would like to highlight here. Firstly, within the Māori cultural identity programmes at that time 
there was no sense of rehabilitating Māori prisoners from a state of criminal offending to a condition of non-offending. Rather, the focus was on strengthening the Māori cultural identity status of Māori people who are seen as being cast adrift from their own culture as a result of over a century of colonialist experiences. Ana Tia perceived that the rapid social shifts that Māori had experienced had led them to an urban wilderness. Her work, in establishing the Auckland Māori Community Centre as a place of refuge, and her commitment to prisoners, was based on a perspective that multiple generations of Māori had been forced to the margins of a Pākehā dominant society and experienced poor social, economic, political and cultural habilitation. Māori lawyer Moana Jackson's seminal research, on the subject of the intersection between Māori and the criminal justice system, He Whaipaanga Hou (1988), supports this approach. His work, which involved three years of research among the wider Māori community, advanced the view that a history of colonialist policies and practices have marginalised Māori people and that the disproportionate rate of offending and imprisonment is inextricably bound to the status of Māori at the margins of New Zealand society. Further, he argued that the high rates of Māori crime are related to the intersection of Māori, predominantly Māori men, acting in a negative way to the imposition of a mono-culturally myopic system of power and the subsequent detrimental reaction of the criminal justice system towards Māori. The consequences are found to be manifest in an increase in Māori vulnerability toward offending and punishment. In this context, the criminal justice system's focus on the rehabilitation of Māori offenders and prisoners is negated by the reality that, for many Māori, the omnipresent effects of marginalisation that colonialism has brought to bear on generations of Māori communities have not provided an environment of good habilitation that can be returned to.

Secondly, the Māori cultural identity programme that Ana Tia delivered was distinctly Māori and reflected the Māori world view from which it was sourced. The values and practices that she drew upon for her work were Māori, and were the same values and practices that had shaped her own life and Māori cultural identity status. The belief that programmes that are designed to be delivered to a Māori audience need to be grounded in kaupapa Māori in order to be capable of achieving success has been argued by Winiata (1997). His research, which analysed four large scale Māori events (Te Māori, Te Aurere Waka Hourua, Waka 1990 Celebrations and Te 
Wānanga-o-Raukawa) in order to identify key elements of success that were displayed in each event, has led to the development of a Māori framework that may predict successful Māori activities. Key among these elements is the belief that the framework that envelops them needs to be kaupapa Māori based, and that the content of any programmes needs to emerge organically from a Māori world view.

Thirdly, and finally, a defining feature of Ana Tia, and her work, was that she never saw the Māori people she worked with in prison as deviant offenders needing some form of therapeutic programming in order to help them distinguish the difference between right and wrong. Rather, she treated them as if they were her own children, with aroha and respect. Gilgen (2002) describes the process of Māori developing professional therapy-based relationships in this manner as a practical example of whanaungatanga, an organic process of viewing the world and our relationships with those within it in a genealogical framework that binds us together. Further, he argues that this is an area of conflict that exists at the interface of the Māori and Pākehā therapeutic communities, where the professional relationship-based boundaries that are expected between therapist and client differ as a result of the importance that Māori place on whanaungatanga in a working capacity. A documentary on the contribution that Ana Tia made in this area (McCarthy 1992) highlighted both the work she did but, more importantly, the legacy she left behind. In particular, it exposed the depth of feeling experienced by many Māori people whose lives she changed in prison as a result of her guiding aroha. Beyond the value of introducing Māori prisoners to the cultural practices of their ancestors, the aroha she gave so freely seemed to have been a critical aspect in her work that found resonance amongst those who learnt from her. Clearly, this was a feeling that was reciprocated when she stated to them:

I can't express how much aroha I have seeing you fullas here today. I guess it's because we've been together so long, that we've actually become a whānau. I don't know whether I've become like you or you've become like me. That we fight for the things that we know are right for us, that we actually have succeeded. Not only fighting the system, not only fighting the Pākehā, but fighting our own people. To open the doors for us to do the things that we know is right for all of us. And for me it's the greatest achievement of 
anything that I've done in my life, to have my whānau come back and share a meal with us (McCarthy 1992:42m:48s).

As I am going to illustrate later in this chapter, the manner in which Māori cultural identity policies and programmes are designed and delivered was set to change substantively. Despite the fact that, in the decades since Ana Tia was actively involved in this area of work, there have been has been a steady stream of Māori cultural identity policies and programmes, the shape and the fundamental framework of them has detrimentally altered. These changes, as I argue in the next section, are the result of Māori cultural identity policies and programmes being entrenched in an ad hoc manner throughout the criminal justice system.

\section{Embedding Māori Cultural Identity in Criminal Justice Policy}

The drive to formally entrench Māori cultural identity policies across the criminal justice system occurred as a result of a number of social and political factors that converged to produce an environment that was perceived by the Crown as being more culturally responsive towards Māori. One important element of culturally focused change was the impact that Māori activism played in shaping the nature of the Māori focused policies that occurred from the mid 1970's onwards. In Chapter Three, I described the rise of Māori awareness to an unexpected consequence of Māori urbanisation: the loss of Māori cultural identity among the majority of urban born Māori children whose parents had migrated from a traditionally based rural environment to the urban sprawls that began to emerge during the post World War II economic boom. However, another consequence of urbanisation occurred whereby a number of young educated Māori emerged and spearheaded a cultural movement that became known as the Māori renaissance. This group of Māori were articulate and armed with the courage to model their ancestors and advance Māori causes. They were equipped with an:

...increased knowledge of the alienating culture of metropolitan society and its techniques for the maintenance of the structural relationship of Pākehā dominance and Māori subjugation. Freire's observation ${ }^{13}$ that knowledge of the alienating culture leads to transforming action resulting in a culture that is

\footnotetext{
${ }^{13}$ Walker refers to Paulo Freire’s Pedagogy of the Oppressed (1968).
} 
freed from alienation, is an apt description of the dynamic of the Māori cultural renaissance (Walker 1990:209).

Spurred along by challenges made towards colonising nations by indigenous people across the globe, the result was Māori activism. To a very large degree, the 1970's was a decade marked by Māori political and social activism. Defining moments occurred in October 1975 with the passing into legislation of the Treaty of Waitangi Act on the $10^{\text {th }}$, followed three days later by the Māori land rights movement's hīkoi arrival at the foot of Parliament steps to protest against the continued dispossession of Māori land through central and local body legislation. Walking the length of the North Island, and "stopping overnight at twenty-five marae en route" (Walker 1990:214), the numbers of people on the march swelled amidst prime time media coverage. For the first time, Māori protests were televised into homes across New Zealand on a daily basis, and were no longer localised to an area of immediate concern. As a response, Government policies from the late 1970's onwards developed to reflect what Māori academic Walker (1979:41) describes as 'cultural pluralism'. The Treaty of Waitangi established a governmental need to forge a partnership between Māori and Pākehā.

The Treaty did little, however, to change the conditions under which Māori lived. Over the ensuing decade, it was recognised that Māori were disproportionately represented in negative outcomes across the entire socio-economic spectrum in New Zealand, and that this was becoming more firmly entrenched (Alcohol Advisory Council and the Ministry of Health 2001; Benton 1988; Coupe 2005; Davies 1982; Durie 1999, 2003; Fergusson and Horwood 2000; Harpham 2012; Hill and Brosnan 1984; Justice Sector Strategy Group 2010; Statistics New Zealand 2014a; Te Puni Kōkiri 2000; Waldegrave, King, Walker and Fitzgerald 2006). This forced successive Governments to direct increased attention towards the improvement of Māori socioeconomic status. However, in order to achieve such a lofty goal, Māori argued that institutional changes needed to occur. One agency of the Crown that found itself directly in the line of fire was the Department of Social Welfare.

The release of Pūao-Te-Ata-Tū (Ministerial Advisory Committee on a Māori Perspective for the Department of Social Welfare 1988) has become a defining point in the application of Māori cultural policies across the various tentacles of the 
Government in New Zealand. Tasked with providing advice to the Minister of Social Welfare on the "most appropriate means to achieve the goal of an approach which would meet the needs of Māori in policy, planning and service delivery" (ibid:5), Pūao-Te-Ata-Tū gave voice to Māori calls for greater Māori control over Māori issues that fell within the mandate of the Department of Social Welfare. The report exposed that Māori believed that social inequalities were the result of generations of Māori being exposed to institutionally racist and mono-cultural policies and practices within the Department. A key recommendation of P $\bar{u} a o-T e-A t a-T \bar{u}$ was to provide a series of guiding principles and objectives for the Department of Social Welfare. These were: “...to attack all forms of racism in New Zealand that result in the values and lifestyle of the dominant group being regarded as superior to those of other groups, especially Māori, by: (a) Providing leadership and programmes which help develop a society in which the values of all groups are of central importance to its enhancement; and, (b) Incorporating the values, cultures and beliefs of the Māori people in all policies developed for the future of New Zealand" (ibid:9). The critical outcome of the PüaoTe-Ata-Tū report was that it paved the way for how successive Governments would meet their obligations to Māori as a result of the 1840 Treaty of Waitangi by ensuring that policies, and institutional mechanisms, are more culturally responsive towards Māori.

\section{Māori Calls for Change in the Criminal Justice System}

In 1988, a research report was released that was, arguably, to go on and have a critical impact on crime policies throughout the late 1980's and beyond. This was $\mathrm{He}$ Whaipaanga Hou, Moana Jackson’s (1988) research that analysed the interplay between the Pākehā criminal justice system and young, predominantly male, Māori. The basis of his argument is that prior to European contact in New Zealand, Māori had a means of maintaining social order by way of tikanga, which he defined as Māori law. He argued that over the following one hundred and forty eight years, between the 1840 signing of the Treaty of Waitangi and the publication of his report, Māori suffered the imposition of a Pākehā jurisprudence that created a New Zealand environment that was inimical to Māori. He contends that the factors that contribute to the over-representation of young male Māori offenders in offending and imprisonment statistics are bound up in and interrelated to this imposition and the 
resultant hostile relationship between the Māori community and New Zealand society. In Jackson's view, the cause and consequence of Māori crime are linked to a cycle of factors that consists of the intersection between young Māori men reacting negatively to the imposition of law and the systematic responses to those reactions by the criminal justice system. In the third part to his report, Jackson identifies the institutional bias of systematic responses to Māori, such as race based policing and discriminatory judicial sentencing trends, which in the view of his research participants, increased the likelihood of entry into a perpetual cycle of negative contact with the criminal justice system. The consequences of this are manifest in an increase in Māori vulnerability towards crime.

Jackson further argues that the widespread, and ongoing, effects of colonialism have contributed to the denigration of Māori culture resulting in widespread and intergenerational effects of cultural deprivation defining Māori existence. This process, he argues, occurs when:

...a dominant culture employs policies and adopts attitudes which effectively prevent members of a group gaining access to their own cultural values. This has grown largely out of the process of cultural denigration which has led to specific acts of institutional racism and social policy that have denied Māori people the economic and emotional resources to retain and transmit their cultural values...The combined and interrelated effect of cultural denigration and deprivation has been to create the uncertain world of insecurity and weakened self esteem which characterises so much of Māori life today. It is a world of cultural limbo which has a particularly damaging effect on the Māori young. Many in effect grow up without the security of knowing their cultural place and all that that entails in terms of language and identity. In Māori terms, it means that many are unable to answer two questions crucial to the establishment of Māori identity - ko wai koe, no hea koe? Who are you, where do you come from? (Jackson 1988:59).

Further, Jackson argues that if a person's cultural esteem is detrimentally affected by the wider social perceptions of the low worth of that culture, it will have a profound effect on the behaviour of Māori individuals: 
It is not surprising that the combination of this economic inequality and cultural deprivation has established the cycle of confinement in which most of the Māori community exists. Māori people see a clear correlation between this cycle and certain patterns of behaviour which appear to reject its stultifying and depressed modes of control...The instability of existence within the cycle means that the concepts of appropriate behaviour are in a state of flux and often amoral uncertainty. Young Māori, battered in their self esteem by the effects of cultural deprivation and denigration, are denied access to the Māori ideals of right and wrong, and are thereby weakened in their allegiance to any traditional standards of behaviour. The resentment of economic inequality reduces their willingness to abide by the accepted codes of the wider society so that a developing pattern of behaviour emerges which challenges both of those codes...This pattern may take many, often interrelated forms, each of which may eventually lead to behaviour that is defined as criminal. Thus the lack of a positive cultural identity may lead to identification with peer groups and an initiation into the solidarity and sub-culture of a gang. The lack of a legitimately respected economic position may lead to an identification with life-styles which may provide access to illegitimate means of gaining status. The lack of emotional security may lead to an identification with behaviour which provide drug or alcohol-induced escapism. Whatever the scenario, and there are many, the patterns are manifest in the too frequent cost of violence to oneself, to others, or to property (Jackson 1988:102).

Accordingly he focuses his research on what he calls system based factors, by studying the relationship between the Māori offender and the criminal justice system rather than focusing only on the Māori offender. In this context, Jackson's work provides a valuable theoretical basis to the work that Arapeta Awatere and Ana Tia initiated at the prison 'rock face' two decades beforehand. While their work was driven by their instincts that the widespread cultural deprivation they saw among the urban Māori population was a contributing factor in the rising levels of Māori ultimately ending up in prison, Moana Jackson's research, the result of extensive research interviews, hui and focus groups among Māori, supplied much needed empirical support. 
Alongside the policy changes that were occurring, many Māori working at the 'rock face' began to model Ana Tia's Māori cultural identity solution to an ever increasing Māori offending and imprisonment problem. Names like Mita Mohi (Department of Corrections 2005), Te Hata Olson (Department of Corrections 2002), and Herewini Jones (Bird 1998) became synonymous with the ongoing development and deliverance of Māori cultural identity programmes for Māori prisoners. Drawing upon their intimacy with Māori culture, the nature of these programmes reflected the view that Māori prisoners would be benefited by immersion into what is known as 'te ao Māori', the Māori worldview. Despite the fact that each of these Māori programme designers are acknowledged for contributing multiple decades towards this work, there has been little in the way of research to lend much needed empirical support for their efforts.

An emerging feature in the 1990's in the development of Māori cultural approaches was that external Māori cultural identity programme developers working in the community began to apply for, and receive, contracts for the delivery of programmes in a prison environment. This was to impose both a beneficial and negative effect on what until now had largely been a Māori initiative. On the surface, having Māori cultural identity programmes funded in this manner appears a positive development; an injection of capital provided Māori with the means to apply more effort into the development of Māori cultural identity programmes and, importantly, it enabled Māori to increase the capacity to deliver programmes to meet the ever growing number of Māori in prison. According to Winiata (1997), adequate funding from the Crown is one of six critical elements that will determine the relative success of Māori enterprises. However, on a negative note, Māori have experienced a sustained history of Māori cultural denigration that has taken a wide spectrum of forms, including the assimilationist policies that pockmarked early colonial visions for the building a New Zealand free from the influence of Māori culture through to the beating of generations of Māori children for speaking te reo Māori in schools (Selby 1999). As a consequence, Māori have little confidence in Pākehā being overly involved in the development and delivery of Māori cultural identity policies and programmes. As the next section will reveal, this is a concern that has become realised as the Department of Corrections has invested a great deal of effort into meeting its Treaty obligations 
by systematically sprinkling Māori cultural identity initiatives through the New Zealand prison system.

\section{Department of Corrections: Systemising Māori Cultural Identity}

This section begins to narrow the focus by investigating the use of Māori cultural identity in New Zealand's prison system. It is in prison, with its captive audience, that Māori cultural identity policies and programmes begun to be a permanent feature in criminal justice practices. Drawing upon Māori arguments that highlighted the role of colonialism in creating a population of Māori who grew estranged from Māori cultural roots, the state initially mirrored such calls.

For instance, in response to the call for submissions on the report into the prison system, chaired by Sir Clinton Roper (Roper 1989), the Department of Justice prepared a significant contribution that inevitably contained reference to the proportion of the prison population who were Māori. The Department established how this situation had emerged:

It needs to be stated at the outset that the department believes that a major cause of the overrepresentation of young Māori in offending statistics is their estrangement from cultural roots. It is widely accepted that Pākehā cultural institutional dominance has led to the severance and weakening of Māori social structures and a general loss of culture. The department will, therefore, be taking initiatives which provide the opportunities for inmates to learn appropriate cultural values and allow different cultural values to be expressed and respected (Department of Justice 1988:377).

In 1992, Taumata-Le Cleve prepared a report for the Department of Justice detailing Māori led initiatives to provide Māori cultural focused education programmes delivered to Māori prisoners. Programmes, such as "bone and wood carving, waiata and Māori language are popular components of the education programmes" (Taumata-Le Cleve 1992:18) and were viewed as a valuable attempt to connect Māori prisoners "with their own traditions and culture, which previously had been foreign to them" (ibid:44). It was seen that "When this link with their own traditions and culture was forged there was a remarkable improvement in their conduct and tension and distrust of others disappeared". However, in her analysis "Māori education in prisons 
is generally directionless" (ibid:20), a reflection of the fact that at that time the "tutors and education co-ordinators in most prisons were invariably non-Māori...with no evidence of fluency" (ibid:18) in Māori language or culture amongst the education staff. It is interesting, here, to note that during the 1980's and early 1990's, Māori cultural identity was perceived in terms of Māori education. The notion that Māori cultural identity would become such a key element of the prison system's drive to reduce Māori offending and reoffending was yet to be more fully developed and ultimately applied. The following section unpacks that shift in focus, arguing that the newly established independent Department of Corrections looked towards creating a new look prison system with a focus on a more 'scientific' approach to Corrections' policies and practices. In doing so, it looked offshore towards correctional developments occurring in North America that might be applied in New Zealand. This was undertaken to the detriment of Māori who aimed to respond to Māori imprisonment rates from our own perspective.

\section{Māori Cultural Assessment Tools}

On the 30 September 1995, the Department of Justice, the Crown entity that was then responsible for administering New Zealand's prisons, devolved their responsibilities into the Ministry of Justice, the Department for Courts and the Department of Corrections. With Mark Byers heading the new look Department of Corrections, they quickly began to build a prison structure that systemised correctional responses in a scientific framework. Rather than attempt the task of constructing an organic prison system that better reflected its mainly Māori population, the Department of Corrections was guided by a psychology based therapeutic model that included a "menu of accredited offending behaviour programmes increasingly tailored to particular populations and criminogenic needs" (Workman 2009:9) that would "be able to treat the causes and change the behaviour" of imprisoned offenders (Newbold 2008:390). The principal tool that was developed, in order to determine what those 'needs' might be, was known as the Criminogenic Needs Inventory (Coebergh, Bakker, Anstiss, Maynard and Percy 1999). These developments eventually came to form the theoretical basis of modern correctional policies and practices in New Zealand. For this reason it is important to provide a little more detail as to how they function in order to identify how key Māori cultural identity initiatives, such as Māori 
Focus Units and Māori Therapeutic Programmes, became immersed in this new system.

The Criminogenic Needs Inventory is a pre-sentence and post-sentence assessment tool that is focused on convicted offenders who the Department of Corrections determines are at a high risk of re-offending. The pre-sentence part of the Criminogenic Needs Inventory is assessed by probation officers and covers the period from the day before the commission of an offence up to the completion of an offence. The pre-sentence report is tasked with identifying the criminogenic needs that were present close to the time of the offence and is used to determine the presence of a range of predefined risk factors that are then targeted towards reducing reoffending. The completed pre-sentence reports are then supplied to sentencing judges and are used as a sentence recommendation. The post-sentence assessment of the Criminogenic Needs Inventory occurs during the early stages of a prison sentence and is undertaken with high-risk prisoners whose sentences are long enough to allow for rehabilitative interventions. The post-sentence report covers the six-month period immediately prior to the offending period and contributes towards the development of a sentence plan that outlines what interventions will be focused towards prisoners throughout the sentence of imprisonment (Coebergh et al 1999).

Even before its final release, this new framework had become the focus of critical controversy with regards to how it might be applied to Māori. A Department of Corrections Policy Development Report highlighted three main issues when applying overseas assessment tools to Māori offenders:

- These tools have been used primarily upon a western social-psychological empirical worldview, which claims that there is essentially a universal knowledge base applicable, and relevant, to all cultures. As such, these tools assume that Māori and non-Māori are essentially the same and that the reasons for their offending are the same. In addition, these tools implicitly undermine the validity of different worldviews or knowledge bases;

- These tools have been developed and tested in overseas jurisdictions. As such, both the instrument and the theory underpinning it have not been validated with Māori offenders; and, 
- These tools fail to take into account other factors potentially relevant to Māori offenders that could assist with a better understanding of the types of interventions most likely to be effective in promoting behavioural change amongst Māori offenders (Maynard 2004:8)

Inevitably, the Department of Corrections began to explore the notion that there might be Māori specific factors that contribute towards the high rates of Māori offending and imprisonment. The first step in this process was to acknowledge the impact of colonialism on Māori society, and then argue that the resultant status of Māori as a culturally marginalised population produced certain 'risk factors' that could be considered in the context of criminality. While attention is drawn to colonialism, the litany of consequences that have affected generations of Māori people has been left out of the analysis. There is no mention of: the large scale land loss that left Māori bereft of a basis for economic development; social marginalisation, from a majority population of Pākehā that stigmatised Māori; or, the detrimental results of mass migration from our traditional homelands to an urban environment that has produced generations of Māori with few social and cultural support mechanisms. Rather, colonialism was discussed in relatively simple terms with a Department of Corrections policy development report just noting that "Māori culture has been generally compromised and discouraged in the process of colonisation and it is likely that a number of stressors and/or tensions have developed in connection with differences in cultural values between both Māori and non-Māori, and amongst Māori” (Maynard, Coebergh, Anstiss, Baker and Huriwai 1999:50). While the basic historical factors are presented, the role that colonialism, racism and marginalisation have played in generating an environment that is criminogenic in its own right is omitted. Instead, the argument has been towards a Māori pathology that focuses on an insecure sense of Māori cultural identity that leaves Māori more prone towards offending behaviour:

...the level of confusion a Māori offender has about their identity appears to be an important variable to consider. Such confusion could lead to the further development of negative emotions such as anger and frustration, in addition to anti-social thoughts and feelings, such as a negative image of one's self (Maynard et al 1999:49). 
It was seen that "such negative emotions and cognitions could increase an individual's vulnerability toward crime” (ibid:49).

With this report as a guide, the Department of Corrections developed a Māori-focused assessment tool that would be utilised in the psychotherapeutic framework that was being applied across the general prison population, the Māori Cultural Related Needs Inventory. The assessment tool contained four Māori Cultural Related Needs which were used to explain the causes of Māori offending. First, cultural identity. This need was measured "in two ways. It assesses how strongly an individual identifies as Māori, and the individual's perception of what being Māori constitutes. This is to be assessed on the basis of how proud and comfortable the offender feels about their identity as Māori and their perception of what constitutes pride and comfort" (ibid:7). Second, cultural tension. Assessment of how this caused offending focused attention towards "the level of distress a particular cultural tension has created for the offender and the ways in which the offender typically deals with such tension” (ibid:7). Third, whānau. This Māori Cultural Related Need was said to determine whether a "breakdown in customary whānau structures, values and strengths has led to a loss of discipline, values and role models for Māori youth to emulate" (ibid:7). And, fourth, whakawhanaunga. This explanation was said to explain "why some Māori offenders tend to form associations with anti-social gangs, where there is an absence of prosocial whānau support. Membership in such a group increases substantially the likelihood that criminal behaviour will be socially endorsed and/or practically supported” (ibid:8).

Within three years of being rolled out for use in October 1999, the Māori Cultural Related Needs inventory had become one of the more controversial Māori cultural identity practices that were developed by the Department of Corrections. The Māori Cultural Related Needs assessment tool became the focus of a 2002 Waitangi Tribunal Claim brought about by both Napier Probation Officer Tom Hemopo as well as my own iwi, Ngāti Kahungunu. The basis of the claim was that the Māori Cultural Related Needs inventory disadvantaged Māori offenders because:

- the tool classified positive aspects of Māori culture and family as causing crime or as aggravating factors for sentencing; 
- it failed to acknowledge that the cultural criteria it used were equally applicable to other cultures and ethnic groups in New Zealand; and that,

- the outcome of a Māori Cultural Related Needs assessment influenced the sentencing, sentence management, and sentence termination processes (Waitangi Tribunal 2005:2).

In doing so, it was alleged by the claimants, that the Department of Corrections had by its conduct breached its Treaty obligations:

- to act with utmost good faith towards Māori;

- to actively protect the interests of Māori;

- to consult with Māori on policies that affect them;

- $\quad$ to treat Māori equally with non-Māori; and

- to remedy breaches of the Treaty when these are identified (ibid:3).

While the Tribunal acknowledged that there were "inconsistencies with Treaty principles in the Department of Corrections' conduct and policies” (ibid 2005:16), in the development and subsequent application of the Māori Cultural Related Needs inventory, the Tribunal did not believe that "those inconsistencies with Treaty principles have caused prejudice to Ngāti Kahungunu within the meaning of the Treaty of Waitangi Act 1975” (ibid:17).

Despite the controversy that had been created with the development of a Māori cultural assessment tool to fit within the prison systems psychotherapeutic framework, in 2002 the Department of Corrections began to pilot a second sentence planning Māori cultural identity assessment tool in Hamilton and Auckland, known as the Specialist Māori Cultural Assessment. The Specialist Māori Cultural Assessment is said to be "an exploration of the cultural needs and strengths of Māori offenders" (Department of Corrections 2007b:1) and was designed by merging a well-known Māori model of well-being and health known as Te Whare Tapa Whā (Durie 1994) together with "re-developments to align with Corrections specific processes for offender management” (Ministerial Review Unit 2007a:1). 
Initially designed as an adjunct to the Māori Cultural Related Needs inventory, the Specialist Māori Cultural Assessment is applied "if the Māori Cultural Related Needs inventory assessment indicates a deeper or more complex cultural issue” (Ministerial Review Unit 2007a:2). The actual assessment is conducted by an independent Māori assessor with a Māori offender serving a prison or community based sentence of more than 26 months, and includes a series of "open ended questions, taking two to four hours to administer, and occurs during the sentence planning phase of sentence management" (Department of Corrections 2007b:1). Included in the assessment framework is a series of what are described as Māori Wellbeing Indicators which include: whanaungatanga, tikanga Māori, Māori cultural values, te reo Māori, Oranga, Wairua, identification as Māori, mate Māori.

An important distinction between the Māori Cultural Related Needs inventory and the Specialist Māori Cultural Assessment is that the language is more refined, and on the surface, appears more culturally appropriate. For instance, unlike the Māori Cultural Related Needs inventory, the Specialist Māori Cultural Assessment does not list whānau as a criminogenic variable. Whānau are considered "the heart of Māori society" (Mikaere 1994:135), and the destruction of the whānau was "one of the most damaging effects of colonisation" (ibid:133). To describe whānau in a context that they may "socially endorse or practically support offending behaviour" (Maynard et al 1999:50), or that the Department of Corrections assessment tool would be able to accurately "identify incidents affecting the whānau that have influenced the offenders personal functioning” (Maynard et al 1999:50) is to suggest that whānau are criminogenic.

Despite the fact that the Department of Corrections reviews on the Māori Cultural Related Needs inventory and Specialist Māori Cultural Assessment state that Māori have been consulted throughout the development of these tools, neither the Māori Cultural Related Needs inventory or Specialist Māori Cultural Assessment are open to broader Māori peer reviews. The theoretical development of these tools as well the actual assessments that are applied to Māori prisoners are not openly accessible to view. This is alarming given that the assessment tools, together with the resultant sentence plans, are aimed at prisoners who are classified by the Department of Corrections as being Māori and who are determined to be at high risk of reoffending. 
Further, like the Māori Cultural needs inventory, the Specialist Māori Cultural Assessment "still identifies Māori needs according to, and using, a cognitive psychological understanding of offending" (Webb 2008:7). As a result "Māori philosophies have been grafted onto the existing theoretical explanations, and have been limited to making existing responses to Māori offenders appear more culturally suitable to address their needs” (ibid:7). While the Māori Cultural Related Needs inventory has subsequently ceased to be applied by the Department of Corrections, the Specialist Māori Cultural Assessment continues to be a key component of sentence planning. It is the key point at which Māori cultural identity initiatives inside prison are officially included as a part of Māori prisoners' sentences. What follows in the next section is an analysis of two of the more widespread of these, the Māori Focus Units and the Māori Therapeutic Programmes.

\section{Māori Focus Units}

Māori Focus Units, the largest Māori cultural investment advanced by the Department of Corrections, have been created to provide an environment that would allow for the inclusion of "kaupapa Māori philosophies into the rehabilitative framework of the corrections process” (Cram, Kempton and Armstrong 1998:iv). They would provide Māori prisoners with the opportunity to "embrace Māori cultural values, identity and affiliations” in turn leading towards a goal of "attitudinal change and avoidance of reoffending" among Māori prisoners (Department of Corrections 2009:6).

The initial idea for the development of Māori Focus Units was first outlined in the 1988 Department of Justice's submission towards the Roper Prison Review (Roper 1989):

...the development of units or centres within the existing prison structure which focus on Māori language and culture. Such centres would help strengthen cultural values, kinship and knowledge while meeting the state's responsibility to imprison offenders. Regional prisons would be able to offer such facilities within particular tribal areas. Further development along these lines taking account the authority, knowledge and kawa of the tangata whenua is considered the most appropriate way to proceed. Whanaungatanga and other vital Māori social structures are also facilitated on a regional basis. Concepts 
which are central to the process of rediscovering cultural roots include whanaungatanga, awhinatanga and manaakitanga and the use of support systems (such as Mātua Whāngai). These are facilitated regionally. The department believes that adequate services are operating or can be developed in conjunction with local people in regionally based prisons to cater for Māori needs. An adequate level of funding for these services would be imperative (Department of Justice 1988:380).

Once the administration of the New Zealand prison service officially changed hands, the newly established Department of Corrections began to work towards providing a distinct unit for Māori prisoners. Hawkes Bay prison was selected as the proposed site, and a consultation period began involving various arms of Government, local iwi, and wider Māori communities. The initial view, from a Māori perspective at least, was for the establishment of "a kaupapa Māori unit or prison; that is run by Māori, for Māori, in immersion te reo Māori” (Cram, Kempton and Armstrong 1998:13). This is an important point.

The drive for a kaupapa Māori led initiative in prisons, to cater to longstanding disproportionate rates of Māori imprisonment, reflected initiatives that had been developed throughout the 1980's and 1990's in the areas of Māori health (Durie 1994) and Māori focused educational institutions: Kōhanga Reo (Waitangi Tribunal 2013), Kura Kaupapa Māori (Tākao, Grennell, McKegg, Wehipeihana 2010), and Wānanga (Walker 2011). Inspired by the hard fought struggles throughout the Māori renaissance in the decade that preceded them, these Māori led initiatives responded to the disproportionate health and educational gaps between Māori and Pākehā by focusing on the Government's inability to positively address Māori needs, thereby displacing the official focus on Māori inabilities to achieve a better status. In this context, Māori had little faith in Pākehā designed and delivered Māori focused initiatives and the result was that Māori began to demand that, after generations of Government policy failures, greater Māori autonomy was required. Autonomy was seen as the strongest option to improve Māori status and the phrase 'by Māori, for Māori' became a rallying catch cry.

Nonetheless, Māori hopes for a prison unit designed and administered by Māori were dashed as "this vision was deemed too extreme" (Cram, Kempton and Armstrong 
1998:13) and the Department of Corrections decided on the development of an environment for Māori that would be more in line with the therapeutic model that was prevalent through parts of New Zealand's general prison system. The result was that in December 1997 the first Māori Focus Unit, named Te Whare Tirohanga Māori, was opened in Hawkes Bay Prison. Since that time a further four Māori Focus Units, modelled on Te Whare Tirohanga Māori, have been established in Rimutaka, Whanganui, Tongariro/Rangipō and Waikeria prisons.

While, on the surface, five Māori Focus Units seems a committed response, in actuality the limited number of placements available for Māori to be immersed in an environment that is seen as a positive is an issue that may need further reflection. In March 2014, the Māori prison population was 4,319 (Department of Corrections 2014a). With five Māori Focus Units each with a capacity of 60 beds, the Department of Corrections has supplied a Māori environment for 300 prisoners at the most. What this means is that $7 \%$ of the total Māori prison population can be housed in a Māori Focus Unit at any one time. The remaining 93\% of the Māori prison population are immersed into what is in effect a default Pākehā environment. This situation has been proven, over multiple generations of Government led assimilation and integration policies, to be inimical to Māori cultural and social well-being (Walker 1990).

There are a number of factors that distinguish the Māori Focus Units as unique from the general prison population. First is an eligibility criteria for entry into the units that requires that the prisoner: is categorised as either low risk or are higher risked but considered motivated to participate in rehabilitation programmes; has a lower security classification; agrees to sign a contract that accepts their compliance to any Māori Focus Unit requirements; and, is in the later part of a sentence, with the ideal length of stay between 8-12 months (Department of Corrections 2009).

Prisoners are selected to determine their suitability to enter a Māori Focus Unit. However, who actually arrives at the Unit can be reflective of prison administration rather than prisoner need. This, as well as the length of prisoner placement in the units, has been found to be a significant factor in the operational ability of the units:

Maintenance of an enduring positive climate is however always a major challenge for any prison special focus unit. In the MFUs, one factor repeatedly 
identified as a threat to this goal was the continuous turnover of prisoners, and placement in the units of prisoners who did not choose to be there (usually as a result of muster pressure). Further, each of the MFUs reported that they struggled to recruit sufficient numbers of suitable prisoners. The practice of bringing in short-serving prisoners meant that turnover of prisoners was high. This perception was borne out by statistical analysis of MFU placements over a 14-month period, which suggested an average length of stay significantly short of the optimal 8-12 months (Department of Corrections 2009:29).

Nonetheless, there have been signs that Māori Focus Units have been impacting positively in the lives of prisoners who have entered their domains. In 1998, Haami Piripi, who at that time was the Cultural Perspectives Manager for the Department of Corrections, commissioned a formative and process evaluation into the progress of Te Whare Tirohanga Māori which found "that in the short time that it has been operating it has been 'successful' in changing inmates attitudes and behaviour' (Cram, Kempton and Armstrong 1998:96) and that if the success of the unit was measured based on the changes in attitude and behaviour of Māori prisoners, then there was a measure of success in its effectiveness.

Eleven years later, when the Māori Focus Units were once again evaluated, the results produced similar results regarding the engagement of the Māori prisoners with Māori content:

With respect to learning and change, the study generated extensive evidence of MFUs’ participants acquiring new knowledge in relation to Tikanga Māori. This suggests that strengthened cultural knowledge, and enhanced cultural identity, is reliably being achieved amongst participants (Department of Corrections 2009:4).

However, on a less promising note:

...the modest extent of impacts observed across all measures suggests that MFUs are yet to operate to their full potential. The evaluation documented once again the operational issue of recruitment and retention of suitable prisoners. Further work is recommended to resolve this issue, as a high turnover of prisoners in these units inevitably reduces the extent to which the 
units are able to develop and maintain an atmosphere supportive of change (ibid:4).

Nonetheless, despite the modest return the evaluation concluded that "further strengthening of the MFU concept” (Department of Corrections 2009:30) was required. This is precisely what the Department of Corrections set about working towards by 'supersizing' their efforts and incredibly stating that "Māori Focus Units will be the elite environment where we will reduce re-offending by 30 percent by 2017” (Campbell and More 2013:27). A key element of these efforts will be the inclusion of a rehabilitation course that has been designed for delivery in Māori Focus Units, the Māori Therapeutic Programme.

\section{Māori Therapeutic Programmes}

The Māori Therapeutic Programme is the principle Māori focused rehabilitative initiative delivered in the Department of Corrections' five Māori Focus Units. While the Units, it is argued, provide the Māori focused environment that facilitate increased motivation among prisoners to respond positively to the Department of Corrections rehabilitative drive, it is the Māori Therapeutic Programme that "specifically address offending-related needs" (Kāhui Tautoko 2009:14). To achieve this aim, the Māori Therapeutic Programme combines:

...cognitive behavioural therapy (CBT) and tikanga Māori principles to address a range of offending behaviours by helping offenders to identify triggers for offending, and then giving the strategies to overcome or avoid these triggers (ibid:14).

For the prisoners who meet the stringent entry criteria (are in the final third of their prison sentence, be categorised as high-risk of reoffending, have a low-medium or low security classification, have demonstrated motivation to attend, and agree to the rules of the programme), the programme requires 100 hours of contact over ten weeks with a maximum of ten participants in order to work their way through the 544 page Māori facilitators workbook (Department of Corrections 2012d).

The foundation idea that contributed towards the Māori Therapeutic Programme, and for that matter the systematic use of Māori cultural identity in prison-based 
rehabilitative efforts, was the Bi-cultural Therapy Model (Department of Corrections Undated; McFarlane-Nathan 1996). Developed throughout the late 1990's, the Bicultural Therapy Model was the Department of Corrections first programme to systematically merge Māori cultural components into a psychotherapeutic model. Lacking a sound theoretical basis, the programme fell out of favour after reviews found that it suffered from poor iwi relationships, governance issues, lack of buy-in from Māori service providers and staff confusion about the programme (Department of Corrections Undated:3). Nonetheless, in order to respond to these issues as well as to provide a more structured argument for the development of a Māori specific psychotherapeutic framework, the Department of Corrections have refined their efforts through the Therapeutic Programme.

Defined as the "equivalent to the medium intensity rehabilitation programme" (Department of Corrections 2014b:4) the newly designed Māori Therapeutic Programme, known as Mauri Tü Pae (Department of Corrections 2012d), is described as "a core rehabilitation programme which enables prisoners to reflect upon and change the thoughts, attitudes and behaviours that led to their offending. Whānau are involved and the programme helps prisoners develop strategies for maintaining positive change” (Department of Corrections 2014b:6).

Despite being paraded as a key element of the Department of Corrections goal of reducing the disproportionate number of Māori in prison, the theoretical basis of the Mauri Tū Pae therapeutic programme has not been described in any publication including the 544 page Mauri Tū Pae workbook. It has not been peer reviewed by the wider Māori community, and it is not being made freely available.

\section{Conclusion}

In summary, the prison service in New Zealand has conducted almost two decades of experiments on Māori prisoners, drawing upon cognitive therapy programmes and grafting selected elements of Māori culture amongst them. According to Māori criminologist Juan Tauri (2005), this approach is best described as an example of the co-option strategy in which cultural ideas as pre-selected and used to make the Corrections system more culturally appropriate, and to make Pākehā developed programmes and services more likely to ‘work' for Māori. 
This is a far cry from the initial developments in Māori cultural identity that were initiated in Auckland prisons by Peter Awatere and Ana Tia almost five decades ago. Their work developed amidst the widespread Māori renaissance that emerged in response to the social, political, economic and cultural upheavals that marked Māori society. Further, their initial Māori cultural identity endeavours were marked by a strong Māori cultural framework, a conviction that the seed bed of Māori offending was a reflection of the marginalised status of Māori in New Zealand rather than an inherent Māori criminality. Further, their work appeared to have been successful at initiating positive change among the Māori prisoners they had contact with.

There are two key questions that emerge from the discussions so far. Firstly, given that the issues related to Māori offending appear to be rooted in dislocation, marginalisation, racism, low educational achievement, and denial of access to employment, how can these drivers of crime be addressed by a Māori cultural focus? Secondly, can the Māori Focus Unit prison environment or the Māori therapeutic programme delivered in prison be said to be a Māori cultural programme at all? It is these two questions that form the basis of the following two chapters, Chapter Five: The Validity of Māori Cultural Identity and Chapter Six: The Authenticity of Mãori Cultural Identity. 


\section{CHAPTER FIVE: THE VALIDITY OF MĀORI CULTURAL IDENTITY}

\section{Introduction}

In Chapter Four, I highlighted how the criminal justice system, especially the Department of Corrections, have maintained a steady stream of Māori cultural identity initiatives that introduce Māori prisoners to Māori cultural values and practices. Despite the lack of clearly articulated descriptions of whether Māori cultural identity policies and programmes are having a positive effect on reducing Māori recidivism, Māori cultural identity initiatives are now deeply embedded in Correctional practices.

As I have previously argued, the Māori cultural identity initiatives that are now peppered throughout the Department of Corrections actually emerged amongst a broader fight for Māori cultural survival and political rights that Māori believed were guaranteed by the signing of the Treaty of Waitangi. As a result of a history of Māori struggle, therefore, the New Zealand Government is defined by its acknowledged Treaty responsibilities towards Māori (Walker 1990). The Department of Corrections, like all of the agencies of Government, have an obligation to be developing policies with its Treaty responsibilities in mind (Department of Corrections 2001d, 2003, 2008a).

For the Department of Corrections though, these responsibilities have become especially acute as a result of both the degree of disproportionate representation of Māori in prison, at more than 50 percent of the total prison population, as well as the fact that the over-representation of Māori in prison has remained steady at that level for a third of a century (Department of Corrections 2012c:7). Compounding the issue for the Department of Correction's Treaty obligations is that Māori have steadfastly maintained that the widespread, and ongoing, effects of colonialism have contributed to the denigration of Māori culture resulting in widespread and intergenerational effects of cultural deprivation defining Māori existence at the margins of New Zealand society (Jackson 1988). A situation whereby contemporary Māori existence is marked by:

...lifestyles from which there is no escape. Trapped lifestyles, the forerunners of Māori offending and subsequent imprisonment, reflect a complex 
interaction of socio-economic circumstances, confused or partially developed cultural identities, individual and collective journeys which have resulted in diminished self respect, and a lack of voice - the lingering effects of colonisation and political oppression (Durie 2003: 109)

The Māori view of offending, occurring amidst an inherited legacy of colonialism, is in contrast to the fundamental basis of the Department of Corrections' approach which defines criminal behaviour as being the result of certain predefined criminogenic factors present in the offender's lifestyle at the time that the offending happened (Coebergh et al 1999).

This chapter, which opens the results of the interviews that I conducted for this thesis, draws upon the experiences and views of the kaikōrero. It questions the validity of the use of Māori cultural identity prison initiatives as a response to the high rates of Māori imprisonment. Validity, in the context of this thesis, relates to the application of a kaupapa Māori lens with which to investigate the use of Māori cultural identity policies and programmes in a prison setting. From this perspective, kaupapa Māori assumes that the Māori world view is normative, that the experience of colonialism continues to have a devastating impact on Māori society, that Māori research is more able to accurately reflect Māori realities, and that Māori responses to Māori phenomena are more likely to produce positive results. Therefore, to a very real degree, kaupapa Māori is a political as a well as a cultural stance.

As I have shown in Chapter Two, kaupapa Māori research methodology emerged as a result of the negative experiences Māori have had with Pākehā researchers using Māori society and culture as the focus of their scientific gaze. Pākehā researchers, by framing their research within their own Eurocentric cultural traditions and colonising tools, have perpetuated notions of the racial superiority of Pākehā values, processes and knowledge (Smith 1999) and, inevitably, Māori values, processes and knowledge have been presented as inferior (Bishop 1997; Cram 2001). The result is that Māori view researchers and their research with cynicism (Jahnke and Taiapa 1999) and as a point of cultural conflict whereby Māori resist against Pākehā research and its fruits (Smith 1999). One of the central arguments against Pākehā research on Māori is the manner in which positivist researchers have entered the Māori domain with preconceived hypotheses about the meaning of Māori knowledge and practices. Once 
there, they direct their western scientific gaze at aspects of Māori society and culture, and analyse it to "fit in with a Eurocentric framework" (Jahnke and Taiapa 2003:41).

A central concern at this point in my research is that I maintain my kaupapa Māori stance by ensuring that the presentation of the results of the interviews is in a manner that better reflects kaupapa Māori values and not the practices of Pākehā research practitioners. Against that context, I see the results of the interviews with the kaikōrero as the gathering of a collective of Māori voices in a series of hui. Despite the efforts of centuries of Pākehā colonialist practices, whose purpose has been to destabilise Māori society by forcing Māori to conform to Pākehā societal ideals and structures, Māori collectives are still the fundamental foundation of Māori society (Walker 1990).

With this in mind, I intend to follow in the footsteps of the kaupapa Māori researchers who have come before me and approach the presentation of the results of the interviews from a kaupapa Māori perspective (Cram 2001; Irwin 1994; Jahnke and Taiapa 1999; Moewaka-Barnes 2000; Pihama 1993; Smith 1996; Smith 1999; Taki 1996). I present the results of the interviews that I conducted amongst the kaikōrero as reflective of their voices. This will, I believe, provide the kaikōrero with a space where their stories are placed in the dominant position while mine recedes to that of a guide to enable the reader to make sense of the ebb and flow of the text. This is an important aspect of this thesis as my intention has always been to remain mindful of the negative manner in which research is viewed by the Māori community (Smith 1999). Drawing upon kaupapa Māori as a foundation for this research dictates that I provide an environment that can be perceived as an empowering position for the kaikōrero (Bishop and Glynn 1999; Pihama 1993).

Therefore the interview findings are placed into a coherent sequence of sections, that explore kaupapa Māori perspectives on questions such as:

- Is the use of Māori cultural identity in prison appropriate?

- Is there more to Māori offending than Māori cultural identity?

- Is prison an appropriate venue for Māori cultural identity programmes?

- What is it like working with the Department of Corrections?

- What is it like working in a prison regime? 
- Is the funding of Māori cultural identity programmes adequate?

\section{Māori Cultural Identity as a Response to Māori Offending}

I have already illustrated in the opening chapters of this thesis how Māori have experienced multiple generations of suffering as a result of contact with Pākehā. The passage of time since we met has been replete with Māori loss and disarray, politically, economically and socially as a result of being subject to systemic and chronic marginalisation by a dominant Pākehā system of power that has been determined to 'cleanse' Māori of the vestiges of our own culture. In doing so, Māori society has suffered widespread cultural identity loss which, in turn, has resulted in generations of Māori who have little or no knowledge of their language or where their people are from and their culture. This was continually reflected upon by kaikōrero:

So often when I just meet Māori offenders who were going to court you know they knew nothing about tikanga. They knew nothing about kawa, they knew nothing about whakapapa ${ }^{14}$.

...I think one of the common denominators about offenders is that there is a loss of compass, there is a loss of direction. They've either abandoned it deliberately at the heat of the moment where they've been put under pressure about a certain situation and their choice has been to abandon everything that they believe in, that they have lived by, in order to get out of the situation and they've committed a heinous crime then as a result of it. Or, or the cases that there was never a compass in the first place. There was never ever a centre there to have a voice inside the view which some people call your soul. Other people call it your consciousness which they see this is wrong you know it's wrong, we all know it's wrong don't do this. I know of people that don't have such a voice. They don't hear it, it's an emptiness and so they just act out whatever, whatever is, what they believe has to be done that benefits them and the whole concept of legal or illegal is irrelevant. There's no such standard. In fact there are no such standards except I want, I need, I've got to have it. Everybody else is judging those people by well known law and ethics, morals, those are foreign, those are foreign words they have no meaning, they have no

\footnotetext{
${ }^{14}$ Kaikōrero, kōrero-ā-waha, 12th October 2010.
} 
meaning at all. So somehow those people grew up with only a faint regard or faint association with it or nonexistent. They're nonexistent ${ }^{15}$.

As previously described in Chapter Three, the literature repeatedly illuminates the importance that Māori cultural identity continues to hold in contemporary Māori society (Walker 1990). Regardless of the fact that the all-pervading effects of colonialism continue to haunt contemporary Māori society, Māori remain steadfast in the belief that Māori cultural identity is a key determinant of Māori social and personal wellbeing (Durie 2001). Subsequently, a high degree of resources and energy are directed towards improving the Māori cultural identity status of Māori people. It is believed that the resultant strengthened sense of Māori cultural identity status will in turn play a positive role in fortifying Māori people to withstand the onslaught of the ongoing effects of colonisation.

There is support for this assertion amongst the kaikōrero with comments that highlight beliefs around the perceived importance of Māori cultural identity programmes to contribute towards a positive influence upon Māori people. Foremost is the view that:

...being Māori is a positive...I believe that what is fundamental is that, when we create a process for our people, getting to know who they are that's the key ${ }^{16}$.

...my strong belief is that tikanga is definitely a pathway to change ${ }^{17}$.

No kaikōrero perceived Māori cultural identity itself in a negative light. On the contrary, the status of Māori culture as a relevant feature of contemporary Māori identity was a strongly held finding throughout this research project. The focus was that strengthening the personal identity status of Māori people contributes to positive outcomes:

I firmly believe that the more secure a person is about the, what you may call, the self...that brings I think clarity about the purpose and about boundaries.

\footnotetext{
${ }^{15}$ Kaikōrero, kōrero-ā-waha, 21st October 2010.

${ }^{16}$ Kaikōrero, kōrero-ā-waha, 14th May 2010.

${ }^{17}$ Kaikōrero, kōrero-ā-waha, 19th August 2010.
} 
That sets standards and expectations and they give people a measure of achievement and a compass about where it is that they're going ${ }^{18}$.

It was also seen that positive changes can occur when people who may have a history steeped in negative contact with the criminal justice system are immersed in a Māori cultural learning environment. This can contribute to:

...a change in life style... as you learn more about the way our tipuna thought the more it affects your behaviour. We get plenty of gang members come through here, plenty of people who have a colourful past, and the ones who stick with it, and stay right through the whole degree, you see them change over the course of the degree ${ }^{19}$.

A second theme that resonated among many of the kaikōrero was the idea of Māori cultural identity as a 'seed' that once planted eventually grows:

...tikanga Māori courses and your cultural identity courses are there to plant the seed of becoming motivated to look at yourself as a whole ${ }^{20}$.

...You see shit you've just created, you've just facilitated some transformational change there. And maybe they will go back into that prison culture but you've sown a seed eh, it'll grow. So yeah, blinken identity is so important $^{21}$.

The basis of a 'seed being planted' is found in the suggestion that, for many Māori, especially those whose Māori cultural status might be considered compromised (Te Hoe Nuku Roa 1999), the journey of self discovery that Māori cultural identity programmes yields has an unrelenting pull (Marsden 1992). The argument is that the potential of Māori cultural identity programmes resides less in whether or not they permanently change the trajectory of a crime laden lifestyle. Rather, that the compromised standing that identifies the cultural status of so many Māori people in prison provides a fertile environment for engagement with Māori culture.

\footnotetext{
${ }^{18}$ Kaikōrero, kōrero-ā-waha, 21st October 2010.

${ }^{19}$ Kaikōrero, kōrero-ā-waha, 12th July 2010.

${ }^{20}$ Kaikōrero, kōrero-ā-waha, 6th September 2010.

${ }^{21}$ Kaikōrero, kōrero-ā-waha, 5th October 2010.
} 
The overwhelming majority of the kaikōrero saw Māori cultural identity in a positive sense, that it is an important component of Māori identity makeup, and that it contributes towards wellbeing. However, a number also raised a cautionary note. They saw that, in the context of a response to high rates of Māori imprisonment, Māori cultural identity should not be seen as a panacea that will miraculously reduce Māori reoffending:

So I think identity is important because it's a potential attraction point to get into the psyche of the person rather being a panacea, it initiates change ${ }^{22}$.

Culture has to be learned, there is a connection, there is a cultural membrane so these things feel right to you, I believe in that, but I don't think Māori cultural is any better or worse than anything else. But it's mine so it feels better than anything else. But it's not any worse or any better than anything else, it's not a cause of Māori crime it's not a solution to Māori crime either. It's part of the picture. It can be used as a tool, I think, because it can be learned and engaging people in any kind of learning experience has gotta be positive. So I think it's an incredibly important tool but I don't think it's gonna be the panacea to crime, it's part of the answer. I guess I don't go along with people who put it on a pedestal ${ }^{23}$.

Despite the fact that Māori cultural identity might be acknowledged for its importance, this does not indicate that Māori cultural identity can be positively linked with reduced reoffending. This is a relevant point to raise given that two evaluations on the Māori Focus Units have found similar evidence in their findings. For instance, Cram, Kempton and Armstrong (1998) found positive changes in attitude and behaviour of Māori prisoners while the Department of Corrections (2009) found evidence of Māori Focus Units' participants acquiring a strengthened cultural knowledge and an enhanced sense of Māori cultural identity. Nonetheless, "the modest extent of impacts observed across all measures suggests that MFUs are yet to operate to their full potential” (ibid:4):

\footnotetext{
${ }^{22}$ Kaikōrero, kōrero-ā-waha, 6th September 2010.

${ }^{23}$ Kaikōrero, kōrero-ā-waha, 7th September 2010.
} 
...my sense is that making people feel good about themselves doesn't necessarily mean that they're going to stop offending. It may contribute to that outcome but not necessarily. But what we need to understand I think is that you need to do a lot of things - a lot of different things with people not just one thing. One thing is not going to fix a lot of stuff and often the combination of things is what makes the difference. And there may be something in that combination that triggers you know a response ${ }^{24}$.

...I think cultural identity is so complex there will be some people who go, who may end up in prison for whatever reason, and maybe learning te reo or learning kapa haka will be that one thing that will make them feel more secure. I'm sure that's true for some of them. I doubt that it's that many to be honest. That's not to say I don't think it's fine for them to be doing those things while in prison I don't think it does them any harm. I just don't think it stops them wanting to commit crimes ${ }^{25}$.

...does reo reduce reoffending? Does tikanga and kawa reduce reoffending? What we do know is it makes them stronger in their Māoritanga but then all we might get is a clever Māori who's a crim² ${ }^{26}$.

Kaikōrero saw that the issue surrounding Māori cultural identity inevitably becomes fraught with complications when used in conjunction with Māori offending and imprisonment. In this context, Māori cultural identity is seen as providing potential benefits that learning about Māori culture might bring to people, but the idea that Māori cultural identity can be a rehabilitative tool was also dismissed:

...what I have seen it do is help people who otherwise would have just stumbled around until they hit on something that worked for them, but the Māori focus unit, what are they focusing on? Have you been into a Māori focusing unit? What's the focus? Māori culture? Forget it! You heard me! You interviewed me! I will battle to the coal face that representation in court will beat this Māori culture thing. Proper drug treatment will beat all that

\footnotetext{
${ }^{24}$ Kaikōrero, kōrero-ā-waha, 23rd September 2010.

${ }^{25}$ Kaikōrero, kōrero-ā-waha, 14th September 2010.

${ }^{26}$ Kaikōrero, kōrero-ā-waha, 12th October 2010.
} 
Māori culture thing. Don't tell me they're putting money into it. The culture can't fix it, can't stop them smoking 'P' ${ }^{27}$, can't have them badly represented in court, how? Can the culture fix it? No! Māori focus Unit be dammed! No, no, no! My impression is that it is not a matter of the Māori identity it's a matter of self worth that's the problem ${ }^{28}$.

...you can't expect our tikanga to stop people doing wrongs if they live in a world where wrongs are still being done to them you know. So we've got to just keep on plugging away. But if having a Māori private prison is going to be the panacea then you know - apart from all the serious difficulties associated with the whole idea of privatising incarceration. If we think it's going to reduce our people's offending then the evidence clearly shows it doesn't. It might stop some offending, but it's not, it's not the answer. And that's why I think we're constantly playing catch up you know. We're not allowed to front up to the real issues ${ }^{29}$.

Why are we saying we're going to put a tikanga programme in there and they'll all be hunky dory because they're going to learn pepehā or something. Bullshit $^{30}$.

As has been illustrated in Chapter Four, within the criminal justice context, Māori cultural identity has become synonymous with criminogenic needs. In this domain, with Māori cultural identity being viewed by the Crown as a key response to the ever present high Māori crime rates that continue to plague New Zealand society, the question of the impact that Māori cultural identity might have on the Māori crime rates rises to the fore. As a result, the responses put forth by the kaikōrero begin to adopt a cautionary tone. The idea that there are aspects of Māori culture that might link negatively with Māori crime is, to many of the kaikōrero at least, wrong:

Well there's no link. It's a constructive link. It arose out of that whole, what's it called, the MaCRNs programme that developed in Corrections you know. That there might be cultural factors that will predispose you to crime and it's

\footnotetext{
${ }^{27}$ Methamphetamine.

${ }^{28}$ Kaikōrero, kōrero-ā-waha, 17th July 2010.

${ }^{29}$ Kaikōrero, kōrero-ā-waha, 24th July 2010.

${ }^{30}$ Kaikōrero, kōrero-ā-waha, 11th October 2010.
} 
as fallacious as saying that we have the warrior gene that makes us violent you know. I think the link is fatuous. The best way to illustrate it is in education, for years they have used what's called the deficit theory. That there's something in Māori culture which prevents Māori kids from learning at school which was an excuse for them really. That their education system was not the system best suited for our kids to be educated within and so from there the notion of criminogenic Māori behaviour and cultural identity is a similar deficit theory that we become criminals because there's something in our culture. You know they never define what that is, you know. Or they say that because they used to say this in the 1930s 'because Māori have a collective view of the world it's very hard for them to distinguish the difference from right and wrong in an individual sense you know', that's bullshit ${ }^{31}$.

To summarize this initial section, there was strong sense of accord among the kaikōrero that Māori cultural identity is an important element of contemporary Māori society. They saw that, despite the cultural changes that Māori society has experienced over the course of colonisation, Māori hold onto and value the cultural markers that define us as a distinct people. In support of the literature that has emerged amongst Māori circles that defines Māori cultural identity as a necessary component of Māori wellbeing, the kaikōrero add their voices to such calls. Similarly, when the subject of exposing Māori prisoners to Māori cultural identity while in prison was raised the responses mirrored general Māori calls that strengthening the Māori cultural identity of Māori in prison is a positive initiative.

Nonetheless, within the context of Māori cultural identity being applied as a response to high rates of Māori offending and imprisonment there is less enthusiasm. With responses that suggest other 'problems' and 'real issues', the views of the kaikōrero indicate a broader interplay of factors at the root of Māori offending. In the following section, the other 'problems' and 'real issues' that the kaikōrero raised during the interviews will be explored.

\footnotetext{
${ }^{31}$ Kaikōrero, kōrero-ā-waha, 24th July 2010.
} 


\section{Māori Status and Māori Offending Rates}

As I have illustrated in Chapter Three, much effort is directed to a key feature of New Zealand society: that in comparison to all other ethnic groups, Māori experience lower rates of educational achievement (Benton 1988), income (Te Puni Kōkiri 1998, 2000a), and home ownership (Waldegrave, King, Walker and Fitzgerald 2006), as well as higher rates of psychiatric illness (Durie 1999), poverty (Davies 1982), unemployment (Hill and Brosnan 1984), poor health (Durie 2001), suicide (Coupe 2005), alcohol abuse (Alcohol Advisory Council and the Ministry of Health 2001), illicit drug use (Fergusson and Horwood 2000), offending (Statistics New Zealand 2014a), imprisonment (Harpham 2012) and victimisation (Justice Sector Strategy Group 2010).

It is generally accepted that socio-economic disadvantage is a social condition, or environment, whereby there is an increased likelihood that criminal offending will occur. The events experienced by Māori throughout colonisation, including large scale asset loss, land alienation and rapid urbanisation have created a situation whereby Māori struggle in all socio-economic domains. It is a status that Jackson (1988) argues is led by systemic factors that are the direct result of the imposition of Pākehā society upon Māori society. The result is a crime generative environment which is marked by the intersection between predominantly young Māori reacting negatively to the imposition of Pākehā law and the systematic responses to those reactions by the criminal justice system. The following section provides the kaikōrero the opportunity to present their views on this subject.

The argument that they explore here is that the high rates of Māori offending and imprisonment reflect the marginalised socio-economic status of Māori. This has remained a compelling argument, for a number of reasons. Firstly, there extensive, well established, international research that links socio-economic disadvantage with a number of social ills. Secondly, the socio-economic status of Māori in New Zealand is equally unequivocal. And thirdly, because the research that examines a relationship between Māori socio-economic status and Māori criminal offending is more in tune with a Māori view of the cause of Māori offending. This work indicates that, ultimately, the cause of the alarming rates of Māori offending lies within broader New Zealand society, and specifically the status of Māori within it. In other words, 
the socio-economic hypothesis predicts "that when due allowance is made for socioeconomic factors, Māori children are at no greater risk of offending than non-Māori” (Fergusson 2003:140). For some kaikōrero, the idea of Māori cultural identity in order to engage Māori prisoners was seen as a positive response, yet simultaneously they raised the point that the response is inadequate if the wider environment that Māori exist in remains unchanged:

...I see value in how young men, wherever they are, [are] learning the reo, learning all of those things. But we shouldn't be giving them those things as an excuse for not doing the other things because if you just give them those things then it does two things. I think it actually criminalises our tikanga 'I've got to go to prison to learn it' you know. So it's like you know the Māori Language Act, the reo was an official language which you can only use it in court, only use it when you're going to go to jail. You know what does that say about our reo, what is the symbolism of that presumption? So I tautoko our people being able to learn the reo say wherever they are. And if prison is where they are, accept the reo and I said that twenty years ago I still believe that. But the reo alone, learning the taiaha alone, all of those things are actually not going to work if we don't change stuff out here... ${ }^{32}$.

In some cases it will actually work. But then you know if you do all that and you save one person then you know it's worth it actually because if you save that person and you save that person's children...Turn one person around you actually do make a difference. So I'm not saying that it's not worth doing, it's just that I'm not sure that it's enough, yeah it's definitely not the panacea. And I suppose what sometimes offends me about it is not the fact that our people get enthusiastic about it and see a way forward...it is that it's something that Pākehā people can get enthusiastic about it because I think their motivations are different and maybe it's just because I'm incredibly cynical because I spent a long time working with Pākehā. But you know Māori get enthusiastic and see it as being one potential small thing that can lead to some kind of communicative change I suppose and that's cool. But for Pākehā people it looks like an easy fix I think. It's something they can throw a few dollars that

\footnotetext{
${ }^{32}$ Kaikōrero, kōrero-ā-waha, 24th July 2010.
} 
way and it can ease their conscience that they're doing something to fix the Māori criminal which also really bugs me because what's created the Māori criminal is actually the enormity of the experience that they have visited upon us which is yes the stripping of identity, but stripping of a whole lot of other things as well. So you know, them throwing a few dollars at some kind of cultural strengthening programmes in the prisons, it never addresses the underlying issue which is the power relations between the state and us. So unless they're prepared to address that I find that on their part a really token gesture and something that does no more than make them feel as though they're doing something ${ }^{33}$.

For some kaikōrero, the idea that Māori cultural identity is a primary response amidst an environment that continues to marginalise Māori, politically, socially, and culturally is nonsensical.

I think there are layers of things and you know some Pākehā researcher says 'oh it's socio-economic', you know, crime is the poor person's thing and it's mainly poor people who get sent to jail and so on. Well the question then is if it's a poor people's thing why is it that Māori are disproportionately poor? That's the way it appears to me. Not how come there's a disproportionate number of Māori in prison but why is it that Māori are disproportionately poor? Now I think that's because we are being dispossessed....not going to solve the problem with Māori wrongdoing until you address the history of dispossession...the culture of colonisation and until that happens the best we can do is to try to do what we can to re-establish - I don't know what the word is - re-establish the World if you like in which our people can reclaim what has been taken from them. So we reclaim who we $\operatorname{are}^{34}$.

Further, it was seen that Pākehā use Māori cultural identity as a pathological explanation for Māori offending and as a means to explain Māori 'deficits':

...the part about it that really offends me is that it very much feeds into their whole deficit theory 'look at this Māori person, they can’t even speak Māori

\footnotetext{
${ }^{33}$ Kaikōrero, kōrero-ā-waha, 14th September 2010.

${ }^{34}$ Kaikōrero, kōrero-ā-waha, 24th July 2010.
} 
as if they don't even know who they are, they need remedial action' and that really bugs me, it really, really bugs me. So I suppose it's one thing for us to think it's the way forward, it's another thing for those people who've done this to us to tell us what's good for us now. I find that really offensive ${ }^{35}$.

Kaikōrero saw that this was undertaken at the same time as the continuation of oppression towards Māori in New Zealand society:

...so the idea that you can take someone from that place put them in prison and say 'better not do that again because you're betraying your whānau obligations' it's just not going to work you know..... So I just think when they use kōrero like that in...cultural development programmes or whatever they call them I think what the Pākehā colonisers are doing is actually escaping responsibility. They are saying it's your fault. You sort it out. We'll help you sort it out by giving you the tikanga to sort it out, but we'll continue to oppress your whānau. We'll continue you know under the current recession you know the Māori unemployment rates $22 \%$ and they worry that Pākehā unemployment had gone to $7 \%$ you know. So we'll continue to let your people go on the scrap heap, we'll continue to do this and this and this to our people but by god you'd better come out oozing tikanga you know. So it's a cop out for them. It's victim blaming of us ${ }^{36}$.

Without a positive change in the environment that generates Māori offending, trying to make a population of culturally aware Māori offenders who exist in a society where Māori remain at the margins is to create a population who may be more culturally aware yet:

...let's say tomorrow every Māori woke up and knew who they were culturally, let's say that just happened. That wouldn't stop criminal offending because all we'd have is a lot of really culturally aware stupid people still living in a colonising society. We'd have Māori burglars who could do kapa haka you know because what you've got to do is change all those wider things. If you then had a decolonised society so it was no longer a colonising

\footnotetext{
${ }^{35}$ Kaikōrero, kōrero-ā-waha, 14th September 2010.

${ }^{36}$ Kaikōrero, kōrero-ā-waha, 24th July 2010.
} 
place, you'd have no more crime. But you would still have hara, you'd still have wrongdoing, because humans will do wrong you know. Our tippuna didn't live in a world free of hurt and a world free of wrong. What we did was we defined what the wrong was, we dealt with the wrong within our own processes and our own ways of understanding what it was ${ }^{37}$.

I don't think a cultural identity will solve that problem. It will contribute to a solution if it makes kids feel good and makes kids feel part of a positive network which is what there is the option to do. Every time they're doing a haka they're part of a positive network. Every time they're learning te reo, part of a positive development, I think that's good but I think by itself I don't think it's enough. I think the key has got to be...the world they go home to...how to make people in prison leave a protected environment and use the skills that they learned there and hopefully over here on the marae side of it or the kawa side of it to cope with a, a world which is unprotected. How do they get better and better at managing risks in the environment, identifying and managing them? You know the old people are good at it a hundred, a thousand years ago, they arrive here with no knowledge of Aotearoa and they worked it out to stay away from dangerous things. They're tapu. That's what tapu is about basically. This is a risk attached to this, treat it with respect. This one's okay, it's noa, okay you can be pretty relaxed with that. But if there's something dangerous be very cautious how you approach it. We seem to be encouraging kids to tackle every new thing that comes along and to not know about risk. Not being able to modulate it...You would hope that prison has prepared them to understand relationships a bit better, to be a bit better at identifying a risk and working out options to manage the risk. I don't know - I don't really know how you would teach people that in prison...I don't think tikanga Māori will by itself solve that problem, I think it will help. I think that if there are people if we can, if we can inject into the Māori cultural identity programme, this notion of what tapu was about...kids might try identifying what in their normal environment is a risk and label it tapu ${ }^{38}$.

\footnotetext{
${ }^{37}$ Kaikōrero, kōrero-ā-waha, 24th July 2010.

${ }^{38}$ Kaikōrero, kōrero-ā-waha, 1st November 2010.
} 


\section{Prison as a Venue for Māori Cultural Identity}

This section presents responses on the more general issue of a prison environment as the site for the delivery of Māori cultural identity programmes. For some of the kaikōrero this was a subject that elicited strongly held convictions. As well, this was an area of enquiry that has been supported by research that the Department of Corrections (2003:14) has conducted before; as one of their respondents remarked, “I believe we should have the resources to actually take it away from those places and take it back to how our tipuna did it, in wānanga style”. Some kaikōrero questioned the way in which Māori programmes had been planned and implemented in prisons:

...I am of the opinion that it's unlikely that anybody's ever really seriously sat down and planned a programme, a complete holistic tikanga Māori programme, and been given the mana and the backing to go in and deliver it in jail. I think what's been done so far is quite piecemeal...I question, I question the understanding of some the deliverers, what I've seen of some, of what's happening in my own rohe, is that you're getting a mixture of Mormonism and tikanga Māori. Which is actually twisted it's not solely tikanga Māori, its influenced with other stuff that's foreign. Which to me, our people are searching for our spirituality, not someone else's and I think wairuatanga is a big part of it, the more you learn. It has the opposite effect of what you want to happen, so the programmes have gotta be very carefully designed ay. And the deliverers have got to be really carefully selected. You know it takes a special kind of person to walk into Maxi and do this kind of stuff. And it requires the involvement of people actually really sitting down and planning it and overseeing it, every last detail. This is why it's got to be done in a Māori separate unit. Completely separate, it's got to be micro managed. If not gonna, it's actually more likely to make them worse, I believe ${ }^{39}$.

Kaikōrero also saw that, over time, Māori Focus Units had become distorted so that they were led by Correctional needs rather than Māori values:

\footnotetext{
${ }^{39}$ Kaikōrero, kōrero-ā-waha, 12th July 2010.
} 
They've been turned into prison unit's not Māori Focus Units ${ }^{40}$.

...the first Māori Focus Unit we had was almost like an island in the stream. You know it was very Māori; Māori language, Māori people, Māori everything. But over time, two or three years, they stripped it out and they turned it into just a very Māori prison unit, You know, a very Māori 60 bed unit as opposed to a very Pākehā one, but they didn't actually change the 60 bed unit ethos. They just put a Māori gloss over it, and that's really what the Māori Focus Unit has become now. They're not what they originally were intended to do, they don't do any of that, which was to address Māori behaviour $^{41}$.

Given these problems, kaikōrero began to question where rehabilitation should be done. Some viewed that Māori tikanga programmes should be reserved as community endeavours, and to reflect community engagement:

My own personal view is that your rehabilitation programmes cannot be done in prison, it's got to be done in the second tier place. There's prison and then there's home or there's prison and there's community. There has to all of that stuff needs to be done in a separate second place that lies between prison and home. Yeah. The more it looks like an appendage, an appendix of prison it's not real. If you buy in to the thought that these people have been culturally brutalised. All of us have been colonised but in a sense a lot of these people in prison their colonisation has been brutal you know. And quite cruel. Their culture is colonisation. That's it. That's why...I'm advocating [for] quite a separate independent institution...in order for there to be customised Māori tikanga programmes. A lot of them are what I call historical by nature. It introduces and gives you a part in acquaintance to history but most people don't, cannot make the dotted line connection between that history and the relevance of it today. So when they come out of prison what they've been taught on the course is what they think exists you know. So they walk out and they, they see very little of that they saw on the course you know. So the tikanga, the tikanga programmes I think have to concentrate on, on things not

\footnotetext{
${ }^{40}$ Kaikōrero, kōrero-ā-waha, 18th October 2010.

${ }^{41}$ Kaikōrero, kōrero-ā-waha, 18th October 2010.
} 
only how you behave on the marae but part of being part of membership in the culture is about the way you think and the way you make decisions and your morals and your ethics. That to me is the gap, that's the missing link. It's not about do you know your whakapapa from Hoturoa down to you. Do you know where the Tākitimu canoe landed and can you all sing three waiata? No. There's no relevance. There's no relevance ${ }^{42}$.

Some responses went further with this theme and suggested a notion that had been voiced before, that a kaupapa Māori prison may be an option worthy of further investigation (McDonald 1999):

Yeah well the thing is we've never had control of the prisons. And that's the problem $^{43}$.

I think that it's not going to work too well in the current prison system we have, I think that it's only, you'll only really see the full benefit if its fully controlled by Māori, and by that I mean the entire prison. So the whole place operates as kaupapa Māori ${ }^{44}$.

What I'm in favour of is Māori control of the whole thing, of the entire unit. Not running a classroom, but run the entire prison. Because what happens is, you have the Crown running your correctional facility, if you like, and you're trying to run this Māori thing within it, and the problem is that tikanga Māori does not fit into the Pākehā model that they are running, what they are trying to achieve and what they're doing basically. And because of that, the person that has the mana, which is the Crown, or the Ministry of Justice, or the super overseeing the prison, gets to actually to call the final shots on what's allowable and what's not. And invariably, it's my opinion that the tikanga Māori and all of that stuff gets squashed out of shape so it becomes something else, and really if it's going to work it has to be in an environment where's its tikanga Māori ${ }^{45}$.

\footnotetext{
${ }^{42}$ Kaikōrero, kōrero-ā-waha, 21st October 2010.

${ }^{43}$ Kaikōrero, kōrero-ā-waha, 17th March 2011.

${ }^{44}$ Kaikōrero, kōrero-ā-waha, 12th July 2010.

${ }^{45}$ Kaikōrero, kōrero-ā-waha, 12th July 2010.
} 
Nonetheless, for some, the idea of Māori advocating the benefit of prison was abhorrent. This is not a comment that could be considered new "Why do our people have to go to prison to learn our tikanga? The tikanga should be taught on the marae" (Department of Corrections 2003:14):

Prison is a prison is a prison. We don't need prisons in Māori communities. It's bad enough the bald heads are locking us up, you know, we need to be able to tread safe sanctuaries for our people to transition from that into being productive members of our community and prisons don't do that ${ }^{46}$.

...to me a Māori prison is a contradiction in terms because a prison is probably the most Eurocentric institution there is. You know prisons were invented in Europe you know. So I just think it's like many things that we, we plug on as best we can to keep our people safe. We run whatever programmes we can to help our kids but we've got to keep working on those broader issues as well. And too often, and understandably, we get so bogged down with the little issues and so bogged down and how do we help our rangatahi in prison that we lose sight of the, the broader things you know ${ }^{47}$.

These 'broader' things were consistently reflected upon:

To be honest. My guess is, and I've read a lot of the background stuff, my guess is Māori Focus Units were introduced, perhaps genuinely. I'll give them the benefit of the doubt, grudgingly, I'll give them the benefit of the doubt because they thought it would help reduce Māori offending you know. Well it doesn't. If there was a World outside prison that was respectful of us, where our values were lived as the norm then of course it would work, of course it would work... ${ }^{48}$

\section{Working With the Department of Corrections}

Kaikōrero identified several issues that relate to Māori external providers who secure contracts to deliver Māori cultural identity programmes in prisons. They saw that

\footnotetext{
${ }^{46}$ Kaikōrero, kōrero-ā-waha, 18th October 2010.

${ }^{47}$ Kaikōrero, kōrero-ā-waha, 24th July 2010.

${ }^{48}$ Kaikōrero, kōrero-ā-waha, 24th July 2010.
} 
these contractors were often placed in the challenging position of having to 'weaken' their Māori cultural approach, to fit in with other dominant Correctional aims and practices. This was seen to occur despite the Department of Corrections acceptance that Māori cultural identity approaches were important to affect positive change among Māori prisoners:

Because for me in the work I did for my whānau in South Auckland and the mahi Māori that I’ve done since, I've got into a lot of shit because I stood up and made it very clear my kaupapa is tikanga Māori. And in Corrections, psych services, I had managers who hated me for that. They tried to take my feet out from under me. They tried to impede my education and becoming qualified as a clinical psychologist. Why? Because I wasn't whakamā to stand up and say, you know, 'I support the whenua and I support the Māori models of operation ${ }^{49}$.

I think the difficulty is even worse than what we might think because one of one of the unfortunate aspects of Correction's culture is this mistaken belief that they have [that] they can do reformation or transformation better than anyone else and that that you are there, the provider is there under sufferance really and even moving to the point where they might be tempted to say well actually we don't need these Māori programmes any more. We know how they work let's either (a) put them out for, into the public domain to see who else is out there who might be interested in delivering the programme even though something like Mahi Tahi has been around for 22 years ${ }^{50}$.

On one level, Corrections were seen to be reticent to fully engage with Māori cultural approaches. At the same time, Corrections were viewed as being too prescriptive about programmes, and to use them to suit their own ends:

...it's not unknown for the Department of Corrections to realise that a programme, you know kaupapa Māori programme, is working exceptionally well, to get the intellectual property around that and then to run it themselves

\footnotetext{
${ }^{49}$ Kaikōrero, kōrero-ā-waha, 14th May 2010.

${ }^{50}$ Kaikōrero, kōrero-ā-waha, 23rd September 2010.
} 
or to describe the programme and tender it out to people who don't understand it $^{51}$.

...what's wrong with it [Māori cultural identity] is the meddling from the top which doesn't give Māori the freedom to create something beautiful ${ }^{52}$.

...what I worry most of all I think about cultural programmes in prison is that if they do measure them against recidivism and if the recidivism rate doesn't change then we get the blame. You know 'oh well you Māoris now you can all speak your reo but you're still bloody criminals' you know. So we get the blame. And it becomes very easy then to fob off all the other stuff that actually is to blame you know. And that's what worries me the most ${ }^{53}$.

I think there's another issue that sort of compounds that is when Corrections gets hold of a programme that looks to have a lot of promise, they tend to want to prescribe it and so they'll spend a lot of effort into determining what the boundaries of that programme should look like. They will describe it in such a way that you can't ever be flexible...but it's an organic thing rather than a instrumental thing ${ }^{54}$.

Compounding the usage of Māori cultural identity policies and programmes in prisons is the status of Māori working within Corrections who were seen to be relegated to the margins. Given that for more than thirty years the majority of people in prison have been Māori, it seems inadequate that:

...Māori staff were only advisors and they were answerable to Pākehā. So you had situations where Pākehā didn't know how to provide a direction for the Māori staff they had as Māori advisors, so they would do things like 'do the pōwhiri', or 'can you go and suss out a tohunga' that type of thing ${ }^{55}$.

Well I don't see them improving anything. I worked for Corrections... and I made a point of visiting a prison at least once a month. If I hadn't done it that

\footnotetext{
${ }^{51}$ Kaikōrero, kōrero-ā-waha, 23rd September 2010.

${ }^{52}$ Kaikōrero, kōrero-ā-waha, 12th April 2011.

${ }^{53}$ Kaikōrero, kōrero-ā-waha, 24th July 2010.

${ }^{54}$ Kaikōrero, kōrero-ā-waha, 23rd September 2010.

${ }^{55}$ Kaikōrero, kōrero-ā-waha, 24th August 2010.
} 
month I'd go to Mt Crawford just to visit you know, just to get a bad buzz to remind myself of where I was and what I was doing you know. But there are people that I worked with there at Head Office who had never ever been to a prison. Weren't even going to go to a prison, but they're running prison policy. You know, that's bullshit, absolute bullshit ${ }^{56}$.

\section{Length of Programmes}

Key amongst the problems that emerged through discussions was the issue of the time that is allocated to the delivery of Māori cultural identity content in prison. A major feature of Māori cultural identity concepts developed by the Department of Corrections is that they have been co-opted into psychotherapeutic programmes that have a relatively short operational timeframe. Measured in terms of being delivered over the period of weeks, in the views of the kaikōrero, this practice created an insurmountable obstacle that virtually guarantees failure in the course of their delivery of Māori cultural identity programmes:

It is possible to learn culture, it is possible to internalise cultural things, and I think people like me we can see the changes in action. So I think it's possible. But I don't think you can do it in a six week course ${ }^{57}$.

...when you are either repatriating somebody, for want of a better word, to be a tikanga which makes them tika. Because that's where the word comes from, it makes you right, it makes you centred. When you repatriate somebody to be in a state of tikanga, if they had it before or if they have a memory of it or a semblance of it at least you've got a niche, you stand some hope of getting them back there. But if somebody grew up entirely without one then you have a very, very difficult job on your hands. Just because let's say the person is Māori then you assume we'll fill them up with Māori tikanga. Well that's a huge assumption isn't it, yeah when they've grown up with nothing, empty totally empty. So no, a six week course ain't going to do it and you know 20 minute videos and a visit to the marae. You might as well be taking a Greek person along to a marae, same thing. Because what you're praying for is some

\footnotetext{
${ }^{56}$ Kaikōrero, kōrero-ā-waha, 18th October 2010.

${ }^{57}$ Kaikōrero, kōrero-ā-waha, 7th September 2010.
} 
kind of imprinted instinct that's in them that kind of erupts out into an interest. But there's a lot of 'if', 'maybe' and 'hope' involved there. And you've got to be prepared for failure as well in that it's not going to hit the mark all the time you know and I believe that such an exercise is not an event it's a process, right. I’ve grown up very close to tikanga for all of my life and I need retraining every second week. So for someone that has grown up without it a six week one off event ain't going to do it ${ }^{58}$.

Compounding the limited amount of time that Māori cultural programme deliverers have in order to deliver their programme is that:

....at the end of a particular wānanga...there is a follow-up wānanga which is only two days, basically to run over the things that you talked about at the main wānanga, but that's it. Hopefully you'll see them again in the next wānanga but you know prison policy says you're only entitled to be at one, one course - to enrol in one course and that's it per year. If you done a course you can't do it again. And they are the frustrating bits that we can't get around $^{59}$.

Another concern was the apparent disconnection between attendance at a Māori cultural identity programme delivered in prison over a specified period of weeks, and the eventual release back into the community at the conclusion of a prison sentence:

...it needs to be sustained not just seven weeks. There needs to be a follow up, what happens after those seven weeks, whose following them up? At this stage there's nothing in place. We need to take our people through and then have another environment that's not in those sort of environments in the cities, where they can, you know, work together with their families, and progress where they wanna go. We need houses like that, of progression, that's only the first step. The problem is the after effect, after seven weeks they go back into society, everything's out in front of them again ${ }^{60}$.

\footnotetext{
${ }^{58}$ Kaikōrero, kōrero-ā-waha, 21st October 2010.

${ }^{59}$ Kaikōrero, kōrero-ā-waha, 21st October 2010.

${ }^{60}$ Kaikōrero, kōrero-ā-waha, 21st July 2010.
} 
...on the first day you could see them moody and then five days later or four days later these blokes would be crying ah, that they were given their certificates and things like that. And so it motivates them, there is this motivational stuff like that. Six months down the track though, two ended up back in prison because there was no follow up. There's no ongoing support and so somewhere along the line we've got to get those connections back with the communities so that they can back these people up. You know, put them back in those communities and get them supported. That's one of the biggest failings that we do because what we tend to do is once we've delivered our programmes inside it's not our worry any more. But we haven’t done anything to make that connection with communities, so these guys are going to have a tikanga Māori programme and they'll finish their sentences and they're going to come back into the community. Someone's going to have to be there, around to mentor them, support them. If that doesn't happen they're going to come back to us ${ }^{61}$.

\section{Because:}

It's not just a course, it's the way you see, it's the way you conceptualise the world around you, it's the way you see other people in the street, it's incredibly all-pervasive, so it takes a long, long time to pick up Māori identity ${ }^{62}$.

\section{Working in a Prison Regime}

Many of the kaikōrero whose careers involve negotiating with prison regimes in order to gain access to prisoners cite similar experiences of being at the whim of internal prison policies that place restrictions on their ability to perform to their fullest capacity:

With that Te Ihi Tū programme we would talk to men about it and we would have 90 sometimes 94 or 95 applicants for our programme. We only had 12 on the programme but by the time they got through all the traps and the mirrors

\footnotetext{
${ }^{61}$ Kaikōrero, kōrero-ā-waha, 24th August 2010.

${ }^{62}$ Kaikōrero, kōrero-ā-waha, 7th September 2010.
} 
and everything in the Department they said 'oh we've only got four for you, for your programme'. I said 'what happened to the other 90'. 'Oh no their sentence orders didn’t fit ${ }^{63}$.

...the difficulty sometimes about working in there is that you know you've got these time constraints and stuff and sometimes we'd have officers walk in there and you were in the middle of something deep like that and it's just boom you're expected to change straightaway and you're back out into another culture, prison regime and it's quite frustrating really ${ }^{64}$.

...we Māoris came in, in the ' 80 s and particularly the ' $90 \mathrm{~s}$ and ran programmes, built on what Ana Tia had done but there were mana talks, there was vocational talks there was classes of all kinds but you see for example in our taiaha class we had guys from two blocks, we had thirty guys in there working on taiaha and because they had nothing else to do you just teach twenty foot movements in one day and you come back the next day they've learned it all perfect 'cos that's all they got to do you know and so it was perfect class to have. But we were told 'this is your last class cos now they changed to another class, you've got to give the other options a chance'. I said 'what's the other option', they said 'oh Jazzercise' which was the word in those days and I said how many enrolled and they said two, I said 'well two against thirty, that's a bit stupid isn't it'. They said 'I'm sorry but that's how it is, the programme's going' so they closed it and just ran the jazzercise for two people ${ }^{65}$.

...you know what happens with the add-ons if there was a muster blow out or say there's a whole lot of new prisoners come or say there was a riot, the first things that will always go will be Māori programmes. The first thing to be just clamped down. There will be no more programmes, they'll move people that are on the tikanga Māori programme within prisons move them down for no reason at all...So that's the add on bits to it. If it's an add on that's how you get treated you know. Now kaupapa Māori prisons there's a doubled edged

\footnotetext{
${ }^{63}$ Kaikōrero, kōrero-ā-waha, 18th October 2010.

${ }^{64}$ Kaikōrero, kōrero-ā-waha, 5th October 2010.

${ }^{65}$ Kaikōrero, kōrero-ā-waha, 17th March 2011.
} 
sword there. You've got to allow Māori to run it. If you don't allow Māori to run it, if you don't allow Māori to set the standards or set the scene for those kaupapa Māori prisons it will just be another departmental prison with a lot more tikanga programmes that's all it will be ${ }^{66}$.

So Māori programmes are not prioritised, and have to fit within administrative and logistical remit of prisons. This indicates that, despite the apparent centrality of Māori cultural programmes as a means of rehabilitation, it can be quickly dismissed in favour of mainstream demands.

\section{Funding Issues}

The limited amount of financial input from the Crown towards Māori initiatives has been well documented, "The Department expects a lot from Māori programme providers but provides very little funding” (Department of Corrections 2003:25). This was a sentiment that was reiterated with frustration among the kaikōrero:

...we had put in a twelve month budget and we were given six months of that budget and told that you will be assessed after six months to see whether or not you will receive the final six months of your budget. Now can you think of any organisation that is going to start up and operate on terms like that? No!! ${ }^{67}$.

...I guess the frustration for me is that when we went into this training down in Wellington on CBT and stuff and there was a smattering of tikanga in there where they brought a fellow in to do the tikanga aspect. A lot of us Māori were there, we challenged a lot of that stuff. I said 'you know that's okay from where you come from bro, but where I come from I want to be able to teach Kahungunutanga'. And so I have a six month battle with Corrections to get a variation in the contract to increase the hours from 100 to 120 so that we could incorporate Kahungunu tikanga ${ }^{68}$.

\footnotetext{
${ }^{66}$ Kaikōrero, kōrero-ā-waha, 24th August 2010.

${ }^{67}$ Kaikōrero, kōrero-ā-waha, 12th October 2010.

${ }^{68}$ Kaikōrero, kōrero-ā-waha, 5th October 2010.
} 


\section{Conclusion}

The primary focus of chapter has been to investigate the validity of the use of Māori cultural identity initiatives in prison by drawing upon the collective voices of the kaikōrero that took part in the research project. Despite the fact that they are described in terms of a collective, their voices have indicated a range of responses. At times their voices reflected an accord, both with the literature and amongst themselves. For instance, no-one stated that, in and of itself, Māori cultural identity was a negative. On the contrary, in line with the literature that emerges from Māori circles, Māori cultural identity is seen as a positive contribution to Māori personal wellbeing. Further, they saw that strengthening the Māori cultural identity status of Māori people regardless of their circumstances contributes to a positive outcome. A strong finding was that for many Māori, especially those whose Māori cultural status might be considered weakened as a result of generations of enforced isolation from traditional Māori cultural values and practices, the journey of self discovery that Māori cultural identity programmes yields has an unrelenting pull on certain Māori people.

Nonetheless, there was a note of caution among the kaikōrero that Māori cultural identity not be perceived as a panacea that will miraculously reduce the offending behaviour of Māori. Despite the strength of conviction regarding the potential benefits that might be gained as a result of strengthening the Māori cultural identity status of Māori people, this should not be interpreted that Māori cultural identity can be linked with reducing offending behaviour. On the contrary, there was almost universal accord among the kaikōrero that the cause of Māori offending was the social, political and cultural devastation that has resulted from generations of enforced marginalisation of Māori people by Pākehā throughout colonisation. Against that backdrop, the idea that Māori cultural identity loss should form the criminal justice system's fundamental response to Māori offending while the wider social environment that sees Māori continuing to scratch out a marginal existence at the socio-economic fringes of New Zealand society elicited responses of contempt. Further, that the Māori cultural identity status of offenders is applied by the Department of Corrections in the context of an inventory of criminogenic needs, the sense of disagreement of the majority of the kaikōrero became palpable. 
Compounding the issue is that many of the kaikōrero suggest that Department of Corrections use the prison system to lock Māori out of the ongoing theoretical development that undermines current Correctional practices. Further, that the Department of Corrections have created an environment whereby Māori external professionals who are eventually co-opted into the prison are placed in the challenging position of having to validate their Māori cultural approach to an entity that employs their services to deliver Māori cultural identity content. All of this occurs inside a regime of prison rigidity, whereby Māori cultural identity programmes can be stopped at anytime, prisoners can be transferred with no thought to whether they may be engaging in a positive manner to the programmes, the length of time afforded to programmes is predetermined to twelve week periods, and that Māori cultural identity are seen as addendums and are underfunded accordingly.

The next chapter is going to continue this line of critical enquiry by starting to narrow the focus to the content of the programmes themselves. While this chapter has looked towards the broader issue of the validity of the Māori cultural identity approach to current Correctional practices, the following chapter will investigate the Māori cultural identity content of the programmes. 


\section{CHAPTER SIX: THE AUTHENTICITY OF MĀORI CULTURAL IDENTITY}

\section{Introduction}

This chapter continues the analyses from the interviews with the research participants. Here, the dialogue moves from the historical analysis in the previous chapter to a critical view of what impact Māori cultural identity programmes and policies are having on the high rates of Māori crime. The chapter considers the manner and means in which cultural programmes have been implemented within prison environments. It starts with a reminder of the value of Māori cultural identity and its positive impact on offenders. From here, it considers the attributes needed by programme deliverers before moving to an examination of current programmes. It is argued that contemporary programmes provide a narrow, and highly formal, version of Māori culture that does not have long-term resonance for many participants. The chapter progresses to consider the distorting impact of psychological approaches upon programmes. The dominance of Western frames of knowledge has resulted in a situation in which Māori cultural programmes have not fully engaged with Māori culture. The chapter concludes by detailing the incremental changes, suggested by kaikōrero, to address these problems.

\section{Māori Cultural Identity}

This section proceeds by presenting the views of the kaikōrero on the meaning of Māori cultural identity. As earlier chapters have illustrated, Māori cultural identity is considered an essential element of Māori well-being and this is a point that was reiterated during the interviews:

The main three pillars that all human beings need is some sense of culture, language and identity and those things are interconnected they're not separate. And they charge each other up or when one is down it affects the others, so there's an interdependence and co-dependence between them ${ }^{69}$.

\footnotetext{
${ }^{69}$ Kaikōrero, kōrero-ā-waha, 21st October 2010.
} 
...it's so important because with our marae being the only place left for us, when we come on there you can see their heads lift and it gives a sense of $\operatorname{mana}^{70}$.

...It's about personal mana ${ }^{71}$.

A key element of Māori cultural identity is related to the idea that Māori, especially those who feel 'lost', need a sense of connection to the Māori collective:

...a lot of them don't know where they come from, a lot of them are lost ${ }^{72}$.

One of the most therapeutic things for me is 'ko wai koe' not 'what are you'... and the way that I work therapeutically is beginning to explore what that means ${ }^{73}$.

As detailed in the previous chapter, kaikōrero saw that they had a role in reconnecting this 'lost generation' to their cultural traditions and whānau, in a bid to provide them with positive connections:

...building up a sense of cultural identity I think is actually the key for Māori people. Feeling good about yourself, feeling strong in yourself has an enormous impact ${ }^{74}$.

...it's trying to provide from a Māori framework some strength, resilience around how I feel about myself and how I respond about what comes towards $\mathrm{me}^{75}$.

I believe that the cultural identity, the tikanga or whatever, is one of those pathways then there's something that happens in you. And so I sort of saw that as a real opportunity to go in there and, you know help strengthen them ${ }^{76}$.

\footnotetext{
${ }^{70}$ Kaikōrero, kōrero-ā-waha, 7th October 2010.

${ }^{71}$ Kaikōrero, kōrero-ā-waha, 21st October 2010.

${ }^{72}$ Kaikōrero, kōrero-ā-waha, 21st July 2010.

${ }^{73}$ Kaikōrero, kōrero-ā-waha, 14th May 2010.

${ }^{74}$ Kaikōrero, kōrero-ā-waha, 7th November 2010.

${ }^{75}$ Kaikōrero, kōrero-ā-waha, 7th July 2010.

${ }^{76}$ Kaikōrero, kōrero-ā-waha, 19th August 2010.
} 
The key to it is how to maintain that growth and self confidence, the restoration of pride, of mana...that's what it's all about ${ }^{77}$.

Māori cultural identity could be a 'gateway' to connect with people and a means of establishing pride, self-belief and strength. Some kaikōrero had relatively similar ideas on how cultural identity could be developed, as they reflected on the importance of whakapapa and whanaungatanga:

...knowing who you are, where you come from, being able to whakapapa back to your point of birth and before that, that's cultural identity, that's really, really important ${ }^{78}$.

The notion that whakapapa is an organising principle central to Māori identity and Māori society, yeah I get that...it's all about a whakapapa of ideas that's a big one for me...I don't think there's anything exclusive about Māori society that you can't find anywhere else, I don't think we are so special that other human beings don't have the same values but they call it something else $^{79}$.

Well, for a start they realise that they have self worth. In my opinion the underlying thing is whanaungatanga which is about knowing that you are a part of a wider unit. And within that unit you are valued, no matter what your skills are, the people will find what your skills are and find a place for you to fit in. So you become a valued member of your crew, your hapū, your whānau. Rather than being an individual in the big wide world ${ }^{80}$.

...one of the goals is to rekindle whanaungatanga among whānau, hapū and iwi... ${ }^{81}$

Within a prison context, this meant that prisoners had to learn aspects of cultural tradition, but they also had to have meaningful relationships with whānau, both inside and outside the prison walls:

\footnotetext{
${ }^{77}$ Kaikōrero, kōrero-ā-waha, 21st October 2010.

${ }^{78}$ Kaikōrero, kōrero-ā-waha, 7th July 2010.

${ }^{79}$ Kaikōrero, kōrero-ā-waha, 7th September 2010.

${ }^{80}$ Kaikōrero, kōrero-ā-waha, 12th July 2010.

${ }^{81}$ Kaikōrero, kōrero-ā-waha, 12th October 2010.
} 
I think it's all about rebuilding those communities, those societies, those whānau, those support groups, so that none of us are standing on our own ${ }^{82}$.

Expose them to a whānau programme. They have to come in, their whānau have to come in, be a part of the wānanga that goes on inside of the prison system towards the end of their sentence. Whānau has to come in. We stay together, we live together, we eat together and all of that sort of stuff but at the same time the men will have to be exposed to different skill bases as well. It may be just literacy and numeracy and that's all good or it may be carving or whatever, whatever the programme we decide for these particular individual we have to have a relationship with an educational outfit ${ }^{83}$.

The importance of having - bringing these people inside of the prison and working with them in there and also working with them outside of the prison, with the whānau outside of the prisons to make sure that that connection remains intact for all of that time ${ }^{84}$.

For many kaikōrero, the focus had to be on the future cultural skills and connections of the individual they were dealing with, rather than their past behaviour. In this respect, they took a different approach from the mainstream Corrections system that prioritized previous offending as the starting point for rehabilitation:

Guys that have lived with us we’ve never looked at their rap sheet. In fact, I intentionally don't. I tell them I don't want to know. I don’t need to know how they screwed up or whatever, that's not my business really. What I do need to know is that they are open to getting some exposure to what could possibly become in terms of being whānau. And it's in the context of our home that they begin to, to experience and enjoy eventually over time and yeah and participate in being whānau. I don't have any rules on the walls. There's only two things I've ever asked of anybody that's come with us is how you know that they would learn and discover what respect looks like: respect of a home and a family, respect for each other. Don’t assume that they know it now. So

\footnotetext{
${ }^{82}$ Kaikōrero, kōrero-ā-waha, 26th October 2010.

${ }^{83}$ Kaikōrero, kōrero-ā-waha, 21st October 2010.

${ }^{84}$ Kaikōrero, kōrero-ā-waha, 21st October 2010.
} 
also make it clear that the assumption is that they're going to mess up so it's okay. When you screw up I'm not going to kick you out because that's dumb. No you come, you'll be part of what we're doing...you've got to keep rules and that, just become aware of the hope and the dream of something that's better and we'll walk together long enough to make it happen. Because to me that was the model ${ }^{85}$.

For this kaikōrero and others, Māori cultural identity and the whānau provided the supportive environment in which Māori could change and grow. It was the starting point to build better lives, and it was a means to restore self-esteem and confidence:

We need to sort out our young Māori men. We need to give them hope...I think we're inspiring self confidence and self esteem, absolutely ${ }^{86}$.

Building a more positive sense of self within a whānau that offered hope was vital to Māori moving forward.

\section{Māori Cultural Identity and Strengthening the Self}

It became clear, during the research, that kaikōrero viewed that engagement with Māori cultural identity was not an 'academic' exercise, in which Māori solely learnt norms. Rather, they continually expressed that this engagement would have a profoundly positive impact on how individuals understood themselves and approached the world. As an example, many kaikōrero related that Māori who had 'done well' often had a strong sense of their cultural identity:

I think if you look at the Māori middleclass you'll find that there's a lot who they might be on good incomes but they're also very positive about their identity. They don't feel they have to apologise for that identity and they're into things Māori and they see their identities as a legitimate part of the national complexion ${ }^{87}$.

\footnotetext{
${ }^{85}$ Kaikōrero, kōrero-ā-waha, 11th October 2010.

${ }^{86}$ Kaikōrero, kōrero-ā-waha, 11th October 2010.

${ }^{87}$ Kaikōrero, kōrero-ā-waha, 6th September 2010.
} 
For many Māori, there is not a total lack of Māori cultural understanding. Kaikōrero reflected that most Māori had some experience of cultural values even if they could not name those aspects of their lives, or understood their significance:

...most Māori and most of these guys you know, even though they say they know nothing, have heard something about some of these concepts, some of these values, some of these principles... They know that you don't go into the whare with your shoes on. They just instinctively know that. They went through the funeral parlour yesterday as part of the orientation around here. They know when they come out; they've got to wash their hands. They're looking for a tap. There's no tap right there by the funeral parlour, they've actually got to come down here to the corner... of the offices there to find the first tap, but they're looking for it. Instinctively know these things ${ }^{88}$.

...although our kids might not be brought up in it [tikanga] and although our kids might not understand it, it's in the blood that's my view and I've seen how quickly they go to it when you when you start to apply some of the Māori principles. They gravitate to it very quickly and it can't be in the blood, the Darwinian theories tell us that that can't possibly be right but it just seems to me to happen ${ }^{89}$.

Many Māori have experienced elements of cultural values and norms. Yet, at the same time, those who are imprisoned have often lived in a state of disempowerment, disadvantage and disengagement. They were frequently disconnected from cultural identity, and developing Māori cultural identity values was a way to build their cultural self-esteem and confidence:

Because the whole thing depends on empowering Māori people and Māori identity ${ }^{90}$.

Kaikōrero reflected that there were different steps that had to be taken to build selfbelief, engagement and change. The first of these was that Māori people needed to

\footnotetext{
${ }^{88}$ Kaikōrero, kōrero-ā-waha, 12th October 2010.

${ }^{89}$ Kaikōrero, kōrero-ā-waha, 7th November 2010.

${ }^{90}$ Kaikōrero, kōrero-ā-waha, 18th October 2010.
} 
understand that they can make changes to their own lives, even when it feels that nothing can be done:

...the first thing I try to restore is the self belief, that you have a valid contribution to make to where you're going. You've got to where you are not because of failure, something worked along the way that's just never been validated. So we rediscover that and then we leverage off that ability into creating a pathway toward a different future. So the process does that. It's like what I call a spiral where, where we are moving toward an envisaged future...I just say to the guys 'Have you looked in the mirror today?' and most of them don't. I said 'Well if you did look in the mirror, what do you do, what do you see?'. They hop on board and have a bit of fun. And then said 'well we can't change what we see' and I said 'Well, why? Because...if you're out working covered in sweat and you want to go out for the evening you look in the mirror to see what needs to be done so that you can, can, look appropriately, you can look appropriate for the occasion' and they understand that ${ }^{91}$.

The second aspect was that Māori cultural identity, which emphasised relationships, could act as a 'protective force' as it gave Māori the necessary tools and supports from which to activate change:

I think it's got several, several dimensions to it. One is...built into cultural identity - first of all it's much more than repeating things or learning the haka and simply leaving it there. It's much more about the underlying premise on which relationships are established and I think what Māori cultural identity does is to give people the skills, the tools and the knowledge and the values that enable them to suss out relationships and maintain healthy relationships and I think that's a key part of cultural identity, relationship building. Because you think about tikanga, if you can come to that is really about relationships... The other thing that I think that's built into it, what today many people would call a risk management procedure, and that is a culture in tikanga... and the way of relating to people has built into it a cautionary note

\footnotetext{
${ }^{91}$ Kaikōrero, kōrero-ā-waha, 11th October 2010.
} 
about 'is there risk'? This is most obvious on a marae of course where the whole marae procedure is not about welcome to the marae but 'can we trust you to come across and be part of our community?'. And that's why it takes so long I think whaikōrero is essentially about building a relationship that underneath the building relationship there the purpose of it is 'can we expect that this will be a useful relationship, not necessarily an enduring one but a useful one? ${ }^{92}$.

However, these relationships had to be carefully considered so that they were sustainable for people in the longer-term and that they could develop over time:

I think in terms of tikanga Māori it has to be customised...The designers of that programme have got to be looking bifocal, at what's here and what's there, and creating a bridge. In order for both parties, for all parties are to benefit and profit from this. Yeah. You don't want the bridge just to be an introductory note, you want the bridge to be something that invites people to be included, to participate. And the highest form I think of culture is that when you become an ambassador, a representative of it, a decision maker and a leader. There are tiers of, of being part of a community. One is to have a, I have an interest in being Tūhoe...I've got dot 000 point one percent interest in the land. It starts off like that I think. Then there's a sense of inclusion, then there's a sense of participation you know. Then there's a sense, after participation, is to represent in some way. It could be the secretary of the marae committee or a trustee... all of that is part of the community. It doesn't have to necessarily be marae based you know. You, you can engage in your community by being part of the fire fighters thing or the, the Lions or the putaiao looking after the river or studying the mating habits of the Urewera possums and its relevance on farm whatever, as well as the marae and the hapū. So participation and then I think that, the highest form of, of regard about one's culture and identity is when the people say to you, 'you should

\footnotetext{
${ }^{92}$ Kaikōrero, kōrero-ā-waha, 1st November 2010.
} 
represent us, you should speak on our behalf, you be our leader'. You can't jump straight there...it has to be an engagement ${ }^{93}$.

Relationships were viewed, therefore, in terms of contributions from all sides. Everyone had a part to play in the long-term advancement of Māori communities. Kaikōrero saw that building relationships that engaged Māori cultural identity was a way in which trust can be built between those who had previously been 'strangers'. It is an opportunity for individuals to be safely integrated into the whānau, and to find their place within the collective:

I think being able to, to engage collectively in...the group and to learn about the values you know that underscore our culture is really important. Especially around collectiveness, collectivism and sharing and belonging and not being an island to one's self you know all those things I think. Now those values can also be found in other places but I think that's really important ${ }^{94}$.

It is a kind of Māori cultural conversion:

...so you can see by their kōrero how it's lifting their spirit up and lifting their mana $^{95}$.

I've seen with people who have embraced Māori culture that they - their lives have been transformed ${ }^{96}$.

The process of building a strong Māori cultural identity required the development of individual agency, so that Māori understood they could create change, but it also demanded long-term connections with whānau. In summary, it is a personal and collective endeavour. Kaikōrero reiterated that Māori cultural identity required wide scale engagement.

\footnotetext{
${ }^{93}$ Kaikōrero, kōrero-ā-waha, 21st October 2010.

${ }^{94}$ Kaikōrero, kōrero-ā-waha, 23rd September 2010.

${ }^{95}$ Kaikōrero, kōrero-ā-waha, 7th October 2010.

${ }^{96}$ Kaikōrero, kōrero-ā-waha, 1st November 2010.
} 


\section{Key People Making a Difference}

Kaikōrero regularly talked about specific people who had made a difference in connecting Māori to cultural identity norms and practices. They understood that whether a programme succeeded or failed was often on the experiences, skills and mana of the person leading the programme:

And so, often you know you might get a kaupapa Māori programme so you might get someone like Mita Mohi running a programme or Selwyn Jones or Duke Kaitapu you know and they have a profound effect on the people taking part and then you know twelve months down a road you've got somebody else doing it who doesn't really understand or who doesn't have the passion or the charisma and it becomes just another programme ${ }^{97}$.

...fellows like Duke Kaitapu, because Duke is a person who has been there done that. He's been on the wrong side of the law and so he's been catered to in terms of tikanga and stuff like that and since he's come out, he's learned from it. Retrained or trained or whatever - sent back in to deliver the same messages and the importance of that around those guys that have been there and done that sort of thing is that...there is an immediacy of a rapport if you like between him and the prisoner unlike me, unlike me going back in there going in there and well talking tikanga until I fall over at the end of the night $^{98}$.

They were often concerned that Corrections did not consider these elements within the recruitment processes for programme deliverers. This meant that, sometimes, deliverers did not have the right attributes to guide participants:

I think the present low barriers for entry to anybody to deliver this means that the quality can be very patchy and one bad operator out of 50 can pretty much torpedo the other 49 . And I think that's one of the reasons why I agree that we need to start finding a way of qualifying this and accrediting it. The risk of course, is that we get over bureaucratised and then you lose what is essentially

\footnotetext{
${ }^{97}$ Kaikōrero, kōrero-ā-waha, 23rd September 2010.

${ }^{98}$ Kaikōrero, kōrero-ā-waha, 21st October 2010.
} 
something that is operated from the puku, but needs to be operated from the puku with skill and I suppose I met more than my fair share of practitioners and they're pretty they - the, the I won't say the real ones, the good ones, identify themselves really quickly from those who can talk a lot but still don't have the practical skills to bring it together. In other words so they have a good sense of the theory but their implementation, their practical implementation, is all over the place and it's those teaching skills their ability to order their knowledge in a way that actually makes it useful to somebody as opposed to impressing them ${ }^{99}$.

The 'good practitioners' were those who were able to connect with others, and to present and engage others with Māori culture in a way that was meaningful. In many ways, this was something that could not be learnt and delivered by rote, rather it was something that also had to be embedded within deliverers. Māori cultural identity had to be lived by them. Kaikōrero reflected that Māori cultural values were often felt and experienced, and not demanded:

...value is not necessarily something that is taught but something that is felt. And I mean you tell someone 'Don't do that, don't do that, don't do that, do this, do this, do this'. They may or may not listen because they're just relying on an instruction and what is missing from that exchange is the sense of a genuine relationship. Now I don't think you can teach that. It's something that you experience and I think that if you do experience it, you can pass it on to others not by what you say, but by how you react to them and what you're doing and then, it's that's part of tikanga I think. You feel that very strongly on a marae. It's actually interesting when people are in that environment working together, they behave quite differently to each other to when they're not in that environment. Kids on a marae - we've had a group of kids at the Aorangi marae this weekend, ratbags all of them, but on marae their behaviour is very, very different. The teacher is absolutely amazed that these are the same kids and they're the same kids not because anyone has said 'Don't go there, don’t go there, take your shoes off, don't do this'. It wasn’t that that was

\footnotetext{
${ }^{99}$ Kaikōrero, kōrero-ā-waha, 26th October 2010.
} 
different, there was a different set of expectations I think and I think they sensed the expectations that went with it ${ }^{100}$.

To be effective, programme deliverers would need the skills to be able to develop relationships of trust in which engagement was directed by positive values rather than enforcement. Given the experiences and skills of some deliverers, this was not always made possible within Correctional programmes. Alongside this concern of personal attributes were also concerns about the actual attributes of the programmes being taught. It is to this which this chapter now turns.

\section{Narrow Focus of Current Practices}

Kaikōrero had a lot to say about the ways in which Correctional programmes narrowed the scope of what was considered to be Māori culture. This partly happened because programmes had to fit in with mainstream Correctional logistics:

...they never did what we wanted them to do because they never had freedom. They were governed by the mainstream prison they belonged to, they shoved anybody in there, they shoved people in at the beginning of their lag instead of the end of their lag, they just never expected them to do much in there. There was no sort of good programmes run in there except ceremonial stuff which is only skin deep in some ways ${ }^{101}$.

Many kaikōrero saw that programmes focused on aspects of ceremony and 'activities' rather than the actual values that are linked to contemporary Māori culture:

The culture they were teaching them was just simply material culture like pōwhiri and stuff like that like physical culture and stuff and not about who they were and their mana and integrity and manaakitanga and all those things that we talk about so they have not succeeded to any great extent ${ }^{102}$.

...you do wonder a little bit about the standard of cultural identity content...a Māori world view is presented that many people actually feel good and become quite expert at different aspects of it but don't really understand the

\footnotetext{
${ }^{100}$ Kaikōrero, kōrero-ā-waha, 1st November 2010.

${ }^{101}$ Kaikōrero, kōrero-ā-waha, 12th April 2011.

${ }^{102}$ Kaikōrero, kōrero-ā-waha, 17th March 2011.
} 
underlying value nor commit to the underlying purpose of it so I think there's a bit of work to be done there ${ }^{103}$.

...in terms of giving them some tools to live by, it's absolutely absent of it you know. If Corrections thinks that just going in there and having a hui with a karakia to begin and a karakia at the end and talk about olden days Māori stuff is gonna do it well, no! That's not it, that's very not it ${ }^{104}$.

Moreover, in the focusing upon ceremonial aspects, Māori culture could be designated as something for 'special occasions' rather than everyday life. Some kaikōrero were worried that, in taking this approach, it downgraded the encompassing values of Māori culture:

...those programmes are good insofar as they engage people and presumably if you've got a taiaha team for example, you learn something about working together as a team...I do think you learn something just by doing it. You know by doing a haka, you learn about rhythm, you learn about working as a team, you learn about listening to the leader, you learn about making your own contribution or you have the potential to do all those things, whether that is transferred beyond the haka is a moot point. Whether the marae pōwhiri is transformed, not transformed, transferred into homes and into workplaces and into recreational sites is a moot point. I think sometimes we run the risk of isolating Māori culture and Māori cultural identity to specific cultural occasions and it doesn't transfer easily to the situations that most people live their day to day lives in. Most people don't live their day to day lives in that sort of situation ${ }^{105}$.

Māori culture was transformed, in these programmes, into something that was formal. This approach was troubling, in the sense that Māori cultural values were cast as something for specific occasions. However, it also undermined the collective basis of Māori traditions and action:

\footnotetext{
103 Kaikōrero, kōrero-ā-waha, 1st November 2010.

${ }^{104}$ Kaikōrero, kōrero-ā-waha, 12th April 2011.

${ }^{105}$ Kaikōrero, kōrero-ā-waha, 1st November 2010.
} 
...let's teach you how to do a whaikōrero on a marae. And he'll go back with his piece of paper written by me, he'll memorise it you know. And he'll go all round the motu reciting this thing and boring everybody to pieces you know. Yep. Plastic you know...he doesn't need to learn a whaikōrero... What, you going to come out of prison and then you're going to sit on the pae? No. Likely you're going to come out of prison and go to the back of the marae and help cut up the meat, put the hāngi down, clean the toilets, set the tables. Learn that shit first you know because that is your mana to get to the pae, that's how you do it, you've got to do it right. Too many tikanga programmes take the front look of the hapu marae and just teach that stuff, the nice beautiful photograph stuff. Not the ones at the back who haven't had a wash for a week, yet marae and hapū cannot be sustainable without those people. That's the real power. Not the ones sitting up on the bench up the front talking with the Prime Minister or the Governor-General, na, the power of Māori culture are the people who turn up even when there are no cameras and your manuhiri is ten kōhanga reo babies who've come to see the wharenui and you still turn up and you cook them the kai. That's the powerhouse of, of all $\operatorname{hapu}^{106}$.

Further, these approaches meant that many other aspects of Māori cultural life were omitted, including those elements that would allow Māori to become more selfsustaining:

...we also wanted to include the extra parts of things Māori such as te mahi kai Māori, diving, fishing, eeling, kit making and all that, that you grow up working in the kitchen on a marae. Cos that's part and parcel, I think they've forgotten that was part and parcel of being Māori. We only think of reo, kawa, tikanga, whakapapa as, as the integral parts of being Māori ${ }^{107}$.

Overall, kaikōrero saw that Correctional Māori cultural programmes were 'plastic' in that they emphasized a narrow version of cultural identity that was restricted to ceremonial and traditional rituals, disengaged from contemporary values, and that did not apply to everyday life.

\footnotetext{
${ }^{106}$ Kaikōrero, kōrero-ā-waha, 21st October 2010.

${ }^{107}$ Kaikōrero, kōrero-ā-waha, 12th October 2010.
} 


\section{Māori Cultural Identity and the Psychological Influence}

One consistent theme that emerged time and again, in interviews with kaikōrero, was the dominance of the psychological model within Corrections and how that impacted upon programmes relating to Māori culture. It was seen that Corrections had integrated international psychological models and applied them to a New Zealand situation:

The psychology of criminal conduct, which is Andrews and Bonta's framework if you like, of their approach the 'Risk, Need, Responsivity Model' which comes out of that arguably pervades every aspect of the department's functioning $^{108}$.

The psychological framework had become the means by which all activities were judged and through which all responses to offenders were designed. Some saw its reach as systemic and problematic:

...psychology is incredibly insidious you know it's like a virus...Psychology goes right into your mind the more you give out the more it can crawl in there...you can take somebody's experience and if you can get into their head ...you can do some cognitive stuff to where they can then describe their experiences at a cognitive level. They can then lose their association, their reality association with what they're talking about...you've infiltrated the tikanga and you've rendered it into something that it's not...So psychology is really bloody powerful you know it's an affliction of the western world in the way it influences everything you know, it's just marketing and just perception of reality and what we think it's important and what we think is love and everything $^{109}$.

Kaikōrero identified that psychologists could see the value of Māori cultural approaches but did not know how to explain it, or measure it:

...psychologists, and this is my personal view, are the holders of the truth in Corrections. They determine what is and what isn't, what works and what

\footnotetext{
${ }^{108}$ Kaikōrero, kōrero-ā-waha, 29th October 2010.

${ }^{109}$ Kaikōrero, kōrero-ā-waha, 20th October 2010.
} 
doesn't. Why it works and why it doesn't. And so, for a while, Māori culture and cultural, those practices were assigned to the craft, education, hobby kind of thing. Then people started seeing some other benefits coming out of it. They started seeing some results and thought 'hang on, this is doing more than just keeping people occupied for you know six hours a day. It's actually bringing about some profound changes in their life, what, what we in prison might call rehabilitation' and so, so then the psychologists realised that there was something going on here that they - that their science didn't equip them to understand but they could measure the results. Now what they had trouble doing was linking the results to the cause. In other words a Māori would say 'oh that's because they learnt to speak Māori or learnt their tikanga' and then the psychologists would say 'yeah but we notice also at the same time that this person learnt to read ${ }^{110}$.

I could see the value of it you know and just didn't question it any more but what I could see also was that notwithstanding the value of that approach, it wasn't necessarily being embraced willingly by the powers that be in Corrections...the field is still dominated by clinical psychologists in Corrections and essentially what they do is collect evidence, measure that evidence and say on the basis of probabilities, somebody with three eyes is going to be blind in one ${ }^{111}$.

Given the limits of culturally-conscious psychological knowledge within Corrections, kaikōrero understood that Māori cultural programmes would soon be corrupted, to make them 'fit' within scientific, evidential-based approaches (as well as the logistics of Correctional timetables):

But you know it got corrupted in that...if you're talking about psychologists as a group...they just want to actually see things in their own way you know it's sort of like a, we can call it the Pākehā way or call it the western way or whatever...So I, I recognised that pretty early and, and tried to figure out ways where you could kind of influence them despite themselves. You know had to

\footnotetext{
${ }^{110}$ Kaikōrero, kōrero-ā-waha, 26th October 2010.

${ }^{111}$ Kaikōrero, kōrero-ā-waha, 26th October 2010.
} 
kind of you had to kind of outwit them...you know that was going to default back anyway $^{112}$.

Alongside these problems, kaikōrero outlined several concerns about the dominance of psychological approaches to Māori offenders. They saw that the 'treatment' based approach was one that was patronising in the extreme:

... it's the height of arrogance, to walk in to a grown man and say 'you're sick', and to learn this, and you'll be better, that's not going to work with those people... ${ }^{113}$

It was seen that the psychological stance emphasised individual solutions to what were often larger social, cultural, political and structural problems:

Corrections are driven very much by the psychological model. The psychological model focuses entirely on the individual: 'you are not well, you are you are um point 5 not well or you are point 7 and...at high risk of reoffending again'...so you're looking at the individual, so what do you do you throw programmes at these at these individuals. Ah what my belief is that we should have a collective view and that the collective should be sitting out there in the community and we should be working to embrace these people coming out. That's because the psychological model is so embedded and this is where and if I use Pākehā terms the sociological model is a far better fit for Māori than the psychological model. So the sociological model is the collective it's you know ah whānau, hapū, iwi, it's communities. That's the sociological model and its strength based it's looking at the positives the strengths of those communities that can support. You go to the psychological model and they will always look at the negative the deficit base thing start from there. It's been embedded it's been nailed down and that's the biggest problem. They don't want to change and the shame of it all is that it's so embedded in there and until we move away from that we will never drop our recidivism rates ${ }^{114}$.

\footnotetext{
${ }^{112}$ Kaikōrero, kōrero-ā-waha, 20th October 2010.

113 Kaikōrero, kōrero-ā-waha, 12th July 2010.

${ }^{114}$ Kaikōrero, kōrero-ā-waha, 24th August 2010.
} 
This stance emphasized negative behaviours to be fixed, rather than encouraging positive behaviours. Further, it minimized opportunities to engage with other disciplines that might offer other solutions to offending behaviours:

I think there's a broader issue and that is that this love affair with cognitive behavioural programmes and the clinical approach has excluded the possibility of other programmes that could be based on social psychology or anthropology or criminology that could be equally effective you know. And so anything that didn't fit within that very narrowly defined model of risk, needs, responsivity was not considered to be rehabilitative ${ }^{115}$.

The psychological model ignored potential contributions from other western forms of knowledge. However, kaikōrero also saw that this dominant approach was one that prioritized Western values, sometimes in forceful ways:

Although sometimes I think it's given the macho twist...sometimes I think they become more almost aggressive about their culture. Not aggressive, it's the wrong word, but overly assertive, whakahīhī I think. But, you know, some people tell us that Kahungunu are prone to that too! ${ }^{116}$.

...the Pākehās you know that write all these things and stuff like that because they think everyone thinks the same, what they don't understand is that a lot of people don't actually use cognitive thinking in the same way ${ }^{117}$.

Kaikōrero discussed, too, how Māori cultural values were seen to have been subverted and redefined to fit with psychological standards, and to be made acceptable to a Correctional audience:

...psychologists at the time, and I was part of it, started developing what they called a Bicultural Therapy Model, which always struggled from being a takeover by a western set of values of Māori culture and then of it's of it being confined and redefined and all those sort of things. What it did do was that it opened a whole lot of psychologists to a whole another way of thinking but

\footnotetext{
${ }^{115}$ Kaikōrero, kōrero-ā-waha, 23rd September 2010.

${ }^{116}$ Kaikōrero, kōrero-ā-waha, 6th September 2010.

${ }^{117}$ Kaikōrero, kōrero-ā-waha, 20th October 2010.
} 
the problem with it was that they needed to bring that that tikanga Māori, that Māori cultural approach into a framework that they could relate to and in doing so I mean you, you end up making an assessment of one culture by standing inside the values of another and it's just worthless ${ }^{118}$.

I think what worried me and subsequently was the co-option of that by Pākehā and the development of western models of you know they call it bicultural therapy $^{119}$.

The way of thinking that emerges from te ao Māori is a different way of thinking. It is not the same as western psychology and one of the dangers I think of trying to align them too closely is to begin to explain one through the eyes of the other. So you begin to explain Māori cultural identity through the eyes of western psychology and miss the point because they are different bodies of knowledge. There is an interface between those two bodies of knowledge but they are different. The conclusion you can reach, if you take the Māori world view, might be a similar conclusion you can reach if you take a psychological point of view but you're coming at is from different ways and the risk of having something like psychology being the overriding discipline within which cultural identity develops or a Māori world view develops is that you distort it because you're using one set of tools to evaluate and develop another which don't obey the same rules - different ways of understanding knowledge. The interesting point is the interface and most of us live at the interface you know there's very few Māori live exclusively in te ao Māori. Very psychologists live exclusively in a psychological world. There's kind of a bit of a mix somewhere along the line. What happens at the interface is important but I think the risk of assuming that a Māori world view can somehow be explained through psychology is naive and might in fact undermine the world view. By saying oh well this can be explained this way. I don't think it can. The tools they use are not tools that have been derived from te ao Māori ${ }^{120}$.

\footnotetext{
${ }^{118}$ Kaikōrero, kōrero-ā-waha, 26th October 2010.

${ }^{119}$ Kaikōrero, kōrero-ā-waha, 23rd September 2010.

${ }^{120}$ Kaikōrero, kōrero-ā-waha, 1st November 2010.
} 
As described in the last quote, the interplay between psychological and Māori values is not necessarily static; there is opportunity for shifts in control. However, the ability of Māori norms to become dominant has been undermined by other practical issues, such as the approach by Corrections to rely on staff recruitment from overseas:

...when I think of Pākehā, or Corrections, thinking what have they been doing to whakamana Māori, well I can tell you now from my own experiences that they are more than happy to have their Māori clinical psychologists leave the service. At one time, there was the largest clinical Māori psychologists group in the World, there were 15 of us, it was a powerhouse, did they wanna whakamana that? NO! They'd rather spend money in importing Pākehā from America, the UK and South Africa to work with our whānau here. I don't think any of them have been overly interested in learning the reo. But there you go, there's no surprises there ${ }^{121}$.

Added to this, is the fact that even the best 'pilot' programmes can be undermined when they are rolled out across diverse prison environments:

...I was there in ' 92 and ' 93 when the evidence started to come out from Canada around the value of cognitive behavioural programmes and was fully supportive of something that could seen to be clinically provable and the certainly the pilots that were run in Canada were extremely, extremely impressive and, and I guess one of the things that I learnt from that is that when you have a pilot and you're investing so much resource into it, you usually end up with the best facilitators, you know the most skilled presenters and psychologists in the world sometimes...so you invest this amazing skill level into a programme and because it's spotlighted the whole prison changes...the way it does stuff to meet the needs of that programme so the programme is in charge you know. Um and then you try to replicate it a hundred times, and you replicate it with people who are not experienced, who do not understand the kaupapa and often you try and replicate it into in prisons in which they don't give a shit about whether prisoners are rehabilitated or not

\footnotetext{
${ }^{121}$ Kaikōrero, kōrero-ā-waha, 14th May 2010.
} 
and often don't believe in it. And very often will go out of their way to make sure that it's not effective ${ }^{122}$.

Again, the need for programme delivers to have significant skills is emphasised. This is linked to good quality financial and staff support to lead programmes to success.

It seems, therefore, that there are multiple aspects of Correctional thinking, culture and staffing that inhibit the opportunities for Māori cultural programmes to be effective within a prison environment. Despite this, Kaikōrero saw that success was possible for individual participants:

I think that it would have created individual instances where, where probably it was successful because someone could access someone that was useful, useful to them ${ }^{123}$.

It provides an opportunity for these young individuals to actually access a prosocial support network. That in and of itself could be valuable...it may draw them into a social context or a social circle where they're being reinforced more pro-social messages rather than antisocial messages from peers that they normally would hang out with. That's one example ${ }^{124}$.

However, overall, kaikōrero saw that the contribution of psychological services to Māori offenders was a failure:

And Psych Services are the worst they've been going for ten to fifteen years now and they're failing ${ }^{125}$.

...the recidivist recidivism rates you'll see that they haven't come down in any form whatsoever over the last five to ten years. Maybe even further than that but they have not come down so you've got to ask the question 'is the psychological model working? ${ }^{126}$.

\footnotetext{
122 Kaikōrero, kōrero-ā-waha, 23rd September 2010.

${ }^{123}$ Kaikōrero, kōrero-ā-waha, 20th October 2010.

${ }^{124}$ Kaikōrero, kōrero-ā-waha, 29th October 2010.

${ }^{125}$ Kaikōrero, kōrero-ā-waha, 18th October 2010.

${ }^{126}$ Kaikōrero, kōrero-ā-waha, 24th August 2010.
} 
Disappointing that government departments will still be highly critical of something that is, some mātauranga that is absolutely tūturu Māori and they will put that to one side while they bring in some philosophy from some dead white male in Europe and say that because that one is academically qualified it must be able to resolve the Māori problems. Yeah whereas we know it doesn't because otherwise we wouldn’t be building so many prisons. I mean it's got to stand to reason that those philosophies from Europe and even from Australia I hasten to add, are not working here for Māori... ${ }^{127}$

Many saw that psychological advances had done nothing to advance the situation of Māori who faced formal punishments. They viewed that this approach had done nothing to address the dominant, punitive approach to those who break the law in New Zealand. The underlying philosophy of retribution had not been shifted in favour of rehabilitation. In this context, prisoners are left with few options, and have to make the best of their situation, to meet the demands of their sentence plans and parole provisions:

New Zealanders see the whole Corrections department as a business of revenge and punishment, that's it. And, generally New Zealand society get very upset if they find that prisoners are undergoing MA courses and bettering themselves because they see those things as rewards and privileges. You're not in prison to be rewarded and to be privileged, you're there to suffer and to undergo pain and deprivation. And generally in New Zealand society that's what they want to see...So hence you have what I call provisional programmes where you can quickly turn them off. So that's where the Department is now. I remember the time when it had a full commitment to things Māori. That has been watered down in my observation very to a substantial degree in the last five years. They're now turned to clinical sciences for their programmes. There's been a fashion of programmes that have gone through the prisons and I think the prisoners they're just glad for anything you know. If you practice witchcraft as rehabilitation then they'll go for that as well. Because that's much better than sitting in a nine by nine cell

\footnotetext{
${ }^{127}$ Kaikōrero, kōrero-ā-waha, 12th October 2010.
} 
you know. If you said well okay we're going to we're going to make you all religious and you've all got to go to church and pray tell me where it is ${ }^{128}$.

In summary, kaikōrero identified that psychological approaches have not been beneficial to the majority of prisoners in New Zealand. The guiding norms of psychology had undermined Māori cultural norms, at the same times as cultural programmes were being implemented. The reliance on a psychological framework meant that Māori knowledge, approaches and people (as well as those from other academic disciplines) were misunderstood, subverted and distorted. This approach emphasizes the negative attributes of Māori offenders and their whānau, and it establishes that they are in need of individual 'treatment'. These Western values are enticing and, to some degree, measurable. Yet, if imprisonment rates are to be considered, the evidence demonstrates that Māori have not been helped by these psychological experiments. From here, kaikōrero saw that there had to be change.

\section{Māori Cultural Identity and Further Development}

Addressing questions about how Māori cultural identity programmes might be better built within prison environment, kaikōrero had many ideas for incremental change within Correctional approaches. A dominant idea was that programmes should be reworked to address values and principles rather than procedure and ceremony:

So I think it's looking at the world... and having it more principle focused rather than a procedural focus which is kind of how I would read it - maybe paying too much attention to ritualistic aspects and ritualistic phenomena such as pepehā, mihi and so on. Those things are important but...they're not even the core of the story in my view. I think it's more about having a principle focus which may or may not be informed by traditional Māori culture but I think if there's a place where Māori culture could have a major impact that that would be the place. But also I think it's about being careful about not having too many top down expectations that 'oh well if you're a Māori offender then you must be into this'. You know and 'cos no doubt from your

\footnotetext{
${ }^{128}$ Kaikōrero, kōrero-ā-waha, 21st October 2010.
} 
own experience there's a number of our Māori offenders couldn't give a fuck to be fair ${ }^{129}$.

The more I think about it, the more I think that one of the challenges is for whānau to be able to develop a kawa that helps them in their relationships with each other at home, even when the going gets rough, they have a kawa that they work from to help some of their eating because they have a kawa about eating. It helps them with their drinking because they have a kawa which says okay if we're going to drink, we do this, this and this so that these risks are minimal. If they're going to play sport, they have a kawa about that. It think that all those kawa of course are based on values. We tend to think sometimes that a kawa is something you do on a marae. There is a marae kawa but it isn't the same. And it's a kawa that people live their lives at homes, most of them certainly grow up in a home. Quite a lot of homes don't have any kawa there's no system. Things just happen. And quite often it all works out quite alright but quite often, it doesn't work out alright. So that's the challenge I see that that you'd that a bit more really about how do you apply cultural values and tikanga to situations where people actually live ${ }^{130}$.

...it's a question of sticking - being relevant... They think they can all do the fantastic pōwhiris and weros and stuff like that, some can speak on their behalf in Māori and as one of them said 'and we get out there...and it's irrelevant'. And, and to a certain extent he's right and so it's about doing the right meaningful stuff in there ${ }^{131}$.

The idea that cultural programmes should more readily connect with the daily experiences of participants, and to set them up to succeed on this basis, was continually emphasised. In this way, programmes have to consider how Māori can positively ‘function' and to move away or desist from crime:

...if we're going to create some sort of change in behaviour at least try and facilitate that and arguably we're talking about desistance, we're talking about

\footnotetext{
${ }^{129}$ Kaikōrero, kōrero-ā-waha, 29th October 2010.

${ }^{130}$ Kaikōrero, kōrero-ā-waha, 1st November 2010.

${ }^{131}$ Kaikōrero, kōrero-ā-waha, 12th April 2011.
} 
behaviour change over time, we really need functional models. So my challenge to Māori scholars would be in this area would be to look more closely at functional models that and, and maybe they may not work in that context but that would be my challenge. To get more functional models so that they are effective ${ }^{132}$.

Alongside changes within the actual nature and scope of programmes, kaikōrero identified that there needed to be closer scrutiny and training of those who had the task of delivering programmes:

...if we don't have people who are competent to work with our people then it's not gonna work. So what does competency mean from where I sit in regards to Māori cultural identity? Well it's understanding what makes Māori tick...but they have to come with the right attitude, be prepared to do what it takes to become competent with working with Māori ${ }^{133}$.

...some teachers don't have the skills, some teachers don't have the full grasp of the language, some don't have the personality. And some are so narrow in their view that, you know, and some are good and well it's the same in any field but...the question is how would you train them ${ }^{134}$

Shifts within those who provide programmes needed, too, to be accompanied by cultural shifts within prisons, to respect the needs of programme deliverers and to prioritize Māori values across the environment:

It has to be a viable, well respected and reputable institution that know the hell what they're doing, what the goals are, you know and, and it's not really a hobby where you move from your prison cell into the 'Rec' room and then you sit down and listen to somebody for two hours and there it is. And then you go back to your cell it's not...it will never work in my view. It has to be a really well thought out programme of rehabilitation and not something that's

\footnotetext{
132 Kaikōrero, kōrero-ā-waha, 29th October 2010.

${ }^{133}$ Kaikōrero, kōrero-ā-waha, 14th May 2010.

${ }^{134}$ Kaikōrero, kōrero-ā-waha, 12th April 2011.
} 
just called rehabilitation but is there just as entertainment from the relief of the prison cell ${ }^{135}$.

Māori cultural identity programmes could not just be an 'add on'. Kaikōrero saw that prison logistics should revolve around accommodating Māori cultural needs, rather than the other way around. In the same way, it was articulated that the ways in which programmes were evaluated needed to be considered from a Māori cultural worldview. This might mean an acceptance that certain 'success' factors might not be measurable:

...is it sufficient to cover things Māori such as tikanga, such as reo, such as kawa, such as wairua. But then the big question then is how do you measure wairua. It's one of those intangible things that you can’t measure ${ }^{136}$.

Testing had to accommodate kaupapa Māori principles, it had to be rigorous and to be able to explain cultural nuances:

...they haven't supplied the research. I mean there won't be evidence to say that this is working because no one has taken the trouble to do the - set up a programme to see, to test that theory so you can't throw out that it hasn't been tested $^{137}$

...if we're going to measure the impact we need the right tools to measure impact and need to know what are the best indicators that can be useful in saying well this is an impact. It's negative under these circumstances, positive under these circumstances, neutral under these circumstances. That's the sort of research that we do need, I agree entirely we shouldn't just do this on the idea that's a really good idea that everyone knows their whakapapa ${ }^{138}$.

I worked with some of the evaluators in Corrections and some of the requirements to evaluate a programme were so stringent that most Māori providers would have just found them too difficult. They used all sorts of

\footnotetext{
${ }^{135}$ Kaikōrero, kōrero-ā-waha, 21st October 2010.

${ }^{136}$ Kaikōrero, kōrero-ā-waha, 12th October 2010.

${ }^{137}$ Kaikōrero, kōrero-ā-waha, 7th November 2010.

${ }^{138}$ Kaikōrero, kōrero-ā-waha, 1st November 2010.
} 
reasons for it but what it comes down to was there was this mix of one world and another. I'll give you an example of that, when I went to see Nau Epiha and Pakake Winiata you know a long time ago, it was when I first started kind of stumbling around on this. Yeah oh there was Tu Williams and I think the other one was Mereana Pitman anyway we went there and you know there was a lot of kōrero but the thing that really bit me and it still continues to hold onto me is somebody stood up and they were talking about the kaupapa for their research and it kind of went something like this - kia tū rangatira ai te tangata, te whānau, te hapū, te iwi, kia tutuki ai te kōrero e kore au e ngaro, he kākano i ruia mai i Rangiātea. You know seemed to me that that was exactly what this whole approach was. It was about reo, it was about watering and nurturing that seed inside every one of us, that makes us Māori so that we can then absolutely state that that seed was planted in us in Rangiātea will never be lost and so we can all stand in the chief way that kind of thing struck me as the essence of it ${ }^{139}$.

From this view, the development and consideration of Māori cultural programmes had to be understood in terms of their collective contribution. Relatedly, the final necessary development was that whatever happened within prison walls had to have flow-through into the wider collective of the community. In particular, many kaikōrero saw that great gains could be made within a prison environment as individuals had the time, and often the focus, to engage with the norms and practices of Māori cultural identity. However, these advances could be soon undermined when Māori left prison without the support of whānau:

I think one of the things we have underestimated is not so much what happens within the prison but what happens when one comes out. My own sense is that culture is at its most effective when it assists people in reintegrating people back into the community, not in the sense of rehabilitative therapeutic approaches within the prison. So that if the environment when somebody is discharged from prison is highly supportive and engaging and there's a level of accountability to a greater social entity that is both supportive of the person and holds them accountable for their behaviour, you can reduce reoffending

\footnotetext{
${ }^{139}$ Kaikōrero, kōrero-ā-waha, 26th October 2010.
} 
by a significant amount. Some people would say that you can reduce reoffending within the first six months by around 40\%, and I think that's probably true $^{140}$.

One of the problems that we have is that when these guys leave the prison, the kōrero's still there, the wānanga's still in their heads, but they don't implement it when they come out. They somehow leave that behind in some of the prisons and so it's about trying to maintain contact with these guys. It's about trying to maintain the drive of tikanga and fully reminding them that the word tika means right and the word tikanga means the act of being right and all of these things around tikanga ${ }^{141}$.

Kaikōrero identified that both cultural values and relationships had to be strengthened on release from prison:

I really think that te ao Māori and the notion of kawa has got to be embedded in families. That's where I would put my effort. I think if we say well it's the marae or the kura, or the kōhanga to do it we are giving people a partial answer which is kind of outside their norm. Their norm is not on a marae you know that's not norm. You can kind of feel good about being there and that's great. Then you go home and the worlds completely different. All the things, all the kawa and things that apply there suddenly disappears ${ }^{142}$.

Māori cultural identity, while emphasized within specific prison units and programmes had to be further strengthened across all aspects of society.

\section{Conclusion}

Overall, this chapter has demonstrated that Māori cultural identity has an important part to play in offender's desistance from crime. Kaikōrero emphasized that building cultural identity is important in strengthening the self-esteem, confidence and mana of Māori people. Developing whakapapa and whanaungatanga, for example, were important elements to these processes. Many talked about the importance of building

\footnotetext{
${ }^{140}$ Kaikōrero, kōrero-ā-waha, 23rd September 2010.

${ }^{141}$ Kaikōrero, kōrero-ā-waha, 21st October 2010.

${ }^{142}$ Kaikōrero, kōrero-ā-waha, 1st November 2010.
} 
relationships with whānau, particularly outside the prison walls, and the necessity of focusing upon positive attributes and contributions of those who had previously offended.

The development of cultural identity was also shown to be an approach that required understanding as well as practice. At a personal level, prisoners had to accept that they had agency over their lives. However, individual change would not happen from individual effort alone and kaikōrero were at pains to point out the need for collective engagements.

This research has shown that, within a prison environment, current approaches to Māori cultural identity programmes are problematic in several ways. It is evident that the institutional commitments to Māori culture can be less than supportive. Added to this, programme deliverers sometimes do not have the experience, skills or mana to lead groups of people in cultural norms and values. However, cultural identity programmes were also seen to be deficient: they were undermined by logistics; they were overly focused on formal aspects of culture and ceremony; they downgraded everyday values; and they undermined collective approaches. Kaikōrero also saw that the dominance of psychology within the Corrections model was detrimental to Māori. This framework systematically downgraded and misunderstood Māori culture, and patronised Māori. Under this approach, Māori-focused programmes were inevitably corrupted: the emphasis was given to individualized, Western norms that had no real relevance to Māori. In this realm, cultural identity programmes could never succeed.

The chapter concludes with the suggestions kaikōrero gave for change within Correctional approaches to Māori. These are incremental changes that focus on addressing the values of programmes, the skills of deliverers, institutional culture shifts, changes in evaluation approaches, and further whānau connection. All of these are possible and may make a difference to the success of Māori culture identity programmes within the current sphere of Corrections. This, together with further issues, is considered in the next discussion chapter. 


\section{CHAPTER SEVEN: DISCUSSION}

\section{Introduction}

The preceding chapters have illustrated the nature of the discourse on Māori cultural identity and its relationship with reducing Māori recidivism. There is a confusing array of explanations that have been offered in response to the phenomenon of overrepresentation of Māori in the criminal justice system, and the loss of Māori cultural identity figures highly amongst them. This chapter discusses the findings of the research that I conducted amongst the kaikōrero, and merges the results of their stories with the existent literature on Māori and offending. As this chapter will reveal, there are a number of competing themes that have weaved their way through this study: historical Māori cultural identity loss and reclamation; and, contemporary forms of Māori cultural identity loss and reclamation.

The following two sections will begin by recapping key elements of the Māori cultural losses that occurred throughout the history of colonisation as well as the Māori cultural resurgence that occurred throughout the process of the Māori renaissance. Despite the fact that this history has been articulated in greater depth throughout earlier chapters, it is important for the context of the argument that runs through this chapter to reiterate these points again.

The key argument is that Māori have experienced two distinct waves of Māori cultural identity loss. The first, as has previously been discussed, occurred throughout the historical course of colonisation that left Māori marginalised socially, politically and culturally in contemporary New Zealand. As a result of an increasing surge of Māori voices though, gains have been made whereby Māori have fought for the recognition of Māori cultural identity as an essential element that Māori are not willing to relinquish.

With cultural changes in the field of education that occurred as a result of the efforts of people like Professors' Whatarangi Winiata and Ranginui Walker, Māori now have educational institutions from preschool through to tertiary level studies. Similarly in the field of health, Māori medical practitioners like Professor Mason Durie and Dr Irihapeti Ramsden have laid the foundation for a raft of Māori cultural practices that 
have become so normalised that the health industry cannot openly ignore them. We experienced cultural losses, and fought for and reclaimed Māori cultural spaces.

In many ways, the importance of Māori cultural identity has been agreed by many parties, including the government. Across the field of criminal justice, there has been an acceptance that the loss of cultural norms and values is unsettling and detrimental to Māori, as well as to wider New Zealand society. For this reason, within Corrections especially, Māori culture has begun to take a central role in policies and practices of offender rehabilitation.

However as this chapter will argue, with the liberal use of Māori cultural identity policies and practices by the Department of Corrections over the course of the last two decades, Māori are again facing a detrimental threat to Māori cultural values and practices by Pākehā. The nature of the contemporary threat that we are facing now though is distinct from the methodologies that were used through our colonialist past. Whereas the practices that were employed against us in the past were overt and brutal, the challenges to our culture in New Zealand's prisons are covert and subtle. Nonetheless, I believe they still emerge from the same fundamental basis that values a Pākehā world view and processes over Māori.

\section{Māori Cultural Identity Loss}

The losses that Māori have experienced over the course of colonisation are well documented and unquestionably recognised as the fundamental basis of widespread Māori disarray, at social, political, economic and cultural levels. Māori have been placed at the margins of New Zealand society, and the foreign systems and processes that appeared with the arrival of Pākehā have cleansed Māori of our culture. In doing so, Māori have been forcefully isolated from the key cultural features that had previously defined us as a people up to the arrival of Pākehā. This has resulted in what are now multiple generations of Māori who have been born into a cultural milieu with little or no knowledge of the Māori cultural features that defined our ancestors' lives. For many Māori, there has been a disconnection from our language, traditions, social networks and our view of the world.

Two key histories that played a significant role in creating a sense of inevitability in the process of cultural disenfranchisement were the urban migration and the 
subsequent urbanisation of Māori society. As has been illustrated in earlier chapters, prior to World War Two, Māori were predominantly a rural people. With migration and urbanisation, all of this changed. Māori were funnelled into towns and cities, in the search for employment, and soon found that their difference led to their socioeconomic marginalisation, discrimination and criminalisation. Surviving in these environments required Māori to adhere, to some extent, with Pākehā-defined ways of being. The result has been that, unlike their parents and grandparents, the majority of contemporary Māori cannot speak or understand te reo Māori, they do not know or adhere to their parent's Māori values, and have not experienced the traditional collective unity of their people. At the same time, this population of Māori were barred from acculturating into the dominant Pākehā culture. They may have spoken English, gone to Pākehā schools, lived in an urban individualised environment but they never 'passed' into the dominant culture's values either. Subsequently, a new urban Māori culture was created that, Moana Jackson (1988) argued, was a culture that normalised conflict with a justice system that had warred with their grandparents and marginalised their parents.

As this generation attempted to navigate their way through an environment that was overtly hostile to their presence, they found themselves embedded in a society where Māori culture existed in a subordinate position to Pākehā culture. They ended up existing in an environment that was a cultural wasteland bereft of Māori cultural markers to help them make sense of the world. This was a state of existence that Māori had not experienced before and there were no systems in place to deal with the ensuing social disorder that marked that generation of Māori. The result was the emergence of Māori youth who were stuck between two realities: not able to find a meaningful existence in Pākehā culture while simultaneously failing to find refuge in Māori cultural society. Inevitably, they became disenfranchised, not engaging in the formal institutions available to them, while simultaneously unable to locate the informal Māori networks that may have assisted them to better socialise into their social environment, a new culture emerged that had no few values, which resulted in confrontational behaviours, including delinquency.

The status of Māori at the margins of New Zealand society became deeply embedded from the late 1960s in particular. From this point, young, urban Māori were identified 
as an unruly and problematic group, and their behaviours (as well as that of their families) became subject to official attention. As time passed, thousands of young Māori were placed into Department of Social Welfare institutions, often for 'hanging out on the streets' or for non-serious offending. These institutions were structurally, psychologically and physically damaging, and had a profound effect (Stanley 2014). These criminalizing responses, as well as the general disenfranchisement of large numbers of Māori youth from mainstream New Zealand society, had a bearing on their continued offending behaviour. By the time they had reached their twenties, this generation of culturally bereft Māori had become more firmly entrenched in what Mason Durie described as the "trapped lifestyles" of disenfranchisement and socioeconomic marginalisation. For too many, it ultimately led to lifestyles of offending behaviour and imprisonment.

\section{Māori Cultural Identity Reclamation}

Throughout the 1970's and 1980's, during a period of time in New Zealand that has been known as the Māori renaissance, many Māori voices joined in chorus under the uniting catch phrases of 'tino rangatiratanga' and 'Māori self-determination' (Durie 1998). There was an increasing Māori awareness of, and open resistance to, the ongoing and insidious nature of colonialism. While the New Zealand Wars that ravaged the landscape of New Zealand over the course of the 1840's and 1860's, together with the resultant large-scale Māori land losses, are often perceived as the defining characteristics of colonialism, the Māori lived experience over the course of time since the 1840 Treaty of Waitangi has demonstrated that the negative impacts are ongoing.

Māori renaissance emerged against a backdrop of concerns surrounding the ever increasing number of Māori who were struggling socially, politically, and culturally within the isolation of the urban environs. Consisting of an ever increasing number of strong Māori voices, that identified issues seen as detrimental to Māori wellbeing, they challenged the post-colonial status of Māori at the margins of New Zealand society and demanded change. Practically, this had led to some significant developments, including the overhaul of the youth justice system from one built upon retribution and incarceration to one that has prioritised restorative justice and community responses (Stanley 2014). However, at governmental levels, the 
renaissance has also been deeply focused on the reclamation and prioritization of Māori cultural identity. The formal acceptance of Treaty rights has provided some space for Māori cultural values and norms to gain wider legitimacy within New Zealand society. As just one example: there is now acceptance of te reo Māori as an official language.

As a result, there has been significant contemporary Māori cultural identity reclamation within mainstream New Zealand society. This has been dovetailed with numerous developments within Māori society. While, historically, identity in traditional Māori society was determined through the capacity to find genealogical ties to the broader Māori society, contemporary Māori fulfil the fundamental social need to belong in quite different ways. The Māori renaissance has allowed a flourishing of non-genealogical associations that revolve around Māori cultural values; this is seen in social groups and institutions such as kura, sports teams, wānanga, kapa haka groups, and gangs. These 'spaces' are not just where Māori culture is acted and accepted, they are also places where Māori knowledge and values have been re-defined, learnt and progressed.

Māori cultural identity is dynamic. This is clear when we see how knowledge of Māori cultural identity realities are being continually developed within media (from 'Māori TV' to 'The GC') as well as academic and social literature. We know, for example, that there is a diversity of Māori cultural identity realities for Māori society, and that traditional expectations of Māori culture have been adapted to the modern world. At the same time, Māori have been at pains to assert the value, importance and relevance of unifying aspects of Māori cultural identity. This can be seen most clearly in the relatively wide scale acceptance, among Māori, of kaupapa Māori values as a guide for engagement with the world. For instance, it was widely accepted that kaupapa Māori values have an important part to play in offender's desistance from crime. Kaikōrero emphasized that building cultural identity is important in strengthening the self-esteem, confidence and mana of Māori people. Developing whakapapa and whanaungatanga were important elements to these processes. Many talked about the importance of building relationships with whānau, particularly outside the prison walls. They also articulated that approaches could not focus on 'deficit', rather there was a need to engage with offender's positive attributes and 
their potential future contributions. There was a relative uniformity of kaikōrero perspectives on the values of collective approaches to offending as well as the need to focus on the positive status of Māori.

The results of this study have shown, too, that there is a certain degree of accord between the kaikōrero and Corrections with regards to the factors that influence Māori offending. In particular, it is recognized that Māori in prison are perceived as a concentration of a disenfranchised and marginalised population. It is also acknowledged that the loss of Māori cultural identity, or a compromised sense of Māori cultural identity, has been detrimental to Māori, and has left younger generations with a sense of dislocation. There is even acceptance, by all parties, that Māori suffered Māori cultural identity loss as a result of colonisation, and that offending and imprisonment are seen as an effect of the social disarray that resulted from these colonizing realities. In these respects, kaikōrero as well as Corrections have agreed with the literature. Together, they have supported the view that Māori cultural identity is important to Māori people and to governmental engagement with Māori people.

No-one stated that, in and of itself, Māori cultural identity was a negative. On the contrary, in line with the literature that emerges from Māori circles, Māori cultural identity is seen as a positive contribution to Māori personal wellbeing. Further, all saw that strengthening the Māori cultural identity status of Māori people regardless of their circumstances contributes to a positive outcome. A strong finding was that for many Māori, especially those whose Māori cultural status might be considered weakened as a result of generations of enforced isolation from traditional Māori cultural values and practices, the journey of self discovery that Māori cultural identity programmes yields has an unrelenting pull on certain Māori people. Cultural identity connections can offer a 'way-in' to positively influence attitude and behaviour, and to encourage pro-social lifestyles.

From these conditions, the incorporation of Māori cultural identity programmes within New Zealand's prisons seems to offer nothing but positives. It was hoped by many, including quite a few kaikōrero, that these Correctional programmes might offer a completely new way of engagement with Māori. Kaikōrero understood, all too well, that Pākehā dominance within the criminal justice system had failed them 
miserably, and had only served to embed them increasingly further into lives of control, surveillance and imprisonment. The commitment to taking a Māori focus to offending, and moving away from crime, was enticing. Yet, as this thesis has shown, the expected results have not flowed through. At the time of writing, Māori remain over $50 \%$ of the prison population (and over $60 \%$ within womens' prisons). While it is clear that Cultural Assessments, Focus Units and Therapeutic Programmes have assisted some individual Māori, they have not addressed Māori rates of offending, imprisonment or recidivism in any substantive way. Further, this thesis progresses the argument that these cultural identity programmes have had another detrimental effect upon Māori, in that they have subverted and changed the meanings of Māori cultural identity in ways that we never thought previously possible. Under the guise of progressive reform has been a significant loss.

\section{Loss}

This thesis has already shown how Māori experienced a loss of cultural identity through 'historical' processes of colonisation. The initial Māori cultural losses occurred as a result of overt and racist practices. For instance, the Pākehā removal of land impacted negatively on Māori abilities to live within collective, sustainable communities; similarly, te reo Māori was beaten out of Māori children by school teachers because the children spoke in the only language they were able to at that time, te reo Māori. These 'losses' were deep and profound, and while these practices could often be dressed up in terms of the best interests of the country or even for Māori, their outcomes were clear and recognizable. Māori were to be subjugated on their own land. These losses, as shown above, were subject to significant challenge from significant numbers of Māori who collectivised and struggled, and this led to an eventual reclamation of value in Māori culture.

This section argues that there has been a new loss of Māori culture. In many ways, this loss is more worrying as it is more hidden, it is subversive, and it is insidious in that it has affected formal interactions between government agencies and Māori. This loss has, at its heart, the integration of Māori cultural norms and language into governmental policy and practice. These developments have, from the outside, appeared to be progressive and to be culturally-conscious. However, as this thesis has indicated with regards to Corrections, all is not well in how Māori cultural identity 
has been applied and reworked to fit institutional ends. The effects of this loss are subtle and, as a result, are harder to reclaim. Moreover, the formal adaptation of Māori culture into official practices has required Māori as enablers. In this sense, Māori are participants to these developments. Within Corrections, we have worked to develop and deliver programmes, and have provided legitimacy to cultural approaches. At a personal level, many Māori may see benefit from programmes (individuals may progress their careers and they may well recognize the impact of a growing cultural awareness on course participants).

Today, community based Māori cultural identity initiatives are successful as they provide meaningful interactions between Māori, within a whānau setting. These engagements are collective, they incorporate formal traditions as well as everyday values of moral life, they focus on the potential of participants, and they 'reach out' to those who feel lost and offer an opportunity for inclusion. They provide environments in which Māori can grow, build self-esteem and confidence. In these conditions of secure identity, Māori are more able to develop other skills and successes. Such initiatives have been enticing to policy-makers. Incorporating cultural initiatives provides institutions with the ability to 'glow': the 'boxes' for Treaty obligations can be ticked, and governmental legitimacy can be enhanced as it is seen that cultural identity programmes replicate the successful community based efforts. However, as seen with this study of Correctional practices, there is no equivalence in these cultural identity practices. The lack of the transparency in these areas means that the Māori cultural identity losses are subtle.

This loss of Māori cultural identity is wrapped up in the language of Māori culture and the Correctional units and programmes that are dedicated to it. The rest of this section shows that the application of Māori culture with New Zealand's prisons is problematic for many reasons, including: (i) Māori cultural identity is being 'taught' within an environment of cultural myopia; (ii) Māori cultural identity has become 'frozen' through official incorporation; (iii) Māori cultural identity has been misappropriated, as a cover for psychological engagements; (iv) Māori cultural programmes have been distorted through the dominance of individualized narratives of offending; (v) the incorporation of cultural programmes, with their attendant Western frames, have hidden the social and structural disadvantages experienced by 
Māori; (vi) Māori have been co-opted into these processes of cultural 'attack', and (vii) Māori have been unable to transparently view how cultural identity is articulated or implemented; in short, this is a deceitful process. The overall argument is that Māori cultural identity programmes within Corrections are damaging, not just to Māori prisoners, but to prison workers, as well as to the whole basis of Māori culture. This is a cultural loss in operation, with Māori involvement.

\section{Cultural Myopia}

Despite the fact that Māori have been the majority of the prison population over the last 30 years, the default environment of Corrections is led by Pākehā culture and norms. This can be seen in the very make-up of Correctional staff: while Correctional newsletters will often incorporate pictures of brown-faced prison staff and contractors, the majority of managers and senior policy makers within Corrections are Pākehā. As a result, the mainstream operations and activities of the prisons - how Units are managed, the logistical operations, the focus of most rehabilitation efforts reflect a Pākehā worldview. Māori cultural identity programmes have been developed and introduced in this context. They offer 'islands' of cultural engagement within a world that remains 'other' for Māori. It is not unusual to hear anecdotes about how positive values within Māori therapeutic programmes are quickly undone by Correctional officers who snarl at prisoners as they lock them up for another very long night. Further, as some experiences from kaikōrero have shown, Pākehā agendas can quickly 'trump' Māori-led programmes on a whim (with programmes even being closed for jazzercise).

In these contexts, Māori cultural identity developments are clearly seen to just be a 'nice to have'. The values of Māori culture have not displaced Correctional agendas and norms; here, the cultural myopia continues. This is ironic given the situation that prisons are a majority Māori environment. However, it also underlines the point, to Pākehā and Māori, that Māori cultural identity is lesser. The colonial dominance of Pākehā culture and norms is once more emphasized and re-established. In taking this approach, we have lost part of our hard-won cultural reclamation and standing. 


\section{Freezing Māori Cultural Identity}

A second loss concerns the Department of Corrections' interpretation of what constitutes Māori cultural identity. This interpretation lacks a comprehensive distinction between traditional Māori culture and the contemporary Māori cultural reality that Māori experience today. In a sense the current proponents of Māori cultural identity within criminal justice circles have frozen Māori cultural identity into a pre-Pākehā definition and ignored the complex history of cultural identity loss that Māori have endured. As I have shown, colonisation involved the supplementation of Māori cultural values and practices amongst Māori society and the establishment of a criminal justice system based upon British law. Inevitably, this meant that Māori traditional values and practices, that for a millennia had defined and controlled Māori behaviour, were effectively negated.

As time has progressed, Māori values and practices have evolved, and they are acted out on a daily basis within Māori communities. Yet, from the perspectives of kaikōrero it is clear that these changes are not reflected within the workbooks that comprise cultural identity education. For example, many kaikōrero were aggrieved that programmes frequently revolved around formal aspects of cultural life that held lesser relevance for Māori or made them 'plastic'. In taking this approach, these programmes have 'frozen' culture into something that is not easily accessible to Māori. Further, it has had the impact of isolating Māori culture to specific cultural occasions. The true value of Māori cultural norms, and their importance as a guide to Māori people, has been lost.

\section{Misappropriation of Māori Cultural Identity}

The third loss relates to how Māori cultural identity programmes have acted as a 'cover' for psychological interventions on Māori offenders. In other words, Māori cultural identity has been misappropriated by the Department of Corrections. This can be seen very clearly through the content of the Māori Therapeutic Programme (MTP). The Department describes the programme as:

...similar to that used in existing mainstream rehabilitative programmes, centering on understanding the patterns of behaviour, emotion and interaction that lead up to "relapse” into new offending. Participants are taught social, 
cognitive and practical skills necessary to avoid such relapses. In exploring such issues, the MTP uses Māori cultural language, values and narratives to assist participants’ learning and change (Department of Corrections 2009:6).

The Māori Therapeutic Programme workbook, Mauri Tū Pae (Department of Corrections (2012d), is something to behold. In its 544 pages of explanation and exercises, which deliverers must follow over the course of 12 weeks, the content pursues mainstream cognitive thinking. There are Māori names given to case-studies, and Māori words to explain certain aspects of 'wrong' or 'right' thinking; however, the fundamental imprint of the workbook is psychological. The result will always be a psychological programme with Māori cultural identity grafts.

As kaikōrero have indicated, what the Department of Corrections has been delivering to prisoners in New Zealand are elements of Māori culture that have been grafted onto Western psychological programmes. That is not Māori culture. At the most charitable, it is an intensely skewed version of Māori culture. From this, it is worth pointing out that when evaluations emerge to show that Māori cultural identity programmes have not brought anticipated results (for example, with inconclusive outcomes in reducing recidivism) it cannot be attributed to Māori cultural education (Corrections 2009:29). Further, making the argument that Māori culture has failed can, once more, be seen as a re-assertion of Pākehā cultural dominance. It unfairly undermines the status of Māori cultural perspectives.

\section{Dominance of Individualism}

The fourth loss relates to the continuing dominance of Western individual priorities, and the subjugation of Māori collective values and practices. As explained earlier in this thesis, the dominant perspectives on the individual and whānau failures of Māori have a long history. For example, Hunn's report (1961) offered explanations that Māori had not adapted well to Pākehā society and that their 'retardation' required further examination, to address their flaws in culture and character. Part of Hunn's reflections was about Māori psychological deficiencies. However, related to this was the perspective that Māori offending was individualised and that an individual had to be held accountable, individually challenged and changed for their behaviour. The contemporary mainstream view is that offending behaviour has to be linked to 
individual attributes, responsibilities and thinking. The correctional system has, for decades, pursued work that takes a pathological focus on Māori individuals, and increasingly, whānau.

While the constant stream of policy documents that emerge from the Department of Corrections acknowledges the impact of colonisation on Māori society, the response is always focused on the individual 'unit' and their deficits. This fundamentally undermines the Māori cultural norms of collective action and collective responsibility, such that we will ask questions of our wider relationships and supports if conflict or harm is done. The responsibility for change is not attributed to the individual alone. Yet, the dominant criminal justice approach in New Zealand, and the focus of 'Māori' cultural programmes, is solely on the individual. In taking this approach, these cultural programmes once more emphasise Western values and present Māori norms in the most twisted way. It is another element of misappropriation. The output, officially stamped off as Māori culture, is a distortion.

\section{Colonial Subterfuge}

The fifth loss relates to the above two points, and builds on them, as it concerns the loss of acceptance about continuing structural and social disadvantages faced by Māori. In progressing Western traditions within Māori cultural identity programmes, we have emphasised individual and psychological explanations for offending. In doing so, we have taken our 'eye off the ball' on the real factors that impact heavily on Maori, and that lead them to become offenders and prisoners. The continuing nature of marginalisation, the economic inequalities faced by Māori, the continuation of overwhelmingly negative statistics for Māori across every aspect of social life....all of these things are not subject to scrutiny. The colonial heritage since the arrival of Pākehā, and the hundreds of years of racism that Māori have experienced, do not come under the same degree of psychological 'treatment' or examination for 'cure'.

Kaikōrero continually cautioned that Māori cultural identity should not be perceived as a panacea that will miraculously reduce the offending behaviour of Māori. Despite the strength of conviction regarding the potential benefits that might be gained as a result of strengthening the Māori cultural identity status of Māori people, this should not be interpreted that Māori cultural identity can be linked with reducing offending 
behaviour. On the contrary, there was almost universal accord that the cause of Māori offending was the social, political and cultural devastation that has resulted from generations of enforced marginalisation. There was also wide acceptance that criminal justice processes continued with practices that were institutionally racist and that placed Māori on a clear path to criminalisation. Against that backdrop, the idea that Māori cultural identity loss should form the criminal justice system's fundamental response to Māori offending while the wider social environment that sees Māori continuing to scratch out a marginal existence at the socio-economic fringes of New Zealand society elicited responses of contempt. In many ways, the loss suffered here is one that reflects the neo-colonisation that affects Māori on a daily basis, and that is regularly denied or minimised by mainstream society and government agencies.

\section{Co-option of Māori}

The sixth loss is one that may be difficult to address. It reflects the ways in which Māori are co-opted as contributors to these endeavours. While some Māori may have felt that they do 'well' out of these engagements, many feel that they are relatively powerless in front of the Department of Corrections. This is not the partnership that was guaranteed in the Treaty.

Māori have been co-opted into the process of cultural misappropriation in a number of ways: as advisors, consultants, programmers, evaluators, prison staff and prisoners. From interviews with Kaikōrero, it is evident that Māori programmers and deliverers do not necessarily have: a strong grounding in Māori cultural identity; understanding of theories relating to offending behaviour; understanding of Correctional practices; or even, understanding of psychotherapeutic models of rehabilitation. Yet, these contributions are seen to give legitimacy to the Correctional version of Māori cultural identity.

Some kaikōrero suggested that their attempts to challenge what was being taught, or to instil kaupapa Māori values into programmes, were not met with acceptance. It seems that Māori engagement with cultural identity has to conform to Correctional expectations. It seems, then, that deliverers are placed in an insidious position in which they must validate a specific set of cultural attributes. As detailed above, all of this occurs inside a regime of prison rigidity, whereby programmes can be stopped at 
anytime, prisoners can be quickly transferred, and programmes are determined by logistics rather than actual need. The engagement of Māori in these processes can be seen as a subservient one. Again, this affirms that cultural dominance of the Pākehā worldview and power.

\section{Cultural Deceit}

The final loss relates to the ways in which all of these programmes and interventions are done without transparency. It is, for example, difficult to get hold of Māori Therapeutic Programme workbooks. The content of these programmes, devised under contracting-out conditions, are hidden away under the guise of intellectual property. While there may be broad-brush discussions of what is covered, detailed descriptions of programme content cannot be seen (Wehipeihana, Porima and Spier 2003:5). This means that these interventions, that are so important to the fundamental futures of Māori individuals and whānau, are not opened up to Māori peer review.

While Māori are often involved in these developments, the fundamental access to programmes is negated under the guise of contracting out and the author's intellectual property. Māori culture, it seems, is something that has economic appeal, and it can be bought, sold, silenced and distorted for a good price that is worth protecting. This new development of knowledge reflects the old colonial practices: most Māori have had little participation into this knowledge construction, despite their central focus; and they have limited input into research design, process or final analysis. The endresults reflect those of colonial knowledge: Māori barely recognise themselves in the definitions of our own cultural heritage, we are disappointed that the focus remains on Māori deficit; and we are still waiting for beneficial results that may serve the Māori people.

At the same time, it is evident that non-Māori researchers have continued to 'capitalise' on Māori focused research projects, including within evaluations for Māori cultural identity programmes in prisons. Certain criminologists and policy analysts, who do not speak te reo Māori, have no history of engaging with Māori society, and really should consider themselves unqualified to comment on the authenticity of Māori cultural identity policies and programmes, continue to undertaken 'authoritative' research on these matters. As I have read through reports 
and analyses of Māori cultural identity programmes throughout the course of this research I have been struck by the degree of care that researchers take to legitimise their research by describing western research frames, such as validity and reliability. Yet simultaneously, their work tacitly accepts the working definition of Māori cultural identity that is provided by the agencies of the criminal justice system, especially the Department of Corrections (see, for example, Marie 2010). From a kaupapa Māori perspective, the fruits of their labour are neither valid nor reliable.

Overall, here, Māori have faced a further loss in how collective action has been systematically shut out of Correctional practice. A key aspect of Māori cultural life is, once more, undermined and subjugated.

\section{Conclusion}

The losses that have been experienced by Māori, through the Correctional implementation of cultural identity responses to offending, have been deep and wideranging. In many ways, these losses have reflected previous losses endured through previous waves of colonisation: they have asserted Pākehā dominance at every turn, and have subjugated and distorted Māori cultural identity so that Māori are once more coerced into a Pākehā norm. Some of these losses can also be attributed to the realities of institutional life. The prison environment is one that is rigid and stuck, and it does not provide space for the continuing emergence of norms and practices - these things require flexibility to which the system does not often respond. Further, the managerialism of prison practices means that elements have to be recorded, ticked off and evaluated.

With these contexts, of continuing structural disadvantage and institutional control, the colonial approaches to the control of Māori will remain embedded. However, perhaps the new element, here, is the incorporation of Māori into these tasks. This cooption presents a new issue for Māori in terms of how cultural identity may once more be reclaimed. Another corresponding issue is that, while these new developments have brought a series of losses for Māori, they are often seen as being progressive initiatives, that appear reasonable, legitimate and culturally-conscious. From the outside, looking-in, they appear as having all the right elements. They appear to operate by securing compliance, rather than engaging in coercion. In this 
regard, these neo-colonial activities are different from many of the actions that occurred through the 19 th and early $20^{\text {th }}$ centuries. These realities mean that reclamation may, again, be made more difficult.

\section{Reclamation}

The discussion in this thesis concludes with a consideration of how these losses can be reclaimed, if at all. This was not something that was fully discussed with kaikōrero however, along the way, many gave suggestions on how such changes might be addressed. Some of them were incremental changes, while others reflect more substantive corrections to how we currently 'do justice' in New Zealand.

Despite the previous, negative description of what may be wrong with formalising Māori cultural identity, kaikōrero saw potential benefits in using culture as a response to Māori harms and problems. For as long as Māori have been arguing for a greater control and management over Māori services, especially services of great need like justice, health and education, Māori have been confronted with 'shifting goal posts'. Many individuals saw that formalising cultural controls over criminal justice would reduce the power of the Crown to continually change the requirements, standards and rules for the development of programmes, approval of programmes, of organisers, facilitators and so on. What some wanted was Māori control over matters Māori, and they articulated the need to ensure a defined Māori standard around the development, facilitation and administration of Māori cultural identity programmes. How this was to be done, however, was some source of debate.

To summarise the options that were recorded: all kaikōrero saw that the current application of Māori cultural identity programmes was inappropriate in some ways. In response, various options can be put forward:

- That Corrections make incremental changes to the Māori cultural identity interventions within prison. They improve the Māori framework and assert Māori control over operations of Unit. With Māori driving Māori cultural identity policies and programmes, that are framed in a Māori world view, it is anticipated that Māori could develop and deliver a more systematic kaupapa Māori approach. Part of this package could involve kaupapa Māori approaches as a key performance indicators (that would be measured and reported upon). 
- That Corrections completely cease to use Māori cultural identity as a focus and tool within the prisons. The current programmes and approach do not reflect Māori culture and this 'experiment' should be disbanded immediately. From this perspective, Māori culture should be distorted and misappropriated in order to tick the 'Treaty obligations' box.

- That the governance of prisons should systematically be given over to Kaupapa Māori principles. Given the nature of prison populations, and the fact that Western responses to offending behaviour are not effective, the control and management of prisons should be given to Māori. This would mean that prisoners were designed and operated with prisoner empowerment and collective action as an end-goal. It would fundamentally change the nature of imprisonment, including the connections between prisoners and outsiders, and would progress rehabilitation efforts in a way that was culturally appropriate and relevant to contemporary Māori.

- That fundamentally new approaches should be given to responding to offenders who currently receive a prison sentence, the majority of whom are Māori. This would mean that Māori with an interest in criminal justice responses direct all their energies to the process of decarceration and community responses to crime. This option would mean that Māori cultural identity interventions would only be supported within a community environment.

Clearly, the opportunities for reclamation require further development of thought. It is hoped that this thesis will provide the springboard for future discussions about how Kaupapa Māori principles can be truly developed within a criminal justice framework. Regardless of the practical means of the interventions, change has to occur. Māori have been approximately 50 percent of New Zealand's prison population since 1980. Some of the prisons in the North Island have an even higher proportion of Māori. At the time of writing then, that is 34 years, or a third of a century, where Māori have been a majority of the prison population. There is nothing 
on the horizon to suggest that this status will change with Western principles towards rehabilitation. I argue that the time has come for a Kaupapa Māori approach that: engenders respect, increases participation of Māori in their own futures, recognises the experiences and discrimination that Māori face, focuses on enhancing mana and self-respect, takes care, and provides a collective approach to the social problems of disadvantage and crime. 


\section{CHAPTER EIGHT: CONCLUDING WORDS}

Māori are $15 \%$ of the New Zealand population, and yet are $45.3 \%$ of annual police apprehensions and $51 \%$ of the prison population. This status of Māori 'overrepresentation' in the criminal justice system has remained steady for the last 34 years. One principle explanation of this status is that Māori have limited access to a secure Māori cultural identity. As a result, criminal justice authorities, especially the Department of Corrections, have progressively focused policies and programmes towards the perceived Māori cultural related needs of Māori offenders and prisoners. This focus is undertaken not only to reduce rates of recidivism but also to provide culturally relevant environments for Māori prisoners and increased opportunities for successful rehabilitation.

The result is that New Zealand's prison system now contains a number of unique strategies such as the Māori Therapeutic Programme, the New Life Akoranga Programme and Māori Focus Units. Despite these developments, there remains a dearth of clearly articulated descriptions of how, why or even if Māori cultural identity has a positive effect on reducing Māori offending and imprisonment. This thesis is designed to address this gap in the research.

This thesis has taken a kaupapa Māori perspective to analyse the historical development and subsequent application of Māori cultural identity policies and programmes in the criminal justice system from a Māori perspective. It has charted the historical context of Māori engagement with the criminal justice system in New Zealand, and has shown how colonialism and urbanisation have played a detrimental role in diminishing the Māori cultural status of contemporary Māori society. In the wake of the Māori renaissance, it has become clear that those with a strong sense of Māori cultural identity have a high level of personal self-esteem, and are more likely to achieve educational success, gain meaningful employment, and be less likely to offend. With that in mind, and with the weight of Treaty obligations behind them, the Department of Corrections has engaged cultural identity programmes as a means to reduce Māori reoffending. These interventions have been wide-ranging. However, as this thesis has shown, the resultant outcomes have not been very useful for Māori. 
The thesis has questioned the validity of the use of Māori cultural identity prison initiatives as a response to the high rates of Māori imprisonment. It has shown that the focus on culture has taken attention away from initiatives that might tackle the social, political and cultural devastation that has resulted from generations of enforced marginalisation of Māori people by Pākehā throughout colonisation. In addition, this work has questioned the authenticity of Māori cultural identity programmes and policies. It has outlined that what is currently being implemented within prisons is not Māori culture at all. The dominance of Western frames, that emphasise individual fault that can be monitored and measured, lies in direct contrast to Māori cultural norms.

The loss for Māori cultural identity has been immense. In many ways, the old colonial means of subjugating Māori knowledge and propelling Māori through Pākehādominated initiatives is just more of the same. However, these losses also reflect something new, to which Māori will require renewed strength, strategy and cohesion to resist. The misappropriation of Māori knowledge as a means of control, and the cooption of Māori in this endeavour, must be subject to further challenge. It is hoped that this thesis, with its reminder of the main tenets of kaupapa Māori perspectives, will contribute to that task. 


\section{APPENDIX A: KO NGĀ KAIKŌRERO}

Ani Mikaere (Ngāti Raukawa)

Ani Mikaere is a graduate of Victoria University of Wellington and the University of Waikato, and is a barrister and solicitor. She has a background in legal education and has been Kaihautū of Te Ahunga Tikanga (Māori Laws and Philosophy) at Te Wānanga o Raukawa since 2002. She has published widely on the status of Māori women colonisation, and Māori cultural survival.

Dr Armon Tamatea (Rongowhakaata, Te Aitanga-a-Māhaki)

Dr Armon Tamatea is a Senior Lecturer in the School of Psychology at the University of Waikato. Prior to that, Dr Tamatea held a range of roles in the Department of Corrections including as Senior Advisor (psychological research), psychologist and tikanga Māori programme designer. He has also worked extensively in the assessment and treatment of sexual and violent offenders and has played a key role in the design and implementation of the High-Risk Personality Programme pilot - a violence prevention programme specifically designed for high-risk violent offenders diagnosed with psychopathy.

Aubrey Temara (Ngāi Tūhoe)

Aubrey Temara runs Mahi Tahi Trust, a not-for-profit organisation that has been contracted, since 1995, by the Department of Corrections to deliver the New Life Akoranga Programme to prisoners.

Bruce Stewart (Ngāti Raukawa, Te Arawa)

Bruce Stewart is a fiction writer and dramatist. He lives in Wellington, where he successfully set up Te Kaha Trust, the first Māori work trust and went on to found Tapu Te Ranga Marae in Island Bay. Known as a 'living marae’, Tapu Te Ranga has 
been a 'build in progress' since the mid 1970's and is a centre for Māori cultural teachings, and a natural haven for the redevelopment of native flora and fauna. Apart from being home to young, unemployed Māori in Wellington, the buildings are used by community organisations, Government departments and business groups as a place to hold meetings and hui.

\section{Charlie Tawhiao (Ngāi Te Rangi)}

In 1999, Charlie Tawhiao joined the Department of Corrections and has held a number of Māori cultural focused roles, including Cultural Perspectives Unit Manager and Māori Service Delivery National Advisor. In 2004, he went on to become the Department of Corrections Manager of Treaty Relationships which was designed to build sustainable relationships with iwi.

Sir Edward Taihakurei Durie KNZM (Rangitāne, Ngāti Kauwhata and Ngāti Raukawa)

Sir Edward Durie was the first Māori appointed as a judge of the Māori Land Court. From 1980 he was chief judge of that Court and chairman of the Waitangi Tribunal which he substantially established. In 1998 he was appointed as a judge of the High Court and in 2004 he served as a Commissioner of the New Zealand Law Commission. When he retired in 2006 he was the longest serving judicial officer. He has honorary doctorates from Victoria University of Wellington, Massey University and University of Waikato.

Francis McNally-Te Maari (Ngāti Kahungunu)

Francis McNally-Te Maari is a kaituitui for the Whānau Ora Scheme. He has been a Lecturer at Te Wānanga-o-Raukawa and Te Wānanga o Aotearoa as well as a course facilitator of the tikanga Māori programme, Te Wairua o Ngā Tangata Māori, delivered at Taumata o te Ra marae in Halcombe. As well, he has been involved in 
the delivery of tikanga Māori programmes in the Te Ara Tika o te Whānau Trust which was established to support the Notorious Chapter of the Mongrel Mob in their work to improve the social and economic outcomes of their community.

Garry McFarlane-Nathan (Ngā Puhi)

Garry McFarlane-Nathan was formerly employed as a psychologist by the Department of Corrections. He developed and implemented the Māori focused psychotherapeutic model of rehabilitation programme, the Bicultural Therapy Model. He was also the designer of the widely used Framework for Reducing Māori Offending (FReMO) model that is used by the Department of Corrections to ensure that policies that have been designed to reduce Māori offending and reoffending have included a Māori perspective.

\section{Haami Piripi (Te Rarawa)}

Haami Piripi was the Cultural Perspectives Manager throughout the consultation process towards the establishment of the first Māori Focus Unit (on 10 December 1997), Te Whare Tirohanga Māori. In that role he oversaw all the Māori focused policies throughout, what was at that time, a newly created Department of Corrections. As such he played a pivotal role in the establishment of many Māori cultural identity policies and programmes in a critical stage of such initiative.

Hauraki Greenland (Ngāti Kahungunu)

Hauraki Greenland is the Principal Advisor Māori in the Ministry of Justice. He also publishes on issues related to Māori politics and Māori identity and is an advisor to general policy and research documents on Māori and criminal justice. 
Ihaia Don Hutana (Ngāti Kahungunu)

Ihaia Don Hutana is employed at Te Taiwhenua o Heretaunga in Oranga Hauora. He has also been heavily involved in iwi affairs as a cultural advisor and te reo Māori champion. In addition, Ihaia has been delivering te reo Māori courses, tikanga Māori courses and Māori therapeutic programmes in Hawkes Bay and other prisons for the last few decades.

\section{Jack Taituha (Ngāi Tūhoe)}

Jack Taituha is a renowned kaumatua who is originally from Tūhoe but has lived for 40 years amongst his wife's iwi in Gisborne. Before retiring, he spent 20 years with the Community Probation Service in Gisborne where he is credited with having made a positive impact on the lives of hundreds of Māori offenders and their communities. He has also been a co-founder and deliverer of Te Wairua me ngā Taonga Katoa, tikanga-based programme which helps offenders find a sense of belonging by learning their whakapapa, maunga, awa and iwi.

\section{Jim Moriarty (Ngāti Toa)}

Jim Moriarty is the founder of Te Rakau Hua o te Wao Trust, a Māori cultural focused performing arts organisation working with at-risk young people in Wellington. As well, he has introduced people in prison and youth detention centres to his tikanga programmes, including in Waikeria, Mt Eden and Rimutaka prisons.

\section{John Tamihere (Ngāti Porou, Whakatōhea, Tainui)}

John Tamihere is a lawyer, media personality and former Cabinet minister, and is CEO of the Waipareira Trust, an urban Māori entity that provides health and education services to Māori in the west Auckland region. He has made a significant impact by campaigning on behalf of the urban Māori in west Auckland, who often 
have no remaining links to their iwi, entities that he believes do not reflect the reality of modern Māori life, and have proven inadequate for solving today’s problems.

Jon Royal (Ngāti Tamaterā)

Jon Royal was the National Adviser Māori for the Department of Corrections. A role that meant he was tasked with the development of Māori-specific projects and initiatives, supporting the growth and development of Māori staff, and coach and mentor to the Regional Advisers Māori Service Development.

The Honourable Justice Joseph Williams (Ngāti Pūkenga, Te Arawa)

Justice Joseph Williams is a Wellington based Judge of the High Court. An LLB and LLM (Hons) graduate, he was admitted to the Bar in 1988 and practiced law until 1999 when he was appointed Chief Judge of the Māori Land Court and acting chair of the Waitangi Tribunal. He was chaired the Tribunal between 2004 and 2009, when he was appointed a High Court judge.

Kim Workman QSO (Ngāti Kahungunu)

Kim Workman is a retired public servant, whose career spans roles in the Police, the Office of the Ombudsman, State Services Commission, Department of Māori Affairs, and Ministry of Health, the Children's Commission and the Department of Justice where he was Head of the Prison Service between 1989 and 1993. He has also been involved in the development of Māori cultural identity programmes and contributed towards the development of the first Māori Focus Unit at Hawkes By. He was also instrumental in developing the Faith Based Unit at Rimutaka Prison. Now Chairman of Prison Fellowship New Zealand, he received the Companion of the Queens Service Order (QSO) for his contribution to prisoner welfare. 
Kristen Maynard (Rongowhakaata, Ngāti Porou)

Kristen Maynard has had over 16 years experience in various public service senior policy advisor and manager roles including a period of time with the Department of Corrections. It was with Corrections where she played a key role in the development of the Māori cultural assessment tool, the Māori Cultural Related Needs inventory. She graduated in 1994 with a law and arts degree in political science at Otago University where she held the title of first tūmuaki in 1993/1994 of Te Rōpū Whai Pūtake (the Māori Law Students' Association) of the Faculty of Law. She has also been a key member of the negotiating team in the settlement of the Rongowhakaata Treaty Claims to the Waitangi Tribunal.

Māmari Stephens (Te Rarawa)

Māmari Stephens is currently a Senior Lecturer in law at Victoria University of Wellington where her primary research interests are law and language, Māori and the New Zealand legal system, and social security law. She has been a project leader with Te Kaupapa reo-a-Ture (The Legal Māori Project) which is tasked with developing a Māori language resource of Western legal concepts; The output of which is the published He Papakupu Reo Ture: A Dictionary of Māori Legal Terms. Professionally she has worked in the Māori legal team at Russell McVeagh, in Māori broadcasting, as a Probation Officer, and with the Department of Corrections.

Sir Mason Durie KNZM FRSNZ FRANZCP (Rangitāne, Ngāti Kauwhata and Ngāti Raukawa)

Sir Mason Durie is Emeritus Professor of Māori Research and Development at Massey University. He is very widely published, especially in the area of Māori health and well-being. He is credited with developing a widely influential framework of Māori health known as Te Whare Tapa Whā. This Māori view of health and wellness and has four dimensions: taha wairua (spiritual health), taha hinengaro (mental health), taha tinana (physical health) and taha whānau (family health). Each 
of these dimensions are said to be necessary for Māori health and well-being. Sir Durie has also been a leading advocate for increasing the capacity of Māori higher education and socio-economic advancement for iwi and Māori communities. He has also been a leading figure in the longitudinal study, Te Hoe Nuku Roa, a Māori developed research framework. In the 2001 New Year Honours list, Sir Durie was appointed as a Companion of the New Zealand Order of Merit for services to Māori. In the 2010 New Year Honours list, Sir Durie was appointed as a Knight Companion of the New Zealand Order of Merit for services to Māori health and public health services.

Mate Webb (Te Whānau a Apanui, Ngāti Porou, Te Whakatōhea, Te Arawa, Ngāti Awa, Ngā Puhi)

Mate Webb is a Māori cultural consultant in Auckland Prison's Te Piriti special treatment unit for child sex offenders. Drawing upon both his strong cultural upbringing, combined with a Postgraduate Diploma in Cognitive Behaviour Therapy, Mate also delivers psychotherapeutic programmes in conjunction with Māori cultural components.

Matua (Matt) Hakiaha (Ngāti Awa, Ngāi Tūhoe)

Matt Hakiaha is a member of the NZ Parole Board and a current Trustee of Te Whānau o Waipareira Trust in West Auckland. He has spent a career on justice issues especially from a Māori perspective. He has written extensively on a Māori view of restorative justice theory and processes, and trains facilitators working in the field of victim-offender reconciliation. He has worked as a Probation Officer, as a Youth Justice worker for the Department of Social Welfare, as a government consultant on Youth Justice in Western Australia, as a Youth Justice Worker at CYFS, as a lecturer on Youth Justice.

Maynard Gilgen (Tainui) 
Maynard is a Clinical Psychologist who works as clinical director of Rangataua Mauriora, an Alcohol and Drug Service in the Wellington area. Maynard has also been a psychologist for the Department of Corrections and has been involved in designing and delivering tikanga Māori non-violence programmes to Māori prisoners. Māori cultural identity programmes that are modelled on the work of Haare Te Wehi and Te Rōpū o Te Whānau Rangimarie o Tāmaki Makaurau.

Mike Hinton (Ngāti Raukawa)

Mike Hinton is the Operations Manager of Manukau Urban Māori Authority and, together with June Jackson, oversees the tikanga Māori programmes at Ngā Whare Waatea Marae in Mangere. This marae, at the heart of the Manukau Urban Māori Authority, has since the early 1980s, voluntarily provided housing and support to newly-released prisoners and court referrals.

\section{Mike Neho (Ngā Rauru Kiitahi)}

Mike Neho has spent a great part of his career designing and delivering Māori cultural identity programmes in prison and to offenders in the community. As well, he has been closely associated in administration, management and cultural roles for his iwi Ngā Rauru Kiitahi. He has played a significant role in the settlement of Ngā Rauru Kiitahi historical claims to the Waitangi Tribunal and is currently the Ngā Rauru Kiitahi kaiarahi iwi development manager.

\section{Mita Mohi (Te Arawa)}

Mita Mohi has been a leading figure in the development and delivery of Māori cultural identity programmes for offenders and prisoners for over 35 years. It was Mita who first introduced the Mau Rakau concept into New Zealand Prisons, beginning in Tongariro-Rangipō Prison over 25 years ago. His tikanga-based programme, Moko ia Taiaha Wānanga, was piloted among his Tūwharetoa and Te 
Arawa iwi and the wider Māori community on Lake Rotorua's Mokoia Island in 1980. It has been credited with changing the projectory of many lives and is considered so successful it has been implemented across the prison system. He represented New Zealand in Rugby League, was a runner up in the Aotearoa Māori Tennis Championship and has also been a professional wrestler. He has served on various Marae Committees, Land Trusts, School Trust Boards, the New Zealand Parole Board and an advisory role in WINZ and the Department of Corrections as a kaumatua and kaiwhakamana. He went on to work as a lecturer at Waiariki Polytechnic in Rotorua before eventually retiring. In the 1995 New Year Honours, Mita was appointed a Member of the Order of the British Empire for service to youth. Together with his wife, he received a Rotorua District Council community award for voluntary services in 2007. In 2012 he received two prestigious awards, the Keeper of Traditions Award for his longstanding contribution to mau rākau, and at Te Waka Toi Awards he was given the Ngā Tohu o Tā Kīngi Îhaka award.

Moana Jackson (Ngāti Kahungunu, Ngāti Porou)

Moana Jackson is a well respected Māori lawyer, academic and advocate of Māori and indigenous rights. He authored a Department of Justice Report, titled He Whaipaanga Hou, that is one of the most comprehensive research projects into the intersection of Māori and the criminal justice system in New Zealand. After graduating with an LLB from Victoria University of Wellington he undertook postgraduate research with the Justice Department of the Navajo Nation in Arizona, was a member of the first Māori delegation to the United Nations Working Group drafting the Declaration on the Rights of Indigenous Peoples, and together with now Judge Caren Fox, co-founded Ngā Kaiwhakāmarama i Ngā Ture, the first Māori Law Centre. He currently lectures in the Māori Laws and Philosophy degree programme at Te Wānanga o Raukawa.

Nau Epiha (Ngā Puhi) 
Throughout the 1970's and 1980's, Nau Epiha was involved with Ana Tia and the Maranga Māori Cultural Group teaching Māori cultural identity programmes in Mt Eden and Pāremoremo prisons in Auckland. Together with his wife, he has been involved in drug and alcohol counselling. He has also lectured and developed tertiary degree programmes at Te Wānanga o Raukawa. He is a native speaker of te reo and is a respected kaumatua among his Far North iwi, Ngā Puhi, and he is currently the Cultural Adviser at Te Kura Kaupapa Māori o Kaikohe.

Peter Maru Love (Te Āti Awa)

Peter Love represents the Mana Whenua Te Āti Awa of Wellington on the Māori Partnership Board, by nomination of the Wellington Tenths Trust. He has recently been appointed to the newly established Mental Health sub-committee of the Capital \& Coast District Health Board. He is Chair of the National Māori Advisory Group to the Department of Internal Affairs and is a Director of Capital Hill Ltd, the company which owns the Massey University Campus in Wellington. He has been actively involved in penal reform and justice campaigns in New Zealand, and in the late 1970's and 1980's was involved with Ana Tia and the Maranga Māori Cultural Group visiting Mt Eden and Pāremoremo prisons in Auckland.

Peter Sciascia (Ngāti Kahungunu)

Peter Sciasia has had a long history of studying and working at Te Wānanga o Raukawa. He has had the role of lecturer, and programme director in the Mătauranga Māori degree programme; he has also been associated with the development and delivery of new degree programmes. He has an ongoing role in various Māori cultural research projects and maintains a close working relationship with his iwi, and is a recognised speaker of te reo Māori and Māori cultural advisor.

The Right Honourable Dr Peter Sharples (Ngāti Kahungunu) 
Hon Dr Peter Sharples has been co-founder and co-leader of the Māori Party. As such he has been the Minister of Māori Affairs, Associate Minster of Corrections and Associate Minister of Education. Hon Dr Peter Sharples has also been a staunch, and perhaps the principal Māori, advocate of Māori cultural identity programmes delivered to offenders and prisoners. He has been responsible for many of the Māori cultural identity policies and practices; such as the Māori Focus Units. Recognising that there are very limited opportunities available for rehabilitation in the fullest sense unless there are links beyond our prison communities, he has had a wide range of inputs to the criminal justice system including: tikanga Māori lessons, taiaha classes, te reo Māori classes, seminars, rehabilitation lectures and visiting kapa haka programmes. He have also been involved in numerous wānanga and programmes such as Prisoners Aid and Rehabilitation Society programmes, prison reform submissions and Parole Board discussions. He was also involved in the development of the first Māori Focus Units, Te Whare Tirohanga, at Hawkes Bay Prison.

\section{Piripi Paul (Ngāti Kahungunu)}

Piripi Paul has been a deliverer of tikanga Māori and psychotherapeutic programmes for the Department of Corrections for a number of years. As well he is a graduate and an employee of Te Wānanga-o-Raukawa in the Māori Law and Philosophy programme. He is a speaker of te reo Māori and maintains a close relationship with his iwi.

\section{PJ Devonshire (Ngāti Kahungunu)}

PJ Devonshire is the current CEO of his iwi, Ngāti Kahungunu ki Wairarapa. He has also been a Lecturer at Te Wānanga-o-Raukawa, and is also a kaupapa Māori programme developer and deliverer with Te Kāhui o te Rangi, a kaupapa Māori based group of tane who have developed a series of marae based wānanga to explore the legacy of dysfunctional Māori men who are not connected culturally, who are less present in whānau, and who are not fulfilling responsibilities to society. 
Rangawhenua Paddy Tapiata (Ngāti Porou)

Paddy Tapiata has been a deliverer of tikanga and psychotherapeutic Māori cultural programmes for the Department of Corrections. Alongside PJ Devonshire, he is also a kaupapa Māori programme deliverer with Te Kāhui o te Rangi.

\section{Rawiri Kiriona (Ngāti Raukawa)}

Rawiri Kiriona works for his iwi parent body, Te Rūnanga o Raukawa as a Toiora Whānau worker. Rawiri has a long history in working with whānau and individuals in the areas of whānau ora and the prevention of sexual and domestic violence with Māori. He is also a kaupapa Māori programme developer and deliverer with Te Kāhui o te Rangi.

Sam Chapman (Whakatōhea, Tūwharetoa)

Haami (Sam) Chapman live in Ōtara, Manukau City. Since 1978 he has served with his whānau in communities where for many, genuine hope and opportunity seemed lost. He has been central to Project Awhi, that has a mission to see individuals and families enabled to discover and fulfil their God-given potential. He is a co-founder of Houhanga Rongo, a community organisation with a vision and ministry of reconciliation and community development. Through that role he has been credited with supporting the Notorious chapter of the Mongrel Mob to reduce the use of pseudoephedrine as well as contributing towards positive lifesyle changes among their membership. Sam's tribal affiliation is Ngāti Tūwharetoa, Whakatōhea and Ngāti Porou. In 2010, he was named New Zealander of the Year.

Dr Simone Bull (Ngāti Porou) 
Dr Simone Bull is one of a very small number of Māori criminologists. In that capacity, she publishes and presents on the subject of Māori and the criminal justice system. She is currently a senior policy analyst for the New Zealand Police.

\section{Tamati Kruger (Ngāi Tūhoe)}

Tamati Kruger has been actively involved in iwi and hapū development over the last thirty years and is a respected social/political analyst on Māori society. A graduate of Victoria University and now the programme Lecturer for Te Tohu o Te Reo Māori (Bachelor of Te Reo Māori) at Anamata, a Private Training Establishment in Whakatāne. Of Tūhoe descent, he works in tribal research and development on behalf of the Tūhoe Raupatu. In 2002 he chaired the Second Ministerial Māori Taskforce on Whānau Violence. The members of this Taskforce were responsible for the development of the Mauri Ora Framework. Like many Tūhoe iwi, he is a native speaker of te reo Māori and is a recognized authority in Māori language and customary practices. He has published works in these fields and been a policy advisor in the health, social service and educational field as well as holding various governance portfolios on both government and community institutions. Recently he has spoken to the media on behalf of the Tūhoe iwi particularly concerning the controversial 2007 New Zealand anti-terror raids.

\section{Ted Ratana (Te Rarawa)}

Ted Ratana is the Director and Facilitator for Kawei Ltd, which delivers the Dynamics of Whanaungatanga, a kaupapa Māori training programme used in Men's Stopping Violence, Tikanga Māori and Restorative Justice Programmes for the Ministries of Justice and Corrections. He has also been the director of Hei Taumata Ltd, a consultancy company providing governance and management solutions for Māori organisations and is a founding member of Te Rarawa ki Tamaki, the Auckland taurahere for Te Rūnanga o Te Rarawa. 
Tikirau Ata (Ngāi Tūhoe)

Tikirau Ata is a native speaker of te reo Māori and is recognised for his knowledge of Māori culture and his work in the area of social and cultural arenas. He is the facilitator and deliverer of the Incredible Years Parenting Programme in collaboration with the Ministry of Education and the Tūhoe Hauora. He is also a kaupapa Māori programme developer and deliverer with Te Kāhui o te Rangi.

Professor Whatarangi Winiata (Ngāti Raukawa)

Emeritus Professor Whatarangi Winiata has played a significant role in Māori society over the last 40 years. He graduated with a PhD and an MBA from the University of Michigan, and after returning to New Zealand with his family in 1975 began to take a leading role in a series of Māori initiatives that sought to reverse the decline of te reo Māori speakers as well as provide his iwi, and Māori, the opportunity to further their education. Together with the descendants of Te Āti Awa ki Whakarongotai, Ngāti Toa Rangatira and Ngāti Raukawa, an iwi development plan was designed and initiated in order to improve the social, educational and cultural status of the three iwi over the course of the 25 years between 1975 and 2000. A significant result of that plan was the creation of Te Wānanga-o-Raukawa, a registered tertiary education institute that offers a diverse range of education in the traditional Māori wānanga style of learning. They also put into place educational ventures like kura kaupapa Māori, to foster te reo Māori and tikanga. During that time he was also the Professor of Commerce at Victoria University of Wellington, and was the long standing Tūmuaki at Te Wānanga o Raukawa. As well, Whatarangi was elected the inaugural President of the then newly formed Māori Party in 2004.

\section{$N G \bar{A} H U I \bar{A} R \bar{O} P \bar{U}$}

Ora Toa Mauriora ki Porirua

Te Hika o Papauma Marae 
Te Hurunui-o-Rangi Marae

Te Puke Marae

Te Wānanga-o-Raukawa.

Tūkorehe Marae 


\section{APPENDIX B: EMAIL COVER LETTER SENT TO KAIKŌRERO}

Tēnā koe i ngā tini āhuatanga ō te wā.

Ko Whakapunake te maunga, ko Te Wairoa te awa, ko Takitimu te waka, ko Ngāti Kahungunu te iwi, ko Te Ure-o-Teo te hapū, ko Te Rauhina te marae.

I hope this email finds you well. My name is Riki Mihaere and I'm a PhD student with the Institute of Criminology at Victoria University of Wellington. My supervisors are:

Dr Elizabeth Stanley at the Institute of Criminology at Victoria University of Wellington, PO Box 600, Wellington 6140, elizabeth.stanley@vuw.ac.nz

Dr Robert Webb at the Department of Social Sciences at AUT University, Private Bag 92006, Auckland 1142, robert.webb@aut.ac.nz

My research is focusing on Māori cultural identity in relation to crime. More specifically giving up crime. I'm emailing you because I'm in the process of gathering data by interviewing selected Māori on this topic. This involves semi structured, face to face interviews of about 40 minutes duration.

My goal is to try and draw together the views of about 50 Māori who have been involved in this area and start to articulate a theoretical basis to the idea. I've put together a list of people to talk to who have had some form of interest, or career, or view, or whatever on the subject of Māori cultural identity in relation to crime. Your name is on my list. You probably know many if not all of the people.

As you know the proportion of Māori amongst all criminal justice statistics is too high. As a result there have been many responses to this 'problem' over the last four or so decades. Māori cultural identity has been at the heart of many policies and programmes; from kapa haka being taught to Māori prisoners, to tikanga Māori programmes on marae across the motu, to Māori Focus Unit's, Māori cultural assessment tools, even marae based court appearances. 
In spite of this focus there remains a lack of clearly articulated descriptions of how, why or even if Māori cultural identity has a positive effect on Māori crime. This research project has been designed as a response to this gap in the field.

What follows is an interview schedule that I put together before I started interviewing people. I haven't used it, despite having recorded 19 people for about 40 minutes each. The interviews are semi-structured. Therefore, I don't have a single questionnaire. What I have is an interview schedule that consists of the general themes that I would like to talk about. In the main this consists of five areas: personal; development; theory; practice; and future.

Personal: as the name suggests is kōrero about you. This can be as detailed or not as you choose and could include: pepehā; involvement in this area; what led to you being involved, and so on.

Development: is kōrero related to the historical development of Māori cultural identity in relation to crime. Questions include: Can you tell me what you know about the development of the idea of Māori cultural identity in relation to crime? Where did the initial idea emerge from? Did any particular research inform the development? Has there been adequate Māori input?

Theory: is kōrero relating to the idea of Māori cultural identity. Questions include: Can you describe what you see as essential elements of Māori cultural identity? How, if at all, does Māori cultural identity reduce Māori offending? Do you believe that there is support from Māori about the use of Māori cultural identity in relation to reducing Māori crime? Do you think that Māori want such a strong degree of emphasis on Māori cultural identity in relation to reducing Māori offending?

Practice: relates to the implementation of Māori cultural identity in the criminal justice system. Questions include: Who designs the Māori cultural identity policies/programmes? Are they well designed? How do they operate? Have they been developed with adequate participation of Māori? How have they been measured? Have there been positive or negative effects of Māori cultural identity on Māori offenders/prisoners? 
Future: is kōrero relating to the future of this idea. Questions include: Should the idea of Māori cultural identity and its policies and programmes continue? Be reduced? Extended? Do you have any thoughts on the role that Māori play in the ongoing development of the idea? What is important about Māori cultural identity in relation to reducing Māori offending? Is Māori cultural identity preventing or reducing Māori offending?

As I said, despite having written up an interview schedule, I haven't used it at all. The reason is, firstly, I only put it together to guide me rather than confine me to a specific list of questions. It keeps me focused on the broad themes that I want to talk about while allowing the person I'm talking to dictate the kōrero as well. And secondly, despite that all of the people I'm talking to having some form of interest or connection to Māori cultural identity and crime, the nature of that relationship varies quite a lot. For instance some have quite a historical experience, back to the early 70's, a time when the idea of strengthening the Māori cultural identity of young Māori offenders and prisoners was growing, but was confined to a few Māori volunteering their time. Especially in regards to a kuia that played a considerable role in this area in Auckland at that time, Ana Tia. In this situation my questions would be focused on that historical context. Contrast that to someone who is delivering tikanga Māori programmes to prisoners, or someone in Head Office in a Govt department, or someone who teaches mau rakau on a marae to young offenders and so on. Each of their experiences would be different and each of the interviews would reflect that difference.

So what I tend towards doing is chatting for a while first and then turn on a dictaphone, if it's OK, and keeping the five themes that I described above in my head and try as much as possible to cover them within a 40 minute interview.

So if I could just wrap up with the fact that my research is on the underlying idea of Māori cultural identity in relation to crime. My principal goal is to articulate some form of theoretical basis to the idea. Hopefully we can find the time to sit down and have a kōrero on this subject. I would appreciate, and benefit, from your participation in my research. Until then...

Noho ora mai, nā Riki Mihaere 


\section{APPENDIX C: INFORMATION SHEET SENT TO KAIKŌRERO}

\section{MĀORI CULTURAL IDENTITY AND MĀORI CRIME}

My name is Riki Mihaere and I am a PhD student with the Institute of Criminology at Victoria University of Wellington. As part of this degree I am doing a research project on the criminal justice system's current policies and practices directed at reducing the high numbers of Māori offending and imprisonment. In particular, I am interested in the idea that increasing Māori cultural knowledge is a way to lead Māori offenders and prisoners away from further crime.

The research project includes interviews with people, including Governmental and non-Governmental officials, who have been involved in advancing, developing and implementing policies and practices related to Māori cultural identity with Māori offenders and prisoners.

The interviews will take approximately one hour and will be electronically recorded. The interviews will be at a time and place that suits us both. The interviews will include questions that will elicit responses on the following:

- ideas on Māori cultural identity;

- ideas on Māori cultural identity and giving up crime;

- the historical development of the cultural identity policies, and the subsequent implementation of related programmes for Māori offenders.

There will be an opportunity to be either identified by name, or have all information kept confidential (in which case you will not be identified personally). No other person besides my supervisors, a professional transcriber, and me will hear these recorded interviews or see the subsequent transcripts. All of these people will adhere to this confidentiality agreement.

Information collected from interviews will form the basis of my research project and will be put into a written thesis. The thesis will be submitted for marking to the Institute of Criminology, Victoria University of Wellington and deposited in the 
University Library. If you choose, a summary of the findings will be made available to you. The findings from this research may also contribute towards conference presentations and academic writing at a later date. Recorded interviews and transcripts will be destroyed one year after the completion of this research project (projected as mid 2011).

Should any participants feel the need to withdraw from the project, they may do so without question at any time before the interviews are complete in November 2010.

If you have any questions or would like to receive further information about the project, please contact me:

Riki Mihaere at the Institute of Criminology at Victoria University of Wellington, PO Box 600, Wellington 6140, mihaerriki@myvuw.ac.nz

or my supervisors:

Dr Elizabeth Stanley at the Institute of Criminology at Victoria University of Wellington, PO Box 600, Wellington 6140, elizabeth.stanley@vuw.ac.nz

Dr Robert Webb at the Department of Social Sciences at AUT University, Private Bag 92006, Auckland 1142, robert.webb@aut.ac.nz

Thank you

Riki Mihaere 


\section{APPENDIX D: CONSENT FORM SENT TO KAIKŌRERO}

\section{MĀORI CULTURAL IDENTITY AND MĀORI CRIME}

I have been given, and have understood, an explanation of this PhD research project. I have had an opportunity to ask questions and have them answered to my satisfaction. I understand that I may withdraw myself (or any information I have provided) from this project before November 2010 without having to give reasons.

I have been told that this research has received ethical approval from the Human Ethics Committee, Victoria University of Wellington.

_ _ I agree

_ I do not agree

to having the interview recorded on digital audio recorder;

_ _ I agree

_ I do not agree

to be identified in the final research outputs.

The above permissions are in effect until 31 December 2012. On or before that date, the digital recordings and the subsequent transcripts will be destroyed.

I would like to receive:

a copy of the recorded interview and transcript

a summary of the completed thesis

I agree to participate in the research project described above and will receive a copy of this consent form after I sign it.

signed:

name of participant

Date: 


\section{APPENDIX E: A GLOSSARY OF MĀORI TERMS}

Māori term/phrase Translation into English

Aotearoa

Māori name for New Zealand.

Haka

War dance.

Hapū

The term hapu literally means 'pregnancy'. It is also the term used to describe the second largest of the three main social units in Māori society, the aggregate of whānau (see below) who descend from a common ancestor. Translated into English, the term sub-tribe is used for hapū.

Hara

An act of wrongdoing.

Hauora

Māori health organisation.

Hoturoa

The name of a famous ancestor.

Hui

Gathering/meeting.

Iwi

The term iwi literally means 'bone'. It is also the term used to describe the largest social unit of organisation in Māori society, all of the hapū (see above) descended from a common ancestor and therefore related biologically. Translated into English, the term tribe is used for iwi.

Kahungunu

The name of a famous ancestor.

Kahungunutanga Traditions of the people who descend from the ancestor Kahungunu.

Kaiarahi Guide or leader.

Kaikōrero Speaker/s

Kapa haka $\quad$ Group doing war dance. 
Kaupapa

Kawa

Ko ngā kaikōrero

Kōrero

Kōrero-ā-waha

Kura kaupapa Māori

Mahi

Mahi Tahi

Mana

Māori

Māoritanga

Mau Rakau

Ngā hui ā rōpū

Ngāti Kahungunu

Pākehā

Pepehā
This term is one of a number of terms that is considered crucial to a Māori worldview. It is constructed of two words: 'kau' meaning to rise into consciousness and 'papa', which is short for Papatūānuku or the Earth Mother. Thus, kaupapa means foundational or first principles.

Māori ritual.

The speakers.

Speak/talk.

Interview.

Māori secondary school

Work/activity.

A tikanga Māori programme provider in New Zealand prisons. Prestige or spiritual authority.

Māori literally means 'normal'. It is the term that is used to identify the indigenous people of New Zealand.

Māori culture.

Māori weaponry.

The group meetings.

Descended from the famous ancestor Kahungunu.

A Māori term to describe a non-Māori person.

A pepehā is a description of the genealogical links between a Māori person and his or her broader community. For instance, my pepehā is: ko Tākitimu te waka (Tākitimu is the canoe), Whakapūnake te maunga (Whakapūnake is the mountain), ko Ngāti Kahungunu te iwi (Ngāti Kahungunu is the tribe). By 
naming my canoe I describe the ultimate origins of my people to this land, by naming my mountain I describe the geographical location that my people have settled, and by naming my tribe, I illustrate the principal ancestor that I descend from. Pepehā have an important role in Māori society because they reaffirm in a practical manner in which Māori people relate genealogically to one another.

Rangatahi Youth.

Rohe Geographical area.

Taiaha A long handled striking weapon.

Takitimu The name of one of the famous canoes that brought the ancestors of Māori to New Zealand.

Tapu Sared.

Taurahere Taurahere means binding ropes and is a phrase to describe urban based Māori organisations that seek to unite urban based Māori, often with no links to their traditional iwi.

Tautoko Support.

Te reo Māori The Māori language.

Te Wānanga-o- Māori tertiary institution in Ōtaki.

Raukawa

Te Upoko o te Ika Wellington.

Tika $\quad$ Right (as in opposite to wrong).

Tikanga Ethical behaviour.

Tīpuna/Tūpuna Ancestors.

Tohunga Specialist/healer. 
Tūmuaki

Tūturu

Waiata

Wairuatanga

Wānanga

Whakamā

Whakapapa

Whānau

Whenua

\section{Chief Executive Officer.}

Authentic.

A song/to sing

Spirituality.

Depending on the context either, to think deeply as an individual or collective. Or alternatively, a place of higher learning such as a university where such activities occur.

Embarrassment/shame.

Genealogy.

The word whānau literally means 'to give birth'. It is also the term used to describe the smallest of the three main social units in Māori society. Translated into English, the term family is used for whānau.

Land or placenta. 


\section{APPENDIX F: THE TREATY OF WAITANGI}

Her Majesty Victoria Queen of the United Kingdom of Great Britain and Ireland regarding with Her Royal Favour the Native Chiefs and Tribes of New Zealand and anxious to protect their just Rights and Property and to secure to them the enjoyment of Peace and Good Order has deemed it is necessary in consequence of the great number of Her Majesty's Subjects who have already settled in New Zealand and the rapid extension of Emigration both from Europe and Australia which is still in progress to constitute and appoint a functionary properly authorised to treat with the Aborigines of New Zealand for the recognition of Her Majesty's Sovereign authority over the whole or any part of those islands-Her Majesty therefore being desirous to establish a settled form of Civil Government with the view to avert the evil consequences which must result from the absence of the necessary Laws and Institutions alike to the native population and to Her subjects has been graciously pleased to empower and to authorise me William Hobson a Captain in Her Majesty's Royal Navy Consul and Lieutenant Governor of such parts of New Zealand as maybe or hereafter shall be ceded to Her Majesty to invite the confederated and independent Chiefs of New Zealand to concur in the following Articles and Conditions.

\section{Article The First}

The Chiefs of the Confederation of the United Tribes of New Zealand and the separate and independent Chiefs who have not become members of the Confederation cede to Her Majesty the Queen of England absolutely and without reservation all the rights and powers of Sovereignty which the said Confederation or Individual Chiefs respectively exercise or possess, or may be supposed to exercise or to possess over their respective Territories as the sole Sovereigns thereof.

\section{Article The Second}

Her Majesty the Queen of England confirms and guarantees to the Chiefs and Tribes of New Zealand and to the respective families and individuals thereof the full exclusive and undisturbed possession of their Lands and Estates Forests Fisheries and other properties which they may collectively or individually possess so long as it is their wish and desire to retain the same in their possession; but the chiefs of the United Tribes and the individual Chiefs yield to Her Majesty the exclusive right of 
pre-emption over such lands as the proprietors thereof may be disposed to alienate-at such prices as may be agreed between the respective Proprietors and Persons appointed by Her Majesty to treat with them in that behalf.

\section{Article The Third}

In consideration thereof Her Majesty the Queen of England extends to the Natives of New Zealand Her royal protection and imparts to them all the Rights and Privileges of British subjects.

William Hobson, Lieutenant Governor

Now therefore We the Chiefs of the Confederation of the United Tribes of New Zealand being assembled in Congress at Victoria in Waitangi and We the Separate and Independent Chiefs of New Zealand claiming authority over the Tribes and Territories which are specified after our respective names, having been made fully to understand the Provisions of the foregoing Treaty, accept and enter into the same in the full spirit and meaning thereof: in witness of which we have attached our signatures or marks at the places and the dates respectively specified.

Done at Waitangi this Sixth day of February in the year of Our Lord one thousand eight hundred and forty. 


\section{APPENDIX G: TE TIRITI O WAITANGI}

Ko Wikitoria, te Kuini o Ingarani i tana mahara atawai ki nga Rangatira me nga Hapu o Nu Tirani i tana hiahia hoki kia tohungia ki a ratou o ratou rangatiratanga me to ratou wenua, a kia mau tonu hoki te Rongo ki a ratou me te Atanoho hoki kua wakaaro ia he mea tika kia tukua mai tetahi Rangatira - hei kai wakarite ki nga Tangata Māori o Nu Tirani - Kia wakaaetia e nga Rangatira Māori te Kawanatanga o te Kuini ki nga wahikatoa o te wenua nei me nga motu - na te mea hoki he tokomaha ke nga tangata o tona Iwi kua noho ki tenei wenua, a e haere mai nei.

Na ko te Kuini e hiahia ana kia wakaritea te Kawanatanga kia kaua ai nga kino e puta mai ki te tangata Māori ki te Pakeha e noho ture kore ana.

Na, kua pai te Kuini kia tukua a hau a Wiremu Hopihona he Kapitana i te Roiara Nawi hei Kawana mo nga wahi katoa o Nu Tirani e tukua aianei, amua atu ki te Kuini, e mea atu ana ia ki nga Rangatira o te wakaminenga o nga hapu o Nu Tirani me era Rangatira atu enei ture ka korerotia nei.

\section{Ko Te Tuatahi}

Ko nga Rangatira o te Wakaminenga me nga Rangatira katoa hoki ki hai i uru ki taua wakaminenga ka tuku rawa atu ki te Kuini o Ingarani ake tonu atu - te Kawanatanga katoa o o ratou wenua.

\section{Ko Te Tuarua}

Ko te Kuini o Ingarani ka wakarite ka wakaae ki nga Rangatira ki nga hapu - ki nga tangata katoa o Nu Tirani te tino rangatiratanga o o ratou wenua o ratou kainga me o ratou taonga katoa. Otiia ko nga Rangatira o te Wakaminenga me nga Rangatira katoa atu ka tuku ki te Kuini te hokonga o era wahi wenua e pai ai te tangata nona te wenua - ki te ritenga o te utu e wakaritea ai e ratou ko te kai hoko e meatia nei e te Kuini hei kai hoko mona.

\section{Ko Te Tuatoru}


Hei wakaritenga mai hoki tenei mo te wakaaetanga ki te Kawanatanga o te Kuini - Ka tiakina e te Kuini o Ingarani nga tangata Māori katoa o Nu Tirani ka tukua ki a ratou nga tikanga katoa rite tahi ki ana mea ki nga tangata o Ingarani.

(Signed) William Hobson

Consul and Lieutenant-Governor

Na ko matou ko nga Rangatira o te Wakaminenga o nga Hapu o Nu Tirani ka huihui nei ki Waitangi ko matou hoki ko nga Rangatira o Nu Tirani ka kite nei i te ritenga o enei kupu ka tangohia ka wakaaetia katoatia e matou. Koia ka tohungia ai o matou ingoa o matou tohu.

Ka meatia tenei ki Waitangi i te ono o nga ra o Pepuere i te tau kotahi mano e waru rau e wa tekau o to tatou Ariki. 


\section{APPENDIX H: DECLARATION OF INDEPENDENCE OF NEW ZEALAND}

1. We the hereditary chiefs and heads of the tribes of the Northern parts of New Zealand, being assembled at Waitangi, in the Bay of Islands, on this $28^{\text {th }}$ day of October 1835, declare the Independence of our country, which is hereby constituted and declared to be an Independent State, under the designation of the United Tribes of New Zealand.

2. All sovereign power and authority within the territories of the United Tribes of New Zealand is hereby declared to reside entirely and exclusively in the hereditary chiefs and heads of tribes in their collective capacity, who also declare that they will not permit any legislative authority separate from themselves in their collective capacity to exist, nor any function of government to be exercised within the said territories, unless by persons appointed by them, and acting under the authority of laws regularly enacted by them in Congress assembled.

3. The hereditary chiefs and heads of tribes agree to meet in Congress at Waitangi in the autumn of each year, for the purpose of framing laws for the dispensation of justice, the preservation of peace and good order, and the regulation of trade; and they cordially invite the Southern Tribes to lay aside their private animosities and to consult the safety and welfare of our common country, by joining the Confederation of the United Tribes.

4. They also agree to send a copy of this Declaration to His Majesty the King of England, to thank him for his acknowledgement of their flag, and in return for the friendship and protection they have shown, and are prepared to show, to such of his subjects as have settled in their country, or resorted to its shores for the purposes of trade, they entreat that he will continue to be the parent of their infant State, and that he will become its Protector from all attempts upon its independence.

Agreed to unanimously on this $28^{\text {th }}$ day of October, 1835, in the presence of His Britannic Majesty’s Resident. 
Te Paerata, of te Patu Koraha

Ururoa, of te Taha Wai

Hare Hongi

Hemi Kepa Tupe, of Te Uri Putete

Te Warepoaka, of Te Hikitu

Titore, of Ngati Nanenane

Moka, of Te Patu Heka

Te Warerahi

Rewa

Wai, of Ngai Tawake

Reweti Atua Haere, of Ngati Tau Tahi

Te Awa

Wiremu Taunui, of Te Wiu

Tenana, of Ngati Kuta

$\mathrm{Pi}$, of Te Mahurehure

Kaua, of Te Herepaka

Te Peka

Eurera Pare
Tareha, of Ngati Rehia

Kawiti, of Ngati Hine

Pumuka, of Te Roroa

Te Kekeao, of Ngati Matakiri

Te Kamara, of Ngati Kawa

Pomare, of Ngati Manu

Wiwia, of Te Kapo Tai

Te Tao, of Te Kai Mata

Marupo, of Te Wanau Rara

Te Kopiri, of Te Uri Taniwha

Warau, of Te Wanau Horo

Te Ngere, of Te Uri Kapana

Moetara, of Ngati Korokoro

Te Hiamoe, of Te Uri a Ngonga

Tamati Pukututu, of Te Uri o Te

Hawato

Waikato

Hone Wiremu Heke 
Subsequent signatories to the Declaration of Independence:

Tamati Waka Nene

Te Huhu

Towai

Nopera Panakareao, of Te Rarawa

Kiwikiwi 13.01.1836

Tirarau 09.02.1836

Hamuera Pita 29.03.1836

Whawhai

Mate

Patuone

Parore 25.06.1837

Kaha

Te Morenga 12.07.1837

Mahia

Taonui 16.01.1838

Papahia 24.09.1838

Te Hapuku 25.09.1838

Te Wherowhero 22.07.1839 


\section{APPENDIX I: HE WAKAPUTANGA O TE RANGATIRATANGA O NU TIRENE}

1. Ko matou, ko nga tino Rangatira o nga iwi o Nu Tirene i raro mai o Haurake, kua oti nei te huihui i Waitangi, i Tokerau, i te ra 28 o Oketopa, 1835. Ka wakaputa i te Rangatiratanga o to matou wenua; a ka meatia ka wakaputaia e matou he Wenua Rangatira, kia huaina, "Ko te Wakaminenga o nga Hapu o Nu Tirene”.

2. Ko te Kingitanga, ko te mana i te wenua o te wakaminenga o $\mathrm{Nu}$ Tirene, ka meatia nei kei nga tino Rangatira anake i to matou huihuinga; a ka mea hoki, ekore e tukua e matou te wakarite ture ki tetahi hunga ke atu, me tetahi Kawanatanga hoki kia meatia i te wenua o te wakaminenga o Nu Tirene, ko nga tangata anake e meatia nei e matou, e wakarite ana ki te ritenga o o matou ture e meatia nei e matou i to matou huihuinga.

3. Ko matou, ko nga tino Rangatira, ka mea nei, kia huihui ki te runanga ki Waitangi a te Ngahuru i tenei tau i tenei tau, ki te wakarite ture, kia tika ai te wakawakanga, kia mau pu te rongo, kia mutu te he, kia tika te hokohoko. A ka mea hoki ki nga tauiwi o runga, kia wakarerea te wawai, kia mahara ai ki te wakaoranga o to matou wenua, a kia uru ratou ki te wakaminenga o $\mathrm{Nu}$ Tirene.

4. Ka mea matou, kia tuhituhia he pukapuka, ki te ritenga o tenei o to matou wakaputanga nei, ki te Kingi o Ingarani, hei kawe atu i to matou aroha; nana hoki i wakaae ki te Kara mo matou. A no te mea ka atawai matou, ka tiaki i nga Pakeha e noho nei uta, e rere mai ana ki te hokohoko, koia ka mea ai matou ki te Kingi kia waiho hei Matua ki a matou i to matou tamarikitanga, kei wakakahoretia to matou Rangatiratanga.

Kua wakaaetia katoatia e matou i tenei ra, i te 28 a Oketopa 1835, ki te aroaro o te Rehirenete o te Kingi o Ingarani.

Ko te Paerata, no te Patu Koraha

Ko Ururoa, no te Taha Wai
Ko Tareha, no Ngati Rehia

Ko Kawiti, no Ngati Hine 
Ko Hare Hongi

Ko Hemi Kepa Tupe, no Te Uri Putete

Ko Te Warepoaka, no Te Hikitu

Ko Titore, no Ngati Nanenane

Ko Moka, no Te Patu Heka

Ko Te Warerahi

Ko Rewa

Ko Wai, no Ngai Tawake

Ko Reweti Atua Haere, no Ngati Tau Ko Warau, no Te Wanau Horo Tahi

Ko Te Awa

Ko Wiremu Taunui, no Te Wiu

Ko Tenana, no Ngati Kuta

Ko Pi, no Te Mahurehure

Ko Kaua, no Te Herepaka
Ko Pumuka, no Te Roroa

Ko Te Kekeao, no Ngati Matakiri

Ko Te Kamara, no Ngati Kawa

Ko Pomare, no Ngati Manu

Ko Wiwia, no Te Kapo Tai

Ko Te Tao, no Te Kai Mata

Ko Marupo, no Te Wanau Rara

Ko Te Kopiri, no Te Uri Taniwha

Ko Te Ngere, no Te Uri Kapana

Ko Moetara, no Ngati Korokoro

Ko Te Hiamoe, no Te Uri a Ngonga

Ko Tamati Pukututu, no Te Uri o Te Hawato

Ko matou, ko nga rangatira, ahakoa kihai tae i te huihuinga nei, $\mathrm{i}$ te nuinga o te Waipuke, i te aha ranei, ka wakaae katoa ki te wakaputanga rangatiratanga o $\mathrm{Nu}$ Tirene, a ka uru ki roto ki te wakaminenga.

Ko Tamati Waka Nene

Ko Te Huhu

Ko Tona
Ko Nopera Panakareao, no Te Rarawa

Ko Kiwikiwi

Ko Tirarau 
1836 Ko Patuone

Ko Mohi Tawai

Ko Taonui

Ko Papahia, no Te Rarawa

Ko Parore
1836 Ko Mate

Ko Kaha

1838 Ko Te Hapuku, no Te Whatu-Iapiti

1839 Ko Te Wherowhero Potatau, 


\section{BIBLIOGRAPHY}

Adams P. (1977). Fatal Necessity: British Intervention in New Zealand 1830-1847. Auckland. Auckland University Press.

Alcohol Advisory Council and Ministry of Health. (2001). National Alcohol Strategy 2000-2003. Wellington. Alcohol Advisory Council and Ministry of Health.

Atkinson N. (2007). Trainland: How Railways Made New Zealand. Auckland Random House.

Auerbach C and Silverstein L. (2003). Qualitative Data: An Introduction to Coding and Analysis. New York. New York University Press.

Ausubel D. (1960). The Fern and the Tiki An American View of New Zealand: National Character, Social Attitudes and Race Relations. Sydney. Angus and Robertson.

Awatere H. (2003). Awatere: A Soldier’s Story. Wellington. Huia Publishers.

Babad E, Birnbaum M and Benne K. (1983). The Social Self: Group Influences on Personal Influences. Beverly Hills. Sage.

Barlow C. (1991). Tikanga Whakaaro: Key Concepts in Māori Culture. Auckland. Oxford University Press.

Barrington J. (1970). ‘A Historical Review of Policies and Provisions’ in Ewing J and Shallcrass J (eds). Introduction to Māori Education. Wellington. New Zealand University Press.

Belich J. (1986). The New Zealand Wars and the Victorian Interpretation of Racial Conflict. Auckland. Auckland University Press.

Bennett S. (2002). 'Cultural Identity and Academic Achievement of Māori Undergraduate University Students' in The Proceedings of the National Mãori Graduates of Psychology Symposium 2002. Palmerston North. Massey University. 
Bentley T. (1999). Pākehā Māori: The Extraordinary Story of the Europeans Who Lived as Māori in Early New Zealand. Auckland. Penguin Books.

Benton R. (1988). 'Fairness in Māori Education' in Royal Commission on Social Policy: The April Report. Wellington. Government Press.

Best E. (1974). The Mãori as He Was. Wellington. Government Printer.

Biggs B. (1961). 'The Structure of New Zealand Māori' in Archives of Languages of the World. Bloomington. University of Indiana.

Biggs B. (1968). 'The Māori Language Past and Present' in Schwimmer E (ed). The Màori People in the Nineteen Sixties. Auckland. Blackwood and Janet Paul.

Bird R. (1998). Report on the Review of the New Life Akoranga Programme Run in Prisons by Mahi Tahi Trust. Wellington. Department of Corrections.

Bishop R and Glynn T. (1999). Culture Counts: Changing Power Relations in Education. Palmerston North. Dunmore Press.

Bishop R. (1991). He Whakawhanaungatanga Tikanga Rua: Establishing Family Links - A Bicultural Experience. Unpublished MA thesis. Dunedin. Otago University.

Bishop R. (1994). 'Initiating Empowering Research?’ in New Zealand Journal of Educational Studies 29(1):175-188.

Bishop R. (1996). Collaborative Research Stories: Whakawhanaungatanga. Palmerston North. The Dunmore Press.

Bishop R. (1997). 'Māori People's Concerns About Research Into Their Lives' in History of Education Review 26(1):25-41.

Blagg H. (2008). Crime, Aboriginality and the Decolonisation of Justice. Annandale, New South Wales. Hawkins Press.

Borell B. (2005). Living in the City Ain't So Bad: Cultural Diversity of South Auckland Rangatahi. An Unpublished Masters of Philosophy in Psychology Thesis. Palmerston North. Massey University. 
Broughton J. (1993). 'Being Māori’ in New Zealand Medical Journal 106:506-508.

Buck P. (1955). The Coming of the Māori. Wellington. Government Printer.

Bull S. (2001). The Land of Murder, Cannibalism, and All Kinds of Atrocious Crimes?: An Overview of 'Māori Crime' from Pre-Colonial Times to the Present Day. Unpublished PhD Thesis. Wellington. Victoria University of Wellington.

Bull S. (2004). 'The Land of Murder, Cannibalism, and All Kinds of Atrocious Crimes?: Māori and Crime in New Zealand, 1853-1919' in British Journal of Criminology 44(4):496-519.

Campbell N and More U. (2013). 'Working Effectively With Māori' in Practice The New Zealand Corrections Journal 1(1):27-33.

Charlesworth R. (2000). Understanding Child Development. Albany. Delmar Thomson Learning.

Clarke P. (2003). Where the Ancestors Walked: Australia as an Aboriginal Landscape. Crows Nest. Allen and Unwin.

Coebergh B, Bakker L, Anstiss B, Maynard K and Percy S. (1999). A Seein' “I” to the Future: The Criminogenic Needs Inventory (CNI). Wellington. Department of Corrections.

Coupe N. (2000). Māori Attempted Suicide: A Case Control Study in Auckland, New Zealand. Auckland. University of Auckland.

Coupe N. (2005). Whakamomori: Māori Suicide Prevention. An unpublished PhD thesis. Palmerston North. Massey University.

Cram F and Pipi K. (2000). Māori/Iwi Provider Success: Report on the Pilot Project. Auckland. International Research Institute for Māori and Indigenous Education.

Cram F, Kempton M and Armstrong S. (1998). Evaluation Report: Te Whare Tirohanga Māori Hawkes Bay Regional Prison. Wellington. Department of Corrections. 
Cram F. (1997). 'Developing Partnerships in Research: Pākehā Researchers and Māori Research' in Sites: A Journal for South Pacific Cultural Studies 35:44-63.

Cram F. (2001). 'Rangahau Māori: Tona Tika, Tona Pono - The Validity and Integrity of Māori Research' in Tolich M (ed). Research Ethics in Aotearoa New Zealand: Concepts, Practice, Critique. Auckland. Longman.

Cram F. (2009). 'Maintaining Indigenous Voices' in Mertens D and Ginsberg P. The Handbook of Social Research Ethics. Thousand Oaks. Sage Publications.

Cunningham C. (1997). Measuring the Effectiveness of Corrections Programmes for Māori: An Analysis and Discussion of Recent Findings and Methods. Wellington. Department of Corrections.

Dalley B and Labrum B (eds). (2000). Fragments: New Zealand Social and Cultural History. Auckland. University of Auckland.

Davidson J. (1984). The Prehistory of New Zealand. Auckland. Longman Paul.

Davies P. (1982). 'Stratification and Class' in Spoonley P, Pearson D and Shirley I (eds). New Zealand Society: A Sociological Perspective. Palmerston North. Dunmore Press.

Department of Corrections. (1998). Māori Focus Unit: Hawkes Bay Regional Prison. Wellington. Department of Corrections.

Department of Corrections. (2001a). About Time: Turning People Away From a Life of Crime. Wellington. Department of Corrections.

Department of Corrections. (2001b). Let Māori Take The Journey Na Tau Rourou, Nà Taku Rourou, Ka Ora Ai Te Iwi: Summary of the Hui and Written Submissions on He Whaakinga the Department of Corrections Draft Treaty of Waitangi Policy Statement. Wellington. Department of Corrections.

Department of Corrections. (2001c). Service Description for Tikanga Māori Specifications: Draft Paper for Consultation. Wellington. Department of Corrections. 
Department of Corrections. (2001d). Treaty of Waitangi Strategic Plan 2001-2003. Wellington. Department of Corrections.

Department of Corrections. (2002). 'A Change for Good with Mauri Hauora' in Corrections News: April 2002. Wellington. Department of Corrections.

Department of Corrections. (2003). Māori Strategic Plan: 1 July 2003-30 June 2008. Wellington. Department of Corrections.

Department of Corrections. (2005). 'Mita Mohi' in Corrections News: February 2005. Wellington. Department of Corrections.

Department of Corrections. (2007a). Over-Representation of Māori in the Criminal Justice System: An Exploratory Report. Wellington. Department of Corrections.

Department of Corrections. (2007b). Findings from the Evaluation of the Specialist Māori Cultural Assessment. Wellington. Department of Corrections.

Department of Corrections. (2008a). Māori Strategic Plan. Wellington. Department of Corrections.

Department of Corrections. (2008b). Te Ihi Tü Community Residential Centre: Evaluation Report. Wellington. Department of Corrections.

Department of Corrections. (2008c). Findings from the Evaluation of Community Tikanga Māori Programmes. Wellington. Department of Corrections.

Department of Corrections. (2009). Māori Focus Units and Māori Therapeutic Programmes: Evaluation Report. Wellington. Department of Corrections.

Department of Corrections. (2012a). Lifting the Achievement of Māori Focus Units: Terms of Reference-Māori Governance Board. Wellington. Department of Corrections.

Department of Corrections. (2012b). Project Plan: Lifting the Achievement of Māori Focus Units. Wellington. Department of Corrections.

Department of Corrections. (2012c). Offender Volumes Report 2011. Wellington. 
Department of Corrections.

Department of Corrections. (2012d). Mauri Tū Pae: A Māori Therapeutic Programme to Reduce Re-offending. Wellington. Department of Corrections.

Department of Corrections. (2014a). Prison Facts and Statistics - March 2014. Wellington. Department of Corrections. Available at: http://www.corrections.govt.nz//facts_and_statistics/quarterly_prison_statistics/CP_ December_2014.html

Department of Corrections. (2014b). Corrections Works: Special Māori Services Edition: December 2014. Wellington. Department of Corrections.

Department of Corrections. (Undated). Bi-Cultural Therapy (BTM Resources. Wellington. Department of Corrections.

Department of Justice. (1988). Prisons in Change: The Submission of the Department of Justice to the Ministerial Inquiry into the Prisons System. Wellington. Department of Justice.

Department of Justice. (1994). Cultural Perspectives Planning and Monitoring Guidelines 1994/95. Wellington. Department of Justice.

Diener N and R Crandall. (1978). Ethics in Social and Behavioural Research. Chicago. University of Chicago Press.

Doone P. (2000). Report on Combating and Preventing Māori Crime: Hei Whakarurutanga mō te Ao. Wellington. Department of the Prime Minister and Cabinet.

Duguid S. (2000). Can Prisons Work: The Prisoner as Object and Subject in Modern Corrections. Toronto. University of Toronto Press.

Durie A. (1993). Report on the Evaluation of the Tihei Mauri Ora Teacher Development Contract. Palmerston North. Massey University.

Durie M, Black T, Christensen I, Durie A, Fitzgerald E, Taiapa J, Tinirau E and Apatu J. (1996). Te Hoe Nuku Roa Framework - Māori Profiles: An Integrated 
Approach to Policy and Planning. Palmerston North. Massey University.

Durie M, Black T, Christensen I, Durie A, Taiapa J, Potaka U, and Fitzgerald E. (1995). 'Te Hoe Nuku Roa Framework: A Māori Identity Measure' in Journal of the Polynesian Society 104(4):461-470.

Durie M, Fitzgerald E, Kingi T, McKinley S and Stevenson B. (2002). Māori Specific Outcomes and Indicators. Palmerston North. Massey University.

Durie M. (1994). Whaiora: Māori Health Development 2nd Edition. Auckland. Oxford University Press.

Durie M. (1995). Ngā Matatini Māori: Diverse Māori Realities. Palmerston North. Massey University.

Durie M. (1998). Te Mana, Te Kāwanatanga: The Politics of Māori SelfDetermination. Auckland. Oxford University Press.

Durie M. (1999). 'Mental Health and Māori Development' in Australian and New Zealand Journal of Psychiatry 33(1):5-12.

Durie M. (2001). Mauri Ora: The Dynamics of Māori Health. Auckland. Oxford University Press.

Durie M. (2003). ‘Imprisonment, Trapped Lifestyles and Strategies for Freedom’ in Durie M (ed). Ngā Kāhui Pou: Launching Māori Futures. Wellington. Huia Publishers.

Durie M. (2005). Ngā Tai Matatū: Tides of Māori Endurance. Victoria. Oxford University Press.

Durie M. (2006). 'Measuring Māori Wellbeing'. Presentation delivered at New Zealand Treasury Guest Lecture Series 2006. Wellington. New Zealand Treasury.

Eldred-Grigg S. (1990). New Zealand Working People. Palmerston North. Dunmore Press.

Elsmore B. (1985). Like Them That Dream. Tauranga. Moana Press. 
Evaluation Associates Ltd. (2007). The Māori Culture-Related Needs (MaCRN) Assessment: Evaluation of their Utility and Face Validity. Wellington. Department of Corrections.

Evans, D. and Evans, M. (1996). A Decent Proposal: Ethical Review of Clinical Research. Chichester. Wiley.

Fergusson D. (2003). 'Ethnicity and Interpersonal Violence in a New Zealand Birth Cohort' in Hawkins D (ed). Violent Crimes: Assessing Race and Ethnic Differences. Cambridge. Cambridge University Press.

Fergusson D and Horwood L. (2000) 'Cannabis Use and Dependence in a New Zealand Birth Cohort’ in New Zealand Medical Journal 113(1109):156-168.

Ferro M. (1997). Colonization: A Global History. New York. Routledge.

Firth, R. (1972). Economics of the New Zealand Māori. Wellington. Government Printer.

Forster M. (2003). 'Te Hoe Nuku Roa: A Journey Towards Māori Centered Research' in Ethnobotany Research and Applications Vol 1: 47-53.

Fullilove M and Fullilove R. (1993). 'Understanding Sexual Behaviours and Drug Use Among African Americans: A Case Study of Issues for Survey Research' in Ostow D and Kessel R (eds). Methododological Issues in AIDS Behavioural Research. London. Plenum Press.

Gilgen M. (2002). Boundaries \& Ethics of Practice for Kaimahi Māori in the Field of Health. Wellington. Oratoa Mauriora ki Poneke.

Government Printer. (1976). Facsimiles of the Treaty of Waitangi. Wellington. Government Printer.

Green R. (1970). 'Settlement Pattern Archaeology in Polynesia' in Green R. and Kelly M (eds). Studies in Oceanic Culture History Vol 1. Honolulu. Bishop Museum.

Harpham D. (2008). Offender Volumes Report 2007. Wellington. Department of 
Corrections.

Harpham D. (2012). Offender Volumes Report 2011. Wellington. Department of Corrections.

Health Research Council. (1998). Guidelines for Researchers on Health Research Involving Māori. Auckland. Health Research Council of New Zealand.

Hill C and Brosnan D. (1984). 'The Occupational Distribution of the Major Ethnic Groups in New Zealand' in New Zealand Population Review 10:33-42.

Hohepa M and Smith G (eds). (1992). The Issue of Research and Mãori. Auckland. University of Auckland.

Hook G. (2009). 'Bullock Versus the Department of Corrections: Did the Human Rights Tribunal Get it Wrong’ in MAI Review 2(1):1.

Hunn J. (1961). Report on Department of Māori Affairs with Statistical Supplement. Wellington. Government Printer.

Irwin K. (1994). 'Māori Research Methods and Practices: An Exploration' in Sites: A Journal for South Pacific Cultural Studies 28:25-43.

Jackson M. (1988). The Māori and the Criminal Justice System A New Perspective: He Whaipaanga Hou Part 2. Wellington. Department of Justice.

Jackson M. (Undated). 'An Analysis of the Māori Criminogenic Needs Process of the Department of Corrections'. Record of Documents. WAI 1024: The Offender Assessment Policies Claim, 2005. Wellington. Waitangi Tribunal.

Jahnke H and Taiapa J. (2003). 'Māori Research' in Davidson C and Tolich M (eds). Social Science Research in New Zealand: Many Paths to Understanding. Auckland. Pearson.

James B. (2000). Challenging Perspectives: Police and Māori Attitudes Towards One Another. Wellington. Te Puni Kōkiri and the New Zealand Police.

Jenkins R. (1996). Social Identity. London. Routledge. 
Joseph P. (1997). Māori Youth Suicide in Aotearoa: Selected Interviews with Māori Elders. An unpublished MA thesis. Auckland. University of Auckland.

Justice Sector Strategy Group. (2010). The New Zealand Crime and Safety Survey: 2009 Main Findings Report. Wellington. Ministry of Justice.

Kahler E. (1968). 'Culture and Evolution' in Montagu M (ed). Culture: Man's Adaptive Dimension. New York. Oxford University Press.

Kāhui Tautoko Consulting. (2007). Specialist Māori Cultural Assessment (SMCA) Evaluation Report 2006-2007: Process-Outcome Evaluation of SMCA Assessments for Māori Offenders. Wellington. Department of Corrections.

Kāhui Tautoko Consulting. (2009). Evaluation of the Department of Corrections Māori Focus Units (MFU) and Māori Therapeutic Programmes (MTP). Wellington. Kāhui Tautoko Consulting Limited.

Karetū T. (1992). 'Language and Protocol of the Marae' in King M (ed). Te Ao Hurihuri: Aspects of Māoritanga. Auckland. Reed Books.

King M. (2004). Being Pākehā Now: Reflections and Recollections of a White Native. Auckland. Penguin Books.

Kukutai T. (2003). The Dynamics of Ethnicity Reporting: Māori in New Zealand. Wellington. Te Puni Kōkiri.

Lawton B, Cram F, Makowharemahihi C, Ngata T, Robson B, Brown S and Campbell W. (2013). 'Developing a Kaupapa Māori Research Project to Help Reduce Health Disparities Experienced by Young Māori Women and their Babies' in AlterNative: An International Journal of Indigenous Peoples 9(3):246-261.

Lewis D. (1972). We The Navigators. Wellington. A.H. and A.W. Reed.

Lucas K. (2010). 'A Waste of Time? The Value and Promise of Researcher Completed Qualitative Data Transcribing in North Eastern Research Association Conference Proceedings 2010. Paper 24. Available at: http://digitalcommons.uconn.edu/nera_2010/24 
Makereti. (1986). The Old Time Māori. Auckland. New Women’s Press.

Makwana B. (2007). He Waka Tapu Violence and Abuse Intervention Programme and Caseworker Programme: Outcome Evaluation. Wellington. New Zealand Police.

Marie D. (2010). 'Māori and Criminal Offending: A Critical Appraisal' in Australian and New Zealand Journal of Criminology 43(2):282-300.

Marie D, Fergusson D and Boden J. (2009). 'Ethnic Identity and Criminal Offending in a New Zealand Birth Cohort' in The Australian and New Zealand Journal of Criminology 42(3):354-368.

Marsden M. (1992). 'God, Man and Universe: A Māori View' in King M (ed). Te Ao Hurihuri: Aspects of Māoritanga. Auckland. Reed Books.

Marsden M. (2003). 'The Natural World and Natural Resources: Māori Value Systems and Perspectives' in Royal T (ed). The Woven Universe: Selected Writings of Rev. Māori Marsden. Wellington. The Estate of Rev. Māori Marsden.

Maruna S. (2001). Making Good: How Ex-Convicts Reform and Rebuild Their Lives. Washington DC. APA Books.

Maxwell G and Smith C. (1998). Police Perceptions of Māori: A Report to the New Zealand Police and Te Puni Kōkiri. Wellington. Victoria Link Ltd.

Mayhew P and Reilly J. (2007). The New Zealand Crime and Safety Survey: 2006. Wellington. Ministry of Justice.

Maynard K, Coebergh B, Anstiss B, Baker B, and Huriwai T. (1999). 'Ki Te Arotū: Toward a New Assessment: The Identification of Cultural Factors Which May Predispose Māori to Crime’ in Social Policy Journal of New Zealand 13:43-58.

Maynard K. (2004). Evidence of Kristen Maynard for the Department of Corrections. A submission made to the Waitangi Tribunal in the matter of WAI1024. Wellington. Waitangi Tribunal.

McCarthy J. (1992) Te Whaea: Mother of Change. Auckland. Te Ao Mārama 
Productions.

McCreanor T. (1993). 'Settling Grievances to Deny Sovereignty: Trade Goods for the Year 2000' in Sites: A Journal for South Pacific Cultural Studies 27(Summer):45-73.

McCreary J. (1968). 'Population Growth and Urbanisation' in Schwimmer E (ed). The Māori People in the Nineteen Sixties. Auckland. Blackwood and Janet Paul.

McDonald M. (1999). An Exploration Into What a Kaupapa Māori Prison Might Involve. An unpublished MA Research Paper. Wellington. Victoria University of Wellington.

McDonald M. (2001). Māori Focus Units: National Operating Guidelines. Wellington. Department of Corrections.

McFarlane-Nathan G. (1996). 'The Bicultural Therapy Project' in Te Komako: Social Work Review 22 -27.

McFarlane-Nathan G. (1999). FReMO: Framework for Reducing Māori Offending. Wellington. Department of Corrections.

McIntosh T. (2005). 'Māori Identities: Fixed, Fluid, Forced' in Liu J, McCreanor T, McIntosh T and Teaiwa T. New Zealand Identities: Departures and Destinations. Wellington. Victoria University Press.

McKinnon M (ed). (1997). New Zealand Historical Atlas/Ko Papatūānuku e Takoto Nei. Auckland. David Bateman.

Mead H. (2003). Tikanga Māori: Living by Māori Values. Wellington. Huia Publishers.

Mediawomen of New Zealand. (1984). Celebrating Women: New Zealand Women and their Stories. Auckland. Cape Catley Ltd.

Meredith P. (2007). Seeing the 'Māori' Subject: Some Discussion Points. Hamilton. University of Waikato. 
Metge J. (1964). A New Māori Migration: Rural and Urban Relations in Northern New Zealand. London. The Athlone Press.

Mikaere A. (1994). 'Māori Women: Caught in the Contradictions of a Colonised Reality’ in Waikato Law Review Volume 2:125-149.

Ministerial Advisory Committee on a Māori Perspective for the Department of Social Welfare (1988) Pūao-Te-Ata-Tū (Daybreak): The Report of the Ministerial Advisory Committee on a Mäori Perspective for the Department of Social Welfare. Wellington. Department of Social Welfare.

Ministerial Review Unit. (2007a). 'Appendix Two: Ministerial Review of Department of Corrections Specialist Māori Cultural Assessment' in Review of the Department of Corrections' Targeted Policies and Programmes. Wellington. Ministerial Review Unit.

Ministerial Review Unit. (2007b). 'Appendix Three: Ministerial Review of Department of Corrections' Māori Focus Units (MFUs)' in Review of the Department of Corrections' Targeted Policies and Programmes. Wellington. Ministerial Review Unit.

Ministry of Justice and Te Puni Kōkiri. (1998). Perspectives on Responding to the Over-Representation of Māori in the Criminal Justice System: The Views of Māori Stakeholders. Ministry of Justice. Wellington.

Ministry of Justice. (1998). The Use of Imprisonment in New Zealand. Wellington. Ministry of Justice.

Ministry of Justice. (2001). He Hinatore ki te Ao Māori (A Glimpse into the Māori World): Māori Perspectives on Justice. Wellington. Ministry of Justice.

Ministry of Justice. (2013). Trends in Conviction and Sentencing. Wellington. Ministry of Justice. Available at: http://www.justice.govt.nz/justicesector/documents/trends-in-conviction-and-sentencing-december-2013

Ministry of Social Development. (2008). The Social Report. Wellington. Ministry of 
Social Development.

Moeke-Pickering T. (1996). Māori Identity: Whānau Identity. An unpublished MA thesis. Hamilton. University of Waikato.

Moewaka Barnes H. (2000). 'Kaupapa Māori: Explaining the Ordinary’ in Pacific Health Dialog 7(1):13-16.

Moon P and Biggs P. (2004). The Treaty and its Times. Auckland. Penguin Books.

Moon P. (2006). Fatal Frontiers: A New History of New Zealand in the Decade Before the Treaty. Auckland. Penguin Books.

Morrison B, Soboleva N and Chong J. (2008). Conviction and Sentencing of Offenders in New Zealand: 1997 to 2006. Wellington. Ministry of Justice.

Mudford A. (1990). Cultural Programmes in Prison: A Survey of Programmes Targeted for Māori Inmates. Wellington. Department of Justice.

Nathan L, Wilson N and Hillman D. (2003). Te Whakakotahitanga: An Evaluation of the Te Piriti Special Treatment Programme for Child Sex Offenders in New Zealand. Wellington. Department of Corrections.

Nepe T. (1991). E Hao Nei e Tēnei Reanga: Te Toi Huarewa Tìpuna Kaupapa Māori An Educational Intervention System. Unpublished MA Thesis. Auckland. University of Auckland.

Newbold G. (2008). 'Another One Bites the Dust: Recent Initiatives in Correctional Reform in New Zealand' in The Australian and New Zealand Journal of Criminology 41(3):384-401.

O’Brien M. (2001). 'Doing Ethical Research Legally: Research Ethics and the Law' in Tolich M (ed). Research Ethics in Aotearoa New Zealand. Auckland. Longman.

O’Malley P. (1973). 'The Influence of Cultural Factors on Māori Crime Rates' in Webb S and Collette J (eds). New Zealand Society: Contemporary Perspectives. Sydney. John Wiley \& Sons. 
Oliver P, Porima L and Akroyd S. (2008). Final Report on the Evaluation of Te Ihi $T \bar{u}$. Waiheke Island. Pam Oliver and Associates.

Orange C. (2004). An Illustrated History of the Treaty of Waitangi. Wellington. Bridget Williams Books.

Pere L. (2006). Oho Mauri: Cultural Identity, Wellbeing, and Tāngata Whai Ora/Motuhake. An unpublished $\mathrm{PhD}$ thesis. Wellington. Victoria University of Wellington.

Pere R. (1979). 'Taku Taha Māori: My Māoriness' in He Mātāpuna A Source: Some Māori Perspectives. Wellington. New Zealand Planning Council.

Pere R. (1982). Ako: Concepts of Learning in the Māori Tradition. Wellington. Te Kōhanga Reo Trust National Trust Board.

Pere R. (1991). Te Wheke: A Celebration of Infinite Wisdom. Wellington. Ao Ako Global Learning New Zealand Ltd.

Pfeifer J, Buchanan K and Fisher R. (2005). Report on Māori Focus Unit Initiative. Wellington. Department of Corrections.

Phinney J. (1990). 'Ethnic Identity in Adolescents and Adults: Review of Research' in Psychological Bulletin 108(3):499-514.

Phinney J. (1991). 'Ethnic Identity and Self-Esteem: A Review and Integration' in Padilla A (ed). Hispanic Journal of Behavioural Sciences 13(2):193-208.

Pickering N. (2001). 'Health Experimentation: Can (Scientifically) Good Research be (Ethically) Bad Research' in Tolich M (ed). Research Ethics in Aotearoa New Zealand. Auckland. Longman.

Pihama L and Penehira M. (2005). Building Baseline Data on Māori, Whānau Development and Māori Realising their Potential. Auckland. Auckland University of Auckland.

Pihama L, Cram F and Walker S. (2006). 'Creating Methodological Space: A Literature Review of Kaupapa Māori Research' in Canadian Journal of Native 
Education 26(1):30-43.

Pihama L. (1993). Tungia te Ururua, Kia Tupu Whakaritorito te Tupu o te Harakeke: A Critical Analysis of Parents as First Teachers. Unpublished MA thesis. Auckland. University of Auckland.

Pipi K, Cram F, Hawke R, Hawke S, Huriwai T, Mataki T, Milne M, Morgan K, Tuhaka H and Tuuta C. (2004). 'A Research Ethic for Studying Māori and Iwi Provider Success' in Social Policy Journal of New Zealand Te Puna Whakaaro 23(Dec):141-153.

Pohatu T. (1996). I Tipu ai Tãtou i ngā Turi o o Tātou Mātua Tīpuna: Transmission and Acquisition Processes within Kawai Whakapapa. Unpublished MA Thesis. Auckland. University of Auckland.

Pomare E, Keefe-Ormsby V, Ormsby C, Pearce N, Reid P, Robson B. (1995). Hauora: Māori Standards of Health III-A Study of the Years 1970-1984. Wellington. Huia Publishers.

Poole I. (1991). Te Iwi Māori: A New Zealand Population Past, Present and Future. Auckland. Auckland University Press.

Porima L and Wehipeihana N. (2001). Evaluation of Māori Therapeutic Programmes Pilot. Wellington. Department of Corrections.

Public Health Commission. (1994). Our Health, Our Future: Hauora Pakiri, Koiora Roa: The State of the Public Health in New Zealand. Wellington. Public Health Commission.

Raffe D, Blundell I and Biddy J. (1989) 'Ethics and Tactics: Issues Arising from an Educational Survey' in Burgess R (ed). The Ethics of Educational Research. London. The Falmer Press.

Ragin C and Amoroso L. (2011). Constructing Social Research. Thousand Oaks. Sage Publications.

Ramsden I. (1993). 'Cultural Safety in Nursing Education in Aotearoa' in Nursing 
Praxis in New Zealand 8:4-10.

Rangihau J. (1992). 'Being Māori' in King M (ed). Te Ao Hurihuri: Aspects of Māoritanga. Auckland. Reed Books.

Rei R. (1998). E Kakano i Ruia Mai i Rangiātea: Wānanga Reo as a Learning and Teaching Intervention for the Revitalization of the Māori Language. Unpublished MPhil Thesis. Auckland. University of Auckland.

Reid P and Robson B. (1999). 'Dying to Be Counted' in Proceedings of Te Oru Rangahau Māori Research and Development Conference, School of Māori Studies, Massey University, 7-9 July 1998. Palmerston North. Massey University.

Reilly M. (2004). 'Whanaungatanga' in Ka’ai T, Moorfield J, Reilly M and Mosley S (eds). Ki te Whaiao: An Introduction to Māori Culture and Society. Auckland. Pearson Education.

Riessman C. (2002). 'Analysis of Personal Narrative' in Gubrium J and Holstein J (eds). Handbook of Interview Research: Context and Method. Thousand Oaks. Sage.

Roper C. (1989). Prison Review: Te Ara Hou: The New Way. Wellington. Government Printer.

Royal Commission on Social Policy. (1988). The April Report Vol III(1). Wellington. Government Press.

Royal T (ed). (2003). The Woven Universe: Selected Writings of the Rev. Māori Marsden. Wellington. The Estate of Rev. Māori Marsden.

Royal T. (2000). Kaupapa and Tikanga: Some Thoughts. An unpublished paper delivered at the Mai i te Ata Hāpara: Principles, Influence and Relevance of Tikanga Māori Conference held at Te Wānanga-o-Raukawa, Ōtaki. 11-13 August 2000.

Royal T. (2002). Indigenous Worldviews: A Comparative Study. An unpublished research report. Ōtaki. Te Wānanga o Raukawa. Available at: http://www.charlesroyal.com/assets/indigenousworldviews.pdf.

Royal T. (2006). A Modern View of Mana. A keynote address delivered to the joint 
conference of the Australian Psychological Society and the New Zealand Psychological Society, 26-30 September 2006, SkyCity Auckland Convention Centre. Available at: http://www.charles-royal.com/assets/apspaper.pdf

Salmond A. (1990). Two Worlds: First Meetings Between Māori and Europeans 1642-1772. Wellington. Viking Publishers.

Salmond A. (1997). Between Worlds: Early Exchanges Between Māori and Europeans 1773-1815. Wellington. Viking Publishers.

Schwimmer E (ed). (1968). The Mãori People in the Nineteen Sixties. Auckland. Blackwood and Janet Paul.

Selby R. (1996). A Study of the Factors Which Contribute to Success for Māori Women in Tertiary Education. An unpublished MA thesis. Palmerston North. Massey University.

Selby R. (1999). Still Being Punished. Wellington. Huia Publishers.

Smith G. (1990). 'The Politics of Reforming Māori Education: The Transforming Potential of Kura Kaupapa Māori' in Lauder H and Wylie C (eds). Towards Successful Schooling. Basingstoke. The Falmer Press.

Smith G. (1997). The Development of Kaupapa Māori Theory and Praxis. An unpublished PhD Thesis. Auckland. University of Auckland.

Smith L and Cram F. (1997). An Evaluation of the Community Panel Diversion Pilot Project. Wellington. Office of the Prime Minister and Cabinet.

Smith L. (1999). Decolonising Methodologies: Research and Indigenous Peoples. Dunedin. University of Otago Press.

Smith L. (2006). 'Choosing the Margins: The Role of Research in Indigenous Struggles for Social Justice' in Denzin N and Giardina M. Qualitative Inquiry and the Conservative Challenge. London. Walnut Creek.

Smith L. (2011). 'Story-ing the Development of Kaupapa Māori - A Review of Sorts' in Kei Tua o te Pae Hui Proceeding - The Challenges of Kaupapa Mãori 
Research in the 21st Century. A Compilation of papers presented at a conference at Pipitea Marae, Wellington, 5-6 May 2011.

Spivakovsky C. (2013). Racialized Correctional Governance: The Mutual Constructions of Race and Criminal Justice. Surrey. Ashgate Publishing.

Stanley E. (2014). Institutional Victimisation: The Legacies of Harm and Injustice against Children. Publication in progress (author's copy).

Statistics New Zealand. (2007). Demographic Trends. Wellington. Statistics New Zealand. Available at www.stats.govt.nz

Statistics New Zealand. (2014a). Annual Apprehensions for the Latest Calendar Years (ANZSOC). Wellington. Statistics New Zealand. Available at: http://nzdotstat.stats.govt.nz/wbos/Index.aspx?DataSetCode=TABLECODE7407

Statistics New Zealand. (2014b) Te Ao Mārama 2014. Wellington. Statistics New Zealand. Available at: http://www.stats.govt.nz/browse_for_stats/snapshots-of-nz/teao-marama-2014.aspx

Stokes E. (1985). Māori Research and Development: A Discussion Paper. Wellington. National Research Advisory Council.

Strauss A and Corbin J. (2008). Basics of Qualitative Research: Techniques and Procedures for Developing Grounded Theory (3rd Edition). Thousand Oaks. Sage.

Sutherland I. (1940). The Māori People Today: A General Survey. Wellington. New Zealand Council for Educational Research.

Tajfel H. (1981). Human Groups and Social Categories. New York. Cambridge University Press.

Tākao N, Grennell D, McKegg K, Wehipeihana N. (2010). Te Piko o te Māhuri: The Key Attributes of Successful Kura Kaupapa Māori. Wellington. Ministry of Education.

Taki M. (1996). Kaupapa Māori and Contemporary Iwi Māori Resistance. 
Unpublished MA Thesis. Auckland. University of Auckland.

Taumata-Le Cleve D. (1992). Tuituiā: A Māori Perspective. Wellington. Department of Justice.

Tauri J. (2005). 'Indigenous Perspectives and Experiences: Māori and the Criminal Justice System' in Walters R and Bradley T. Introduction to Criminological Thought. Auckland. Pearson Education.

Te Ariki C and Spoonley P. (1992). Te Whakapakari Te Mana Tangata: The Politics and Process of Research for Māori. Palmerston North. Massey University.

Te Awekōtuku N. (1991). He Tikanga Whakaaro: Research Ethics in the Māori Community. Wellington. Ministry of Māori Affairs.

Te Hoe Nuku Roa Research Team. (1999). Te Hoe Nuku Roa Source Document: Baseline History. Palmerston North. Massey University.

Te Puni Kōkiri (1998) Progress Towards Closing the Gaps Between Māori and nonMāori. Wellington. Te Puni Kōkiri.

Te Puni Kōkiri (2000) Progress Towards Closing the Gaps Between Māori and nonMāori. Wellington. Te Puni Kōkiri.

Te Puni Kōkiri. (1997). National Survey of Marae. Wellington. Te Puni Kōkiri.

Te Puni Kōkiri. (2002). The Health of the Māori Language. Wellington. Te Puni Kōkiri.

Te Whaiti P and Roguski M. (1998). Māori Perceptions of the Police. Wellington. He Pārekereke/Victoria Link Ltd.

Thomas D, Cloher D, Henare J and Savage W. (1998). Evaluation of the Te Ihi Tū Trust Habilitation Centre. Auckland. University of Auckland.

Thomas D. (1988a). 'Development of a Test of Māori Knowledge' in New Zealand Journal of Psychology 17:59-67.

Thomas D. (1988b). 'Culture and Ethnicity: Maintaining the Distinction' in 
Australian Journal of Psychology 33(3):371-380.

Tolich M and C Davidson. (1999). Starting Fieldwork: An Introduction to Qualitative Research in New Zealand. Auckland. Oxford University Press.

Tolich M. (2001). 'Beyond an Unfortunate Experiment: Ethics for Small-Town New Zealand' in Tolich M (ed). Research Ethics in Aotearoa New Zealand. Auckland. Longman.

Waitangi Tribunal. (1986). Te Reo Māori Report. Wellington. Government Printer.

Waitangi Tribunal. (1998). Te Whānau o Waipareira Report. Wellington. Government Printer.

Waitangi Tribunal. (2005). The Offender Assessment Policies Report (WAI 1024). Wellington. Waitangi Tribunal.

Waitangi Tribunal. (2013). Matua Rautia: The Report on the Kōhanga Reo Claim: Waitangi Tribunal Report Wai 2336. Wellington. Waitangi Tribunal.

Waitere-Ang H. (1999). The Kete, The Briefcase, Te Tuara: The Balancing Act Māori Women in the Primary Sector. Unpublished Masters of Educational Administration Thesis. Palmerston North. Massey University.

Waldegrave C, King P, Walker T and Fitzgerald E. (2006). Māori Housing Experiences: Emerging Trends and Issues. Wellington. Centre for Housing Research and Te Puni Kōkiri.

Walker P. (2011). Whakatipuranga Rua Mano 1975-2000: He Tirohanga Whakamuri. Ōtaki. Te Wānanga-o-Raukawa.

Walker R. (1974). 'Māoritanga and the Teacher' In Bray D and Hill C (eds). Polynesian and Pākehā in New Zealand Education Volume II. Auckland. Heinemann.

Walker R. (1979). 'The Urban Māori' in He Mātāpuna A Source: Some Māori Perspectives. Wellington. New Zealand Planning Council. 
Walker R. (1989). 'Māori Identity' in Novitz D and Willmott W (eds). Culture and Identity in New Zealand. Wellington. Government Printer.

Walker R. (1990). Ka Whawhai Tonu Mātou. Auckland. Penguin Books.

Walker R. (1992). 'Marae: A Place to Stand' in King M (ed). Te Ao Hurihuri: Aspects of Māoritanga. Auckland. Reed Books.

Walker R. (1996). Ngā Pepa a Ranginui: The Walker Papers. Auckland. Penguin Books.

Walker S. (1996). Kia Tau te Rangimarie: Kaupapa Māori Theory as a Resistance Against the Construction of Māori as the Other. Unpublished MA Thesis. Auckland. University of Auckland.

Webb R. (2003). Māori Crime: Possibilities and Limits of an Indigenous Criminology. Unpublished PhD Thesis. Auckland. University of Auckland.

Webb R. (2008). Risk Factors, Criminogenic Needs and Māori. Auckland. Auckland University of Technology.

Webb R. (2012). 'Culture and Crime Control in New Zealand' in Crime, Justice and Social Democracy: An International Conference. Held at School of Justice, Faculty of Law, Queensland University of Technology, 26-28 September 2011.

Wehipeihana N and Porima L and Spier P. (2003). Research on the New Life Akoranga Programme of the Mahi Tahi Trust. Wellington. Ministry of Justice.

Weigert A, Smith Teitge J and Teitge D. (1986). Society and Identity: Towards a Sociological Psychology of Identity. New York. Cambridge University Press.

Wilkinson T. (2001). 'The Core Ideas of Research Ethics' in Tolich M. (ed). Research Ethics in Aotearoa New Zealand. Auckland. Longman.

Williams H. (1992). Dictionary of Mãori Language. Wellington. GP Publications.

Willmott B. (1989). 'Culture and National Identity' in Novitz D and Willmott W (eds). Culture and Identity in New Zealand. Wellington. Government Printer. 
Winiata P. (1997). He Hauminga Tangata: Te Whakairo i Tetehi Tauira Whakaora i te Iwi. Unpublished Masters of Mātauranga Māori thesis. Ōtaki. Te Wānanga-oRaukawa.

Winiata P. (2002). Guiding Principles/Kaupapa of Te Wānanga-o-Raukawa: A Discussion Paper. Ōtaki. Te Wānanga-o-Raukawa. Available at: http://www.wananga.com/index.php/about-us/wananga-documents

Winiata W. (1988). 'Hapū and Iwi Resources and their Quantification' in Royal Commission on Social Policy. The April Report Vol III:(2).

Winiata W. (2002). Theory (and Understanding) of Wānanga. Ōtaki. Te Wānangao-Raukawa. Available at: http://www.wananga.com/index.php/about-us/wanangadocuments

Workman K. (2009). The Moral Performance of New Zealand Prisons. Presentation at Institute of Policy Studies Conference, "Ethical Foundations of Public Policy”, Victoria University of Wellington. Available at: http://www.rethinking.org.nz/assets/Papers\%20and\%20Presentations/Moral_Perfor mance_Prisons.pdf 